Netherlands

organization for applied scientific research

TNO Report
Probabilistic Design of Flood Defences
TNO Institute for Building Materials and Structures
Phone +3115606000

Fax +3115620304

Telex $38270 \mathrm{ibbc}$ nl

Title

2600 AA

Lange Kleiweg 5

$2288 \mathrm{GH}$ Rijswijk

The Netherlands

Report no. B-87-404

Date

22 June 1987

Project no. $\quad 64.3 .0923$

Author A.C.W.M. Vrouwenvelder

Key-word Flood Defences

To

Members TAW 10

IBBC-TNO is one of the institutes of the TNO
Delivered reports shall only be published verbatim and in full by the 



\section{PROBABILISTIC DESIGN OF FLOOD DEFENCES}

Authors :
E.O.F. Calle
D. Dillingh
W. Meermans
A.C.W.M. Vrouwenvelder
J.K. Vrijling
L. de Quelerij
A.J. Wubs

(Delft Geotechnics)

(Rijkswaterstaat, Highways and Hydraulics Division)
(Delft University of Technology)
(Institute TNO for Building Materials and Structures)

(Rijkswaterstaat, Locks and Barrages Division)

(Rijkswaterstaat, Highways and Hydraulics Division)

(Institute TNO for Building Materials and Structures)

For further inquirements please contact:

$\begin{array}{lll}\text { M. Koster } & \text { J.K. Vrijling } & \text { A. Vrouwenvelder } \\ \text { RWS-DWW } & \text { RWS - Sluizen en Stuwen } & \text { TNO-IBBC } \\ \text { Van der Burghweg 1 } & \text { Griffioenlaan 1 } & \text { Lange Kleiweg } 5 \\ \text { P.0. Box 5044 } & \text { P.O. Box 20.000 } & \text { P.O. Box 49 } \\ \text { 2600 GA Delft } & \text { 3502 LA Utrecht } & \text { 2600 AA Delft } \\ \text { tel: 31-15-569307 } & \text { tel: 31-30-859111 } & \text { tel: 31-15-606409 } \\ & & \end{array}$



The design of dykes, embankments and other flood defences has undergone great development in the last few decades. Traditionally dykes were designed purely on the basis of experience. The crest level was established with reference to the highest known water level.

The Delta Commission (installed in 1953 to make recommendations for flood protection of the Dutch Delta Area) took an important step by applying statistical techniques for determining the "design water levels". However, the approach still represents a deterministic design method: fixed design values were adopted for the various parameters of the problem.

As a next step the probabilistic design method was developed. In this approach the stochastic character of the various load and strength parameters is taken into account, and the design is based on an analysis of failure probabilities. First applied to the design of steel and concrete structures, this method has been used in hydraulic engineering design since the mid-1970s.

Working Group 10 "Probabilistic method" of the Technical Advisory Committee for Dykes and Flood Defences (TAW) has been assigned the task of making the results of this development applicable to flood defence structures. The ultimate aim is to arrive at a code of practice for flood defence structures on the basis of a probabilistic design philosophy.

The present report, however, in no way has the character of a code of practice, but reviews the developments of the research activities. As will appear from a perusal of this report, the picture is as yet not complete, and there are still many grey areas and blank spaces in the knowledge that is needed. However, it is being endeavoured - where possible - to apply elements of the probabilistic approach in actual practice. The "Recommendations for the assessment of the safety of dunes as flood defences" (1983) and the "Recommendations for the design of river dykes" (1985), both prepared by the TAW, may be mentioned as examples.

The worked examples given in the report should be regarded as illustrating the development of the probabilistic approach. They should not be conceived as presenting an operational procedure to be applied in actual practice to the design of flood defences.

It is hoped that this report will contribute to the dissemination of knowledge concerning the probabilistic design philosophy and its application to hydraulic and civil engineering structures in general and to flood defences in particular.

The Chairman of TAW Working Group 10, Prof. J.F. Agema 


\section{CONTENTS}

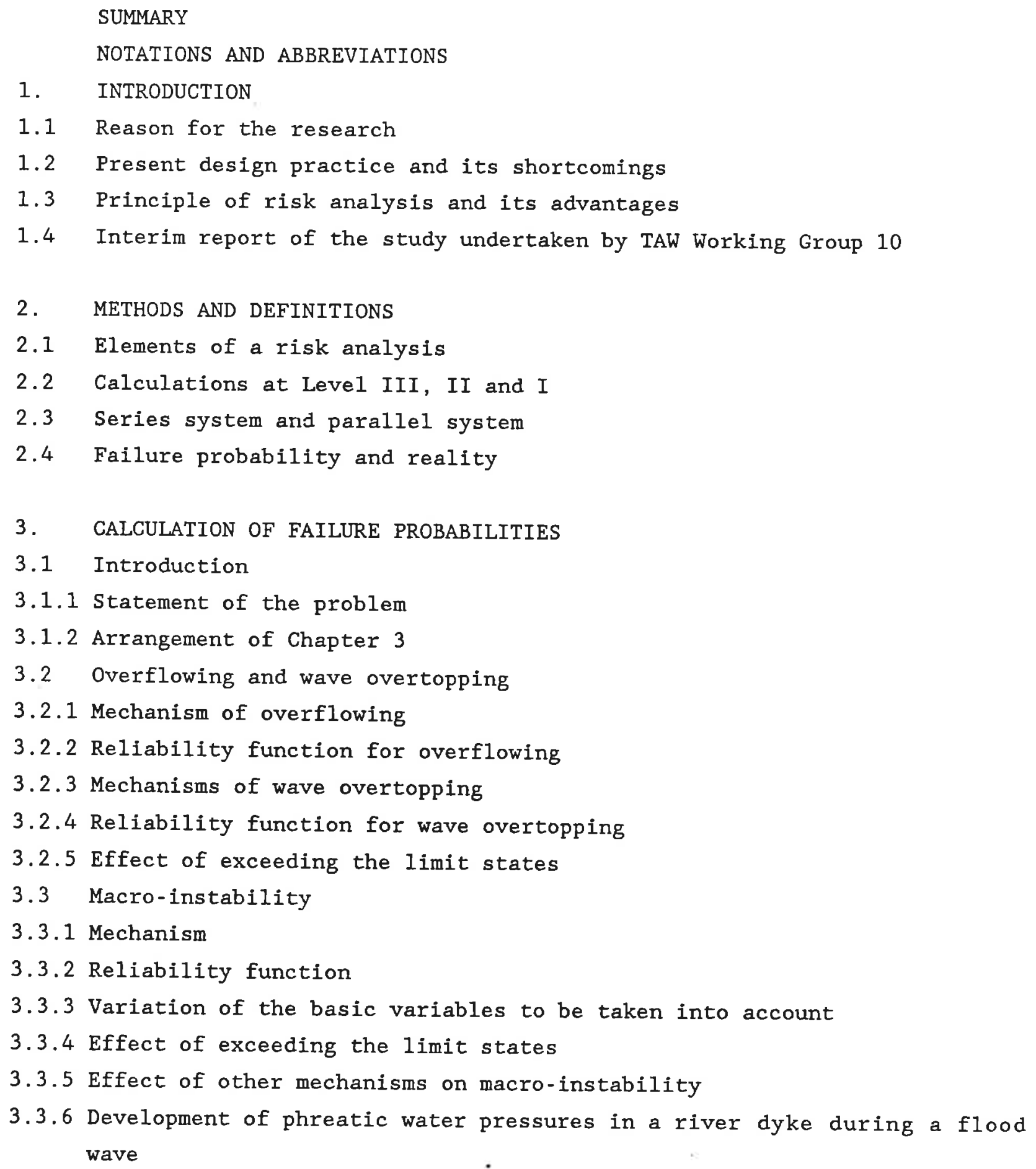


3.4 Micro-instability

3.4.1 Mechanism

3.4.2 Reliability function

3.4.3 Effect of exceeding the limit state

3.5 Piping

3.5.1 Mechanism

3.5.2 Reliability functions

3.5.3 Effect of exceeding the limit state

3.6 Length effect

3.6.1 Introduction

3.6.2 Discrete dyke sections

3.6.3 Methods based on a continuous model

4. CALCULATION OF THE INUNDATION CHARACTERISTICS

4.1 Introduction

4.2 Calculation of the inundation behaviour for a given breach in a river dyke and for overflowing

4.2.1 Inundation depth and inundation speed

4.2.2 Basic equations for river discharge and lateral discharge via a spillway

4.2.3 Discrete approximation for a very short spillway

4.2.4 Discrete approximation for long spillways

4.2.5 Analytical approzimation

4.3 Time-dependence of upstream discharge and lateral discharge

4.3.1 Form and duration of water levels associated with flood discharge

4.3.2 Development of a gap in a dyke

5. CACULATION OF DAMAGE IN THE EVENT OF A GIVEN INUNDATION

5.1 Introduction

5.2 Factors determining inundation factors

5.3 Number of deaths in an inundation

5.4 Material damage associated with an inundation

5.4.1 Classification of property into categories

5.4.2 Damage factors 
6. DESIGN CRITERIA

6.1 Introduction

6.2 Personally acceptable level of risk

6.3 Socially acceptable level of risk

6.4 A concept of acceptable risk

6.5 Some practical considerations in connection with the standard of appraisal adopted

7. WORKED EXAMPLE

7.1 Statement of problem

7.2 Stochastic variables

7.3 Calculation procedure

7.3.1 Optimization of the dyke design

7.3.2 Cost of construction

7.3.3 Capitalized loss expectation

7.3.4 Loss as a function of inundation depth

7.3.5 Inundation depth

7.3.6 Probability density function for inundation depth

7.3.7 Computational scheme

7.4 Results per mechanism

7.4.1 Overflowing

7.4.2 Macro-instability of inner slope

7.4.3 Piping

7.5 Combined failure probability of the dyke

7.6 Optimal dyke design

7.7 Conclusions

8. APPLICATIONS IN PRACTICE

8.1 Introduction

8.2 Eurocodes

8.3 TAW Recommendations for the Design of River Dykes

8.4 TAW Recommendations for Dunes

8.5 Safety considerations relating to the lock at vlaardingen

8.6 Easter Scheldt Storm Surge Barrier

8.7 Dykes around the Easter Scheldt (Barcon)

8.8 Pumpted storage Scheme for IJsselmeer 
$-5-$

9 CONCLUSIONS AND RECOMMENDATIONS

9.1 Conclusions

9.2 Recommendations

REFERENCES 
In the Netherlands the design of sea and river dykes is primarily based upon a water level with a particular frequency of being exceeded. For sea dykes this water level has been laid down by the Delta Commission in the so-called design water levels, and for river dykes by the Commission on River Dykes.

The crest height of the dyke is determined by adding to the above-mentioned design water level an appropriate margin, which should include wave runup. The crest height, however, is only one of the characteristic quantities relating to the cross-sectional profile of a dyke. The other dimensions and characteristics are determined on the basis of requirements associated with stability, construction, maintenance and utilization of the dyke.

The probability of the design water level being exceeded cannot simply be equated to the probability of inundation. Depending on circumstances, a greater or lesser amount of reserve may be available in the extra height provided. Another point to note is that a flood defence structure such as a dyke can fail in many other ways besides overtopping. It can therefore be concluded that with the present design method the probability of inundation is in principle not established in a clear-cut manner. Furthermore it is to be noted that in the present procedure the extent of the damage or loss is insufficiently reflected in the safety margin applied. To summarize, it can be said that the "balance" of the design as now carried out leaves much to be desired.

In the light of what has been said above the Council for Civil Engineering Works advised the Minister of Transport and Public Works that "it should be considered whether it is possible to arrive at a standard for safety against inundation, based on a risk analysis of all the factors involved". The Minister submitted the matter to the Technical Advisory Committee for Dykes and Flood Defences (TAW).

On 20 March 1979 the TAW decided to establish Working Group 10 "Probabilistic Method". The assigned task of this Working Group is the formulation of a new 
philosophy for the design of soundly conceived (i.e., safe and economical) flood defence structures. By soundly based design in this context is understood that the overall probability of failure (or collapse) is known and is sufficiently low and that the probabilities of failure of the various parts of the structure are well interadjusted.

This report reviews the present position of the research that has been carried out. It can broadly be categorized as follows:

a. Determination of the probability of failure of the dyke for a single failure mechanism or for a combination of mechanisms (Chapters 2 and 3 );

b. Determination of the depth of inundation in the event of failure, and the resulting damage, more particularly in terms of financial loss (Chapters 4 and 5);

c. Determination of an acceptable level of risk (Chapter 6);

d. Application, both in a worked example and in present-day design practice (Chapters 7 and 8 ).

The following explanatory comments on these points are offered here:

Re a) Determination of the probability of failure

Chapter 2 gives a short summarizing review of the techniques of risk analysis. Some aids such as fault trees and event trees are indicated. The procedures for level I, level II and level III analysis are described. The combination of two or more mechanisms and the theory of series systems and parallel systems are considered.

In order to calculate the failure probability of a dyke it is necessary to have a mathematical description of the physical process associated with a failure mechanism. Five failure mechanisms for dykes are considered in this study, namely: 
- overflowing (overtopping by high water leve1)

- wave overtopping

- macro-instability of inner slope

- micro-instability of inner slope

- piping

Each of these mechanisms is described, and mathematical expressions are given to enable the reliability functions to be established. For the first four of the above-mentioned failure mechanisms these expressions describe the physical reality as closely as possible. Lane's empirical criterion is used in analysing the mechanism of piping.

The length of the dyke also plays a part in connection with determining the probability of failure. For this reason the influence of the length effect has also received attention within the scope of this research. Progress with regard to this aspect is still slow, however.

\section{Re b) Determination of inundation depth and inundation damage}

An important element in the risk analysis is the consequence of a possible inundation. In determining the depth of inundation this report makes use of the hydraulic formulae for the free-nappe weir and the submerged weir. The cases dealt with are the short lateral spillway in the event of breaching of a dyke and the long lateral spillway in the event of overflowing. No theoretical or experimental research into the development of a gap (breach) in a dyke and the associated flow channel has been carried out.

For estimating the damage and corresponding financial loss associated with a given inundation depth, a study of the consequences of the 1953 flood tide disaster in the Netherlands has been carried out. It has thus been possible to derive relationships between the inundation depth, on the one hand, and the number of deaths and the material damage incurred, on the other. The material damage is divided into:

- damage to agricultural areas;

- damage to industrial areas;

- damage to built-up areas (excl. industrial areas). 
Some examples of damage (loss) calculations are included in the report. Besides the inundation depth there are other parameters which also affect the damage, such as the speed of inundation, the duration of inundation, and the possibilities for rescue and evacuation. These matters have not yet been investigated.

\section{$\underline{\operatorname{Re} c) \text { Acceptable level of risk }}$}

Calculation of the probability of failure of a system of flood defences soon comes up against the question as to what probability of what risk is accept-

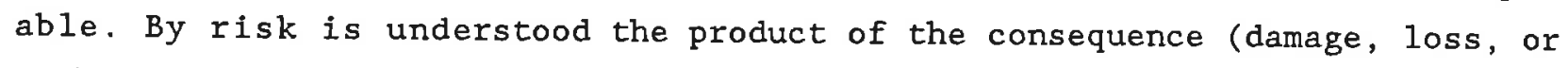
number of victims) and the probability of such failure. The acceptable level of risk is dealt with from two points of view:

- the personally acceptable level of risk;

- the socially acceptable level of risk.

In connection with the personally acceptable level of risk the question whether the risk is voluntary of non-voluntary is of particular importance. In the case of a voluntary risk the individual makes an appraisal in the sense that he balances the direct personal and the social benefit against the risk. Both the probability component and the consequence component are estimated on the basis of his own experience or of the reported experience of others. In the case of a non-voluntary risk the individual can indeed make an appraisal according to his own set of norms, but it is not within his power to alter the choice should his assessment of the consequence be unfavourable.

As regards the socially acceptable level of risk in respect of a particular project, two approaches may be adopted. In the first approach the problem is schematized to a mathumatical-economic decision problem by expressing all the consequences of the disaster in monetary terms. The cross-sectional profile of the dyke is so chosen that the sum of the construction cost items, or of the cost of dyke improvement and the capitalized loss expectation, is a minimum. The second approach has recourse to accident statistics. It starts from the proposition that the result of a social appraisal of risk is reflected in these statistics, and it is attempted to derive a standard of appraisal, or norm, from them. 


\section{Re d) Applications}

To gain experience in designing on the basis of risk analysis, a worked example has been carried out within the scope of this study. For this purpose a river dyke consisting of a sand body with a covering layer of clay on the outer (riverward) slope has been chosen. Eleven of the parameters involved in working out this design example have been assigned a stochastic character. The mathematical-physical models have intentionally been kept simple, as also the number of failure-mechanisms considered, in order to present a complete treatment of the procedure as a whole.

The optimal cross-sectional profile of the dyke is determined on the basis of the sum of the cost of construction of the dyke and the capitalized loss expectation. First, for each failure mechanism the failure probability and the optimal dyke profile are determined. Next, the failure mechanisms are combined. Because of the layer of clay on the outer slope, the mechanisms of macro-instability and micro-instability are of hardly any significance. Despite assumed imperfections, the clay layer is found to be amply able to keep down the water level in the sand body. Hence the other two mechanisms, overflowing (overtopping of the crest by high water level) and piping determine the failure probability of the dyke. The optimal failure probability is found to be associated with a dyke having low angles of slope, this being necessary for obtaining a sufficiently long seepage path length to scope with piping. If the seepage path length is increased by other means, e.g., the presence of a foreland on the riverward side of the dyke, the optimal profile is found to be provided by a dyke having the steepest possible slopes.

The practical significance of the research also receives attention in this report. It is pointed out that probabilistic approaches to dealing with particular problems are increasingly being applied. It is also reported that a number of the results of this study have already been applied in actual practice. The TAW Recommendations for River Dykes and Dune Erosion, and the operational management of the Eastern Scheldt Storm Surge Barrier, call for mention in this context.

Finally, the report presents a number of conclusions and recommendations. It emerges from the conclusions that some of the results of the research are already being given practical application and that more results can be 
expected to become available during the further course of the research. Carrying out the assessment of a complex system of flood defences with the aid of a probabilistic approach will, however, still require much effort. The Working Group is of the opinion that, also having regard to the requirements of engineering design practice, the research should be continued. A number of recommendations are made in connection with this. Among other matters it is recommended that models for failure mechanisms be further developed and calculations be performed with these models, taking account of the lengtheffect and correlations. From a sensitivity analysis of all the relevant factors associated with cost optimization it will then be possible to deduce priorities for closer investigation. 


\section{NOTATIONS AND ABBREVIATIONS}

Some of the symbols occur only in certain chapters or have a different meaning in different chapters. In such cases the relevant chapter is indicated in parentheses.

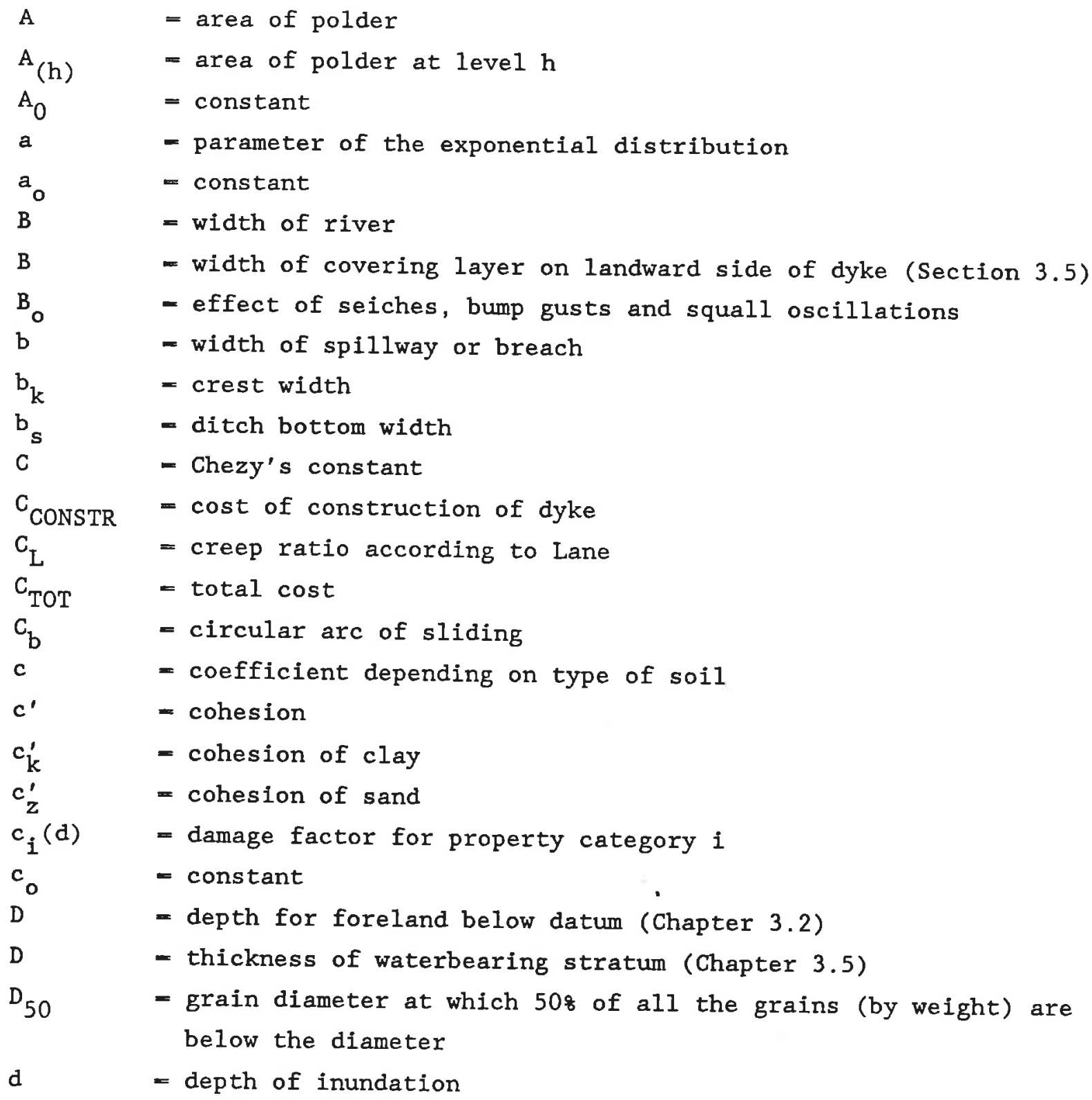




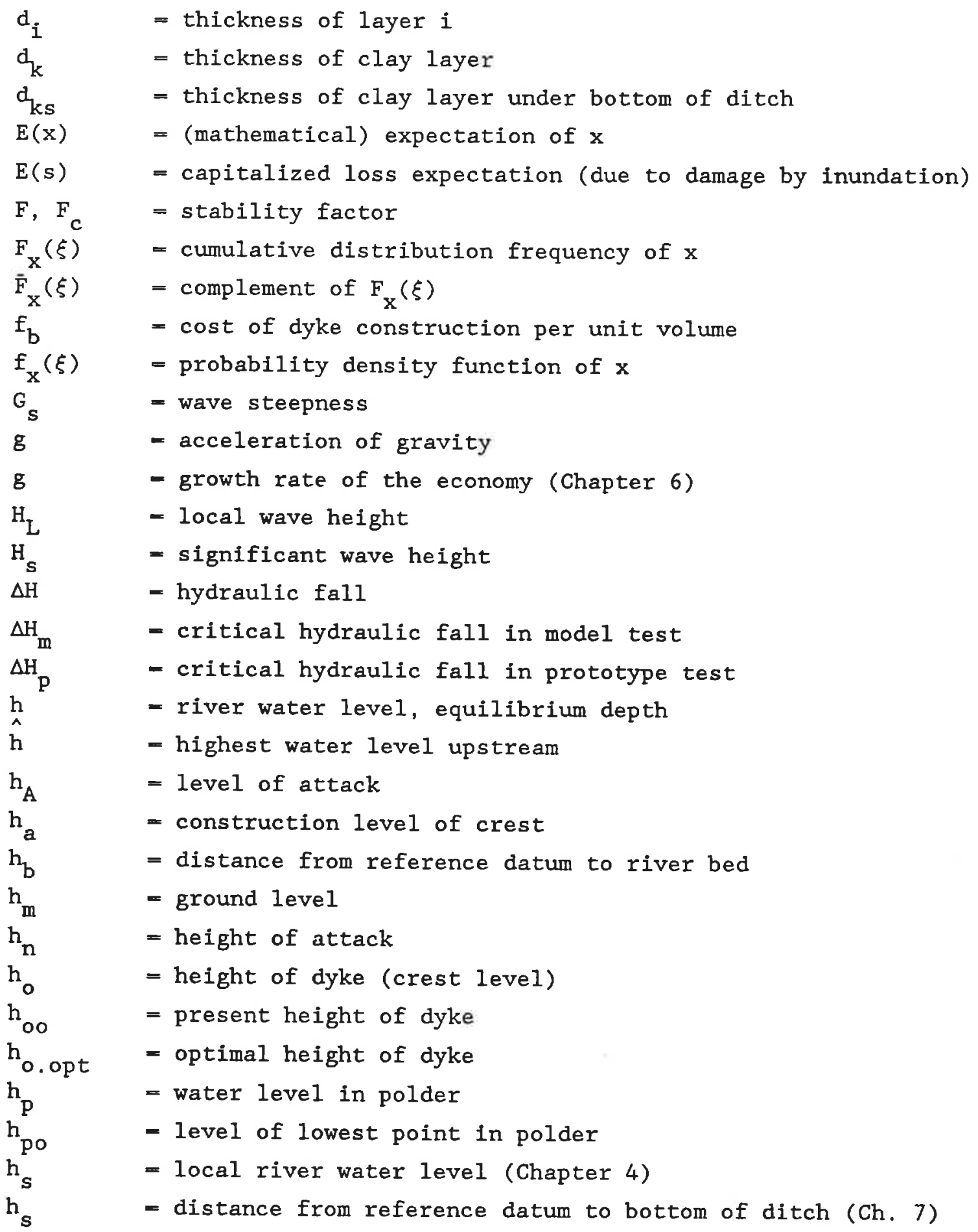




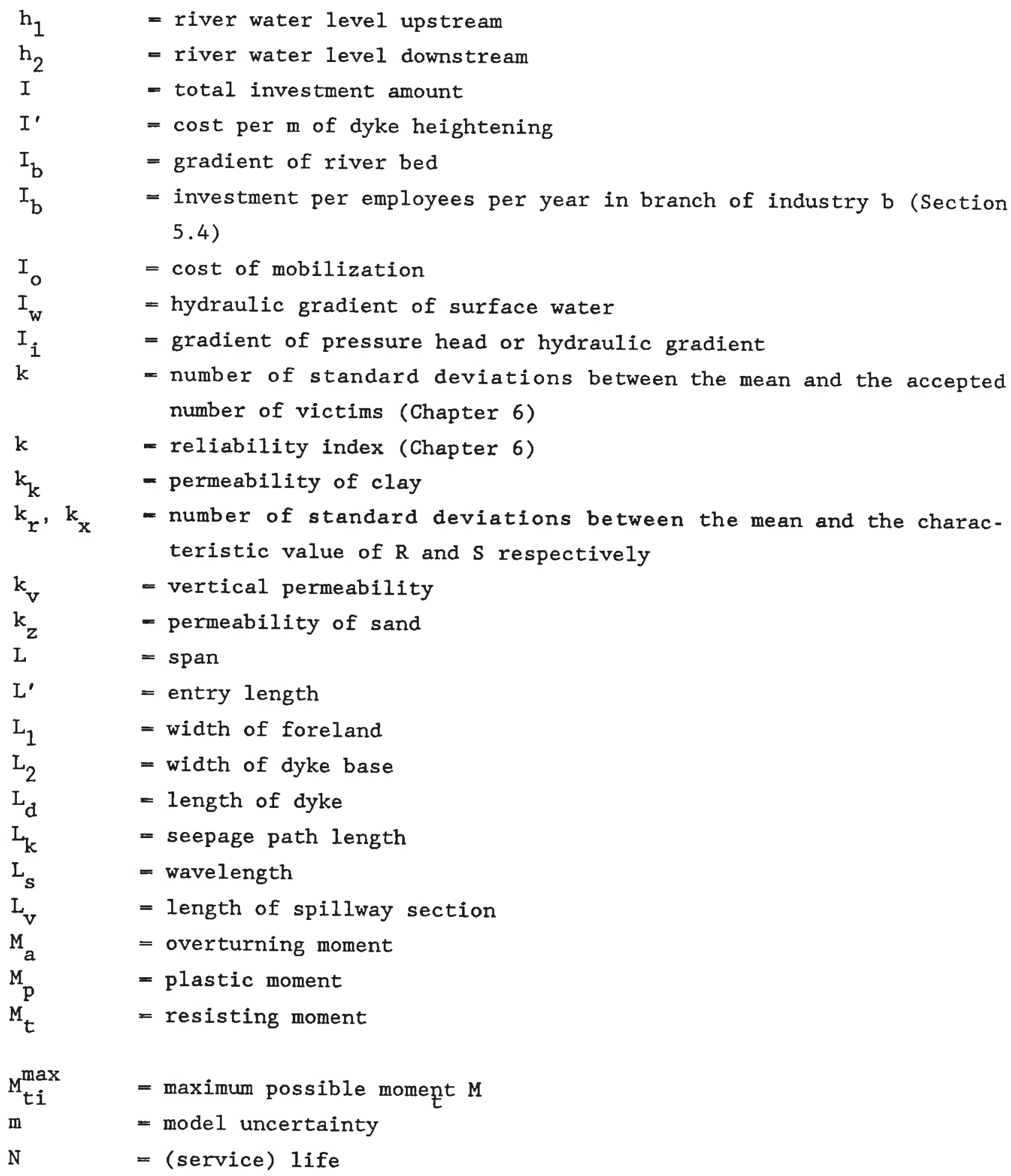




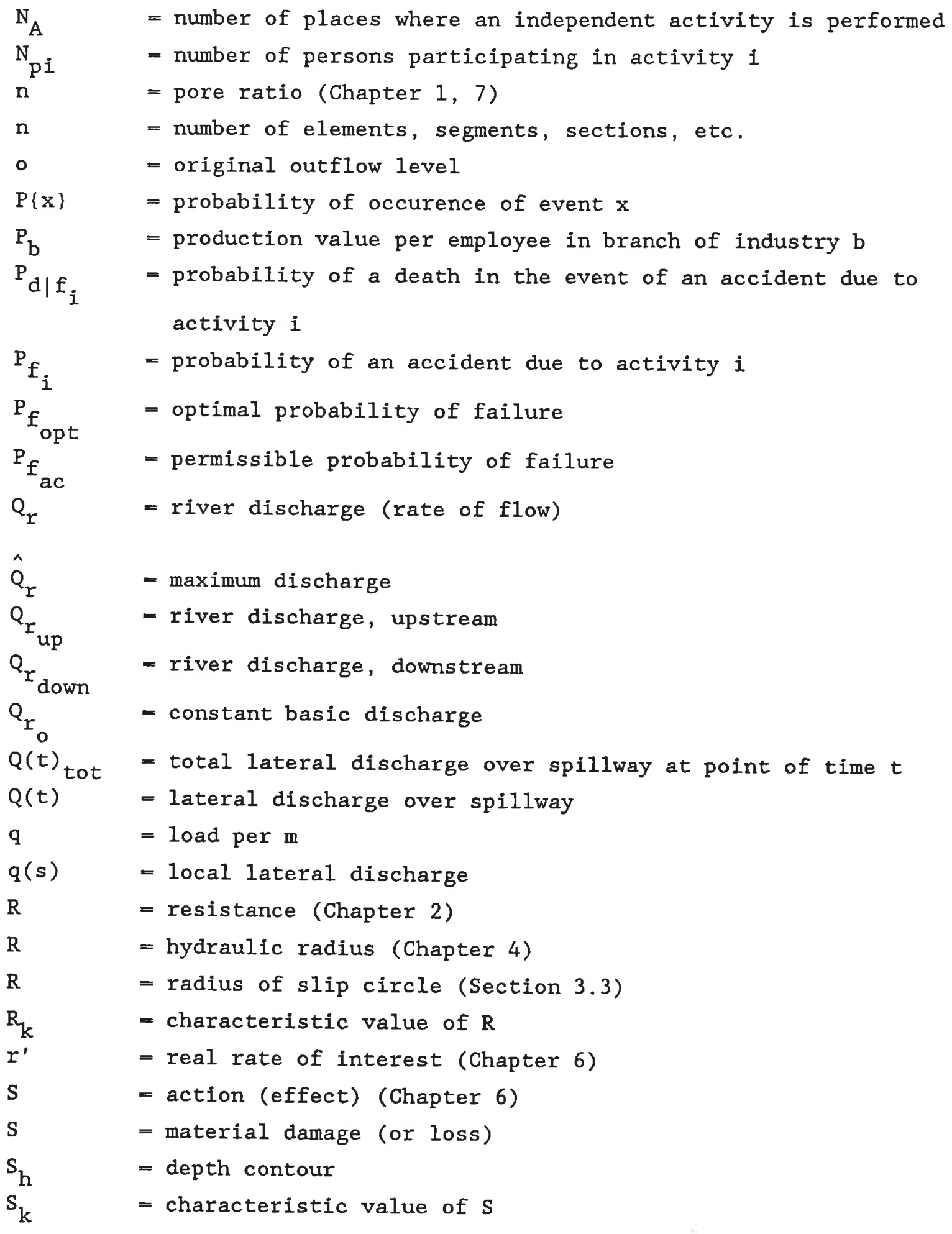




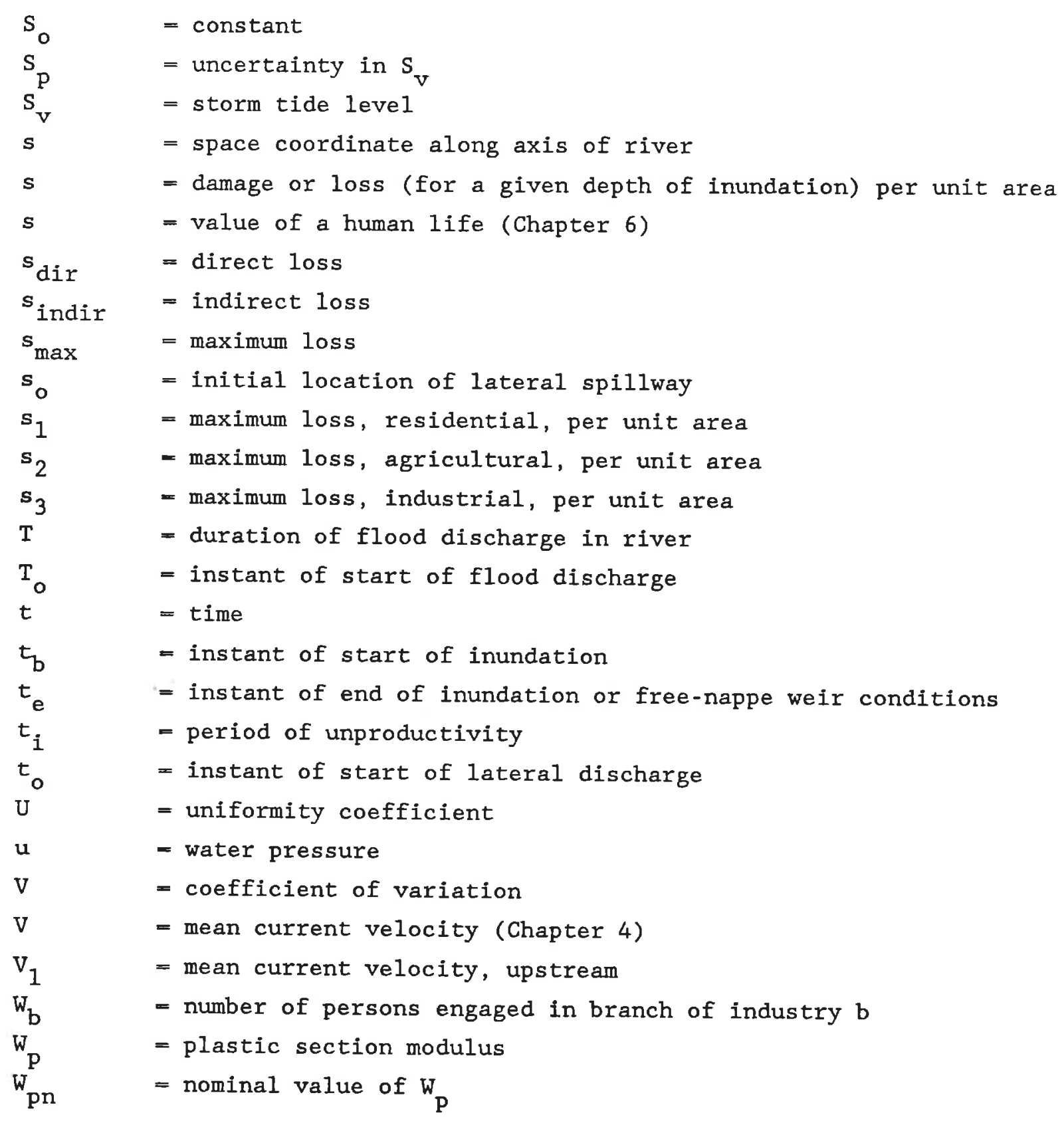




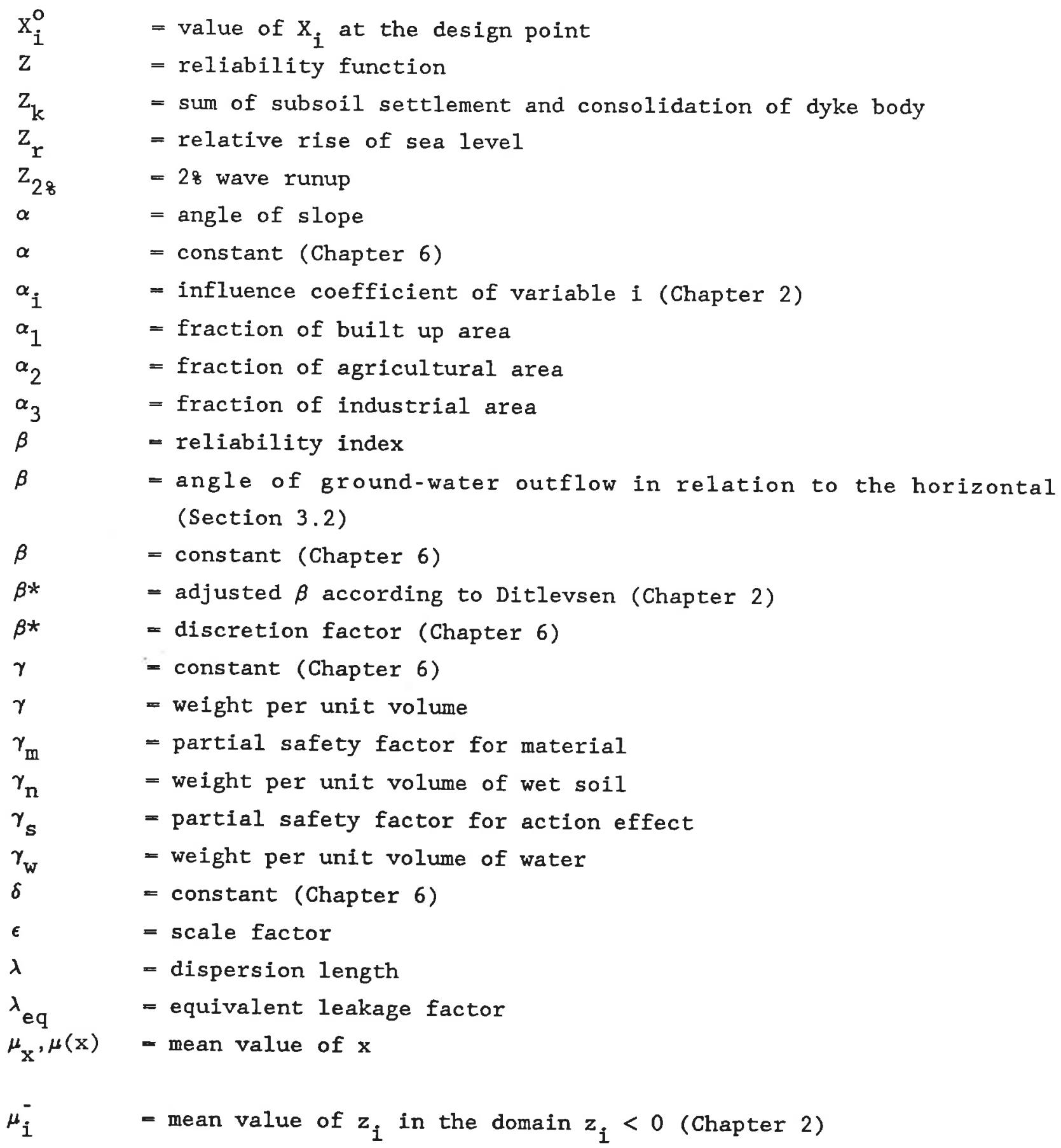




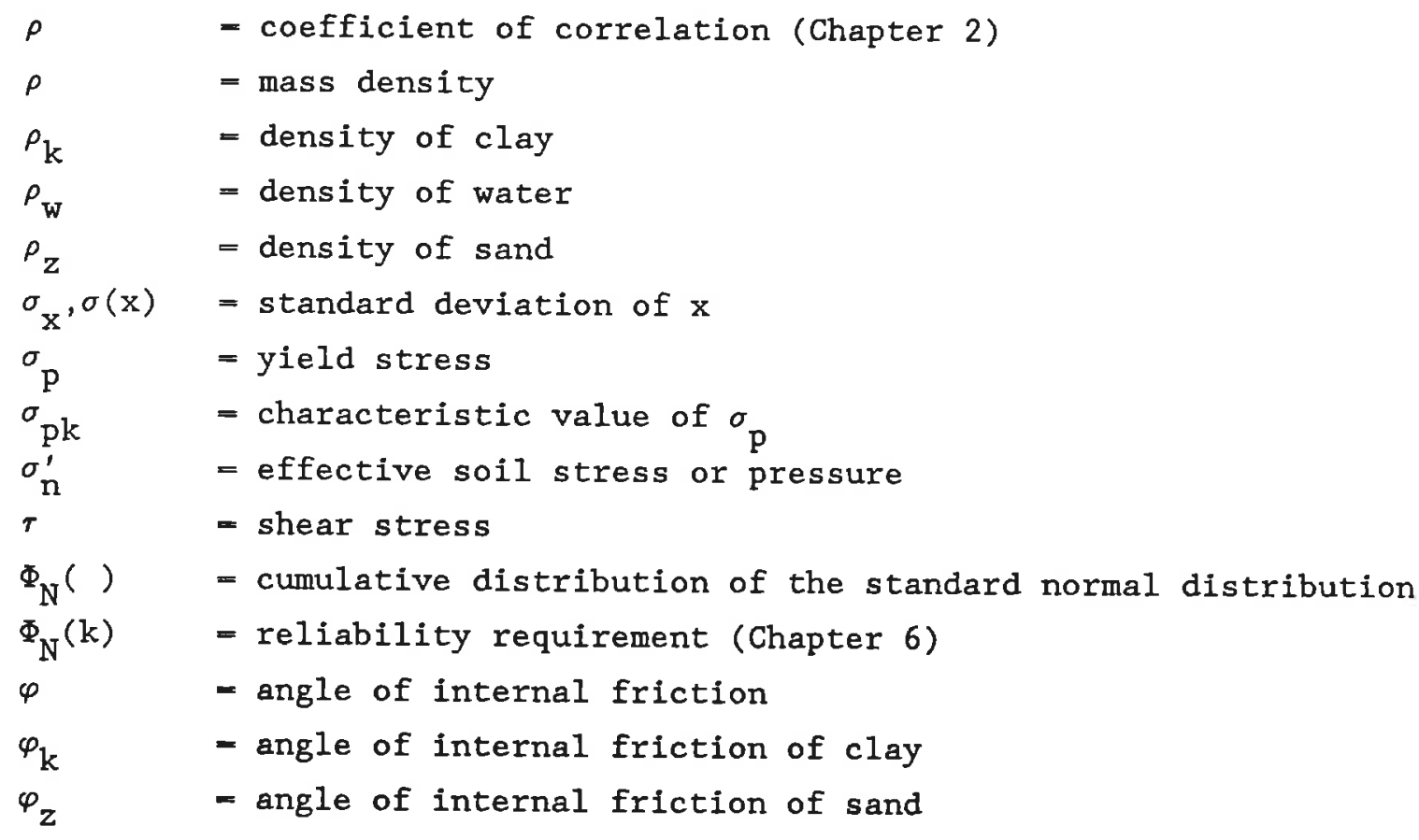

\section{ABBREVIATIONS}

RWS Rijkswaterstat (Governmental Public Civil Engineering Works Department).

TAW Technische Adviescommissie voor de Waterkeringen (Technical Advisory Committee for Dykes and Flood Defences).

COW Centrum Onderzoek Waterkeringen (Centre for Flood Defence Research).

TGB Technische Grondslagen voor Bouwvoorschriften (Structural Principles for Building Structures).

VB Voorschriften Beton (Code of Practice for Concrete Structures).

NAP Normaal Amsterdams Peil (Standard Datum Amsterdam).

TUD Technische Universiteit Delft (Delft University of Technology).

TNO Nederlands Organistie voor Toegepast Natuurwetenschappelijk Onderzoek (Netherlands Organization for Applied Scientific Research).

LGM/GD Grondmechanica Delft (Delft Geotechnics). 


\section{INTRODUCTION}

\subsection{Reason for the research}

In the Netherlands the design of sea and river dykes is primarily based upon a water level with a particular frequency of being exceeded. For the sea dykes these water levels have been laid down by the Delta Commission (1960): the so-called design water levels [1.1].

The Commission on River Dykes (1977) has recommended "to have improvements made to the river dykes in such a way that they can retain water levels associated with a governing rate of discharge of $16500 \mathrm{~m}^{3} / \mathrm{s}$ of the Rhine at Lobith. This discharge is exceeded with a frequency of about $1 / 1250$ per year" [1.2]. These levels are called the "design water levels".

The exceedence frequencies of design levels and governing discharge are widely regarded as constituting a standard for the safety of the region protected by the dykes and are interpreted in terms of inundation probabilities. However, this is correct only in the theoretical case where the dyke fails as soon as the design level is exceeded, but not below that level.

The Delta Commission has clearly stated that the exceedance frequency of the design level must not be conceived as a frequency of failure. In a dyke design complying with the Delta Commission's requirements there will still be a substantial safety reserve when the design level occurs. A possible catastrophic water level will therefore certainly be higher than the design level. The Commission on River Dykes also recognizes that because of many factors involved, the probability of inundation is not determined only by the design high water level being exceeded. It states that in actual practice the dyke could well retain the governing level with an ample margin of safety, but that on the other hand the possibility of dyke failure at levels below the governing level cannot be ruled out.

If all possible causes of dyke failure at high water could be listed and the associated probabilities of their occurence be ascertained, then in principle the probability of inundation could be calculated. Because such a calculation was not feasible at the time and unlikely to become 
feasible in the foreseeable future, the Commission on River Dykes, in its consideration on the desired degree of safety against inundation, was obliged provisionally to equate the probability of inundation to the probability of the governing discharge being exceeded.

Accordingly, the exceedance probability of the rates of river discharge has been adopted in that Commission's report as the standard for judging the safety against inundation. It is acknowledged, however, that this approach is a computational device which is applied for want of something better.

In the light of what has been said above it is not surprising that the Raad van Waterstaat (Council for Civil Engineering Works), in its advisory memorandum to the Minister of Transport and Public Works on the report of the Commission on River Dykes, expresses the opinion that "it should be considered whether it is possible to arrive at a standard for safety against inundation, based on a risk analysis of all the factors involved".

The Minister submitted this matter to the Technical Advisory Committee for Dykes and Flood Defences (TAW) with the request to study it and to advise him.

First, a statement of the problem and a proposal for tackling it were formulated by a Preliminary Working Group [1.3]. Then, on 20 March 1979, the TAW decided to establish Working Group 10 "Probabilistic Method". The assigned task of this Working Group is the formulation of a new philosophy for the design of soundly conceived (i.e., safe and economical) flood defence structures. By soundly based design in this context is understood that the overall probability of failure (or collapse) is known and is sufficiently low and that the probabilities of failure of the various parts of the structure are well interadjusted. The new philosophy should be valid for dykes and flood defences in general, i.e., comprising sea and river dykes and other flood control works (including polder drainage canal embankments).

\subsection{Present design practice and its shortcomings}

As already stated in section 1.1, the present starting point for every dyke design is a water level which is exceeded with a predetermined 
frequency. The crest height of a dyke is obtained by adding a certain extra height to this level.

The safety margin should be at least so large that the amount of wave runup or overtopping will not exceed a particular stated value. If no appreciable overtopping by water is allowed, the Delta Commission recommends adopting as the criterion the wave runup which is exceeded by $2 \%$ of the number of waves. The Commission consideres that the safety margin - the extra height - needed to cope with wave runup will provide a substantial reserve of safety in the event of the design water level being exceeded. This reserve is not quantified. It is less, according as the extra height needed for runup is smaller. In order nevertheless to obtain an equivalent system for safety, it is stated that for main dykes and other flood defence works which are not exposed to appreciable wave action the minimum safety margin will have to be "at least some decimetres".

The practicle value for the safety margin is ultimately determined by extra allowances for gust oscillations and seiches and squall oscillations relative rise of sea level, settlement and subsoil consolidation. The safety margin for river dykes is determined in principle in the same way, though only with allowance for settlement and consolidation. However, in the "Recommendations for the design of River Dykes" of the TAW, the 28 wave runup criterion is not adopted. Instead, an overtopping criterion is applied, the permissible amount of overtopping being made dependent on the quality of the inner slope of the dyke. The minimum crest level for river dykes must be cater for waves due to passing vessels and for the uncertainty in the calculation of the design level. The crest level is only one of the characteristic quantities relating to the cross-sectional profile of a dyke. The other dimensions and characteristics of a dyke design (angles of slope, crest width, berms) are determined on the basis of stability requirements and requirements associated with maintenance, practicability of construction and utilization (e.g., as a base for a traffic route).

Besides the hydraulic boundary conditions, the soil mechanics parameters $\left(c^{\prime}, \phi, k, \gamma, n\right)$ play a very important part in the stability calculations. The magnitude of some of these parameters for a particular length of dyke can be determined only with a limited degree of accuracy. The factors of safety applied in the calculations are based to a great extend on experience, tradition and intuitive judgement. 
In the present design approach the required dimensions are determined always per stretch or section of dyke. The overall "dyke ring" (comprising dykes, dunes, civil engineering works, other objects) of which the section of dykes forms part, is (with a few exceptions [1.4]), left out of consideration, as are also the characteristics of the protected regions (ground level, area, number of inhabitants, invested capital). An exception to this is formed by the Delta Commission's economic reduction applied to the basic water level (exceedance frequency $10^{-4}$ per year) in order to arrive at the design level.

The shortcomings of the present design method can be summarized as follows:

- The various stretches or sections comprised in one dyke ring do not a priori provide the same degree of safety. In those cases where the lowest safety is the determining criterion, this state of affairs is, from the economic point of view, undesirable. Conversely, situations are conceivable in which the failure probability of the dyke ring is equal to the sum of the failure probabilities of the various dyke sections comprised in it. In such cases it may indeed be uneconomic to give all the elements equal safety. It is sometimes better to overdesign the "cheap" sections and to under-design the "expensive" ones a little. Present design practice completely ignores these considerations.

- Per section of dyke there is no question of a balanced design with regard to the various failure mechanisms. It is not known which of the failure mechanisms makes the greatest contribution to the probability of failure of the dyke section in question. For a soundly based design it is desirable that these contributions should be interadjusted in a well balanced manner.

- The overall length of the dyke ring is of no influence upon the design per section of dyke. But the longer the dyke ring, the weaker (depending on the degree of correlation) the weakest link is likely to be .

- The magnitude of the damage or loss is of no influence upon the design of the dyke.

- The actual probability of inundation of the region protected by a dyke ring is not known, so that there is really no clarity as to the matter on which the politicians make their pronouncements. 


\subsection{Principle of risk analysis and its advantages}

In order to judge whether a technical system (such as a dyke ring, for example) satisfies the requirements that society applies with regard to safety and economy it is possible to use risk analysis methods. An approach of this kind has already been adopted for large-scale new technical systems such as nuclear energy plants and installations for the unloading and transport of LPG.

The term "risk" comprises the probability of an undesirable event (explosion, inundation) and the consequences of the occurence of that event (e.g., economic loss, number of deaths). In formula form this is given general expression as: $r i s k$ = probability $x$ consequence ${ }^{i}$. The value 1 (unity) is usually adopted for the exponent $i$, but other values are sometimes also encountered.

By risk analysis may then be understood, the whole set of activities aimed at quantifying, on the one hand, the probability of the occurence of the undesirable event, and, on the other, the consequences of the occurence of that event.

The various uncertainties are expressed in terms of probability. This is further dealt with in Chapter 2. The advantage of such an approach is:

- The technical system "dyke ring" is analyzed and described as a whole.

- The components of the overall system and of the subsystems can be better interadjusted (less over-and under-designing).

- The various uncertainties are rationally incorporated in the assessment of the safety of the system.

- It is possible explicitly to take account of the cost of improving the system and of the damage or loss expectation per protected region; this can lead to greater differentiations of the safety within the country.

- The politicians obtain a clearer conception of the matter on which they have to make pronouncements.

- Better insight into the sensitivity of the failure probability of the system to the various uncertainties is obtained; this enables priorities to be established for further research with a view to improving the description of the system and reducing the margins of uncertainty. 
- Better insight into the priority for improving flood protection systems (or parts thereof) is obtained.

\subsection{Interim report of the study undertaken by TAW Working Group 10}

This report describes the results of the research so far carried out by Working Group 10 "Probabilistic Method" of the Technical Advisory Committee for Dykes and Flood Defences with a view to enabling readers to make their own assessments and giving wider publicity to the results - with recommendations for present-day practice, if possible - and making them accessible for discussion.

Definitions and methods of analysis and calculation which are of importance to risk analysis are described in Chapter 2.

Chapter 3 describes the effect of the failure probability calculation for a number of failure mechanisms, as also the effect of the length of a dyke section on its probability of failure.

Chapters 4 and 5 relate to the determination of the damage or loss associated with the occurence of the undesirable event: inundation. Chapter 4 outlines a method of calculating the inundation behaviour of a polder threatened by a river. Chapter 5 deals with the determination of the damage/loss for a given inundation behaviour.

Chapter 6 describes a number of criteria against which the system "dyke ring" should be assessed and concerning which the politicians must ultimately make their pronouncements.

A worked example of a calculation for a fictitious dyke ring is presented in Chapter 7 with a view to clarifying the main outline of the risk-analytical approach to dyke design and tracking down problems arising in connection with the construction of dykes.

Chapter 8 considers how the Working Group conceives its research results being applied in practice and shows how its concepts and ideas are already exerting their influence in present-day practice. 
Finally, Chapter 9 presents the conclusions drawn from this study and makes recommendations for further research.

The constitution of Working Group 10 "Probabilistic method" of the Technical Advisory Committee for Dykes and Flood Defences at the time of writing this report was as follows:

Chairman : Prof. J.F. Agema (Emiritus Professor Delft University of Technology)

Secretary: D. Dillingh (Rijkswaterstaat, Highways and Hydraulics Division)

Members : W.T. Bakker (Rijkswaterstaat, Tidal Waters Division)

E.O.F. Calle (Delft Geotechnics)
A.M. de Graauw (Public Works Department, Province of Zeeland)

A. Hoekstra (Rijkswaterstaat, Tidal Waters Division)

R.A.J. de Kock (Public Works Dept. Province of South Holland)

P.C. Mazure (Rijkswaterstaat, Highways and Hydraulics Division)

W. Meermans (Delft University of Technology)

L. de Quelerij (Rijkswaterstaat, Highways and Hydraulics Division)

A.C.W.M. Vrouwenvelder (Institute TNO for Building Materials and Structures)

J.K. Vrijling (Rijkswaterstaat, Locks and Barrages Division)

P.J.J. Willems (Public Civil Eng. Dept. of Salland)

("Rijkwaterstaat" is the Netherlands Government Public Civil Engineering Works Department) 


\section{METHODS AND DEFINITIONS}

\subsection{Elements of a risk analysis}

The study of structural safety centres on the concepts of failure and collapse. Although the two terms are commonly used as having almost identical meanings, it is useful to draw a clear distinction:

A structure fails if it can no longer perform one of its principle functions. In the case of a dyke (or other flood defence structures) this function is in general the prevention of inundation, i.e., preventing a protected region from being flooded, attended by loss of human lives and/or damage to property.

A structure or a structural component collapses if it undergoes deformations of such magnitude that the original geometry and integrity are lost. In general, collapse will be attended by a greatly increased probability of failure. It is, however, quite conceivable that collapse occurs but not failure e.g., slip affecting a dyke during a long period of low water level. The opposite may occur in the event of overtopping: the dyke fails, but does not necessarily collapse.

The purpose of the design of a flood defence structure is to obtain a structure which, during its construction and throughout its intended service life, has a sufficiently low probability of failure and of collapse. In order to achieve the best possible assessment of this, a risk analysis is performed (see Figure 2.1.1). The three main elements of the risk analysis are:

hazard - mechanisms - consequence

A risk analysis begins with the preparation of an inventory of the hazards and mechanisms. A mechanism is defined as the manner in which the structure responds to hazards. A combination of hazards and mechanisms leads, with a particular probability, to failure or collapse of the flood defence structure or of its components parts. 


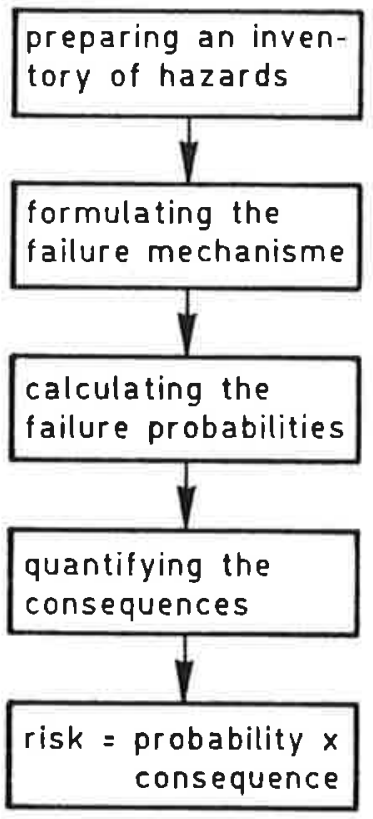

Fig. 2.1.1: Elements of the risk analysis.

The boundary between failure and non-failure, or between collapse and non-collapse, is generally called a limit state. A distinction is to be drawn between ultimate limit states (failure or collapse with regard to principal functions) and serviceability limit states (failure with regard to the other functions).

Finally, the consequences of failure or collapse must be considered. In the event of failure of the flood defence structure as a whole, the relevant inundation characteristics (inundation depth, inundation speed) must be ascertained and the material damage and non-material loss be estimated. The probability of failure multiplied by the damage or loss (= consequence) constitutes the risk. For optimal design it is essential to seek an appraisal in the sense of weighing the risk, on the one hand, against the cost of constructing a flood defence structure, on the other.

In assessing the safety of flood defence structures it is very important to consider the system as a whole. Structures are composed of many components, each of which may be prone to many hazards and mechanisms. 
Collapse of component A may in turn pose a hazard to component B. The failure of some components may lead directly to failure of the system ("series connection"); in other cases components may compensate for one another ("parallel connection"). A useful aid to establishing an ordered pattern in the many hazards, mechanisms and components is provided by diagrams such as fault trees and event trees (see Figure 2.1.2).
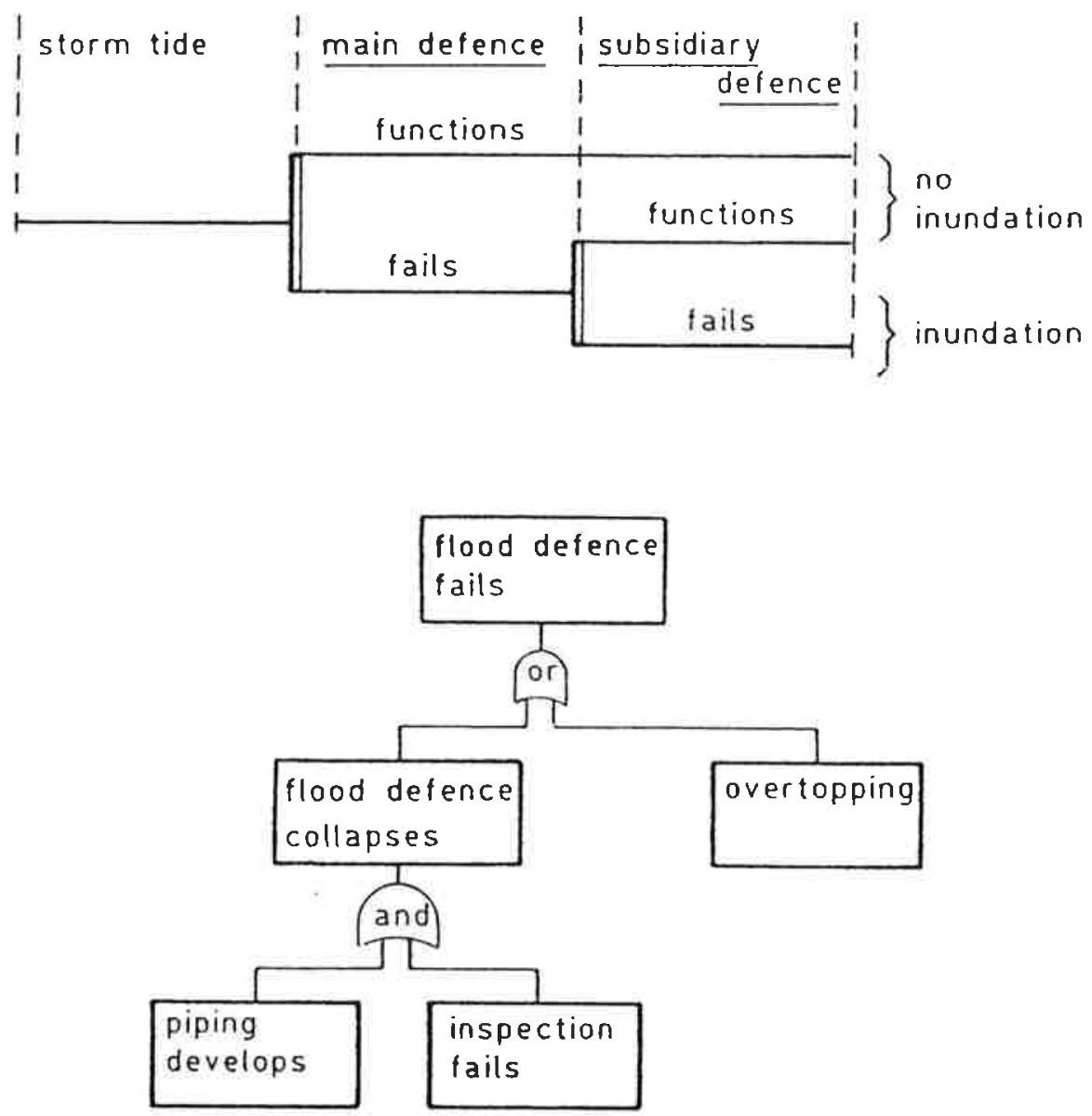

Fig. 2.1.2: Examples of an event tree (above) and a fault tree (below).

In the case of an event tree the procedure consists of going from an undesirable initial event (failure of a component, fire, human error) to the responses of the system and the consequences. A fault tree is based on the opposite procedure: starting from an undesirable event, it is analyzed how this may have been caused. In drawing a fault tree, symbols 


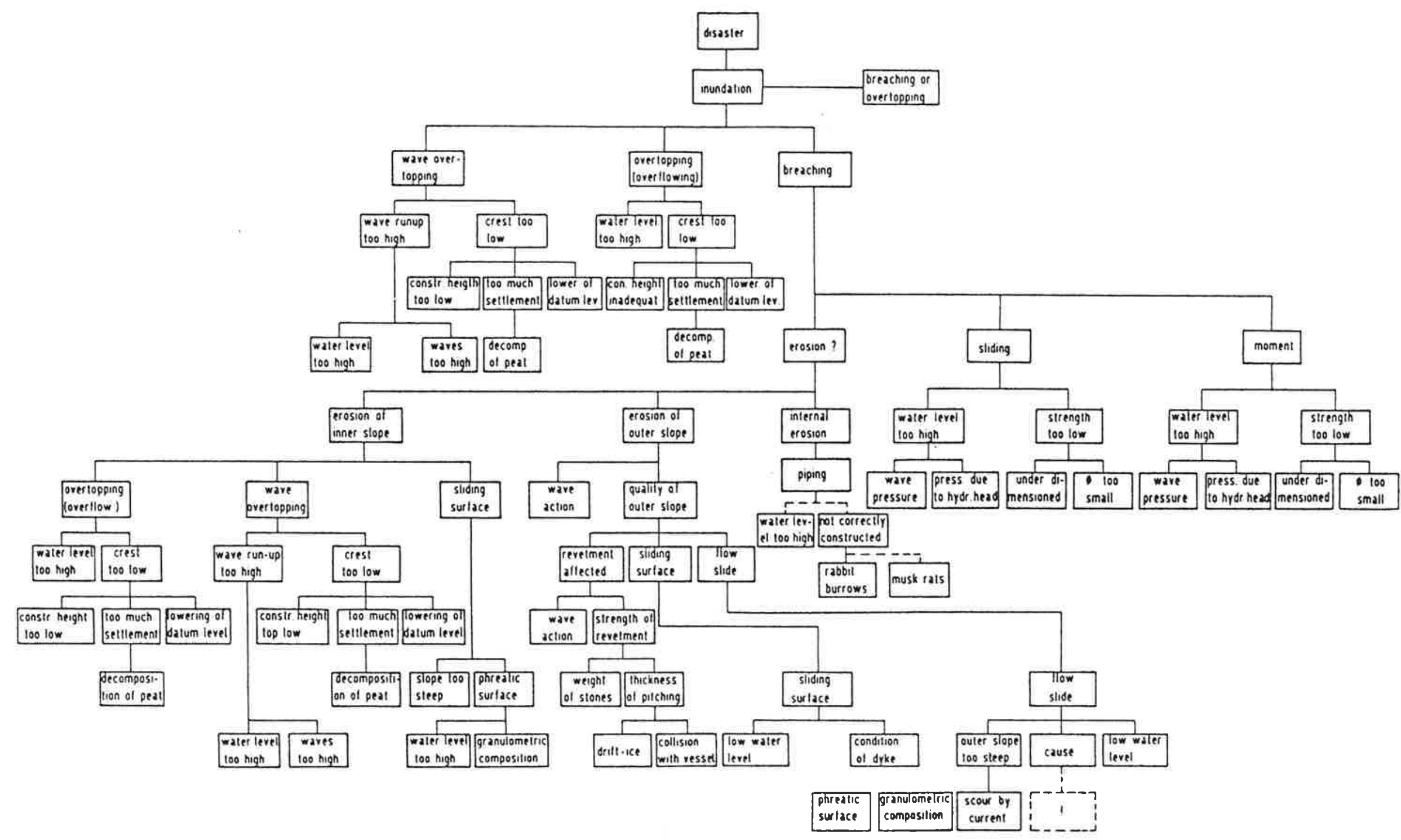

Fig. 2.1.3: Fault tree for a flood defence structure. 
such as AND gates and OR gates are used. The theory for calculating these gates is given in Section 2.4. The AND gate corresponds to the parallel system, the $O R$ gate to a series system. Figure 2.1.3 gives an example of a fault tree for a dyke or other flood defence structures in general (from [1.3]).

The drawback of event trees and fault trees is that they are rather strictly regulated. In an event tree it is in principle not permissible to combine branches, and in a fault tree no dividing of branches is possible. Furthermore, the system is essentially binary in character: an event occurs or it does not. In civil engineering, however, problems of a more continuous character are of fairly frequent occurence. An alternative to event trees and fault trees which overcomes the said objections is provided by so-called cause-consequence-charts (see Figure 2.1.4).

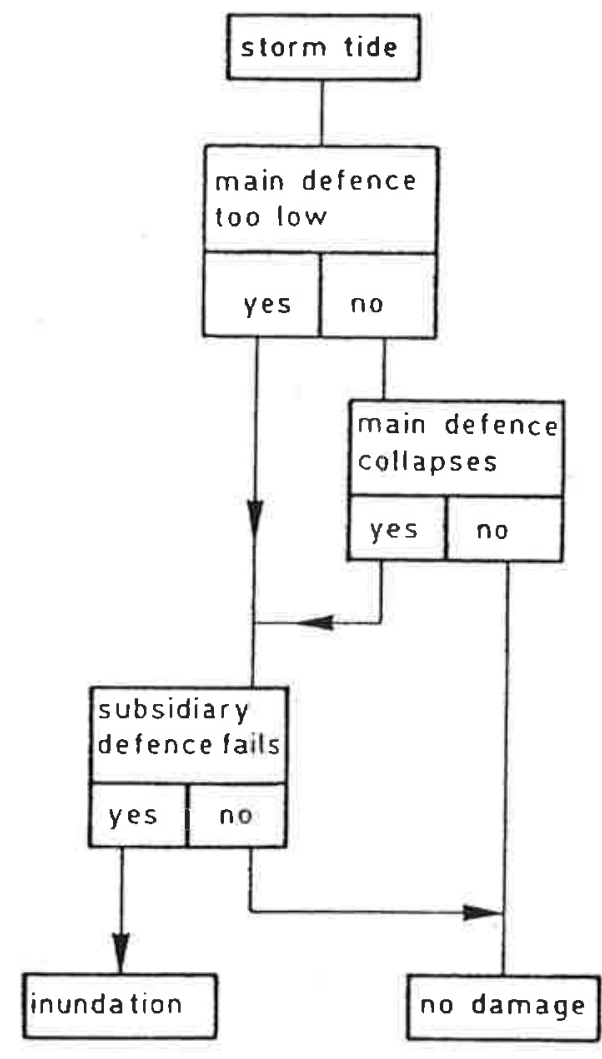

Fig. 2.1.4: Simple example of a cause-consequence-chart . 
It is noted that all the above-mentioned techniques have a recording rather than a generating function. Conceiving what can go wrong, and how it can go wrong, remains the designer's responsibility - and a very important one. It is often considered that thinking of a hazard or a mechanism is of greater importance then the whole analysis that then follows. Aids in preparing an inventory of causes of failure are data banks, literature studies, interviews, study of actual instances of damage, brainstorm sessions, experience with similar structures, etc. For commonly encountered structures most hazards and mechanisms are recorded in guidelines and manuals.

In principle, there are two approaches in ascertaining the probability of failure due to a particular mechanism. One approach is to make a direct estimate of the probability on the basis of experience and intuition. Alternatively, a probabilistic calculation of the failure probability may be performed. For this purpose it is necessary to have a computational model of the mechanism. On the basis of that model a socalled reliability function $Z$ is established with regard to the limit state considered, in such a way that negative values of $\mathrm{Z}$ correspond to failure and positive values to non-failure (see figure 2.1.5). The probability of failure can thus be represented symbolically as $P(Z<0)$. The reliability function is a function of a number of variables, such as

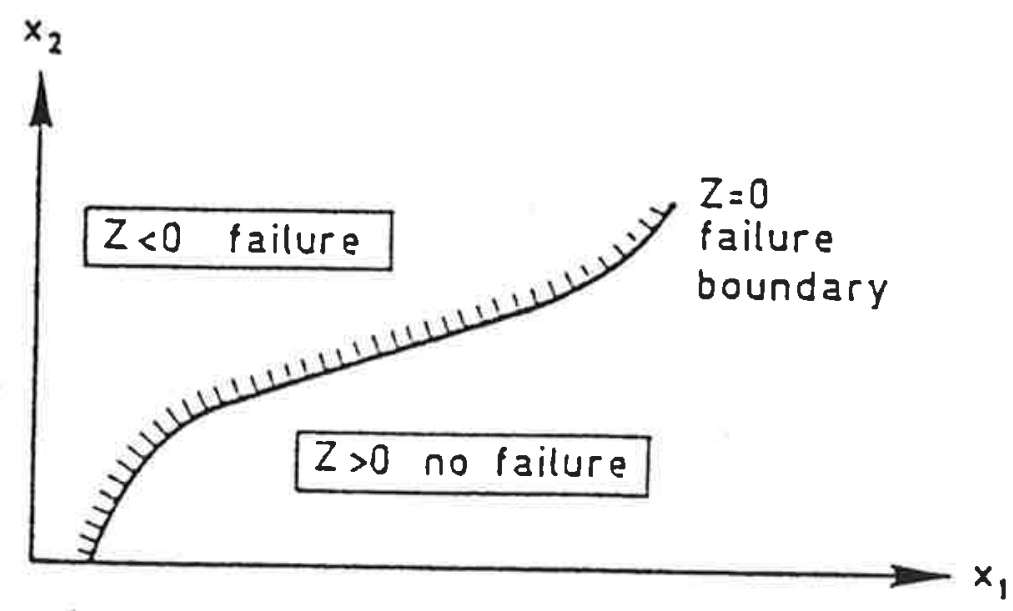

Fig. 2.1.5: Definition of a failure boundary $z-0$. 
the water level, the crest height, the angle of internal friction, etc. The variables with a stochastic character are usually called the basic variables.

There are various techniques available for determining the probability of failure for a given reliability function and given statistical characteristics of the basic variables. For classifying these techniques the following levels are to be distinguished:

Level III: Comprises calculations in which the complete probability density functions of the stochastic variables are introduced and the possibly non-linear character of the reliability function is exactly taken into account.

Leve1 II: Comprises a number of approximate methods in which the problem is linearized and all probability density functions are replaced by probability density functions of normal distributions.

Level I: Comprises calculations based on characteristic values and (partial) safety factors or safety margins.

Strictly speaking a calculation at level I does not involve failure probabilities. It does, however, provide a method of checking whether a defined level of safety is satisfied. This type of calculation is more particularly suitable for everyday design practice. The various levels and their interrelation will be dealt with in Section 2.2.

\subsection{Calculations at level III, II and I}

In many cases the failure of a structure can be reduced to comparing two quantities: the resistance or strength $\mathrm{R}$ and the load or action effect $S$. The reliability function can then be written as:

$\mathrm{Z}=\mathrm{R}-\mathrm{S}$ 
At level III (if $R$ and $S$ are independent) the probability of failure is given by the formula (see also Figure 2.2.1):

$P\{Z<0\}=\iint_{r<S} f_{R}(r) f_{S}(s) d r d s$

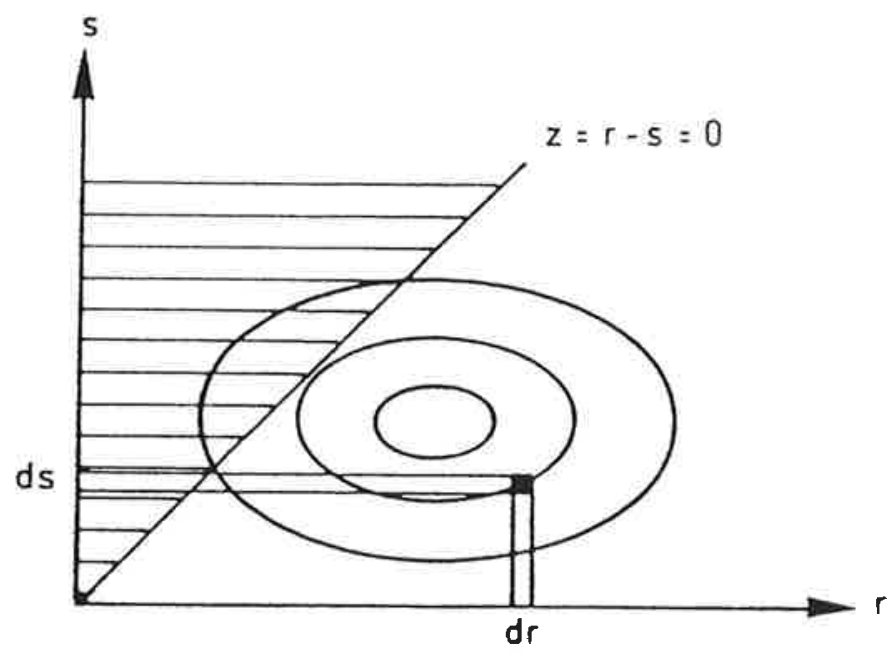

Fig. 2.2.1: "Contour map" for the product $f_{R}(r) f_{S}(s)$;

the hatched area is the failure domain $r<s$.

Here $f_{R}(r)$ is the probability density function of $R$ and $f_{S}(s)$ is the probability density function of $S$. The product $f_{R}(r) f_{S}(s)$ dr ds represents the probability that $R$ is situated between $r$ and $r+d r$, while $S$ at the same time is situated between $s$ and $s+d s$. The probability of failure is then obtained by adding together (integrating) all probabilities of combinations with "strength lower than load".

The double integral in formula (2.2.2) can, by partial integration, be reduced quite simply to a single integral:

$$
\begin{gathered}
P(Z<0\}=\int_{0}^{\infty}\left\{\int_{0}^{s} f_{R}(r) d r\right) f_{S}(s) d s- \\
\int_{0}^{\infty} F_{R}(s) f_{S}(s) d s
\end{gathered}
$$

where $F_{R}(s)$ is the cumulative distribution function for the strength $R$. Similarly, by partial integration with respect to $s$ we obtain: 
$P(Z<0\}=\int_{0}^{\infty}\left\{1-F_{S}(r)\right\} f_{R}(r) d r$

Which formulation is to be chosen may be made dependent on the nature of the problem. Usually $R$ and $S$ are in turn functions of other (basic) variables, as indicated in Figure 2.2.2. The reliability function in general form is then expressed by:

$z=z\left(x_{1}, x_{2}, \ldots x_{n}\right)$

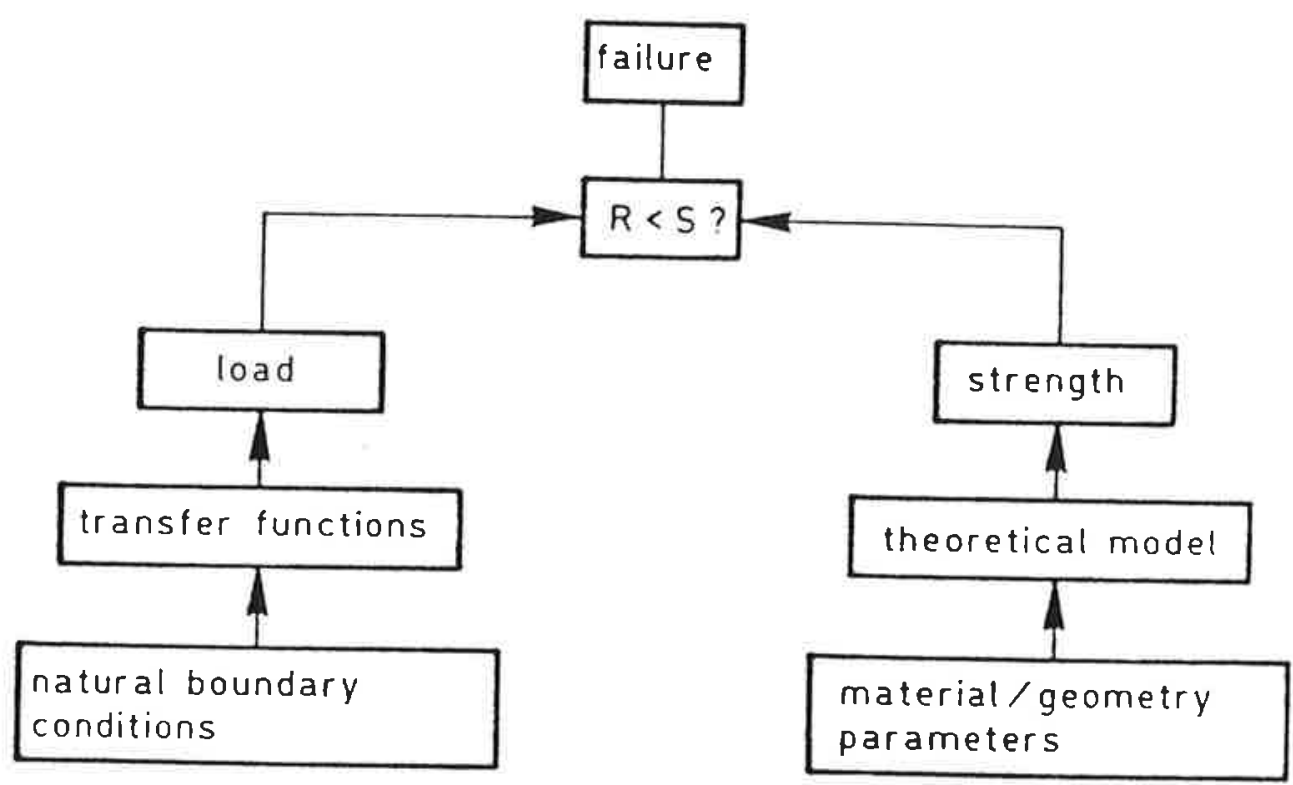

Fig. 2.2.2: General reliability problem.

For this general case the equivalent of formula (2.2.2) is:

$$
\begin{aligned}
& P(Z<0\}=\iint \ldots \int \prod_{i=1}^{n} f_{X_{i}}\left(x_{i}\right) d x_{i} \\
& Z(\underline{x})<1
\end{aligned}
$$

The variables $x_{i}$ are assumed to be independent. Formula (2.2.6) shows that determining a probability failure at level III comes down to calculating an $n$-fold integral, $n$ being the number of stochastic variables. Even with the help of modern computers this is found to be 
too unwieldy a problem, however, if $n$ exceeds 5 or 6 . In some cases it is possible to tackle the problem with a Monte Carlo simulation (especially when dealing with simple reliability functions and not-toolow failure probabilities). Mostly, however, it is advisable to have recourses to approximations at level II.

For an introduction to the calculations at level II, consider again a simple reliability function $Z-R-S$ according the formula (2.2.1). For a full treatment of the method the reader is referred to the literature $[2.1,2.2,2.3,2.4]$. Here it will be dealt with only in brief outline. Suppose that $R$ and $S$ both have normal distributions. From probability theory it is known that $Z$ then also has a normal distribution. The mean value and the standard deviation of $\mathrm{Z}$ can be obtained from:

$$
\begin{aligned}
& \mu(Z)=\mu(R)-\mu(S) \\
& \sigma^{2}(Z)=\sigma^{2}(R)+\sigma^{2}(S)
\end{aligned}
$$

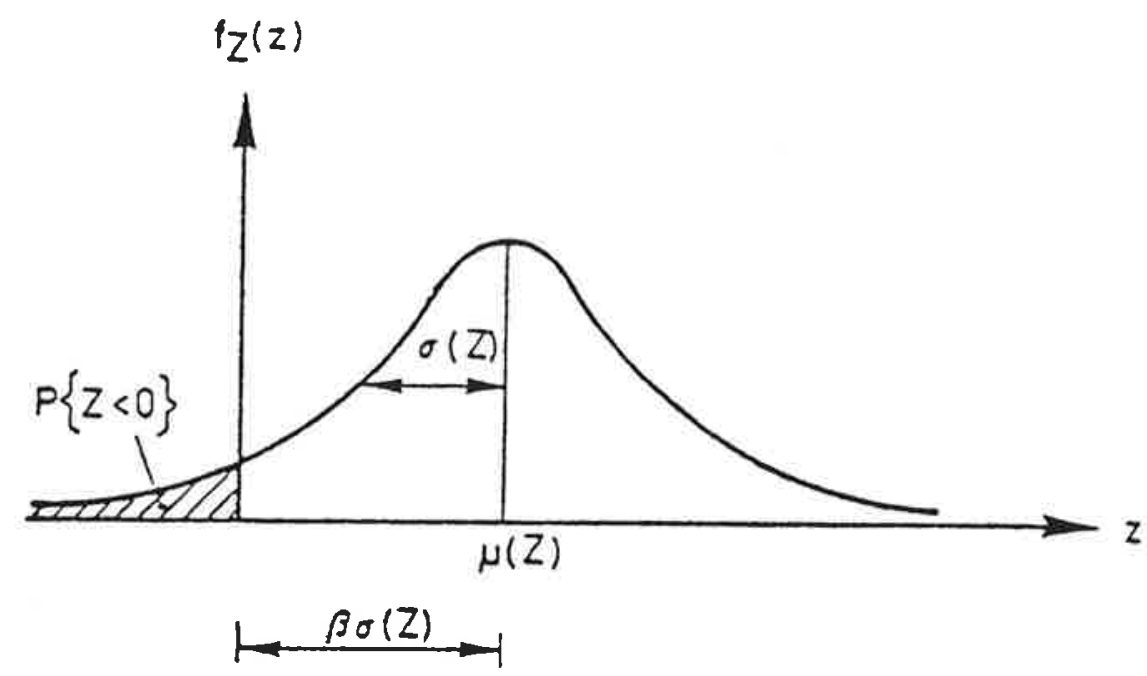

Fig. 2.2.3: Probability density function of the reliability function $\mathrm{Z}=\mathrm{R}$ - S; definition of the reliability index $\beta$. 
The probability of failure of the structure then follows from (see also Figure 2.2.3):

$P\{Z<0\}=\int_{-\infty}^{0} f_{Z}(z) d z=\Phi_{N}(-\beta)$

$\beta=\mu(\mathrm{Z}) / \sigma(\mathrm{Z})$

where $f_{Z}(z)$ is the probability density function of $z, \Phi_{N}(-\beta)$ is the distribution function of the standard normal distribution, and $\beta$ is the so-called reliability index. The function $\Phi_{N}(-\beta)$ must be looked up in Table 2.2.1. For values of $\beta>2$ a good approximation of $\Phi_{N}(-\beta)$ is:

$\Phi_{\mathrm{N}}(-\beta)=\frac{1}{\beta \sqrt{ }(2 \pi)} \exp \left\{-\frac{\beta^{2}}{2}\right\}$

Note that, apart form the possible use of formula (2.2.11), the level II analysis yields an exact answer for the case under consideration.

In the general case, $\mathrm{Z}$ is an arbitrary function of $\mathrm{n}$ stochastic variables $x_{i} \ldots x_{n}$. Suppose that the variables $x_{i}$ are mutually independent and that the mean values and standard deviations are known. The central feature of the level II analysis is the linearization of the function $z$. Suppose that linearization is based on expansion in a Taylor series at a point $\mathrm{x}_{i}=\mathrm{x}_{i}^{0}$ :

$z=z^{0}+\sum_{i=1}^{n}\left(x_{i}-x_{i}^{0}\right)\left(\frac{\partial z}{\partial x_{i}}\right)^{0}$

where $z^{0}$ is the function value of $z$ at the point $x_{i}=x_{i}^{0} ;\left(\partial z / \partial x_{i}\right)$ is the partial derivative with respect to $x_{i}$, likewise evaluated at the point $x_{i}=x_{i}^{0}$. The mean value and the standard deviation of $z$ are then:

$\mu(z)=z^{0}+\sum_{i=1}^{n}\left(\mu\left(x_{i}\right)-x_{i}^{0}\right)\left(\frac{\partial z}{\partial x_{i}}\right)^{0}$

$\sigma^{2}(\mathrm{Z})=\sum_{i=1}^{\mathrm{n}}\left(\sigma\left(\mathrm{X}_{\mathrm{i}}\right)\left(\frac{\partial \mathrm{Z}}{\partial \mathrm{X}_{i}}\right)^{0}\right\}^{2}$ 
Table 2.2.1: Cumulative distribution function for the standard normal distribution.

\begin{tabular}{|ll|cl|ll|}
\hline$\beta$ & $\Phi_{\mathrm{N}}(-\beta)$ & $\beta$ & $\Phi_{\mathrm{N}}(-\beta)$ & $\beta$ & $\Phi_{\mathrm{N}}(-\beta)$ \\
\hline 0.0 & 0.50 & & & & \\
0.1 & 0.46 & 1.1 & 0.14 & 2.1 & $0.18 \times 10^{-1}$ \\
0.2 & 0.42 & 1.2 & 0.13 & 2.2 & 0.14 \\
0.3 & 0.38 & 1.3 & 0.10 & 2.3 & 0.11 \\
0.4 & 0.34 & 1.4 & $0.81 \times 10^{-1}$ & 2.4 & $0.82 \times 10^{-2}$ \\
0.5 & 0.31 & 1.5 & $0.67 \times 10^{-1}$ & 2.5 & 0.62 \\
0.6 & 0.27 & 1.6 & $0.55 \times 10^{-1}$ & 2.6 & 0.47 \\
0.7 & 0.24 & 1.7 & $0.45 \times 10^{-1}$ & 2.7 & 0.35 \\
0.8 & 0.21 & 1.8 & $0.36 \times 10^{-1}$ & 2.8 & 0.26 \\
0.9 & 0.18 & 1.9 & $0.29 \times 10^{-1}$ & 2.9 & 0.19 \\
1.0 & 0.16 & 2.0 & $0.23 \times 10^{-1}$ & 3.0 & 0.13 \\
\hline
\end{tabular}

\begin{tabular}{|cl|cl|cl|}
\hline$\beta$ & $\Phi_{\mathrm{N}}(-\beta)$ & $\beta$ & $\Phi_{\mathrm{N}}(-\beta)$ & $\beta$ & $\Phi_{\mathrm{N}}(-\beta)$ \\
\hline 3.1 & $0.97 \times 10^{-3}$ & 4.1 & $0.21 \times 10^{-4}$ & 5.1 & $0.17 \times 10^{-6}$ \\
3.2 & 0.67 & 4.2 & 0.13 & 5.2 & 0.10 \\
3.3 & 0.48 & 4.3 & $0.79 \times 10^{-5}$ & 5.3 & $0.58 \times 10^{-7}$ \\
3.4 & 0.33 & 4.4 & 0.48 & 5.4 & 0.33 \\
3.5 & 0.23 & 4.5 & 0.34 & 5.5 & 0.19 \\
3.6 & 0.16 & 4.6 & 0.21 & 5.6 & 0.11 \\
3.7 & 0.11 & 4.7 & 0.13 & 5.7 & $0.60 \times 10^{-8}$ \\
3.8 & $0.72 \times 10^{-4}$ & 4.8 & $0.79 \times 10^{-6}$ & 5.8 & 0.33 \\
3.9 & 0.48 & 4.9 & 0.48 & 5.9 & 0.18 \\
4.0 & 0.32 & 5.0 & 0.29 & 6.0 & $0.99 \times 10^{-9}$ \\
& & & & & \\
\hline
\end{tabular}


The probability of failure is again expressed by:

$P\{Z<0\}=\int_{-\infty}^{0} f_{Z}(z) d z=\Phi_{N}(-\beta)$

$\beta=\mu(Z) / \sigma(Z)$

If the mean values of $x_{i}$ are adopted for $x_{i}^{0}$, a so-called mean value approximation is obtained. A more accurate approximation, however, is obtained by putting $x_{i}^{0}$ equal to the design point, which is defined as that point on the failure boundary where the probability density attains a maximum (see Figure 2.2.4). The design point is given by:

$$
\begin{aligned}
& \mathrm{x}_{i}^{0}=\mu\left(\mathrm{X}_{i}\right)-\alpha_{i} \beta \sigma\left(\mathrm{X}_{i}\right) \\
& \alpha_{i}=\frac{\sigma\left(\mathrm{X}_{i}\right)}{\sigma(\mathrm{Z})} \frac{\partial \mathrm{Z}}{\partial \mathrm{X}_{i}}
\end{aligned}
$$

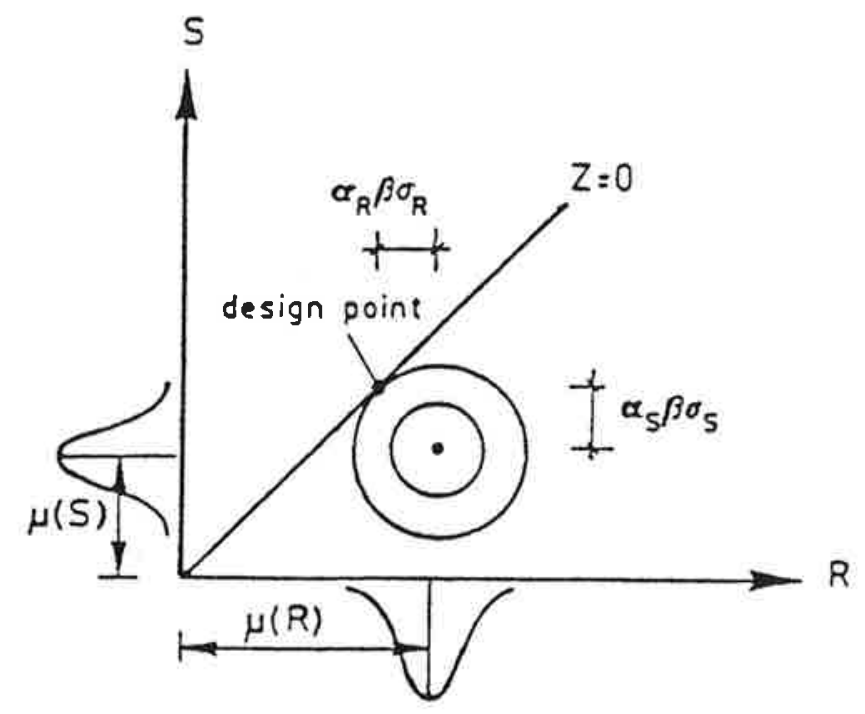

Fig. 2.2.4: Definition of the design point as the point on the fallure boundary where the probability density is greatest.

However, the prublem is that the design point cannot be directly determined (except if $\mathrm{Z}$ is linear) and that therefore an iterative procedure must be applied. A simple iteration scheme for the purpose is as follows: 
(1) Start with $\mathrm{x}_{\mathrm{i}}^{\mathrm{o}}=\mu\left(\mathrm{X}_{\mathrm{i}}\right)$ (mean value).

(2) Calculate $\mu(Z)$ and $\sigma(Z)$.

\{3\} Determine $\beta$

\{4\} Determine $x_{i}^{o}$.

(5) Repeat steps (2) to (4) until convergences has been attained.

(6) Check that $\mathrm{z}^{\mathrm{O}} \approx 0$.

(7) Determine $P(Z<0)$.

This method works satisfactorily so long as $\mathrm{Z}$ is not too markedly nonlinear.

Finally, it is to be noted that there are two different methods of treating variables with non-normal distributions. The more usual procedure consists in replacing the non-normal distributions by equivalent normal distributions for which the values of the density function and distribution functions at the point $x_{i}^{o}$ are the same (Figure 2.2.5).

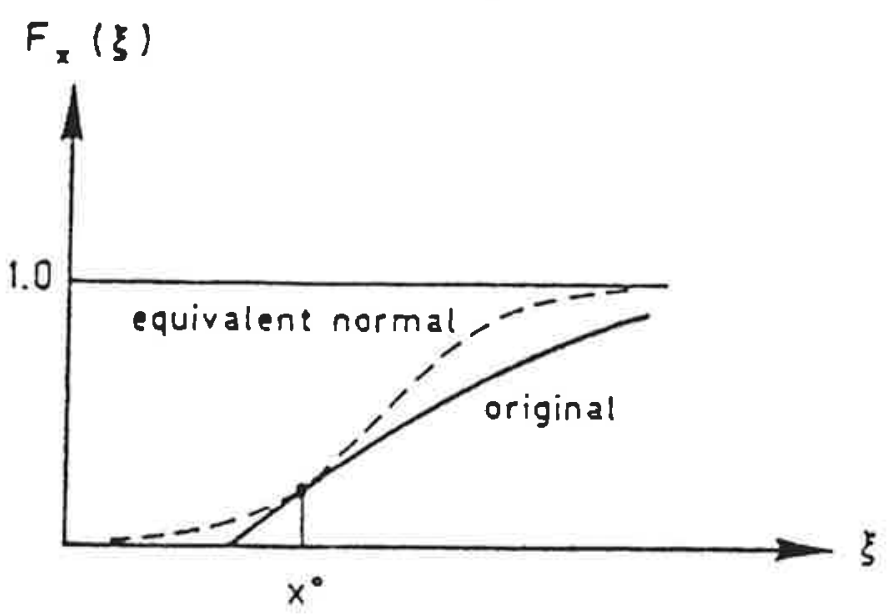

Fig. 2.2.5: A non-normal distribution (solid line) can be replaced by a normal distribution with the same mean value for the distribution function $F$ and the same value for the density function $\mathrm{f}=\mathrm{dF} / \mathrm{dx}$ at the design point $\xi=\mathrm{X}^{\mathrm{O}}$.

Often, however, it is more. convenient to work with formal transformations in such a manner that $Z$ becomes a function of solely normal basic variables. A simple example is a log-normally distributed $X$. Log- 
normal means that $\mathrm{Tn} X$ has a normal distribution and that $\mathrm{X}$ can therefore be replaced by $\exp (Y)$, where $Y$ has a normal distribution.

Besides the calculations at level III and level II there are those at leve1 I. For the basic case (strength $\mathrm{R}$, load $\mathrm{S}$ ) the minimum requirement applied to a structure at level $I$ is that the following condition is satisfied:

$\frac{\mathrm{R}_{\mathrm{k}}}{\gamma_{\mathrm{m}}}>\gamma_{\mathrm{s}} \mathrm{s}_{\mathrm{k}}$

where $R_{k}$ and $S_{k}$ are so-called characteristic values for the strength and load respectively, while $\gamma_{m}$ and $\gamma_{s}$ are partial safety factors ("partial" signifies: to be determined separately per variable). The characteristic values are defined as:

$\mathrm{R}_{\mathrm{k}}=\mu(\mathrm{R})-\mathrm{k}_{\mathrm{R}} \sigma(\mathrm{R})$

$S_{k}=\mu(S)-k_{S} \sigma(S)$

In the design of steel and concrete structures it is usual to adopt $\mathrm{k}_{\mathrm{H}}=$ 1.64 and $k_{S} \simeq 0$, but other values may also be chosen. It is only important to know with what fractile point a load or strength corresponds in the statistical distribution.

The key to the relation between levels I and II is the so-called design point. This is defined as the point on the failure boundary where the probability density of $R$ and $S$ has its maximum. In other words, if $a$ structure collapses, there is a high probability that the strength $\mathrm{R}$ and load $S$ are close to the design point values $R^{\circ}$ and $S^{\circ}$. A probabilistically inspired requirement is therefore:

$R^{\circ}>S^{\circ}$

On comparing formula (2.2.22) with formula (2.2.19) it follows that the relation between levels I and II is given by:

$\gamma_{\mathrm{m}}=\mathrm{R}_{\mathrm{k}} / \mathrm{R}^{\circ} ; \gamma_{\mathrm{S}}=\mathrm{S}^{0} / \mathrm{S}_{\mathrm{k}}$ 
With reference to formula (2.2.17), $\mathrm{R}^{\mathrm{O}}$ and $\mathrm{S}^{\circ}$ are given by:

$\mathrm{R}^{\circ}=\mu(\mathrm{R})-\alpha_{\mathrm{R}} \beta \sigma(\mathrm{R})$

$\mathrm{S}^{\circ}=\mu(\mathrm{S})-\alpha_{\mathrm{S}} \beta c(\mathrm{~S})$

By substituting the formulae for the characteristic values and the design point values the expressions comprised in formula (2.2.23) can be written as follows:

$\gamma_{\mathrm{m}}=\frac{1-\mathrm{k}_{\mathrm{R}} \mathrm{v}_{\mathrm{R}}}{1-\alpha_{\mathrm{R}} \beta \mathrm{v}_{\mathrm{R}}} \quad \gamma_{\mathrm{S}}=\frac{1-\alpha_{\mathrm{S}} \beta \mathrm{v}_{\mathrm{S}}}{1-\mathrm{k}_{\mathrm{S}} \mathrm{v}_{\mathrm{S}}}$

where $V$ is the coefficient of variation:

$\mathrm{V}_{\mathrm{R}}=\sigma(\mathrm{R}) / \mu(\mathrm{R}) \quad \mathrm{V}_{\mathrm{S}}=\sigma(\mathrm{S}) / \mu(\mathrm{S})$

In general a partial factor will be greater according as:

a) the influence coefficient $\alpha$ is greater;

b) the desired reliability level $\beta$ is higher;

c) the uncertainty $\mathrm{V}$ is greater.

The factor ( 1 - $k V$ ) provides a correction for that part of the safety which has already been accomodated in the characteristic value.

The formulae (2.2.24) contain the influence coefficients $\alpha_{R}$ and $\alpha_{S}$. With the aid of formula (2.2.18) it can readily be shown that for $\mathrm{Z}=\mathrm{R}$ - $\mathrm{S}$ the following holds:

$\alpha_{\mathrm{R}}=\sigma_{\mathrm{R}} / \sigma_{\mathrm{Z}}$ and $\alpha_{\mathrm{S}}=-\sigma_{\mathrm{S}} / \sigma_{\mathrm{Z}}$ with $\sigma_{\mathrm{Z}}=\sqrt{(}\left(\sigma_{\mathrm{R}}^{2}+\sigma_{\mathrm{S}}^{2}\right)$

The problem is that $\alpha_{R}$ (and therefore $\gamma_{R}$ is, via $\sigma_{Z}$ dependent on $\sigma \mathrm{S}$ and that $\alpha_{S}$ (and therefore $\gamma_{S}$ ) is dependent on $\sigma_{R}$. Hence it is unfortunately not possible to establish load factors which are independent of the strength variation, and vice versa. In practice this problem is solved by adopting for large classes of cases always the same values of $\alpha$ and $\gamma$. The values should be determined in $s u c h$ a way that 
the deviations from the desired level of safety is minimal. The desired level of safety $\beta$ itself is usually determined by considering relevant structures as they were designed in the past (calibration). In connection with this the assumption is that the average level of safety of existing structures is reasonably good and that only a greater measure of balance in the design must be aimed at.

Just as for the calculations at level II, so also at level I there are in the reliability analysis more stochastic variables than only $R$ and $S$. In the general case a partial safety factor can be derived for each stochastic basic variable, as follows:

$\gamma_{i}=x_{i}^{0} / x_{k i} \quad$ or $\quad \gamma_{j}=x_{k j} / x_{j}^{0}$

The first formulation relates to load quantities, the second to strength quantities. The check for safety is applied by requiring fulfilment of the condition:

$z\left\{\gamma_{i} x_{k i}, \frac{x_{k j}}{\gamma_{j}}\right\}>0$

For practical purposes, however, the approach will consist, not in introducing a partial safety factor for each stochastic variable, but in making combinations, because otherwise the number of factors would become unmanagable large. Consider by way of example the plastic moment of resistance of a steel girder, which is expressed by $M_{P}=m W_{p} \sigma_{p}$, where $m$ is a model uncertainty factor, $W_{p}$ the plastic section modulus and $\sigma_{p}$ the yield stress. Instead of three partial factors (one for each of the three variables), one combined factor is employed, defined as follows :

$\gamma_{\mathrm{m}}=\mathrm{W}_{\mathrm{pn}} \sigma_{\mathrm{pk}} /\left(\mathrm{m}^{\circ} \mathrm{w}_{\mathrm{p}}^{\circ} \sigma_{\mathrm{p}}^{\circ}\right)$

where $W_{p n}$ is the nominal (tabulated) value for the plastic section modulus and $\sigma_{\mathrm{pk}}$ is the characteristic yield stress.

Of course, in further working out the design it will be necessary to take account of many other points, such as the time-dependence and 
position-dependence of loads, long-term effects, etc. To go into these aspects would be outside the scope of this report.

\subsection{Series systems and paralle1 systems}

As an introduction to the theory of the safety of systems, in this section the series system and the parallel system will be considered (see Figure 2.3.1).
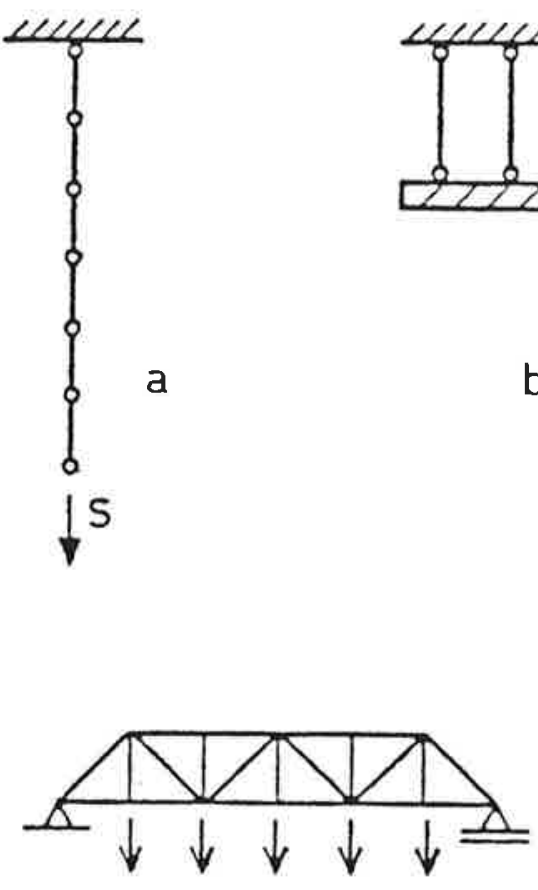

a

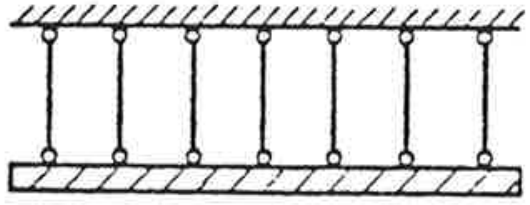

$\downarrow^{5}$

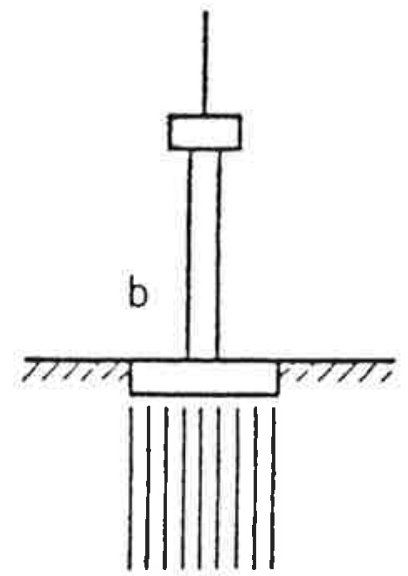

Fig. 2.3.1: Examples of series systems (a) and parallel systems (b).

In a series system the elements are so arranged that the collapse of any one part immediately leads to collapse of the whole system. An example of such a system is a statically determinated truss. In a parallel system it is possible that failure of one element will be compensated by 
other elements. A piled foundation with a large number of piles is an example of such a system.

A series system of two elements will fail as soon as one of the two elements is unable to resist the load sufficiently. In formal notation:

$\mathrm{P}\{$ system fails $\}=\mathrm{P}\left\{\mathrm{Z}_{1}<0\right.$ or $\left.\mathrm{z}_{2}<0\right\}$

$z_{1}$ and $z_{2}$ denote the reliability functions of the first and the second element respectively. Alternatively formula (2.3.1) can be written as follows:

$\mathrm{P}\{$ system fails $\}=\mathrm{P}\left\{\mathrm{Z}_{1}<0\right\}+\mathrm{P}\left\{\mathrm{z}_{2}<0\right\}-\mathrm{P}\left\{\mathrm{z}_{1}<0\right.$ and $\left.\mathrm{z}_{2}<0\right\}$

It can readily be seen that the failure probability of the series system is always higher than the failure probability of the individual elements, but lower than the sum:

$\max P\left\{Z_{1}<0\right\}<P\{$ system fails $\}<P\left\{Z_{1}<0\right\}+P\left\{Z_{2}<0\right\}$

A special case occurs when $z_{1}<0$ and $z_{2}<0$ are independent events:

$P\{$ system fails $\}=P\left(z_{1}<0\right\}+P\left(z_{2}<0\right\}-P\left\{z_{1}<0\right\} \cdot P\left(z_{2}<0\right\}$

If an accurate estimate is required for other cases, a level III analysis may be considered or an approximate formula be used. Nearly all approximations presuppose $\mathrm{z}_{1}$ and $\mathrm{z}_{2}$ to be normally distributed and make use of the correlation coefficient $\rho$ (while $-1 \leq \rho \leq+1$ and $\rho-0$ corresponds to independence).

The formula for determining $\rho$ in accordance with a level II approach is given here without its derivation:

$$
\rho\left(z_{1}, z_{2}\right)=\sum_{i=1}^{n} \alpha_{i}^{(1)} \alpha_{i}^{(2)}
$$


In this formula $\alpha_{i}{ }^{(1)}$ is the $\alpha$-value of $z_{1}$ associated with the variable $x_{i}$ according to formula (2.2.18), and similarly for $\alpha_{i}{ }^{(2)}$. All $x_{i}$ are assumed to be independent. It appears that independence can accur only if the same basic variables are present in $z_{1}$ and $z_{2}$; otherwise it follows that $\rho=0$. The best-known approximation formula for $P\left\{Z_{1}<0\right.$ and $\left.z_{2}<0\right\}$ is that of Ditlevsen $[2.1,2.5]$ :

$\mathrm{P}\left\{\mathrm{z}_{1}<0\right.$ and $\left.\mathrm{z}_{2}<0\right\} \geq \max \left(\Phi_{\mathrm{N}}\left(-\beta_{1}\right) \Phi_{\mathrm{N}}\left(-\beta *_{2}\right), \Phi_{\mathrm{N}}\left(-\beta *_{1}\right) \Phi\left(-\beta_{2}\right)\right\}$

$P\left(Z_{1}<0\right)$ and $\left.Z_{2}<0\right\} \geq \Phi_{N}\left(-\beta_{1}\right) \Phi_{N}\left(-\beta *_{2}\right)+\Phi_{N}\left(-\beta \star_{1}\right) \Phi_{N}\left(-\beta_{2}\right)$

$\beta_{i}^{*}=\left(\beta_{i}-\rho \beta_{j}\right) / \sqrt{ }\left(1-\rho^{2}\right)$

In Figure 2.3.2 the failure probability of the system is given as a function of $\rho$, together with the approximations according to Ditlevsen. Formula (2.3.7) is found to provide a good approximation in the whole domain. It is found, too, that in very many cases the system failure probability is satisfactorily approximated by the sun of the two failure probabilities.

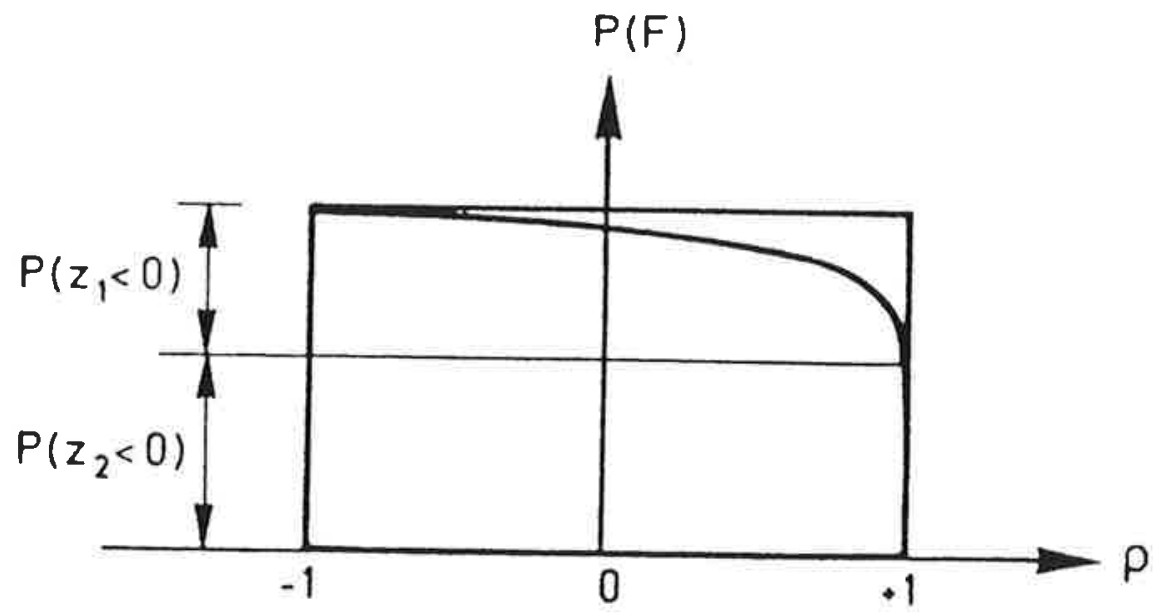

Fig. 2.3.2. Failure probability of a series system of two elements as a function of $\rho$. 
Another approximation is that given by stevenson-Moses [2,6]. Its principle is given by:

$$
\begin{aligned}
\mathrm{P}\left\{\mathrm{z}_{1}<0 \text { and } \mathrm{z}_{2} \div 0\right\} & =\mathrm{P}\left\{\mathrm{Z}_{1}<0\right\} . \mathrm{P}\left\{\mathrm{z}_{2}<0 \mid \mathrm{Z}_{1}<0\right\} \\
& \simeq \mathrm{P}\left\{\mathrm{Z}_{1}<0\right\} . \mathrm{P}\left\{\mathrm{z}_{2}<0 \mid \mathrm{Z}_{1}=\mu_{1}^{-}\right\}
\end{aligned}
$$

The expression after the sign of equality $(\Rightarrow)$ is exact. The value $\mu_{1}^{-}$is the mean of $z_{1}$ in the domain $z_{1}<0$ (see Figure 2.3.3):

$\mu_{1}^{-}-\frac{1}{\mathrm{P}\left(\mathrm{Z}_{1}<0\right)} \int_{-\infty}^{\infty} \xi \mathrm{f}_{\mathrm{Z}_{1}}(\xi) \mathrm{d} \xi$

This method will be applied in the worked example in Chapter 7.

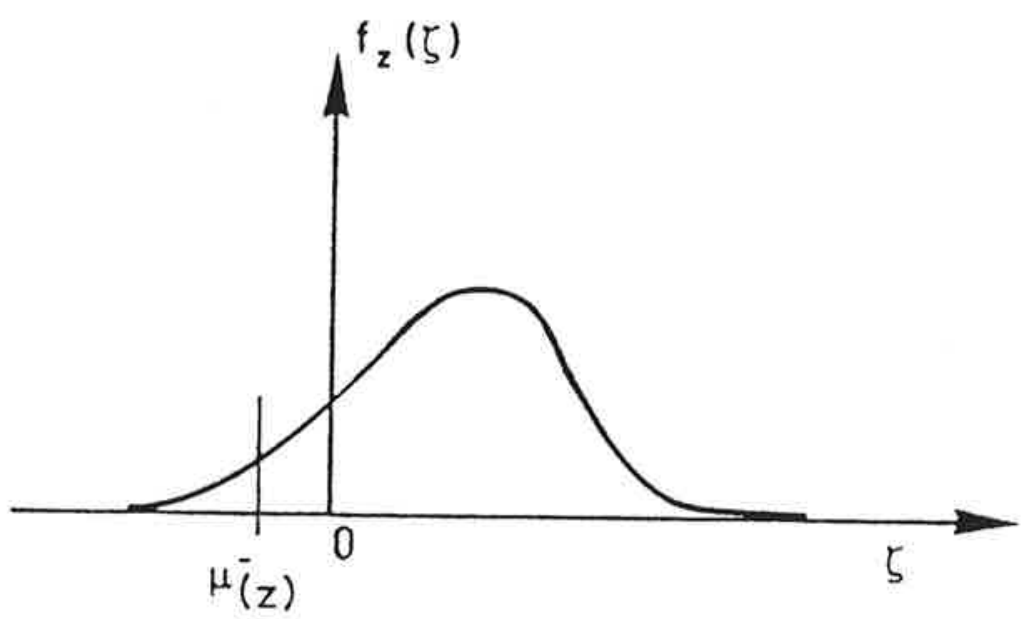

Fig. 2.3.3: The mean value of $\mathrm{z}$ in the domain $\mathrm{Z}<0$.

For a series system with $n$ elements the probability of failure is:

$\mathrm{P}$ (system fails $\}=\mathrm{P}\left\{\mathrm{Z}_{1}<0\right.$ or $\mathrm{Z}_{2}<0$ or $\left.\ldots \mathrm{Z}_{\mathrm{n}}<0\right\}$

The upper and lower bounds in this case are given by: 
$\max P\left(z_{i}<0\right) \geq P($ system fails $) \geq \Sigma P\left(Z_{i}<0\right\}$

The case where there is independence between all mechanisms $z_{i}<0$ can most simply be analysed by considering the probability of non-failure:

$P($ system does not fail $)=P\left\{z_{1}>0\right.$ and $z_{2}>0$ and $\left.\ldots z_{n}>0\right\}=$

$$
-P\left\{z_{1}>0\right\} \cdot P\left\{z_{2}>0\right\} \ldots P\left\{z_{n}>0\right\}
$$

$\mathrm{P}$ (system fails)

$$
=1-\prod_{i=1}^{n}\left[1-P\left\{z_{i}<0\right\}\right]
$$

If all failure probabilities are equal, then:

$$
P(\text { system fails })-1-\left[1-P\left(z_{1}<0\right)\right]^{n}
$$

$P(F)$

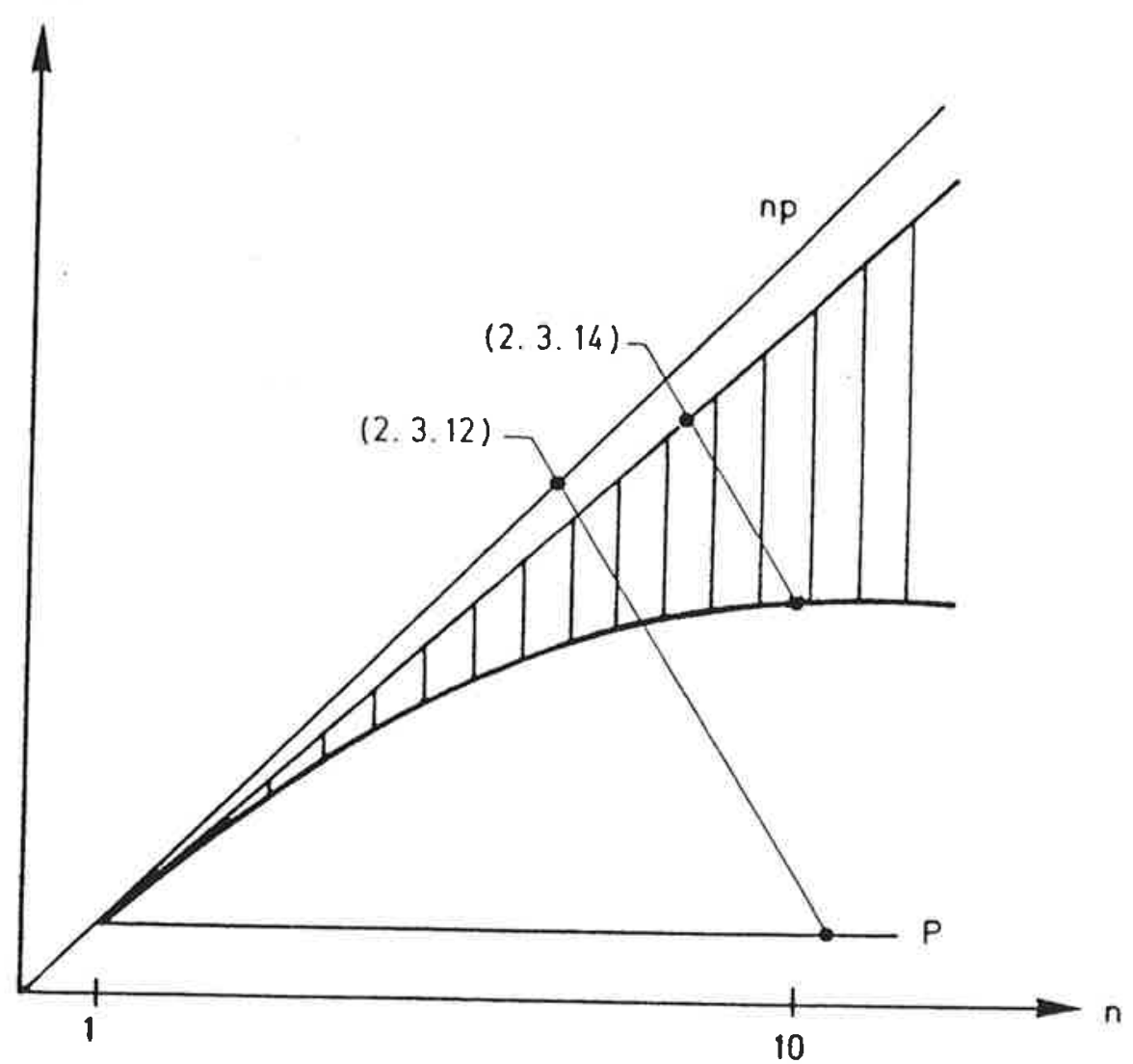

Fig. 2.3.4: Calculated fallure probabilities for a serles system comprising $\mathrm{n}$ elements. 
The bounds given by formula (2.3.12) are rather widely spaced. It is sometimes possible to use more precise bounds, likewise due to Ditlevsen:

$\Sigma\left[P_{i}-\underset{j<i}{\Sigma} P_{i j}\right] \leq P(F) \leq \Sigma\left[P_{i}-\max _{j<i} P_{i j}\right]$

where $P_{i j}-P\left(Z_{i}<0\right.$ and $\left.Z_{j}<0\right)$

Some results of the formulae given here are represented in Figure 2.3.4.

A parallel system is characterized in its generality by the fact that elements can compensate for one another; failure of one element does not automatically lead to fallure of the system. The manner in which such behaviour occurs may vary considerably, however. For example, compare the parallel system shown in Figures 2.3.5a and 2.3.5b.

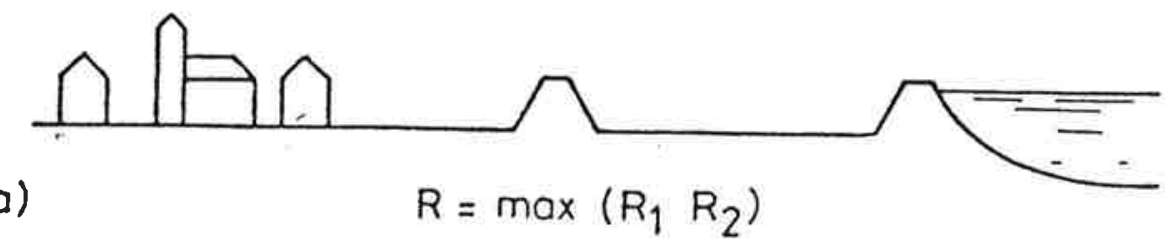

(a)

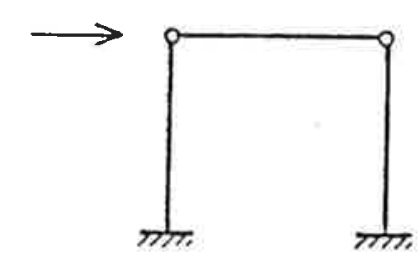

(b)

$$
R=R_{1}+R_{2}
$$

Fig. 2.3.5: Various types of parallel systems. 
In figure 2.3.5a a region of land is protected against inundation by two dykes. If the primary dyke fails, flooding of the section does not immediately occur, because then the second dyke becomes "operational". Only if the second dyke also fails, the system as a whole fails. A system of this kind is indeed the very opposite of the series system: the series system fails if one of its elements fails; the parallel system functions if one of its elements functions. Mathematically the two systems are equivalent if failure probabilities are replaced by success probabilities, and vice versa. Therefore only the other type of parallel system will be further considered here, namely, that represented in Figure 2.3.5b: a portal frame comprising two columns and subjected to a horizontal load. This load is resisted by both columns, and the system fails if the load is greater then the sum of the capacities of the columns. Hence the strength of the system is equal to:

$R=R_{1}+R_{2}$

where $R_{i}$ is the maximum reaction force that column $i$ can develop.

For the validity of formula (2.3.15) it is important that the loaddisplacement diagram of an individual column should have a ductile character.

The strength (loadbearing capacity) of a ductile parallel system with $n$ elements is given by:

$$
\begin{aligned}
& \mathrm{R}_{\text {sys }}=\mathrm{R}_{1}+\mathrm{R}_{2}+\ldots \mathrm{R}_{\mathrm{n}} \\
& \mu\left(\mathrm{R}_{\text {sys }}\right)=\mu\left(\mathrm{R}_{1}\right)+\mu\left(\mathrm{R}_{2}\right) \ldots \mu\left(\mathrm{R}_{\mathrm{n}}\right) \\
& \sigma^{2}\left(\mathrm{R}_{\text {sys }}\right)=\sigma^{2}\left(\mathrm{R}_{1}\right)+\sigma^{2}\left(\mathrm{R}_{2}\right)+\ldots \sigma^{2}\left(\mathrm{R}_{\mathrm{n}}\right)
\end{aligned}
$$

If all $R_{i}$ have the same mean value and the same standard deviation, these formulae can be simplified to: 
$\mu\left(\mathrm{R}_{\text {sys }}\right)=\mathrm{n} \mu\left(\mathrm{R}_{\mathrm{i}}\right)$

$\sigma^{2}\left(\mathrm{R}_{\text {sys }}\right)=\mathrm{n} \sigma^{2}\left(\mathrm{R}_{\mathrm{i}}\right)$

It is seen that the mean value increases proportionally to $n$, whereas the variation increases proportionally to $\sqrt{n}$. Therefore the variation decreases relatively:

$V\left(R_{\text {sys }}\right)=\frac{V\left(R_{i}\right)}{\sqrt{ } n}$

A system comprising 10 elements has a coefficient of variation which is only $V\left(R_{\text {sys }}\right)-0.32 \mathrm{~V}\left(\mathrm{R}_{i}\right)$.

Next, consider the case where the elements $R_{i}$ are completely correlated. Starting from equal mean values and equal variations for the $R_{i}$, it follows that then all the elements have exactly the same strength:

$R_{1}=R_{2}-\ldots-R_{n}$

The strength of the system is given by:

$\mathrm{R}_{\text {sys }}=\mathrm{n} \mathrm{R}_{\mathrm{i}}$

The mean value, standard deviation and coefficient of variation are then respectively:

$\mu\left(\mathrm{R}_{\text {sys }}\right)=\mathrm{n} \mu\left(\mathrm{R}_{\mathrm{i}}\right)$

$\sigma\left(\mathrm{R}_{\text {sys }}\right)=\mathrm{n} \sigma\left(\mathrm{R}_{\mathrm{i}}\right)$

$V\left(R_{\text {sys }}\right)-V\left(R_{i}\right)$

With complete correlation the favourable effect of the parallel system has entirely disappeared. Alternatively, of course, it is possible that in a parallel system there exists partial correlation, which can be represented by means of a correlation coefficient. In Figure 2.3.6 the coefficient of variation of the system $V\left(R_{\text {sys }}\right)$ is shown as a function of $\rho$ and $\mathrm{n}$. 


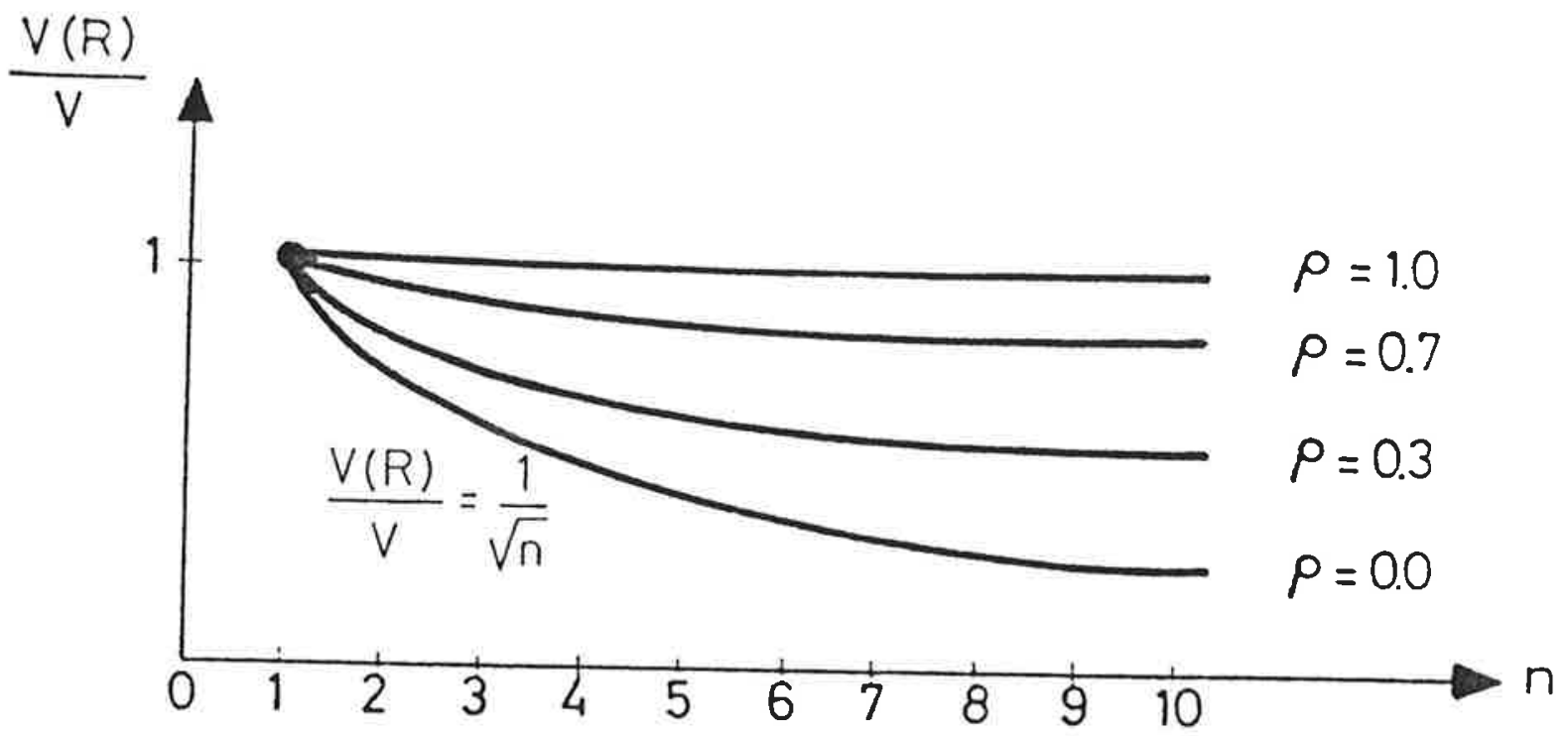

Fig. 2.3.6: The coefficient of varlation of a ductile parallel system as a function of the number of elements $n$ and the coefficient of correlation between the elements $\rho$ (with $V\left(R_{i}\right)=V$ and $\rho\left(R_{i}, R_{j}\right)-\rho$ for all $\left.i, j\right)$.

It is apparent that even a low degree of correlation greatly reduces the favourable parallel effect.

Example
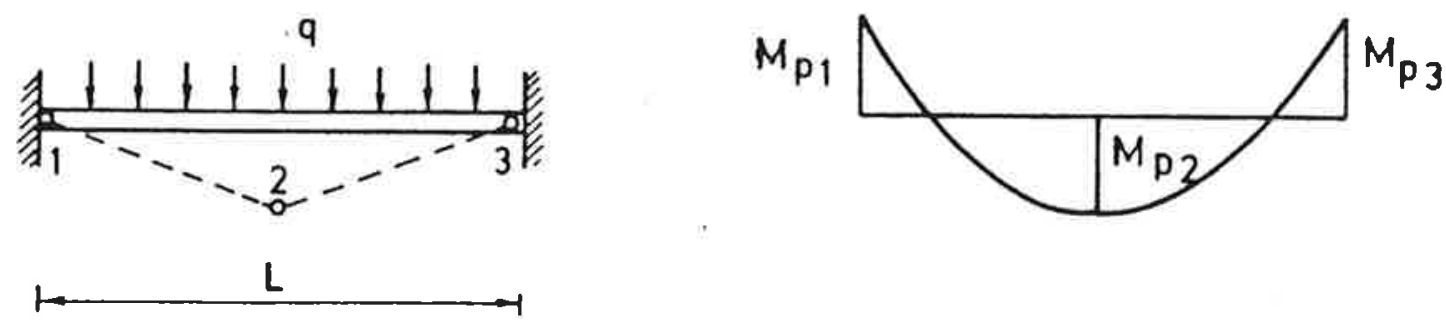

Fig. 2.3.7: Fixed-end beam with bending moment diagram at failure.

A steel girder of span L, fixed at both ends, carries a uniformly distributed load q (see Figure 2.3.7). The girder collapses when three plastic hinges have developed, namely, one at mid-span and two at the fixed ends. The reliability function $\mathrm{Z}$ is: 
$Z=\frac{1}{2} M_{p 1}+M_{p 2}+\frac{1}{2} M_{p 3}-\frac{1}{8} q L^{2}$

This parallel system therefore comprises weighting coefficients. The following statistical properties will be assumed:

\begin{tabular}{|ccr|}
\hline $\mathrm{x}$ & $\mu(\mathrm{x})$ & $\mathrm{V}(\mathrm{x})$ \\
\hline $\mathrm{M}_{\mathrm{p}_{i}}$ & $90 \mathrm{kNm}$ & $10 \mathrm{z}$ \\
$\mathrm{q}$ & $20 \mathrm{kN} / \mathrm{m}$ & 208 \\
$\mathrm{~L}$ & $6 \mathrm{~m}$ & - \\
\hline
\end{tabular}

The dependence of the moment $\mathrm{MP}_{1}$ is furthermore of importance. First, consider complete dependence:

$$
\mathrm{Z}=2 \mathrm{M}_{\mathrm{p}_{i}}-\frac{1}{8} \mathrm{qL}^{2}
$$

$\mu(\mathrm{Z})=180-\frac{1}{8}(20) 6^{2}=90 \mathrm{kNm}$

$\sigma^{2}(\mathrm{Z})=(18)^{2}+(18)^{2}-(25.5 \mathrm{kNm})^{2}$

$\beta=90 / 25.5=3.54$

$P(F)=0.20 * 10^{-3}$

Next, assume complete independence for $\mathrm{Mp}_{i}$. The mean value of $\mathrm{Z}$ does not change as a result of this, but the standard deviation does:

$$
\begin{aligned}
\sigma^{2}(z) & =(4.5)^{2}+(9)^{2}+(4.5)^{2}+(18)^{2}=(21.1 \mathrm{kNm})^{2} \\
\beta & =90 / 21.1=4.3 \\
P(F) & =0.8 \times 10^{-5}
\end{aligned}
$$


The reality will be in between the two extremes, but probably closer to complete correlation. There are indeed unlikely to be any major differences within a steel girder $6 \mathrm{~m}$ in length. Supposing that $\rho_{12}=$ $\rho_{23}=0.9$ and $\rho_{13}=0.8$ (because of the greater distance), then:

$\sigma^{2}(z)=\left\{\Sigma \Sigma \rho_{i j} c_{i} c_{j} \sigma\left(M_{P_{i}}\right) \sigma\left(M_{p_{j}}\right)\right\}+\frac{1}{64} L^{4} \sigma^{2}(q)$

where $c_{i}$ are the coefficients associated with $M_{P_{i}}$ in the reliability function, or $c_{1}=c_{3}=0.5$ and $c_{2}=1.0$.

On working this out, we obtain:

$$
\begin{aligned}
\sigma^{2}(Z)= & \sigma^{2}\left(M_{p_{i}}\right)\left\{\Sigma \Sigma \rho_{i j} c_{i} c_{j}\right\}+\left\{\frac{1}{8} L^{2} \sigma(q)\right\}^{2}= \\
- & \sigma^{2}\left(M_{p_{i}}\right)\left\{c_{1}^{2}+c_{2}^{2}+c_{3}^{2}+2 \rho_{12} c_{1} c_{2}+2 \rho_{13} c_{2} c_{3}+2 \rho_{23} c_{2} c_{3}\right\}+ \\
& \left\{\frac{1}{8} L^{2} \sigma(q)\right\}^{2}= \\
= & 9^{2}\left\{(0.5)^{2}+(1)^{2}+(0.5)^{2}+2(0.9)(0.5)(1)+2(0.8)(0.5)^{2}\right. \\
+ & 2(0.9)(1)(0.5)\}+18^{2}=(25.0 \mathrm{kNm})^{2}
\end{aligned}
$$

With this we finally obtain:

$$
\beta=90 / 25=3.60 \text { and } \mathrm{P}(\mathrm{F})=0.16 \times 10^{-3}
$$

As was to be expected, the correlation almost entirely wipes out the favourable parallel effect.

\subsection{Failure probability and reality}

The application of probability theory to the assessment of structural reliability leads to the question whether the calculated probability of failure corresponds to reality. It is often supposed that a probabilistic safety analysis is meaningful only if it is based on accurate computational models and on sufficient statistical data. In actual practice these requirements are seldom fulfilled, however. In 
most cases it is just the lack of (statistical) data and the absence of an adequate computational model that are important features of the reliability problem. In other words, the uncertainties associated with them are often even greater than the uncertainties due to the instrinsically stochastic character of load and strength.

Obviously, these uncertainties must be taken into account in determining the margins of safety. Theoretically the most attractive procedure consists in first translating all the uncertainties into probability terms (especially coefficients of variation) and then determining the necessary safety factors. Of course, in the case if "model uncertainties" ind "statistical uncertainties" the coefficients of variation can only be estimated subjectively. As a consequence of this, a calculated probability of failure can no longer be interpreted as the "frequency of cases of damage", but solely as "a measure of the confidence in a particular design". In the relevant technical language this is called replacing the objective or frequentistic concept of probability by the subjective or Bayesian concept of probability. However, the probabilities and the coefficients of variation applied in establishing codes of practice or design rules reflect the collective opinion of a large number of professional colleagues rather than the subjective opinion of one person. Hence the probabilities and parameters have the character of design quantities, and for this reason the designation "notional probabilities" is sometimes used in the literature. Besides, in most cases it will suffice just to have an approximate idea of the order of magnitude of the failure probabilities.

It should be borne in mind that the purpose of a reliability analysis is not so much to calculate the failure frequency exactly as to produce as good and balanced a design as possible with the available information. A difference of a factor of 10 in the failure probability often corresponds to, for example, a difference of merely a few centimetres in the height of a dyke. 


\section{CALCULATION OF FAILURE PROBABILITIES}

\subsection{Introduction}

\subsubsection{Statement of the problem}

The purpose of failure probability calculations is to make possible a prediction of the probability of inundation of a region protected by a system of dykes or other flood defence works. In reality the determination of the probability of failure of such a system is an extremely complex matter, this being attributable to four factors.

- In the first place there is the often considerable variety of the types of structure which together form the system of flood defences. For example, a system may comprise a combination of dykes (sea, river, lake, canal dykes), embankments, dunes, earth-retaining structures (quay walls), and incorporated civil engineering structures (locks, sluices). Besides, other objects such as pipelines and various kinds of structure (not primarily intended to perform a water-retaining function), may be present on or in the dyke.

- Secondly, a complicating factor consists in describing the structural properties of the water-retaining elements separately. The variation of the properties (including strength, deformation, permeability, thickness of layers) of the natural subsoil and the artificially deposited layers of soil (often deposited in different periods of time) plays a part in connection with this. The uncertainty with regard to the quality of execution of the completed work is also a point to consider.

The influence of the length of a dyke (see section 3.6) should likewise be taken into account in calculating the probability of failure. Furthermore, the time-dependent character of the structural behaviour (e.g., consolidation of the soil strata) may be of importance.

Besides the uncertainty in determining the magnitude of the structural parameters for the limit states to be analyzed, there is the problem that for most limit states no reliable mathematical descriptions of the physical processes are available. This manifests itself in, among 
other instances, the description of the mechanism of piping and in the erosion of grass slopes. In such cases it is not known what the relevant design parameters are.

- A third complicating factor in the determination of failure probabilities under practical conditions is formed by the complex nature of the potential hazards or loads. Besides the obvious hazard posed by "water", manifesting itself in high water levels and wave action, the effect of heavy rainfall and ice-drift should also be considered. In some cases the loading due to traffic, dead weight or adjacent buildings should likewise be taken into account in the failure probability analysis. Apart from the above-mentioned loads there may also occur biological attack (e.g., by growth of organisms or by burrowing animals). Finally, special loads may occur in consequence of explosions, impact effects in the event of collisions, earthquakes, etc.

- The fourth complicating factor, which in part is of a numerical character, is constituted by the summation of all the above-mentioned aspects, resulting in an overall probability of inundation of the region concerned. A problem associated with this factor is that the limit states - per water-retaining element and also between different elements - are partly correlated. This applies to correlation both of the load parameters (consider the water levels) and of the design parameters (e.g., geometry parameters and strength properties of the soil strata). The magnitude of this correlation, and how it may be taken into account, is at present still a subject of debate (see Section 3.6).

As stated, failure probability calculations serve as an aid in determining the risk of inundation of the region to be protected. However, as risk equals probability time consequence, also the consequences of the inundation must be treated in great detail. From studies on the problem it emerges that inundation should be specified in terms of the inundation depth, the inundation speed and the inundation duration [3.1]; the quality of the water (salt of freshwater) also plays a part. 
This means that inundation must be expressed in the total rates of "flow through" of "flow over" (determined by, among other factors, the length of the overflow, the width and depth of the breaches, the adjacent ground levels, and the sea or river water levels) and in the duration thereof.

Besides failure of the flood defence structure, the properties of the region to be protected are important for determining the anticipated inundation behaviour. This relates, among other features, to the area and topography of the region, the polder water level and the pumping capacity.

\subsubsection{Arrangement of Chapter 3}

Despite the above-mentioned complexity of estimating the probability of inundation, the Working Group can claim to have achieved progress in respect of a number of requirements, which has in part already resulted in scope for practical application. In such cases a greatly schematized situation has always been adopted on the basis.

In this chapter the Working Group's activities will be described in so far as they relate to the failure probability calculations for the element "dykes". As for the element "dunes" the reader is referred to Chapter 8. Chapter 4 deals with the analysis of inundation.

Of the many limit states associated with the water-retaining capacity of dykes, a limited number have been studied by the Working Group. These are substantially the same limit states as those incorporated in the worked example (Chapter 7), namely:

- Overflowing and wave overtopping (Section 3.2).

- Macro-instability (Section 3.3.).

- Micro-instability (Section 3.4).

- Piping (Section 3.5). 
For each limit state the mechanism is briefly outlined, followed by a review of the present position as to the formulation of the reliability function. In this context, points requiring attention ("blank spots") with a view to further development will also be mentioned. Furthermore, separate attention is focused on the effect of exceeding the relevant limit state - in view of the possibility that this may induce other limit states and, moreover, in order to establish the link-up with inundation.

Finally, in Section 3.6 of this Chapter, the length effect is considered, in connection with the correlation of some parameters in the longitudinal direction of the dyke.

As already noted, the various limit states are found in parts to be determined by the same strength and load parameters, so that correlated limit states exist. For a further examination of this aspect the reader is referred to the worked example (Chapter 7).

\subsection{Overflowing and wave overtopping}

\subsubsection{Mechanism of overflowing}

If the water level at a dyke is higher than the crest of the dyke, ingress of water into the region protected by it will increase and inundation may occur (see Figure 3.2.1).

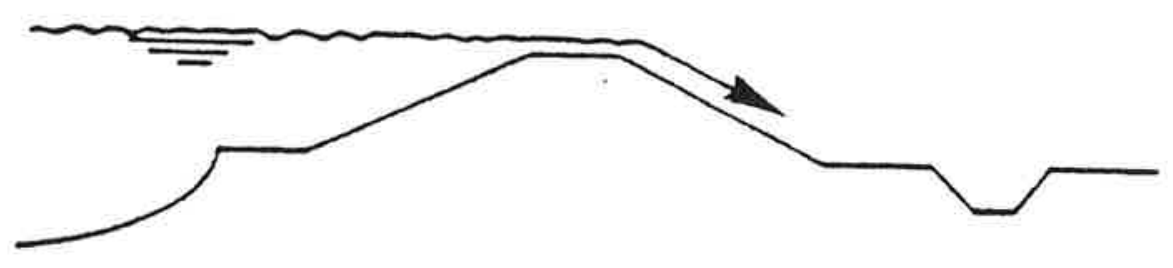

Fig. 3.2.1: Mechanism of overflowing. 
The mechanism "overflowing" (overtopping by high water level) will be dealt with for a situation in the Delta region of the Netherlands (south-western part of the country). This mechanism is of importance with regard to dykes which are situated "facing away from the wind", i.e., are not exposed to wave action.

For locations in the regions upstream of the tidal parts of the country's major rivers the Working Group has (hitherto) considered only a highly schematized case. With regard to this the reader is referred to Chapter 7 of this interim report. In so far as the transitional region between the non-tidal parts of the rivers and the Delta region is concerned, the Working Group has not started any activities.

When the limit state is exceeded, water will flow over the dyke and along the inner (landward) slope, so that other failure mechanisms may then be induced, as will be further considered in Section 3.2.5.

In the following section only "overflowing" will be envisaged. The dyke will be deemed to remain completely intact. The same holds for "wave overtopping" in section 3.2.4.

\subsubsection{Reliability function for overflowing}

With regard to the mechanism "overflowing" it is investigated with what probability the high water level at the dyke (H) will exceed the level of the crest $(h)$. The high water level to be taken into account is found by summation of the storm tide level $s_{v}$ (which in turn is a summation of the astronomic tidal level and the wind setup) and the effects of seiches, gust bumps and squall oscillations [3.2]. One also has to take account of the expected relative rise of the sea level and settlement effects.

The reliability function then becomes:

$z=h_{a}-s_{v}-s_{p}-B_{o}-z_{r}-z_{k}$

where:

$\mathrm{h}_{\mathrm{a}}=$ construction height (crest level of the dyke)

$\mathrm{s}_{\mathrm{v}}=$ storm tide level

$S_{p}=$ uncertainty in $S_{v}$ due to extrapolation

$B_{0}=$ effect of seiches, gust bumps and squall oscillations

$z_{r}=$ relative rise in sea level 
$z_{k}=$ effect of subsoil settlement and consolidation of the dyke fill material itself

In the Delta region the frequency distribution of the storm tide level $\mathrm{S}_{\mathrm{v}}$ at the dyke can be found by statistical extrapolation of high water levels [3.2]. In general, this frequency distribution can be modelled by:

Freq $\left(S_{v}>S\right)=\exp \left\{-\left(S-S_{0}\right) / a\right\}$

where:

Freq $\left(S_{v}>S\right)=$ frequency per year with which the storm tide level $S_{v}$ exceeds the level $\mathrm{s}$

$S_{0}$, a constants deduced from the observations for each location

The above-mentioned frequency distribution is, for frequencies of less than 0.1, sometimes used as an extreme-value distribution for the probability that a particular storm tide level will be exceeded in a year. Alternatively, a complementary Gumbel distribution may be used for the purpose:

$P\left(S_{v}>S\right)=1-\exp \left[-\exp \left(-\left(S-S_{0}\right) / a\right)\right]$

where:

$\mathrm{P}\left(\mathrm{S}_{\mathrm{v}}>\mathrm{S}\right)$ = probability that the storm tide level $\mathrm{S}$ is exceeded per year.

The results of these two alternative approximations do not differ much from each other.

In consequence of the extrapolation to very low exceedance probabilities an uncertainty is introduced [3.2], Part 1, pp. 30, 31 and Part 3, p. 43]. Provisionally the Working Group proposes modelling this uncertainty or variation $\left(S_{p}\right)$ by adopting a normal distribution with a mean value 0 (zero) and a standard deviation which depends on the storm tide level: 
$\sigma\left(\mathrm{S}_{\mathrm{p}}\right)=\mathrm{a}_{0}\left(\mathrm{~S}-\mathrm{c}_{0}\right)$

where $a_{0}$ and $c_{0}$ are constants. According to the guidelines given by the Delta Commission, in the absence of wave action the effects of seiches, gust bumps and squall oscillations should be completely catered for by the extra height (safety margin) provided. For want of statistical data there is, in the Working Group's opinion, no alternative but to model the effects of seiches, gust bumps and squall oscillations with the aid of the normal distribution while mean values and standard deviations should follow from local measurements.

The Delta Commission indicated that the relative rise in sea level may be between 0.15 and $0.2 \mathrm{~m}$, calculated over the last century. Because of this uncertainty the relative rise in sea level can be conceived as a stochastic variable.

The Delta Commission, however, required that "... in the event of a water level equal to the design level there should still be complete safety against breaching" [3.2, Part 1, p. 36]) and accordingly recommended: "... the crest level should be such that, in the event of water levels equal to the design level, no appreciable overtopping is to be expected" [3.2, Part 1, p. 86]). Since the crest level (h) under the influence of (time-dependent) settlement, soil consolidations and inaccuracies in constructing the dyke is a stochastic quantity, a probability distribution will also have to be assigned to it. This probability distribution will be bounded on one side by the construction height (barring tectonic phenomena, the crest level will never be higher than that actually achieved at the time of construction) and on the other side by inspection and maintenance, i.e., if part of the dyke subsequently becomes lower than a certain minimum, its height will certainly have to be raised. To what extent it is indeed meaningful to take account of the above-mentioned bounds to the probability distribution of the crest level, and what probability distribution can most suitably be adopted, is currently being studied by the Working Group. 


\subsubsection{Mechanisms of wave overtopping}

As with overflowing, so also with overtopping of a dyke by waves ingress of water into the region protected by it will increase (see Figure 3.2.2).

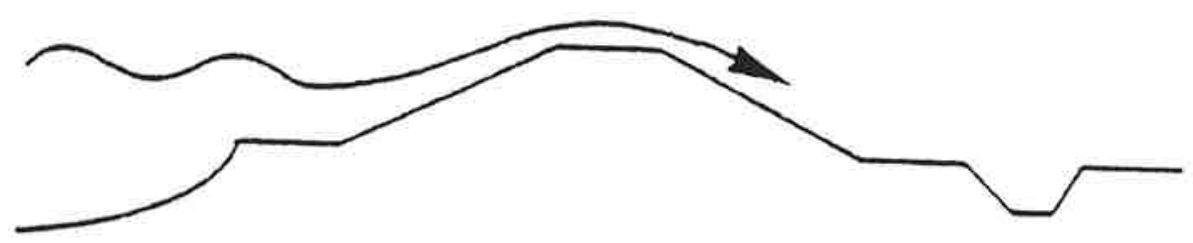

Fig. 3.2.2: Mechanism of wave overtopping.

If a dyke is exposed to wave action its safety margin should in general be greater than in the case where no wave action occurs. Wave runup is now also taken into account in dyke design in the non-tidal upstream river regions and in the transitional region. In the following treatment of the subject only locations in the Delta region will be considered. Attention will be confined to the mechanism "wave overtopping" as such.

\subsubsection{Reliability function for wave overtopping}

If no more than a minimal amount of overtopping is accepted, the construction height according to the Delta Commission's guidelines is found by adding to the terms stated in the preceding treatment of overflowing a height corresponding to the "2z wave runup". In this case the reliability function becomes:

$z=h_{a}-s_{v}-s_{p}-B_{o}-z_{r}-z_{k}-z_{28}$

The parameters mentioned in Section 3.2.2, which determine the storm tide. level, are applicable in this case, too, except that according to the Delta Commission's guidelines [3.2] the effect of seiches, gust bumps and squall oscillations may be reduced. 
Difficulties in connection with taking account of the $2 \%$ wave runup are due to:

1) Determining the wave spectrum just in front of the dyke (more particularly in the case of shallow foreshore depth).

2) The relation between the storm tide level and the wave spectrum just in front of the dyke.

$\operatorname{Re} 1$ )

The formula proposed by the Delta Commission for calculating the 28 wave-runup :

$z_{28}=8 \mathrm{H}_{s} \tan (\alpha)$

was determined for a wave steepness of 58 and should, according to the Delta Commission's report, " ... be used with caution". The wave spectrum just in front of the dyke is important in conjunction with the degree of breaking, reflection etc. and these data are generally not available.

$\operatorname{Re} 2$ )

The storm tide level and the wave runup are both affected by wind. For a given storm tide level, information on the associated wave pattern just in front of the dyke would be desirable. Only then could these two quantities be judiciously combined.

Bruinsma and Van de Graaf experimentally determined a water level/wave height relation for the NAP $-20 \mathrm{~m}$ depth contour line near Hook of Holland (1982) [3.3]*. Starting from these findings, Vrijling (1983) [3.4] established a computational model of wave runup (incorporating possible breaking of the waves on a shallow foreshore), based on the wave runup formula of d'Angremond and Van Oorschot (1968) [3.5]. From this calculation it emerged that the wave steepness is of fairly major influence on the probability of failure. The example given below comprises a calculation in which the above-mentioned parameters have been incorporated.

* NAP $=$ Normaal Amsterdams Peil = Standard Amsterdam Datum. 
The Working Group considers it desirable to make efforts to remove the said difficulties also for locations other than at Hook of Holland.

If the dyke is of adequate strength and has an impermeable revetment, a greater amount of wave runup than the 28 runup proposed by the Delta Commission could conceivably be allowed. Indeed, the Delta Commission itself already pointed this out. What requirements the dyke revetment should then satisfy, and what wave runup percentage will then be permissible, will have to be the subject of further study. It will also have to be investigated whether more particularly in that case the wave runup or the overtopping of the dyke by waves (the volume of water that on average washes over the crest) should be introduced as the determining parameter.

\section{Example}

This example is largely been adopted from [3.4].

The construction height (crest level) of a dyke of which the allignement is perpendicular to the wind direction and which is exposed to wave action is, according to the Delta Commission's guidelines, (deterministically) determined as follows:

Storm tide level $\left(10^{-4} /\right.$ year) (m above NAP) 28 wave runup (m)

Surges, gust oscillations and seiches (m) Settlement and consolidation (m)

Relative rise in sea level (m)

$\mathrm{s}_{\mathrm{v}}=\mathrm{NAP}+5.00 \mathrm{~m}$
$\mathrm{z}_{2 \mathrm{z}}=$
$\mathrm{B}_{\mathrm{o}}=$
$\mathrm{z}_{\mathrm{k}}=$
$\mathrm{z}_{\mathrm{r}}=0.33 \mathrm{~m}$

Construction height (m)

$h_{z}=N A P+13.44 m$

* Foreshore bottom level: NAP $-6 \mathrm{~m}$. Storm tide level: NAP +5 m.

Breaker criterion: $\mathrm{H}_{\text {smax }}=0.5 \mathrm{x}$ water depth, gives $\mathrm{H}_{\text {smax }}=0.5 \mathrm{x}(\mathrm{t}+6)=5.5 \mathrm{~m}$.

28 wave runup calculated with formula (3.2.6) gives $(\tan \alpha-1 / 6)$ : $\mathrm{z}_{28}=8 \mathrm{H}_{\mathrm{s}} \tan \alpha=8 \times 5.5 \times \frac{1}{6}=7.33 \mathrm{~m}$ 
The storm tide level $\left(\mathrm{S}_{\mathrm{v}}\right)$ has been determined from water level gauge readings at the toe of the dyke. The significant wave height $H_{s}$ is linited by the breaker criterion (see Figure 3.2.3).

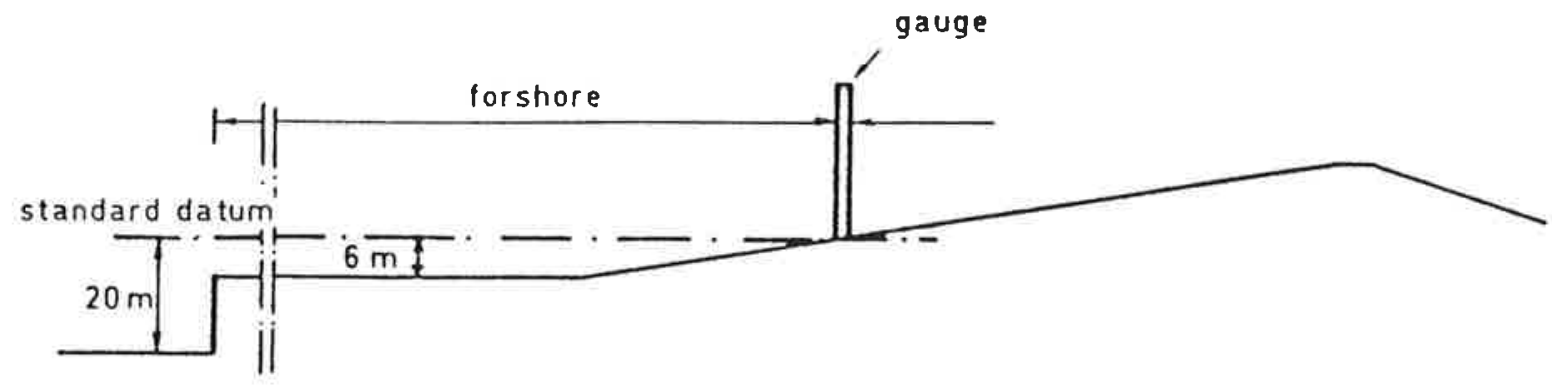

Fig. 3.2.3: Cross section of the dyke.

The data for a probabilistic calculation are as given in Table 3.2.1.

Table 3.2.1: Overview of the basic variables.

\begin{tabular}{|c|c|c|c|c|c|}
\hline & & Distribution & $\mu$ & $\sigma$ & \\
\hline Construction height & $\left(h_{a}\right)$ & Normal & $13.44 \mathrm{~m}$ & 0.1 & $\mathrm{~m}$ \\
\hline Settlement and consolidation & $\left(z_{k}\right)$ & Normal & $0.5 \mathrm{~m}$ & 0.1 & $\mathrm{~m}$ \\
\hline Relative rise of sea level & $\left(z_{r}\right)$ & Normal & $0.1 \mathrm{~m}$ & 0.03 & $\mathrm{~m}$ \\
\hline $\begin{array}{l}\text { Storm tide level } \\
\text { Uncertainty in } \mathrm{s}_{\mathrm{v}} \text { due to }\end{array}$ & $\left(S_{v}\right)$ & 1) & $2.17 \mathrm{~m}$ & 0.423 & $\mathrm{~m}$ \\
\hline $\begin{array}{l}\text { extrapolation } \\
\text { Seiches, gust bumps and }\end{array}$ & $\left(s_{p}\right)$ & Normal & m & $0.11 *(S V-2.25)$ & m \\
\hline $\begin{array}{l}\text { squall oscillations } \\
\text { Uncertainty in } \mathrm{H}_{\mathrm{S}} \text { at } 20 \mathrm{~m}\end{array}$ & $\left(B_{0}\right)$ & Normal & $0.4 \mathrm{~m}$ & 0.1 & $\mathrm{~m}$ \\
\hline depth contour & $\left(S_{h}\right)$ & Normal & m & 0.69 & $\mathrm{~m}$ \\
\hline Wave steepness & $\left(G_{s}\right)$ & Normal & $0.0375 *$ & 0.006 & \\
\hline
\end{tabular}

1) $\exp \{-\exp (-(S-1.98) / 0.33\}]$

* The wave run-up formula $\mathrm{Z}-8 \mathrm{H}_{\mathrm{s}} \tan \alpha$ is valid for a wave steepness of 58 (see 3.2 .8 ). The average wave steepness adopted here is considerably less. 
The following relationship between the average value of the significant wave height at the NAP - $20 \mathrm{~m}$ depth contour line $\left(\mathrm{H}_{\mathrm{s} 20}\right)$ and the storm tide level based on gauge readings has been empirically established *.

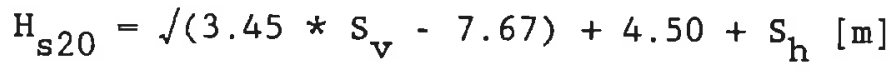

In this formula, which is valid for storm tide levels higher than NAP + $2.50 \mathrm{~m}, \mathrm{~S}_{\mathrm{h}}$ is a normally-distributed stochastic variable with which the variation in the measured results is taken into account.

The wave steepness is considered as stochastically independent from $\mathrm{H}_{\mathbf{S}}$. The wave steepness, however, is defined as:

$G_{s}=\frac{H_{s 20}}{L_{s 20}}$

where $\mathrm{L}_{\mathrm{s} 20}$ is the mean length of the significant wave in deep water (at the NAP - 20 m depth contour line). Besides $\mathrm{H}_{s 20}$ and $\mathrm{L}_{\mathrm{s} 20}$ may be correlated [3.6], so that to consider $G_{s}$ as an independent stochastic variable is essentially incorrect.

On the foreshore a "local" wave $\left(H_{L}\right)$ is generated by wind. This locally generated wave is deemed not to affect the wavelength of the significant wave coming from the NAP - $20 \mathrm{~m}$ depth contour line. The two waves are allowed to be combined as follows:

$\mathrm{H}_{\mathrm{S}}=\sqrt{ }\left(\mathrm{H}_{\mathrm{S} 20}^{2}+\mathrm{H}_{\mathrm{L}}^{2}\right)$

Here a value of $1 \mathrm{~m}$ is assumed (deterministically) for $H_{L}$.

On the shallow foreshore the last-mentioned significant wave will break if its height exceeds 0.5 times the local water depth:

* In this worked example the relationship found by Bruinsma (1982) has been used. This relationship was empirically established for the NAP - $20 \mathrm{~m}$ depth contour near Hook of Holland. 
$\mathrm{H}_{\mathrm{smax}}=0.5 *\left(\mathrm{~S}_{\mathrm{v}}+\mathrm{D}\right)$

where $D$ is the depth of the foreshore below NAP. Here a value of $6 \mathrm{~m}$ is (deterministically) assumed for $D$.

It is further assumed that the significant wavelength $\mathrm{L}_{\mathrm{s} 20}$ does not change on the foreshore.

The breaking of high waves due to limited water depth is modelled by introducing a "censored" distribution for the variable $H_{\text {smax }}$. In so far as significant waves are lower than $\mathrm{H}_{\text {smax }}$ the distribution for $\mathrm{H}_{\mathrm{S}}$ is adopted. Waves higher than $\mathrm{H}_{\text {smax }}$ are modelled as $\mathrm{H}_{\text {smax }}$.

The 28 wave runup is modelled as (see [3.6]):

$z_{28}=1.75 \sqrt{\left(\mathrm{H}_{\mathrm{s}} \times \mathrm{L}_{\mathrm{s} 20}\right)} \tan \alpha$

A value of $1 / 6$ is (deterministically) assumed for the slope angle of the dyke.

The computational procedure diagram will then be as shown in Figure 3.2.4.

The results of the computation are given under DESIGN POINT in Table 3.2.2. 


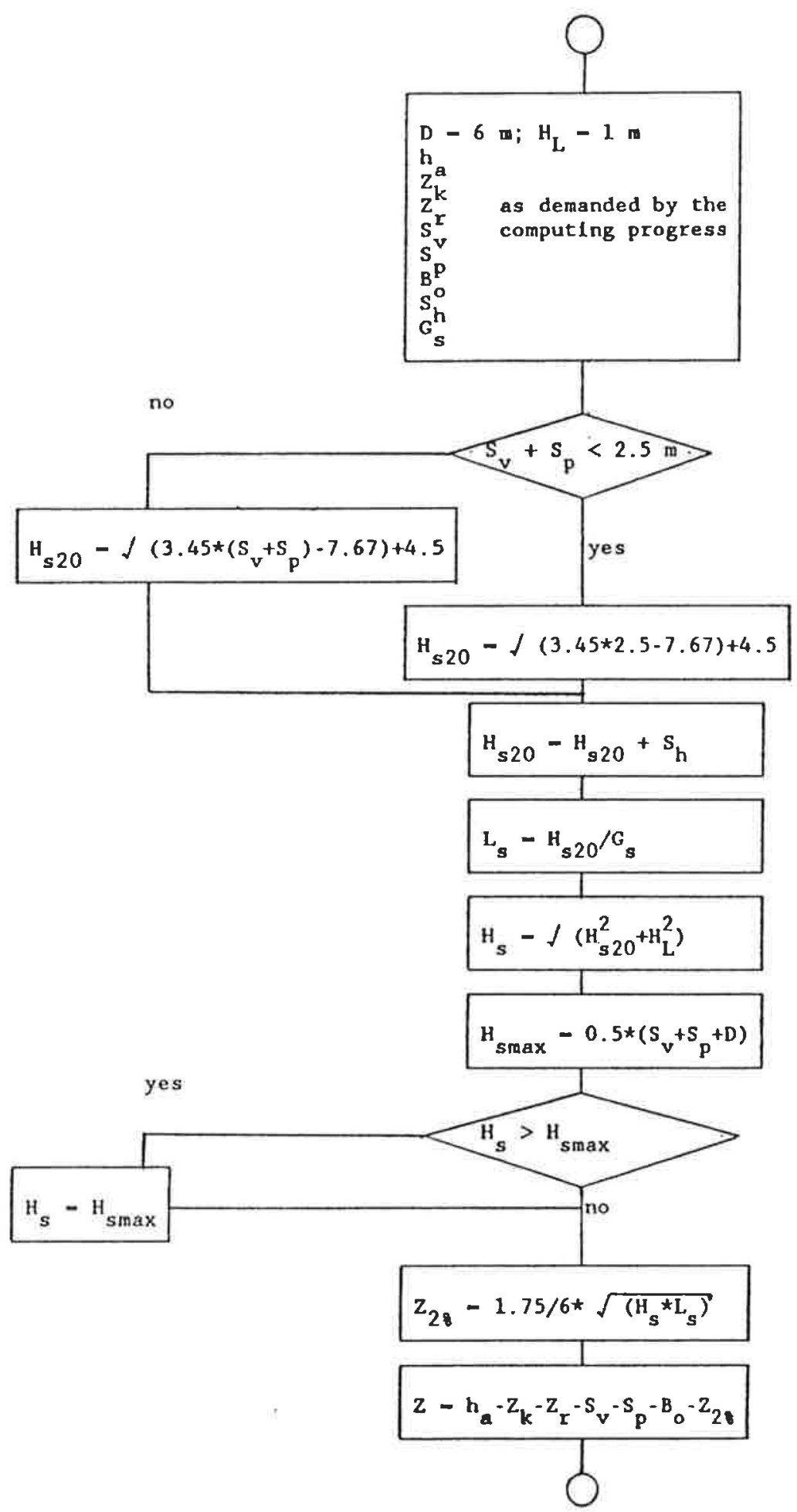

Fig. 3.2.4: Computational procedure diagram for determining the reliability function. 
Table 3.2.2: Results of failure probability calculation for wave overtopping.

Wave steepness (random):

mean $3.75 \%$ Standard deviation $0.6 \%$

Starting values

$\mathrm{X}(\mathrm{I}) \quad \mu(\mathrm{I}) \quad \sigma(\mathrm{I}) \quad$ normal

distribution

$\begin{array}{lllll}\mathrm{AH} & +1.34400 \mathrm{E}+001 & +1.34400 \mathrm{E}+001 & 1.00000 \mathrm{E}-001 & \text { yes } \\ \mathrm{ZK} & +5.00000 \mathrm{E}-001 & +5.00000 \mathrm{E}-001 & 1.00000 \mathrm{E}-001 & \text { yes } \\ \mathrm{RZ} & +1.00000 \mathrm{E}-001 & +1.00000 \mathrm{E}-001 & 3.00000 \mathrm{E}-002 & \text { yes } \\ \mathrm{SV} & +4.50000 \mathrm{E}+000 & +6.17440 \mathrm{E}-001 & 1.17633 \mathrm{E}+000 & \text { no } \\ \mathrm{SP} & +0.00000 \mathrm{E}+000 & +0.00000 \mathrm{E}+000 & 2.47500 \mathrm{E}-001 & \text { yes } \\ \mathrm{BO} & +4.00000 \mathrm{E}-001 & +4.00000 \mathrm{E}-001 & 1.00000 \mathrm{E}-001 & \text { yes } \\ \mathrm{SH} & +0.00000 \mathrm{E}+000 & +0.00000 \mathrm{E}+000 & 6.90000 \mathrm{E}-001 & \text { yes } \\ \mathrm{GS} & +3.75000 \mathrm{E}-002 & +3.75000 \mathrm{E}-002 & 6.00000 \mathrm{E}-003 & \text { yes }\end{array}$

Design point

Reliability Function Z : $\quad-.00000000004$

Mean value of $\mathrm{Z}:=3.87672303823$

Standard Deviation of $\mathrm{Z}: \quad=1.96209511454$

Reliability Index $\beta \quad:=2.30597137668$

Probability of Failure : $\quad-.010556088182$

$\mathrm{X}(\mathrm{I}) \quad \mu(\mathrm{I}) \quad \sigma(\mathrm{I}) \quad$ constitution

of the var. ( 8 )

$\begin{array}{lllll}\mathrm{AH} & +1.3428247 \mathrm{E}+001 & +1.34400 \mathrm{E}+001 & +1.00000 \mathrm{E}-001 & 2.5975 \mathrm{E}-001 \\ \mathrm{ZK} & +5.1175260 \mathrm{E}-001 & +5.00000 \mathrm{E}-001 & +1.00000 \mathrm{E}-001 & 2.5975 \mathrm{E}-001 \\ \mathrm{RZ} & +1.0105773 \mathrm{E}-001 & +1.00000 \mathrm{E}-001 & +3.00000 \mathrm{E}-002 & 2.3378 \mathrm{E}-002 \\ \mathrm{SV} & +3.1909050 \mathrm{E}+000 & +1.66333 \mathrm{E}+000 & +7.80541 \mathrm{E}-001 & 7.2029 \mathrm{E}+001 \\ \mathrm{SP} & +2.6859213 \mathrm{E}-002 & +0.00000 \mathrm{E}+000 & +1.03500 \mathrm{E}-001 & 1.2665 \mathrm{E}+000 \\ \mathrm{BO} & +4.1175260 \mathrm{E}-001 & +4.00000 \mathrm{E}-001 & +1.00000 \mathrm{E}-001 & 2.5975 \mathrm{E}-001 \\ \mathrm{SH} & +3.8163744 \mathrm{E}-001 & +0.00000 \mathrm{E}+000 & +6.90000 \mathrm{E}-001 & 5.7530 \mathrm{E}+000 \\ \mathrm{GS} & +3.1289430 \mathrm{E}-002 & +3.75000 \mathrm{E}-002 & +6.00000 \mathrm{E}-003 & 2.0149 \mathrm{E}+001\end{array}$ 
Table 3.2.3: Results of failure probability calculation for wave overtopping.

Wave steepness $=58$ deterministic.

\begin{tabular}{|ccccc}
\hline \multicolumn{2}{|l}{ Starting values } & & & \\
& & & & \\
& $\mathrm{X}(\mathrm{I})$ & $\mu(\mathrm{I})$ & $\sigma(\mathrm{I})$ & dis \\
& & & & \\
$\mathrm{AH}$ & $+1.34400 \mathrm{E}+001$ & $+1.34400 \mathrm{E}+001$ & $1.00000 \mathrm{E}-001$ & yes \\
$\mathrm{ZK}$ & $+5.00000 \mathrm{E}-001$ & $+5.00000 \mathrm{E}-001$ & $1.00000 \mathrm{E}-001$ & yes \\
$\mathrm{RZ}$ & $+1.00000 \mathrm{E}-001$ & $+1.00000 \mathrm{E}-001$ & $3.00000 \mathrm{E}-002$ & yes \\
$\mathrm{SV}$ & $+5.00000 \mathrm{E}+000$ & $+1.78260 \mathrm{E}-000$ & $1.30172 \mathrm{E}+001$ & no \\
$\mathrm{SP}$ & $+0.00000 \mathrm{E}+000$ & $+0.00000 \mathrm{E}+000$ & $3.02600 \mathrm{E}-001$ & yes \\
$\mathrm{BO}$ & $+4.00000 \mathrm{E}-001$ & $+4.00000 \mathrm{E}-000$ & $1.00000 \mathrm{E}-001$ & yes \\
$\mathrm{SH}$ & $+0.00000 \mathrm{E}+000$ & $+0.00000 \mathrm{E}+000$ & $6.90000 \mathrm{E}-001$ & yes \\
$\mathrm{GS}$ & $+5.00000 \mathrm{E}-002$ & $+5.00000 \mathrm{E}-002$ & $0.00000 \mathrm{E}+000$ & yes
\end{tabular}

Design point

Reliability Function : $\mathrm{z}=.00000000005$

Mean value of $\mathrm{Z} \quad: \quad=5.84116196574$

Standard Deviation of $\mathrm{Z}: \quad=1.96270214366$

Reliability Index $\beta \quad: \quad=3.11016683375$

Probability of Failure : $\quad=.000934976242$

$\mathrm{X}(\mathrm{I}) \quad \mu(\mathrm{I}) \quad \sigma(\mathrm{I}) \quad$ constitution

of the var. ( 8 )

$\begin{array}{lllll}\mathrm{AH} & +1.3424154 \mathrm{E}+001 & +1.34400 \mathrm{E}+001 & +1.00000 \mathrm{E}-001 & 2.5959 \mathrm{E}-001 \\ \mathrm{ZK} & +5.1584635 \mathrm{E}+001 & +5.00000 \mathrm{E}-001 & +1.00000 \mathrm{E}-001 & 2.5959 \mathrm{E}-001 \\ \mathrm{RZ} & +1.0142617 \mathrm{E}-001 & +1.00000 \mathrm{E}-001 & +3.00000 \mathrm{E}-002 & 2.3363 \mathrm{E}-002 \\ \mathrm{SV} & +4.1454858 \mathrm{E}+000 & +9.20359 \mathrm{E}-001 & +1.07998 \mathrm{E}+000 & 9.2192 \mathrm{E}+001 \\ \mathrm{SP} & +1.2021033 \mathrm{E}-001 & +0.00000 \mathrm{E}+000 & +2.08503 \mathrm{E}-001 & 3.4363 \mathrm{E}+000 \\ \mathrm{BO} & +4.1584635 \mathrm{E}-001 & +4.00000 \mathrm{E}+001 & +1.00000 \mathrm{E}-001 & 2.5959 \mathrm{E}-001 \\ \mathrm{SH} & +4.0543202 \mathrm{E}-001 & +0.00000 \mathrm{E}+000 & +6.90000 \mathrm{E}-001 & 3.5692 \mathrm{E}-000 \\ \mathrm{GS} & +5.0000000 \mathrm{E}-002 & +5.00000 \mathrm{E}-002 & +0.00000 \mathrm{E}+000 & 0.0000 \mathrm{E}+000\end{array}$




\subsubsection{Effect of exceeding the limit states}

Water overtopping the crest of the dyke will result in flooding of the protected region and may initiate other failure mechanisms of the dyke. For example, water flowing down over the inner slope may penetrate into it, as a result of which ground-water flow may occur partly saturated and partly unsaturated in the protective covering of the inner slope. Slip of the inner slope may then occur in consequence of the pressures set up by such flow (this is called the "Edelman effect"). Also, water penetrating into the covering layer may displace air from within it towards the core of the dyke. As a result of this - whether or not in conjunction with a rise in the phreatic surface (water table) in the dyke - the intergranular pressure may be reduced so that the shearing resistance needed to maintain stability of the inner slope is no longer available; or air compressed by the penetrating water may find a path of escape through the protective covering on the crest of the dyke, so that cracks are formed ("Lisse effect").

Erosion of the inner slope may be caused by overtopping water which flows down this slope. In consequence of erosion and the mechanisms possibly initiated by it (e.g., macro-instability) a gap and flow channel may develop. The development of this phenomenon as a function of time (which affects the inundation speed) has not yet been sufficiently studied. In the Working Group's opinion it is a problem that merits investigation with high priority.

The Working Group has not (yet) Investigated the effect of overtopping on the "other failure mechanisms" mentioned in the preceding paragraph.

\subsection{Macro-instability}

\subsubsection{Mechanism}

A slope forming the transition between two ground levels is maintained in position by mobilization of the internal shearing resistance (or shearing strength) of the soil. In the absence of (sufficient) mobilizable shearing resistance the slope will slide, i.e., it becomes 
unstable. The term macro-instability is applied to denote that slope failure occurs along a large failure surface, as opposed to microinstability, by which a much more local phenomenon is understood (see Section 3.4).

In practice, a slope is checked for macro-instability by considering the equilibrium of moments acting upon a mass of soil bounded by the ground levels, the slope and a potential failure surface (failure mode). The soil mass (see Figure 3.3.1) is acted upon by gravity and external forces (striving to induce sliding along the surface through the socalled overturning moment $M_{a}$ ) and, on the other hand, by the shearing forces which is mobilized along the surface (striving to prevent sliding via the so-called restisting moment $M_{t}$ ). The shearing resistance is composed of contributions from the cohesion $c^{\prime}$ of the soil and from the internal shearing resistance $\sigma_{n}^{\prime} \operatorname{tg} \varphi$, where $\sigma^{\prime}{ }_{n}^{i s}$ the effective soil stress perpendicular to the sliding surface and $\varphi$ the angle of internal friction of the soil. When the resisting moment is equal to the overturning moment, the soil mass is in equilibrium (a stable condition). Assuming the cohesion and the internal friction to be involved in the same degree (as envisaged in the method of, among others, Bishop and Fellenius [3.7]). This can be written as:

$M_{t}=R_{C_{b}} \int \frac{1}{F_{C}}\left\{c^{\prime}+\sigma_{n}^{\prime} \cdot \operatorname{tg} \varphi\right\} d C_{b}=M_{a}$

where $C_{b}$ symbolically represents the failure surface (normally a circle with radius $R$ ). The quantity $1 / F_{C}$ is the degree of mobilization, while $F_{C}$ is called the stability or equilibrium factor. In the methods of calculation the potentially failure mode is divided into a number of vertical slices. The integral (3.3.1) can then be written as a summation over slices (see Figure 3.3.1a). The effective normal stress on the sliding surface is calculated by considering the vertical force acting on a slice. In Bishop's method, which is most extensively in use for the analysis of slope stability, the forces exerted by the adjacent slices are assumed not to result in a vertical force component acting on the slice under consideration. For an assumed failure surface, the stability 
factor can be solved by means of an iterative procedure from the discretized version of equation (3.3.1). The failure surface corresponding to the lowest stability factor is found by systematic trial and error. This circle is called the critical failure circle; the associated stability factor is called the stability factor of the slope:

$$
F=\min F_{i} \quad(i-1 \ldots n)
$$

where $F$ is the stability factor of the slope and $F_{1}$ is a finite set of stability factors $F_{c}(i)$ corresponding to the circles which satifactorily represent the infinite set of all potential failure circles.

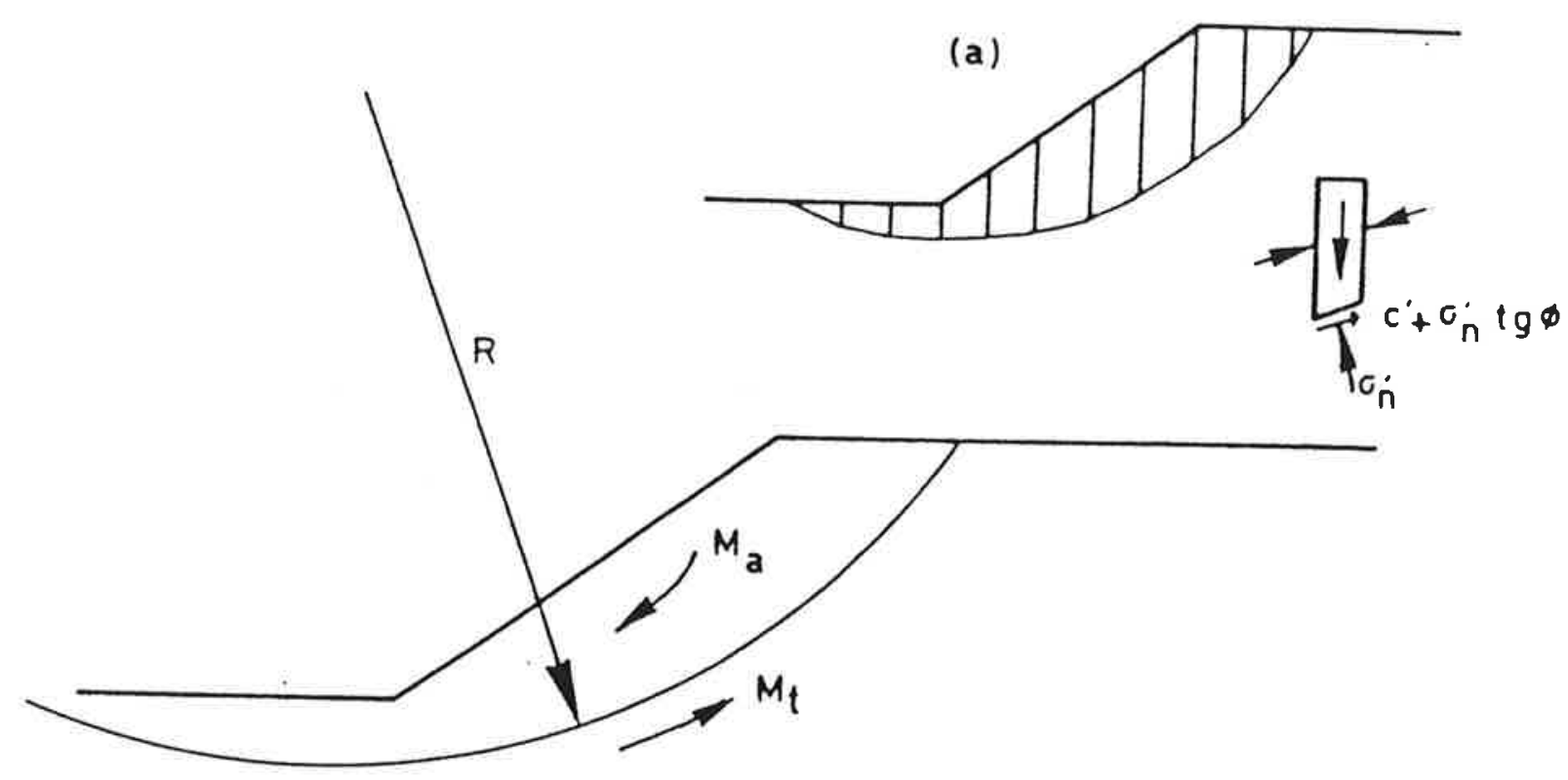

Fig. 3.3.1: Failure mechanism for instability of a slope and discretization by division into slices (a). 
The magnitude of the stability factor depends on a large number of variables, including geometry of the cross-sectional profile of the slope and of thı soil strata, dead weight of the soil and external loads, shearing strength parameters of the soil and (excess) porewater pressures, if any. In principle these quantities are uncertain variables and therefore the stability factor, too, is an uncertain quantity. In a probabilistic analysis the variables mentioned can be conceived as stochastic quantities. From the probability distributions of these so called basic variables, the probability distribution of the stability factor can be derived, and from this in turn can be deduced the probability that the stability factor is less then 1.0. Provisionally this will be designated as the probability of instability of the slope. This will be further considered in Section 3.3.4.

The uncertainty in the variables is sometimes expressed by a relative measure of variation, namely, the coefficient of variation, which is the ratio of the standard deviation and the mathematical expectation. The coefficients of variation are not equally great for all the variables in question and not every variation equally affects the stability factor. Figure 3.3 .2 gives an idea of the contributions that the various basic variables make to the variance of the stability factor. This diagram has been adopted from Alonso [3.8]. Although, strictly speaking, this distribution applies only to the case investigated by that author, there is a strong suggestion that especially the variables which affect the resisting moment dominate the uncertainty of the stability factor. The most important of these are the porewater pressures and the shearing strength properties of the soil, particularly the cohesion. 


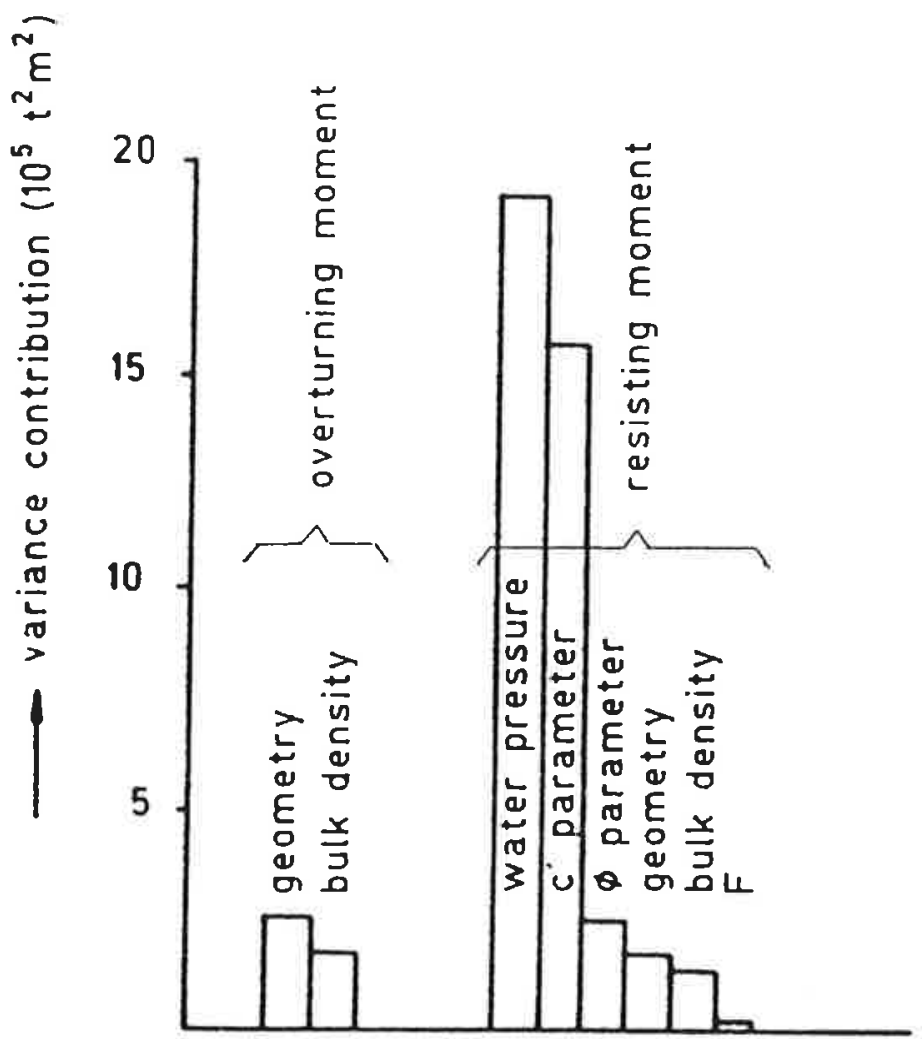

Fig. 3.3.2: Contributions to the variance of the stability factor (adopted from ref. [3.8]).

The first studies of the stability of slopes in a probabilistic context date from the early 1970s (Wu and Kraft [3.10], Cornell (3.11]). Since then there have been numerous publications in the international literature, among which the following may be mentioned: Alonso [3.8], Morla Catalan and Cornell [3.12], Tang Yucemen and Ang [3.13], Vanmarcke [3.14], Veneziano [3.15], Matsuo and Asaoka [3.16].

Without exception these studies relate to circular failure surfaces and to Bishop or Fellenius-type calculation procedures. Evidently there exists deep-rooted confidence in the correctness of these models. Stability factors calculated with Bishop's sliding circle method generally differ a little, or hardly at all, from those calculated by other methods (e.g., analyses according to spencer, Morgenstern and 
Price, or finite element analysis) in so far as determinstic calculations are concerned. On the other hand, so far as is known, the various methods have not been investigated with regard to their agreement in the results This aspect therefore offers scope for interesting investigation, which may moreover provide indications of the uncertainty associated with the sliding circle model.

\subsubsection{Reliability function}

It is provisionally assumed that a potential failure mode associated with a failure circle will or will not actually develop if the stability factor associated with this circle is, respectively, smaller than or larger than 1.0. The probability of occurrence of such a failure mode is therefore equal to the probability that the associated stability factor is less than 1.0:

$P\left(f_{i}\right)=P\left(F_{i}<1\right) \quad(i=1 \ldots n)$

where $f_{i}$ represents the event "the failure mode associated with circle $i$ occurs". The reliability function for the failure mode can be written as :

$\mathrm{Z}_{i}=\mathrm{F}_{\mathrm{i}}-1 \quad(i=1 \ldots \mathrm{n})$

and the corresponding reliability index:

$\beta_{i}=\frac{\mu_{Z_{i}}}{\sigma_{Z_{i}}}=\frac{\mu_{F_{i}}-1}{\sigma_{F_{i}}} \quad(i=1 \ldots n)$

where $\mu$ and $\sigma$ respectively denote the expectation and the standard deviation. In analogy with the definition of the stability factor of the slope the probability of instability of the slope is defined as: 
$P\{f\}=P\left\{\right.$ min $\left.F_{i}<1\right\}$

The reliability function of the slope can be written as:

$$
Z=F-1
$$

and with the definition (3.3.2) it follows that:

$Z=\min \left(F_{i}\right)-1=\min \left(F_{i}-1\right)-\min z_{i}$

This is a fairly complex reliability function because of the awkward non-linear character of the "minimum" function. Actually equation (3$.3 .6 a)$ indicates that the failure modes associated with the sliding circles form a series system (see Chapter 2):

$P(f)=P\left(\min \cdot z_{i}<0\right)=P\left(\bigcup_{i=1}^{n} z_{i}<0\right\}=P\left\{\underset{i=1}{n} f_{i}\right\}$

where the operation $U$ stands for union of events. The reliability functions $z_{i}$ of this series system are all correlated to a greater or lesser extent. The largest contributions to the system failure probability are to be expected from the sliding circles having a high failure probability. A substantial series effect will be present if the reliability functions of these circles are weakly correlated with one another. It is often assumed that the influence of the series effect for slopes will in general be slight. Besides the circle with the lowest reliability index (called the critical circle in the probabilistic sense) there is generally only a small number of circles that are not strongly correlated with the critical circle and which also have a failure probability that is not negligable. The failure probability of the slope is taken as identical with the failure probability of the sliding circle rated as critical in the probabilistic sense. Incidentally, it should be noted that this circle does not necessarily coincide with the sliding circle rated as critical in the deterministic sense, i.e., with the circle associated with the lowest deterministic stability factor. 
Note that the event $F_{i}<1$ is equivalent to the event $M_{t i}^{\max }<M_{a i}$, where $\mathrm{M}_{\mathrm{ti}}^{\mathrm{max}}$ is the maximum mobilizable resisting moment for the sliding circle $i$ under consideration. An equivalent definition of the reliability function for a sliding circle $i$ is therefore:

$\mathrm{z}_{\mathrm{i}}=\mathrm{M}_{t i}^{\max }-\mathrm{M}_{\mathrm{ai}}$

\subsubsection{Variation of the basic variables to be taken into account}

The variation of the basic variables is determined from measurements in the fieid (geometry variables, porewater pressure) or in the laboratory (shearing strength, mass density). By definition, these (point) measurements yield the variation as it manifests itself from point to point in the field (point variation).

The failure mechanism is actually a parallel system in which local variations of soil properties are at least partly averaged out. The same may apply to other basic variables.

Because of this it will, in a reliability analysis, have to be ensured that this averaging effect is properly taken into account. In most calculation procedures this is done by reducing the point variations.

It is possible to indicate theoretical relationships for the ratio between the magnitude of point variation of a variable and the magnitude of variation of the value thereof averaged over a volume under consideration. Besides being dependent on the magnitude of the averaging domain, this ratio is dependent on the variational pattern, which is expressed in the autocorrelation function (Vanmarcke [3.17]). Although a few indications relating to the auto-correlation function of some soil properties are known from the literature and although it is possible to develop some conception of these on the basis of more or less tentative 
reasoning (Calle [3.18]), it must be said that in fact little is known on the subject. Also because of the importance of the autocorrelation for the length effect to be discussed in Section 3.6, research in this field is needed. Working Group 3 of the TAW recently initiated a project into the spatial auto-correlation structure of soil properties.

As for the determination of the averaging effect there is also another matter involved. Even if the autocorrelation function is already known for the various basic variables, it is still necessary to indicate a relevant measure for the width of the fallure mode mass in the longitudinal direction of the dyke. It is possible to establish estimates for this width with the aid of a somewhat more refined model for the failure mechanism associated with macro-instability (Vanmarcke [3.14], Calle [3.19]). The estimated width is, incidentally, again dependent on the auto-correlation function. Apart from that, the length effect and the effect of the finite dimension of an instability (contributions of the end section surfaces to the resisting moment) are incorporated in these refined models. The averaging effect is consistently taken into account in the model. However, in order to keep the - already quite complicated - first step to an integrated safety analysis as simple as possible, these models have not yet been applied in the worked example of Chapter 7.

\subsubsection{Effect of exceeding the limit state}

The event $" Z<0 "$ is referred to as "exceeding the limit state of stability". In the worked example relating to a river dyke (Chapter 7) this event is assumed to imply that instability actually occurs and that it is of such extent that it leads directly to inundation of the protected region. Both assumptions are debatable.

That a stability factor less than 1.0 need not necessarily result in actual instability can be demonstrated with the aid of a refinement of the computational model in which the contributions of the end surfaces to the resisting moment of a soil slide of finite length are also taken 
into account. Due to these contributions the probability that a failure of finite width will occur is less than the probability that the stability factor (in the conventional sense) is less than 1.0 . It is to be noted, however, that in the definition of the probability of unstable behaviour (according to equation 3.3.3) the length effect that would result in a higher assessment of the failure probability is not included (see Section 3.6).

Nor does it follow at all necessarily that an actual instability would thereupon result in complete loss of function of the dyke. A failure not leading to (any appreciable) lowering of the crest level of the dyke does not present any direct danger of flooding. It can be said, however, that the dyke has suffered a local loss of strength, so that the probability of disastrous loss of stability in the event of a sufficiently high water level may have considerably increased.

The supposition that loss of stability must lead directly to inundation danger is, it would appear, indeed a conservative one, but not unrealistic.

\subsubsection{Effect of other mechanisms on macro-instability}

The occurence of other mechanisms could lead to an increased risk of macro-instability and thus to a higher probability of inundation than can be expected on the basis of the mechanism itself.

For example, the mechanism "overflowing" need not necessarily lead to catastrophic inundation of the polder if the rate of overflow is sufficiently small in relation to the water storage capacity of the polder, taking into account the reserve drainage pumping capacity. However, overflowing water will infiltrate into the inner slope of the dyke, in consequence of which the reserve of strength against macro-instability drastically decreases due to saturation (Edelman effect) or to air inclusions (Lisse effect). Should this lead to unstable behaviour of the inner slope, the dyke could be breached and catastrophic inundation of the polder occur in consequence. 
A similar line of reasoning can be developed with regard to microinstability. Characteristic of this mechanism, as formulated in Section 3.4 .3 , is that initial micro-instability leads to scour of the inner slope of the dyke until a state of equilibrium is reached, by which time the crest level of the dyke may or may not have been lowered. In the latter case this mechanism is assumed not to result in a dyke breach; but it is conceivable that an increased probability of macro-instability will occur in consequence of scour of the inner slope.

In the Working Group's opinion the effect of such "trigger" mechanism calls for further investigation.

\subsubsection{Development of phreatic water pressures in a river dyke during a}

\section{flood wave}

Because of the importance thereof with regard to possible unstable behaviour of the inner slope, in the worked example for a river dyke considerable attention has been paid to finding a simple computational model with which the time-dependent position of the phreatic surface as a function of the water level in the river can be estimated [3.21].

In the first place, the effect of any revetment or protective covering layer on the outer (riverward) slope has been assumed to be negligible. This assumption is not uncommon for the purpose of a deterministic check of dyke stability. On the basis of assumed horizontal flow of the ground-water in the body of the dyke (so-called Dupuit assumption), formulae have been derived for estimating the position of the phreatic surface and the magnitude of the seepage area on the inner surface of the dyke as a function of the time-dependent river head fluctuation during flood flow. It proved possible greatly to simplify the formulae, so that the reliability calculations could be performed with very simple formulae.

Later on, a computational model has been developed in order to investigate the effect of a more or less impervious covering layer on 
the ground-water flow behaviour. By simplification it subsequently again proved possible to establish an extremely simple procedure for reliability calculations. In broad outlines, the computational model comprises the following. The covering layer is assigned leakage properties in which the thickness and permeability of the layer, the degree of cracking and possible perforation, and leakage at the junction between the covering and the other dyke and subsoil material, can play a part. All these influences are combined in a leakage factor for the covering layer. With the aid of this factor and the potential head drop across the layer, the leakage flow rate through the layer is calculated. This flow feeds the (horizontal) phreatic ground-water flow through the core of the dyke. The position of the phreatic surface and the magnitude of a seepage area, if any, can be estimated from this. On the bas is of simple assumptions it was possible to make a theoretical estimate of the leakage factor in the design presented in the worked example. It emerged from the reliability calculations that the estimated probability of instability was drastically reduced by considering a more or less impervious covering layer. The effectiveness of such layers therefore deserves further (empirical) investigation.

\subsection{Micro-instability}

\subsubsection{Mechanism}

Micro-instability is a particular mode of slope instability, analogous to the macro-stability mechanism (see Section 3.3). Micro-instabilities occur at the surfaces of slopes (above or under water) where soil particles are removed from the slope under the influence of the flow of ground-water seeping out.

In the case of dykes this phenomenon usually occurs in the lower section of the inner slope, during or shortly after high (river or sea) water levels. The area over which the ground-water emerges from the dyke is called the seepage area. In practice, micro-instability occurs more particularly in non-cohesive materials (e.g. sand). Deeper slips are more likely to occur in cohesive materials (e.g. clay). 
The mechanism can be described with reference to considerations of critical equilibrium on similar lines to those applicable to macroinstability. However, in view of the small-scale character of the phenomenon (washing-out of small soil elements), it is usual to consider, not the equilibrium of moments, but the equilibrium of forces parallel to the slope. The following volume forces can be conceived as acting on a small soil element located at the surface of the slope (see Figure 3.4.1):

- Effective weight (vertical): $\gamma_{n}-\gamma_{w} \gamma_{w}$ - mass density of water; $\gamma_{n}$ - unit weight of wet soil

- Force exerted by flow : $i \cdot \gamma_{w}$ ( $i$ - hydraulic gradient).

This flow force acts in the direction of the ground-water flow emerging at an angle $\beta$ with respect to the horizontal.

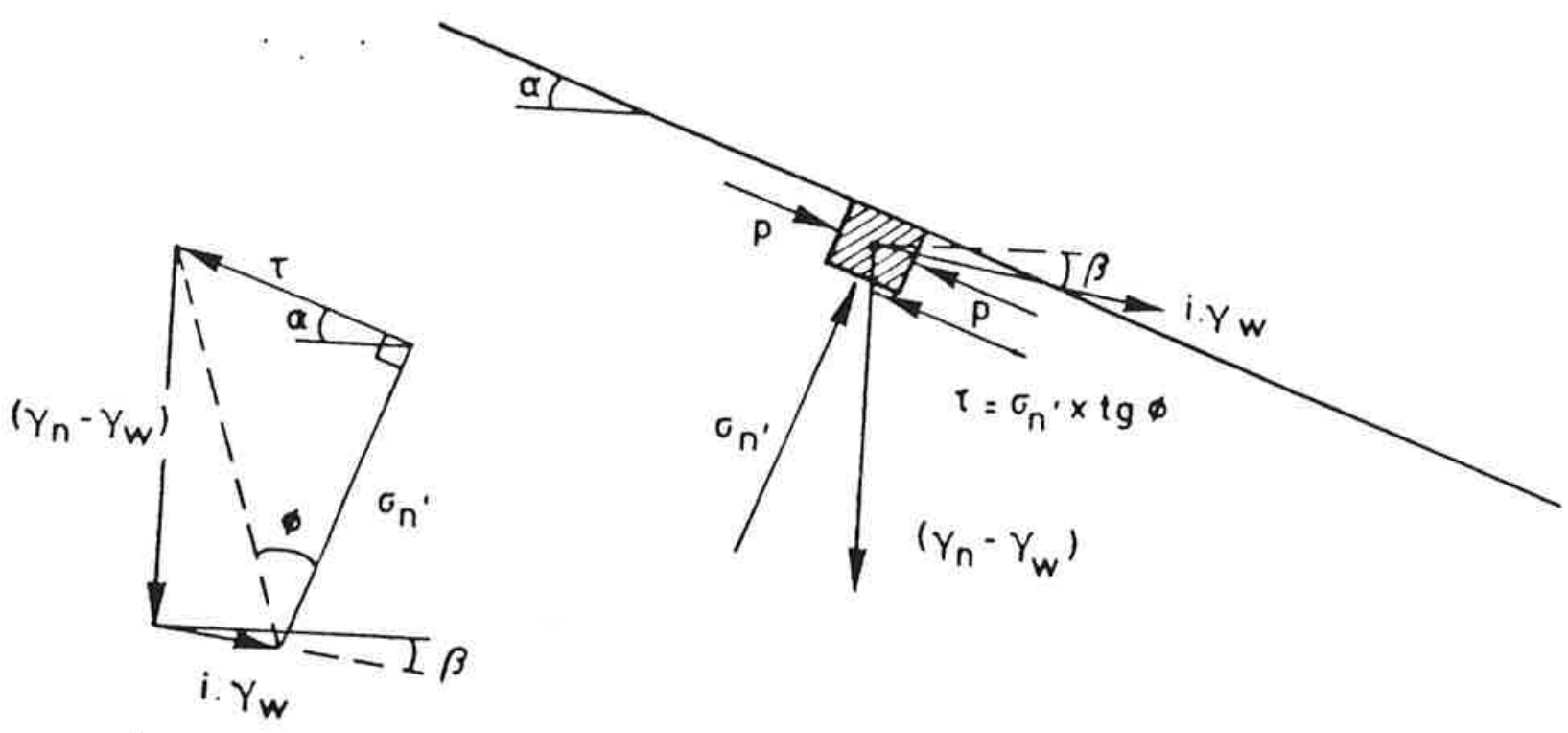

Fig. 3.4.1: Forces acting on a volume element at the surface of an earth slope with outflow of ground-water.

The resisting "force" acting on the underside of the soil element is the shear stress $\tau$, the maximum value of which is $\sigma_{n}^{\prime} \operatorname{tg} \varphi$, where $\varphi$ denotes the angle of internal friction of the soil and $\sigma_{n}^{\prime}$ the normal effective stress at the underside of the element. The effective forces $p^{\prime}$ acting 
on the two side faces are assumed completely to compensate each other. Actually, this is correct only for a slope of infinite length in which, on the basis of symmetry considerations, these forces are equal. From the equilibrium parallel to the slope (see figure 3.4.1) with angle $\alpha$ it can be deduced that the element is stable if the following condition is satisfied:

$\frac{i \cdot \gamma_{\mathrm{w}} \cdot \cos (\alpha-\beta)+\left(\gamma_{\mathrm{n}}-\gamma_{\mathrm{w}}\right) \cdot \sin \alpha}{-i \cdot \gamma_{\mathrm{w}} \cdot \sin (\alpha-\beta)+\left(\gamma_{\mathrm{n}}-\gamma_{\mathrm{w}}\right) \cdot \cos \alpha}<\operatorname{tg} \varphi$

\subsubsection{Reliability function}

With the aid of formula (3.4.1) the reliability function can be determined for a number of conditions:

1. Ground-water flowing out of slope above water level

For water flowing out of a slope located above the water level we have $i=\operatorname{tg} \alpha$. The outflow direction is assumed to be horizontal ( $\beta$ - 0) for which, according to formula (3.4.1), the most unfavourable situation is obtained.

(Note: upward-directed flow on the slope abovewater level $(\beta<0)$ is, because of the descending character of the phreatic line, for the present assumed not the be real).

The variability of $\gamma_{n}$ for sand is relatively small compared with the variability of the friction angle $\varphi$. Hence the quotient $\gamma_{n} / \gamma_{w}=$ can be treated as a deterministic parameter.

With the above assumptions, and substituting $\gamma_{n} / \gamma_{w}=2$, the formula (3.4.1) can be rewritten to give the reliability function:

$$
Z=\operatorname{tg} \varphi-\operatorname{tg} 2 \alpha
$$

The basic variable of the reliability function are limited to the angle $\alpha$ of the slope and the internal friction angle $\varphi$.

\section{Ground-water flowing out of slope below water level}

Under water it is, by definition, only possible to have perpendicular outflow (equipotential line perpendicular to streamline); therefore $\beta=\alpha-90^{\circ}$. With this relation and again substituting $\gamma_{\mathrm{n}} / \gamma_{\mathrm{w}}=2$, formula (3.4.1.) can be rewritten as: 
$z=\operatorname{tg} \varphi-\frac{\sin \alpha}{\cos \alpha-i}$

So in this case it is found that, besides the angle $\alpha$ of the slope and the soil strength parameter $\varphi$, the magnitude of the gradient $i$ is also an important basic variable..

In general, the gradient can be determined with the aid of groundwater flow calculations. A number of models are available for the purpose, including electric analogue models, numerical models based on finite element methods (SEEP-GD, SOPHIA-TUD) * and on finite difference methods (MOTGRO-RWS and others). Furthermore, for a number of highly schematized cases there are analytical expressions available.

\subsubsection{Effect of exceeding the limit state}

If the limit state of micro-instability is exceeded, this will not necessarily lead at once to loss of the water-retaining function of the dyke. In general, the material removed by scour will be deposited close to the slope. Besides, scour will remain confined to that zone where the stability criterion is not satisfied.

For slopes below the water level the start of the scour and sedimentation zone is not directly and straightforwardly determinable. By means of supplementary ground-water flow calculations for assumed sedimentation zones, however, it can be ascertained whether the process stops or proceeds further.

For slopes above the water level it is possible to make an approximate estimate of the damage profile on the following assumptions (see Figure 3.4.2):

- The material cannot be removed by scour at a higher level than the original point of exit on the seepage area (outflow level 0 ).

- The material that is carried away with the flow is deposited at an equilibrium slope of $\varphi / 2$.

- The material located higher up can subside so that it attains the natural angle of repose $\varphi$.

* RWS $=$ Rijkswaterstaat (Public Civil Engineering Works Department); GD = Delft Geotechnics; TUD = Delft University of Technology. 


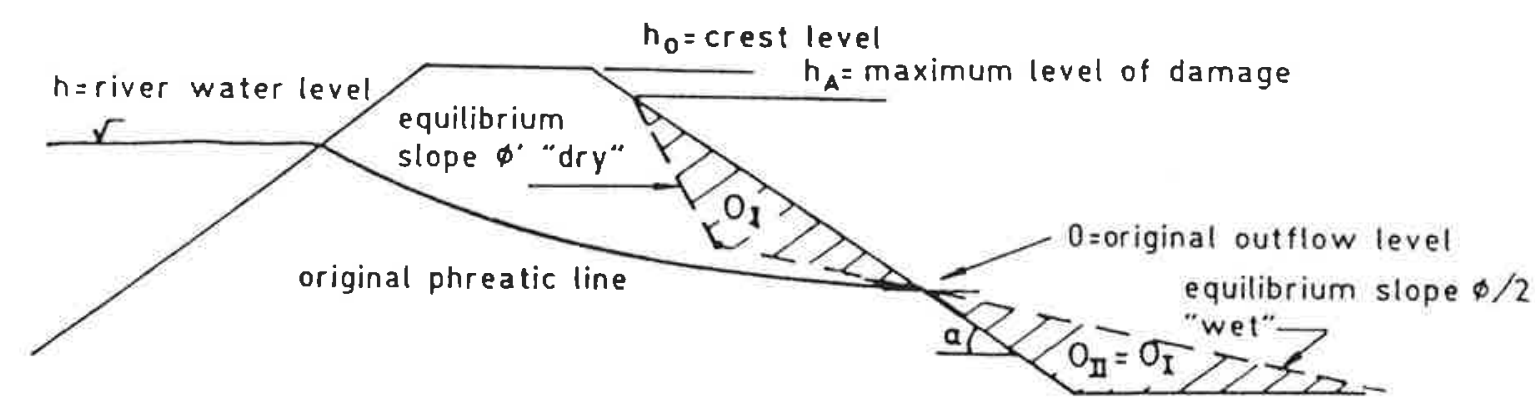

Fig. 3.4.2: Damage profile due to micro-instability of a slope above water.

In Appendix $V$ of [7.1] the maximum level of damage $h_{A}$ is, for simple dyke geometry, expressed as a function of the outflow level 0 , the angle of the slope $\alpha$ and the angle of internal friction $\varphi$.

If it is assumed, as a closer definition of dyke failure due to microinstability, that failure occurs if the damage level $\mathrm{h}_{\mathrm{A}}$ advances into the crest level $h_{0}$, then the following reliability function is obtained:

$\mathrm{z}=\mathrm{h}_{\mathrm{O}}-\mathrm{h}_{\mathrm{A}}(0, \alpha, \varphi)$ if $\alpha>\frac{1}{2} \varphi$

The outflow level 0 is determined by the river water level $h$, the duration thereof $T$, the dyke geometry, and the permeability $k_{i}$ of the (various layers composing) the body of the dyke. Analytical expressions for the outflow level relating to highly schematized dyke crosssectional profiles exist [3.22]:

$$
0=f\left(h, T, k_{i}, \text { geometry }\right)
$$

The analogue or numerical models mentioned earlier on are available for dealing with more complex situations. 
It is to be noted that with regard to the damage profile described above it is necessary also to check the macro-instability, particularly for surfaces of sliding which pass through the crest of the dyke.

To summarize, it can be said that the limit state of micro-instability can now be described with reasonable accuracy. Besides, adequate measures for the prevention of micro-instability are simple to apply in practice (reducing the steepness of a part of the slope or installing a covering of filter material).

For these reasons further research into the mechanism of microinstability, which would then more particularly have to concentrate on the damage profile associated with this, is not considered urgent for the immediate future.

$\underline{\text { Note }}$

In some publications, including [3.23], the term "liquefaction" is used to denote micro-instability. This is incorrect in principle, however. Liquefaction occurs only if, in consequence of an increase in the pore water pressures, the effective soil stresses become zero (as in quicksand).

\subsection{Piping}

\subsubsection{Mechanism}

Piping under dykes occurs as a result of the entrainment of soil particles by the erosive action of seepage flow. The piping phenomenon is preceded by the formation of springs discharging water in which sand is carried along. Such springs, which manifest themselves especially at periods of high water level retained by the dyke (see Figure 3.5.1), are frequently to be observed not only along river dykes but also along sea dykes (including those in the province of Zeeland [3.24]). 


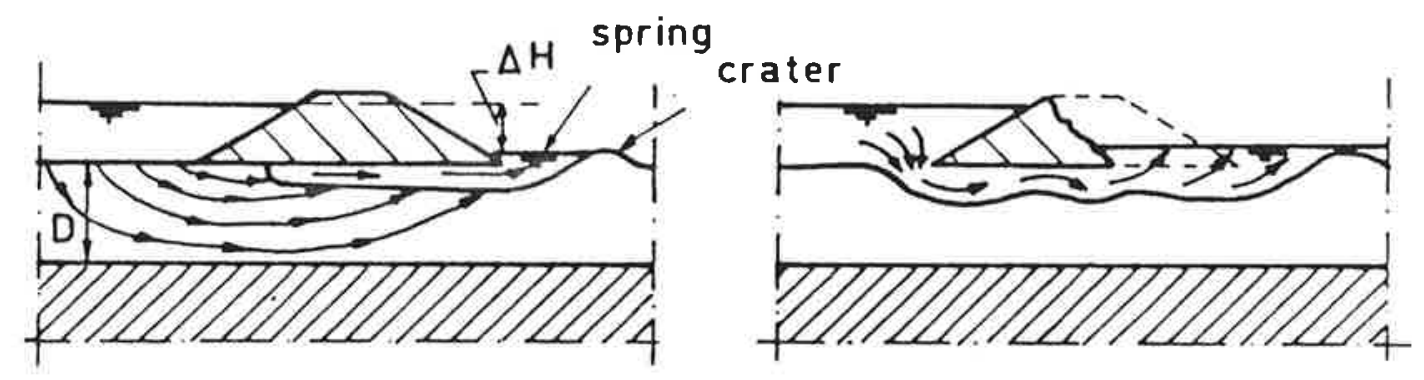

Fig. 3.5.1: Sandbearing springs and piping.

The magnitude of the seepage flow in waterbearing sand stratum under a dyke will depend on the difference between the water level retained by the dyke (intake side) and the water level in the polder (outflow side) and on the geometry and permeability of the sand stratum (including seepage path length and thickness of the stratum). For piping, the intensity of the seepage flow (hydraulic gradients) at the outflow zone is more particularly of importance.

Whether a particular outflow gradient will indeed cause piping is moreover determined by the properties of the sand stratum, of which the mean grain diameter $D_{50}$ and the coefficient of uniformity $U=D_{60} / D_{10}$ are considered to be the principal parameters.

The existing criteria, such as those applied in the Netherlands more particularly to the assessment of river dykes and aiming to prevent incipient piping, relate to water level differences of long duration. For this purpose the seepage flow can be conceived as steady flow.

For river dykes this is an obvious approximation because the relevant flood waves are usually of several weeks duration. On the other hand, in the case of sea dykes such long periods of high water generally do not occur. For this reason the danger of piping has hitherto been regarded 
as not great, despite the fact that a dyke breach which occured at Tholen in 1894 was probably due to piping.

Note

If the inner slope of the dyke has an impervious covering layer, piping through this layer can occur only after it has ruptured. In this situation the conditon for piping is therefore that the rupturing criterion is fulfilled. This occurs if the water pressure $u$ on the underside of the covering layer exceeds the soil stress due to the wet weight of this layer:

$u>\Sigma d_{i} * \gamma_{n_{i}}$

where $d_{i}$ is the thickness and $\gamma_{n_{i}}$ the wet unit weight of the covering layer.

\subsubsection{Reliability functions}

\section{Empirical method of Bligh and Lane}

In the past, design rules were established - by, among others, Bligh [3.29] and Lane [3.30] - with regard to piping and underflow associated with rock-fill dams on the basis of a statistical analysis of such structures which had and which had not failed. In connection with this a minimum necessary seepage path length $L_{k}$ under the structure was determined:

$\mathrm{L}_{\mathrm{k}}=\mathrm{c} * \Delta \mathrm{H}$

where $\Delta H$ is the total head loss (overall difference in water level) across the structure and $c$ is a coefficient depending on the type of soil (see Table 3.5.1). For the definition of the seepage path length $\mathrm{L}_{k}$ and the magnitude of the coefficient $c$, depending on soil type, the reader is referred to $[3.25]$.

These rules, though orlginally intended for structures such as dams, have - in the Netherlands and elsewhere - been applied also to 
river dykes for determining a minimum necessary seepage path length in the sand subsoil of an impermeable clay dyke and of any poorly permeable top layers of soil on the foreland (more particularly the winter bed of the river). For Dutch conditions this comes down approximately to a seepage path length $L_{k} \geq 15 \times \Delta H$ (for example, ranging from $12 \times \Delta H$ for coarse sand to $18 \times \Delta H$ for fine sand, according to Bligh [3.29]).

The entry point of the ground-water flow can be taken as being loca: ed at the toe of the dyke or, if there are poorly permeable layers on the foreland, at a distance $L^{\prime}-\lambda \cdot \tan \left(L_{1} / \lambda\right)$ from the outer toe (see Figure $3.5 .2[3.26]$ ). In this formula $\lambda=\alpha k . D . c$ is the dispersion length, while $k$ denotes the permeability of the subsoil, $D$ the thickness of the water-bearing stratum (aquifer) and $c=d / k_{v}$ the resistance of the top layer (with thickness $d$ and permeability $k_{v}$ ).

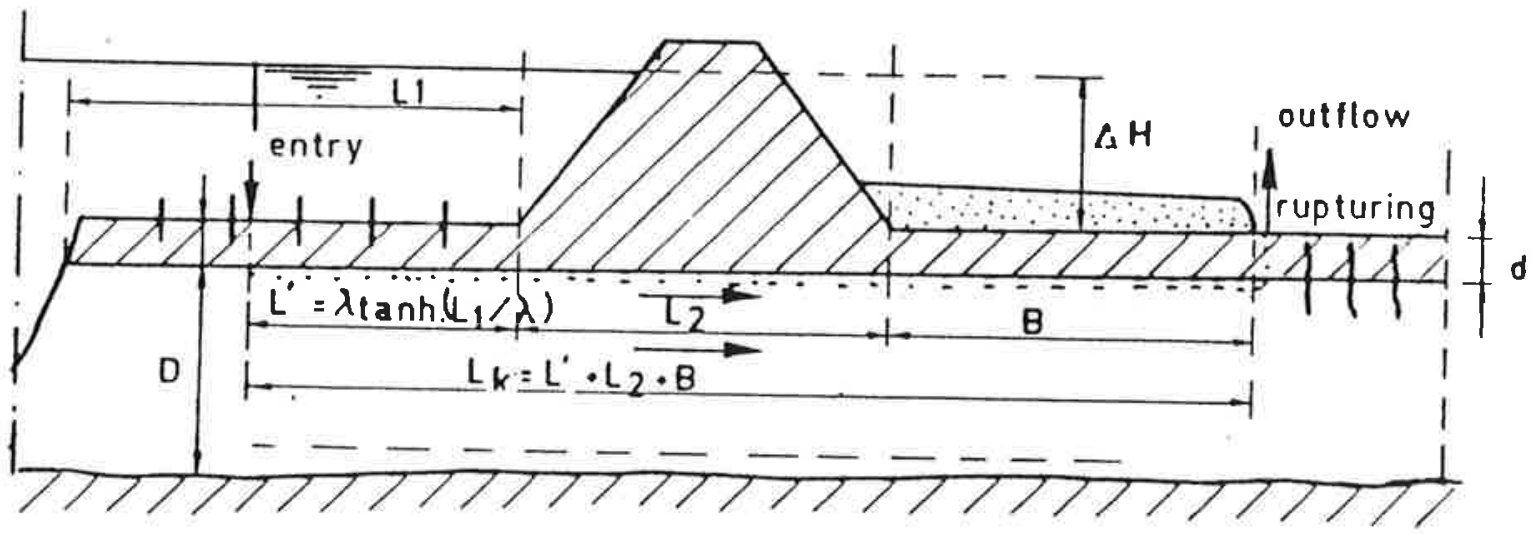

Fig. 3.5.2: Determination of minimum seepage path length.

With the aid of formula (3.5.2) the reliability function can be written as follows:

$Z=m * \frac{L_{t}}{c}-\Delta H$

where:

$L_{t}=L^{\prime}+L_{2}+B+d$ and $c-c_{B}=$ constant depending

on soil type (see Table 3.5.1), according to Bligh [3.29]. 
or:

$L_{t}=\left(L^{\prime}+L_{2}+B\right) / 3+d$ and $c=c_{L}=$ constant depending

on soil type (see Table 3.5.1), according to Lane [3.30].

$\Delta \mathrm{H}=$ Total Head loss (difference in water level retained by dyke and water level in polder).

$\mathrm{m}=$ Model factor taking account of the scatter in empirical observations and also of the poorly representative character of those observations with regard to flood defences in the Netherlands.

The parameters $\mathrm{L}_{2}$ and $\mathrm{B}$ are defined in Figure 3.5.2.

Table 3.5.1: Values of $c$ adopted in the methods of Lane and B1igh [3.25].

\begin{tabular}{|l|c|c|}
\hline Type of soil & c-value Lane & c-value Bligh \\
\hline very fine sand or silt & 8.5 & 18 \\
fine sand & 7.0 & 15 \\
medium-grained sand & 6.0 & - \\
coarse sand & 5.0 & 12 \\
fine sand & 4.0 & - \\
medium grained gravel & 3.5 & - \\
gravel and sand & - & - \\
coarse gravel & 3.0 & - \\
boulders and gravel & 2.5 & - \\
boulders, gravel and sand & - & - \\
soft clay & 3.0 & - \\
medium-firm clay & 2.0 & - \\
hard clay clay & 1.8 & 1.6 \\
very hard clay & & \\
\hline
\end{tabular}

The fundamental objection to the methods of Bligh and Lane is that they do not take account of the potential pattern of the seepage flow in a clear-cut manner. It is known from research into ground-water flow that the seepage into (and therefore the hydraulic gradients at) the ditch at the inner toe of the dyke depends not only on the seepage path length, but also on the thickness of the water-bearing sand stratum (aquifer) and the width of the ditch. For relatively low thicknesses of the sand stratum (< approx. $6.0 \mathrm{~m}$ ) the gradients are considerably smaller than for large thicknesses, so that in such cases the danger of piping is much less. In the "model test extrapolation" method described below, the effects of sand stratum thickness and ditch width are explicitly taken into account. 
2. Method based on model test results

This method is generally applicable to water-retaining structures without the presence of vertical cut-off walls are installed on the downstream side, e.g., dams or dykes on a permeable subsoil.

In general, there are four possible geometries, see Figure 3.5.3:

1. Covering layer on the inner ("landward") side of the dyke is completely absent.

2. Covering layer on the inner side is intersected by a ditch.

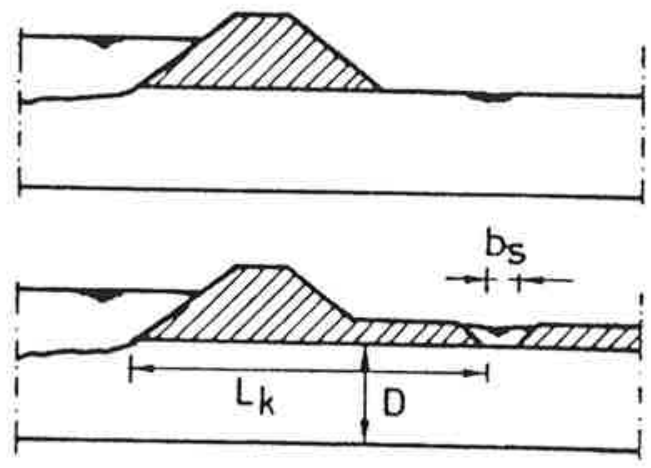

3. There is a hole in the covering layer on the inner side.

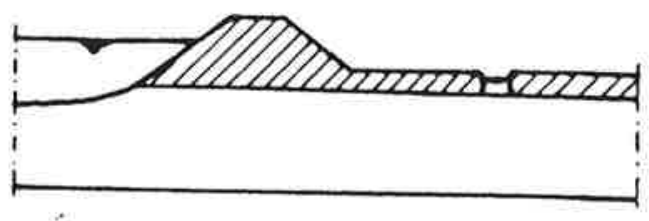

4. Covering layer on the inner side of this dyke is completely present.

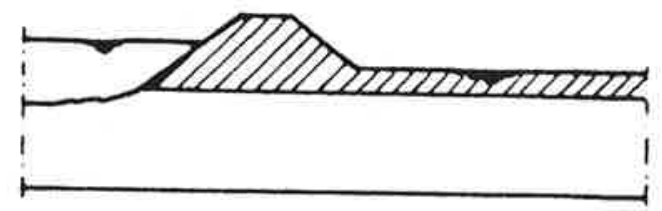

Fig. 3.5.3: Standard dyke geometrics for assessment of the limit state of piping.

Research into the occurence of piping has meanwhile made such progress that for the most hazardous cases the critical head loss across a water-retaining structure can in general be determined, namely, the cases $a$ and $b$. Note that the criterion applied is the instant when the spring which has been formed begins to carry sand along. 
The method employed for determining the critical head loss is based on the results of tests performed with scale models. By means of an extrapolation procedure for a particular case, the result of a model test can be scaled up to a result for a prototype situation. The method is still in the provisional stage because the research has not yet been completed. The effect of a number of uncertainties remains to be tested. It certainly cannot lay claim to general validity, since the geometry of the prototype may vary greatly, and the influence of this may be quite considerable.

The extrapolation procedure for the cases $a$ and $b$ has meanwhile been established, however. In this approach the critical head loss, which has been determined in a model test, is scaled up to give the critical fall associated with the prototype.

The critical head loss is the loss at which piping (formation of sandbearing springs) begins.

Scaling-up proceeds as follows:

$\Delta \mathrm{H}_{\mathrm{p}}=\epsilon \cdot \Delta \mathrm{H}_{\mathrm{m}}$

where:

$\Delta \mathrm{H}_{\mathrm{p}}=$ critical head loss in the prototype situation;

$\Delta \mathrm{H}_{\mathrm{m}}=$ critical head loss in the model test: it is a function of the type of sand $\left(D_{50}, U=D_{60} / D_{10}\right.$ and the porosity);

$\epsilon=$ scale factor determined from the theoretical description of the groundwater flow pattern of model and prototype: it is a function of the seepage path length $I_{k}$, the thickness of the permeable stratum $D$ and the width of the bottom of the ditch $\mathrm{b}_{\mathrm{s}}$.

The reliability function for the limit state "occurence of sandbearing springs" is established as follows:

$\mathrm{Z}=\epsilon\left(\mathrm{L}_{\mathrm{k}}, \mathrm{D}, \mathrm{b}_{\mathrm{s}}\right) * \Delta \mathrm{H}_{\mathrm{m}}\left(\mathrm{n}, \mathrm{D}_{50}, \mathrm{U}\right)-\Delta \mathrm{H}$ 
The function of $\epsilon$ and $\mathrm{H}$ for a number of dyke cross-sectional profiles are known [3.25].

\section{New developments}

- At the request of Working Group 2 of the TAW, research into the theoretical modelling of the piping mechanism is being continued. Besides the determination of the ground-water flow pattern (see factor $\epsilon$ under point 2 above), it was attempted also to describe the erosion process itself on the basis of a stability criterion for the grains at the surface of the piping discharge channels. The first two-dimensional treatment of the problem by GD is encouraging. Further investigation into this phenomenon, including prototype verification tests, should be promoted. Only after a reasonably finialized "deterministic" transport model has been established will further probabilistic treatment be necessary.

- A second aspect, which has more particularly been investigated in connection with piping affecting the Eastern Scheldt dykes [3.24], relates to the time-dependent character of ground-water flow. It appears that with water levels of relatively short duration the seepage cannot develop into fully steady flow. This means that the hydraulic gradients that occur, especially in the outflow zone, are generally smaller than when the dyke retains high water level of long duration. This being so, it is permissible to allow larger head loss across the dyke depending on the duration. For a particular type of Eastern Scheldt dyke profile an analytical expression has been derived for this [3.24]. In the case of river dykes this reduction factor is probably of minor importance because of the relatively long duration of the flood waves.

Note

In those cases where an uninterrupted impermeable covering layer is present on the inner ("landward") side of the dyke it is necessary first to fulfil the rupturing criterion before piping can occur (see also Section 3.5.1). 
The reliability functions (3.5.3) and (3.5.7) should then be extended with the condition:

$$
z=\Sigma d_{i} * \gamma_{n_{i}}-u<0
$$

The pore water pressure $u$ should be calculated with the aid of groundwater flow models (analogue to the determination of $\epsilon$ ).

\subsubsection{Effect of exceeding the limit state}

In considering the limit state of piping a distinction should be drawn between the methods of Bligh and Lane, on the one hand, and the test extrapolation method developed by TAW-GD, on the other.

The first-mentioned methods are based on empirical data relating to dams which did or did not fail. The criteria derived from these structures therefore have reference to their complete collapse, directly resulting in inundation of the region to be protected.

The method developed at the instance of the TAW, however, relates to the prediction of the start of sandbearing springs. In actual practice it turns out that springs which initially discharge (much) sand may, after a time, discharge only water. The deposition of a crater-like conformation around the spring can - besides possible filtering action by the coarse fractions of the soil stratum involved - be considered probably to play an important part in connection with this. This favourable crater effect has been demonstrated also in the context of the new theories that have been developed, as mentioned in Section 3.5.2.

Evidently a distinction must be drawn between a head loss which gives rise to crater formation but after a time results in a state of equilibrium and a head loss (the critical loss) which gives rise to continuing erosion resulting in piping discharge channels forming "short-circuiting" flow paths. It may be expected that in the event of such "short-circuiting" this will very rapidly (within a few hours) lead to complete collapse of the water-retaining structure. The length of time needed for such a pattern of continuous channels to develop (of the order of hours, days or weeks ??) may be an important aspect, however. Hence it is advisable also to include this erosion duration effect in 
theoretical studies. An additional complicating factor with regard to this latter aspect is the possible cumulative effect: the contribution of piping at lower values of the hydraulic fall then the critical value.

\subsection{Length effect}

\subsubsection{Introduction}

The Delta Commission's design guidelines [3.2] for the economic (frequency) analysis state that a dyke fails if the water level (possibiy in conjunction with wave runup) is higher than the crest of the dyke. Assessment of the stability of slopes is based on sliding surface calculations which are of a two-dimensional character. In neither of these two categories of calculations the length of the dyke is taken into cousideration.

In consequence.of (time-dependent) settlement and consolidation, however, the height of the crest will not everywhere (along the length of the dyke) be equally high. Also, the shearing resistance adopted in the slope stability calculations is not constant all along the dyke. Actually, the length effect should be taken into account for all the mechanisms concerned. The parameters will have to be introduced as stochastic quantities which are correlated along the length (and mutatis mutandis also in depth).

\subsubsection{Discrete dyke segments}

Experience shows that overflowing and wave overtopping of the crest of a dyke occurs onl $y$ over a limited length (though possibly in several places along the crest) and that sliding soil masses are also of limited length. These circunstances lead to the conception of dividing the dyke into segments (or sections), all of which have a probability of failure depending on the (stochastic) strength parameters (crest level, shearing resistance, etc.). In this approach the dyke is conceived as consisting, over its entire length, of a series system of consecutive segments. The system fails if, for at least one segment, the load exceeds the strength. According as the dyke is longer, the probability of this occuring can be expected to be higher. 
In the simplest case it can be assumed that the strength and load properties of two dyke segments are completely correlated. The failure probability of $n$ segments is then equal to that of a single segment.

In the opposite extreme case the properties of two dyke segments are completely independent (uncorrelated). If the probability of failure of one segment is known, the probability that $n$ segments will fail can be calculated as:

$P$ (failure $n$ segments) $=$

$1-[1$ - P\{failure 1 segment $\}]^{\mathrm{n}} \approx \mathrm{n} \times \mathrm{P}$ (failure 1 segment

The stochastic parameters of dyke segments which are situated close to one another may in some cases be strongly correlated, whereas those of segments situated farther apart may be less correlated. The degree of interrelationship of the reliability functions of two segments, depending on their distance apart, is given by the coefficient of correlation $\rho\left(Z_{i}, Z_{j}\right)$, where $Z_{i}$ denotes the reliability function of the $i-t h$ and $z_{j}$ the reliability function of the $j$-th segment. The coefficient of correlation is a function of the distance between the segments $i$ and $j$ (autocorrelation function).

The reliability function can be represented by:

$$
Z=R-S
$$

so that: $z_{i}=R_{i}-s_{i}$ and $z_{j}=R_{j}-s_{j}$.

The coefficient of correlation between the reliability functions of the segments $i$ and $j$ is given by: 
$\rho\left(\mathrm{Z}_{i}, \mathrm{Z}_{\mathrm{j}}\right)=\frac{\rho\left(\mathrm{R}_{i}, \mathrm{R}_{j}\right) \sigma\left(\mathrm{R}_{i}\right) \sigma\left(\mathrm{R}_{j}\right)+\rho\left(\mathrm{S}_{i}, \mathrm{~S}_{j}\right) \sigma\left(\mathrm{S}_{i}\right) \sigma\left(\mathrm{S}_{j}\right)}{\sigma\left(\mathrm{Z}_{i}\right) \times \sigma\left(\mathrm{Z}_{j}\right)}$

In many cases the autocorrelation function tends to zero for a long distance between two segments under consideration. The actual parameter values at two locations far apart have no relationship with one another. For the probability of failure of a dyke having a particular length, a good approximation can then be given with the Ditlevsen upper and lower bounds. But in those cases where the auto-correlation function for segments spaces far apart does not tend to zero the upper bound approximation according to Ditlevsen results in greatly overestimating the probability of failure. For such cases a better approximation method or methods will have to be sought.

\section{Example 1: Coefficient of correlation tends to zero for large (i-j)}

For the purpose of a design calculation a dyke with length $\mathrm{L}_{\mathrm{d}}$ is divided into segments of length $1-200 \mathrm{~m}$. For each section a probability of failure due to sliding is calculated with the aid of a level II reliability analysis:

$$
P\left(Z_{i}<0\right)=10^{-4}
$$

The strength properties in the longitudinal direction of the dyke are variable. The strength and load within any one particular segment are assumed to be completely correlated. The correlation between the reliability functions of two sections $i$ and $j$ is given by:

$\rho\left(z_{i}, z_{j}\right)=\exp \left\{-\left(\frac{l \Delta i}{d_{c}}\right)^{2}\right\}$

where $\Delta i=i-j$ and $d_{c}$ is the correlation length which is taken as $500 \mathrm{~m}$. The reliability functions $z_{i}$ are normally distributed.

The problem now is to find:

a. with the aid of Ditlevsen's approximate formulea, the probability of $P\left\{z_{i}<0\right.$ and $\left.z_{j}<0\right\}$ for $i=1,2,3$ and 4 . 
b. the first-order and Ditlevsen lower and upper bounds for the probability of failure of the entire dyke, as a function of the length $L_{d}$ of the dyke.

The results must be presented in a diagram for $0<\mathrm{L}_{\mathrm{d}}<10 \mathrm{~km}$. For $\Delta i>5$ it is permissible to adopt $\mathrm{P}\left\{\mathrm{z}_{\mathbf{i}}<0\right.$ and $\left.\mathrm{z}_{\mathbf{j}}<0\right\}=0$.

a. According to Ditlevsen's formule (2.3.7) we have approximately:

$P\left(Z_{i}<0\right.$ and $\left.z_{j}<0\right\}=\Phi\left(-\beta_{i}\right) \Phi\left(-\beta_{j}^{*}\right)+\Phi\left(-\beta_{i}\right) \Phi\left(-\beta_{j}^{*}\right)$

where $\Phi$ is the distribution function for the standard normal distribution, $\beta_{i}$ the reliability index corresponding to $z \leqslant 0$ (and similarly for $\beta_{j}$ ), and $\beta_{i}^{*}$ is expressed by (and similarly for $j$ ):

$\beta_{i}^{\star}=\frac{\beta_{i}-\rho \beta_{j}}{\sqrt{ }\left(1-\rho^{2}\right)}$

In this case: $\beta_{i}=\beta_{j}=\beta$, so that the formulae are simplified to:

$\mathrm{P}\left\{\mathrm{z}_{\mathrm{i}}<0\right.$ and $\left.\mathrm{z}_{\mathrm{j}}<0\right\}=2 \Phi(-\beta) \Phi\left(-\beta^{*}\right)$

$\beta *=\beta \sqrt{ }\left(\frac{1-\rho}{1+\rho}\right)$

$\rho\left(Z_{i}, Z_{j}\right)=\exp \left\{-\left(l \Delta i / d_{c}\right)^{2}\right\}=\exp \left\{-(0.4 \Delta i)^{2}\right\}$

$\beta$ follows from $\Phi(-\beta)=10^{-4}: \beta-3.72$ (see Table 2.2.1). 
The further calculation is performed in the following table:

\begin{tabular}{|lclll|}
\hline$\Delta i$ & $\rho\left(\mathrm{Z}_{\mathrm{i}}, \mathrm{Z}_{\mathrm{j}}\right)$ & $\beta^{*}$ & $\Phi\left(-\beta^{*}\right)$ & $\mathrm{P}\left(\mathrm{Z}_{\mathrm{i}}<0\right.$ and $\left.\mathrm{z}_{\mathrm{j}}<0\right)$ \\
\hline 1 & 0.852 & 1.05 & 0.147 & $2.9 \times 10^{-5}$ \\
2 & 0.527 & 2.07 & 0.019 & $3.9 \times 10^{-5}$ \\
3 & 0.237 & 2.92 & 0.0017 & $3.5 \times 10^{-5}$ \\
4 & 0.077 & 3.44 & 0.00029 & $5.8 \times 10^{-5}$ \\
\hline
\end{tabular}

The required answers are contained in the last column.

b. The elementary lower and upper bounds are given by:

$\max P\left\{Z_{i}<0\right\} \leq P\{F\} \leq \Sigma P\left\{F_{i}\right\}$

Summation must be applied over all $\left(I_{d} / \ell\right)$ segments, so that:

$10^{-4} \leq \mathrm{P}\{\mathrm{F}\} \leq \frac{\mathrm{L}_{\mathrm{d}}}{\ell} \times 10^{-4}$

For the Ditlevsen upper bound we start form the formula (2.3.14), from which it follows for this case (note that max $P_{i j}=P_{i, i+1}=$ $P\left(z_{1}<0\right.$ and $\left.\left.z_{2}<0\right\}\right)$ :

$P(F) \leq P\left\{Z_{1}<0\right\}+\left\{\frac{L_{d}}{l}-1\right\}\left[P\left(z_{1}<0\right\}-P\left\{z_{1}<0\right.\right.$ and $\left.\left.z_{2}<0\right\}\right]$

$P\{F\} \leq 10^{-4}+\left\{\frac{L_{d}}{\ell}-1\right\}\left[10^{-4}-2.9 \times 10^{-5}\right]$

$P\{F\} \leq 10^{-4}\left\{0.29+0.706 \frac{L_{d}}{\ell}\right\}$

The lower bouid likewise follows from formula (2.3.14):

$P(F) \geq P\left\{z_{1}<0\right\}+P\left(Z_{2}<0\right\}-P\left\{z_{1}<0\right.$ and $\left.z_{2}<0\right\}+$ $P\left\{z_{3}<0\right\}-P\left\{Z_{3}<0\right.$ and $\left.Z_{2}<0\right\}-P\left\{Z_{3}<0\right.$ and $\left.z_{1}<0\right\}+$ 
$P\left(z_{4}<0\right)-P\left(z_{4}<0\right.$ and $\left.z_{3}<0\right)-P\left(z_{4}<0\right.$ and $\left.z_{2}<0\right)-P\left(z_{4}<0\right.$ and $\left.z_{1}<0\right)+$ $\left[P\left\{z_{5}<0\right)\right\}-P\left(z_{5}<0\right.$ and $\left.\left.z_{4}<0 \ldots\right\} \times\left(\frac{L_{d}}{\ell}-4\right)\right]$

Combining all terms with $1>5$ is possible because of all $\Delta i>5$ the correlation is taken as zero.

Substitution of numerical values gives:

$$
\begin{aligned}
& P(F) \geq 10^{-4}\{1+(1-0.29)+(1-0.29-0.039)+(1-0.29-0.039-0.0035)+ \\
& \left.+\left(\frac{L_{d}}{\ell}-4\right)(1-0.29-0.039-0.0035-0.00058)\right\}
\end{aligned}
$$$$
P(F) \geq 10^{-4} \times\left(0.81+0.667 \frac{L_{d}}{l}\right)
$$

The final result of this example is presented in Figure 3.6.1. Note that for $L_{d}=\ell$ the lower bound is slightly incorrect.

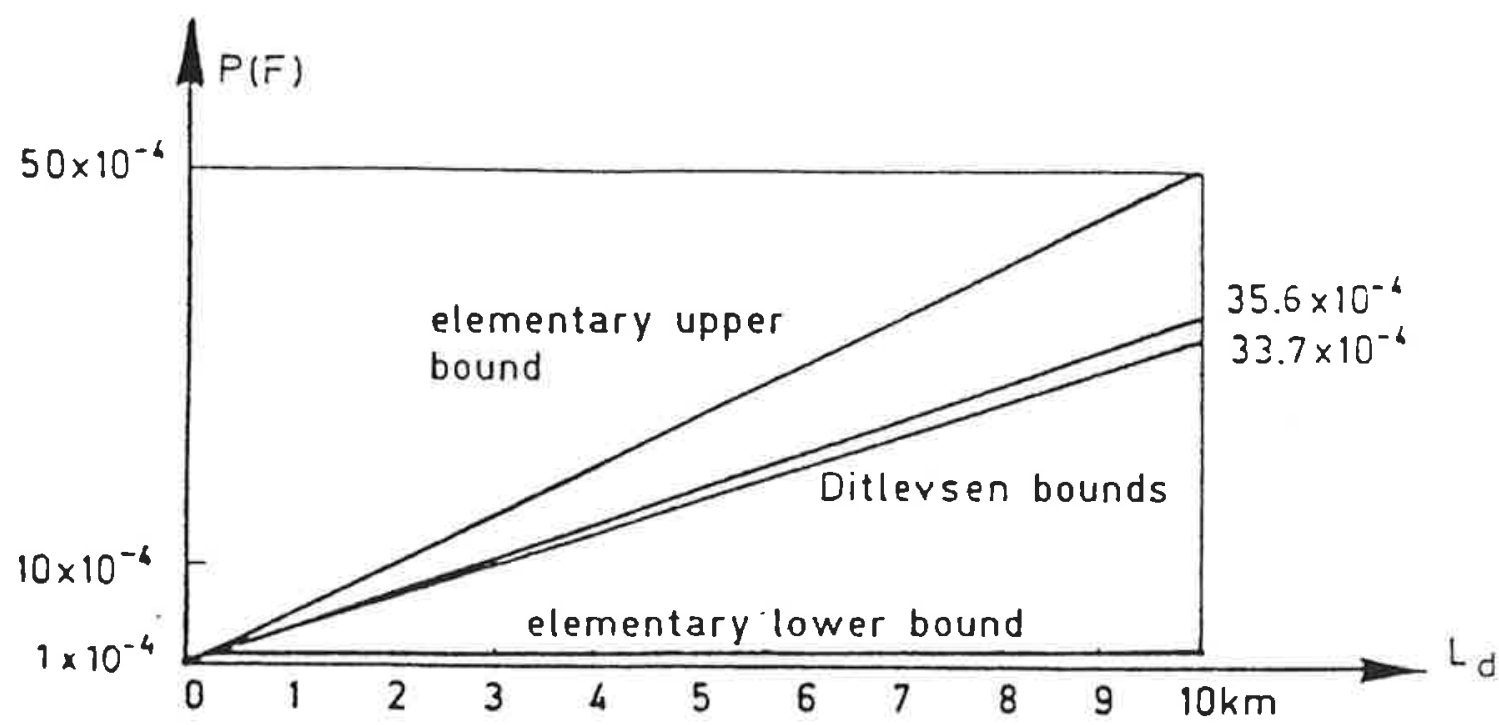

Fig. 3.6.1: Failure probability of the dyke as a function of the length. 


\section{Example 2: Coefficient of correlation does not tend to zero}

On considering the mechanism of overflowing (Section 3.2.1) in its simplest form, the reliability function is:

$$
\mathrm{Z}=\mathrm{h}_{\mathrm{o}}-\mathrm{s}_{\mathrm{v}}
$$

where: $h_{0}=$ height of dyke crest in $m$ above NAP *

$\mathrm{S}_{\mathrm{v}}=$ storn tide level in $\mathrm{m}$ above NAP *

Starting from formula (3.6.3), the coefficient of correlation function for the reliability functions of two sections $i$ and $j$ becomes:

$$
\rho\left(z_{i}, z_{j}\right)=\frac{\rho\left(h_{o i}, h_{o j}\right) \sigma\left(h_{o i}\right) \sigma\left(h_{o j}\right)+\rho\left(S_{v i}, s_{v j}\right) \sigma\left(S_{v i}\right) \sigma\left(s_{v j}\right)}{\sqrt{ }\left(\sigma^{2}\left(h_{o i}\right)+\sigma^{2}\left(S_{v i}\right)\right) \sqrt{ }\left(\sigma^{2}\left(h_{o j}\right)+\sigma^{2}\left(S_{v j}\right)\right\}}
$$

Putting $\sigma\left(\mathrm{h}_{\mathrm{oi}}\right)=\sigma\left(\mathrm{h}_{\mathrm{oj}}\right)=\sigma\left(\mathrm{h}_{\mathrm{o}}\right)$ (for all the dykes segments the standard deviations of the crest levels are equal)

and $\quad \sigma\left(S_{v i}\right)=\sigma\left(S_{v j}\right)=\sigma\left(S_{v}\right)$ (ditto for the storm tide levels for all the dyke segments)

then also: $\sigma\left(\mathrm{Z}_{i}\right)=\sigma\left(\mathrm{z}_{\mathrm{j}}\right)=\sigma(\mathrm{z})$ (ditto for all the reliability functions)

and we thus obtain:

$\rho\left(z_{i}, z_{j}\right)=\frac{\rho\left(h_{o i}, h_{o j}\right) \sigma^{2}\left(h_{o}\right)+\left(S_{v i}, S_{v j}\right) \sigma^{2}\left(S_{v}\right)}{\sigma^{2}(z)}$

On further putting, following the previous example:

$\approx \mathrm{NAP}=$ Normaal Amsterdams Peil = Standard Amsterdam Datum 
$\rho\left(h_{o i}, h_{o j}\right)=\exp \left\{-\left(\frac{l \Delta i}{d_{c}}\right)^{2}\right\}$

and $\rho\left(\mathrm{S}_{\mathrm{vi}}, \mathrm{S}_{\mathrm{vj}}\right)=1$ (which means that for all the dyke sections there is THE SAME storm tide level), the coefficient of correlation becomes:

$\rho\left(z_{i}, z_{j}\right)=\frac{\exp \left\{-\left(\frac{l \Delta i}{d_{c}}\right)^{2}\right\} \sigma^{2}\left(h_{o}\right)+\sigma^{2}\left(S_{v}\right)}{\sigma^{2}(z)}$

The reliability functions remain correlated over over long distances by the storm tide level.

Suppose that the crest levels of all the dyke sections conform to a normal distribution with mean value $\mu\left(\mathrm{h}_{0}\right)=5.00 \mathrm{~m}$ and standard deviation $\sigma\left(h_{\delta}\right)-0.1 \mathrm{~m}$. Suppose furthermore that the probability

distribution of the storm tide levels is a Gumbel distribution (see $(3.2 .3)$ :

$\mathrm{P}\left\{\mathrm{S}_{\mathrm{V}}>\mathrm{S}\right\}=1-\exp \left(-\exp \left(-\frac{(\mathrm{S}-1.98)}{0.33}\right)\right)$

$\mathrm{P}\left\{\mathrm{S}_{\mathrm{v}}>\mathrm{S}\right\}=$ probability that $\mathrm{S}$ is exceeded per year.

The probability that in a year a storm tide level higher than the dyke crest level will occur for a particular section can be determined with a level II approximate full distribution approach, from which the failure probability for one segment is obtained as:

$\mathrm{P}\left\{\mathrm{z}_{i}<0\right\}=1.1 \times 10^{-4}$ in a year $(\beta=3.69)$

For the equivalent normal distribution of $\mathrm{S}_{\mathrm{v}}$ a mean value $\mu\left(\mathrm{S}_{\mathrm{v}}\right)=$ $0.205 \mathrm{~m}$ and a standard deviation $\sigma\left(\mathrm{S}_{\mathrm{v}}\right)=1.29 \mathrm{~m}$ are found.

Again adopting $\ell=200 \mathrm{~m}$ and $\mathrm{d}_{\mathrm{c}}=500 \mathrm{~m}$, we can calculate in a similar manner to that of the previous example:

$\rho\left(\mathrm{Z}_{i}, \mathrm{Z}_{\mathrm{j}}\right)=\frac{\exp \left(-(0.4 \Delta \mathrm{i})^{2}\right) 0.1^{2}+1.29^{2}}{1.29^{2}}$ and $\beta^{*}=\beta \sqrt{\left(\frac{1-\rho}{1+\rho}\right)}$ 
The following table can then be calculated:

\begin{tabular}{|lcccc|}
\hline$\Delta i$ & $\rho\left(Z_{i}, z_{j}\right)$ & $\beta^{*}$ & $\Phi\left(-\beta^{*}\right)$ & $P\left(Z_{i}<0\right.$ and $\left.z_{j}<0\right\}$ \\
\hline 1 & 0.9991 & 0.0802 & 0.46804 & $1.036 \times 10^{-4}$ \\
2 & 0.9971 & 0.1400 & 0.44433 & $9.837 \times 10^{-5}$ \\
3 & 0.9954 & 0.1772 & 0.42967 & $9.513 \times 10^{-5}$ \\
4 & 0.9945 & 0.1946 & 0.42285 & $9.362 \times 10^{-5}$ \\
\hline
\end{tabular}

For the Ditlevsen upper bound we obtain:

$$
\begin{aligned}
& P(F\} \leq P\left\{z_{1}<0\right\}+\left\{\frac{L_{d}}{\ell}-1\right\} \quad\left[P\left\{z_{1}<0 \text { and } z_{2}<0\right\}\right] \\
& P\{F\} \leq 1.1 \times 10^{-4}+\left\{\frac{L_{d}}{\ell}-1\right] \quad\left[1.1 \times 10^{-4}-1.036 \times 10^{-4}\right]- \\
& 10^{-4}\left[1.036+\frac{L_{d}}{\ell} 0.064\right]
\end{aligned}
$$

The lower bound is given by formula (2.3.14); we take the first two terms only, as $P_{i}-\Sigma P_{i j}$ is negative for $i \geq 3$ :

$P(F) \geq 1.1 \times 10^{-4}+1.1 \times 10^{-4}-1.036 \times 10^{-4}-1.164 \times 10^{-4}$

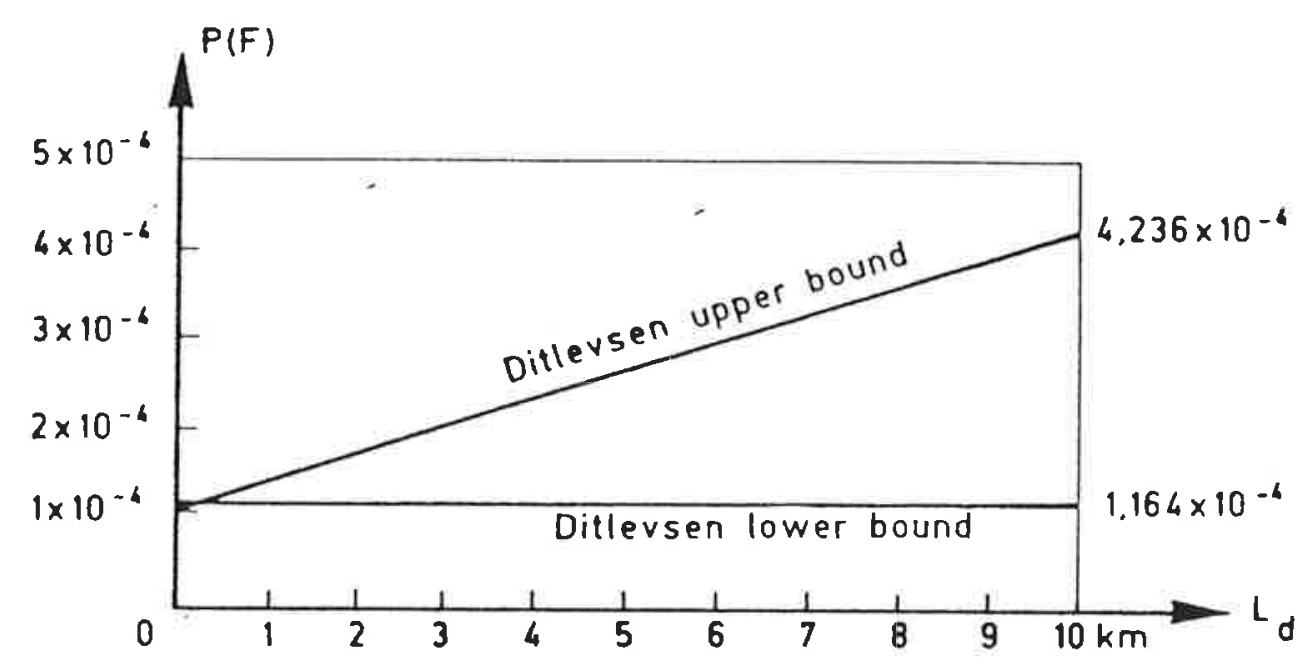

Fig. 3.6.2: Failure probability of the dyke as a function of the length. 


\subsubsection{Methods based on a continuous model}

Variation of load and strength in the longitudinal direction of the dyke will in reality conform to a continuous pattern. The schematization of the dyke into a countable number of sections, each homogeneous in itself, is inspired by the fact that Ditlevsen's formula for establishing probability bounds can be applied to a discrete series system of this kind. This schematization, however, comprises a more or less arbitrary element, namely, the choice of the length of the dyke segments. A decrease of the segment length should not lead to a change in the resulting probability.

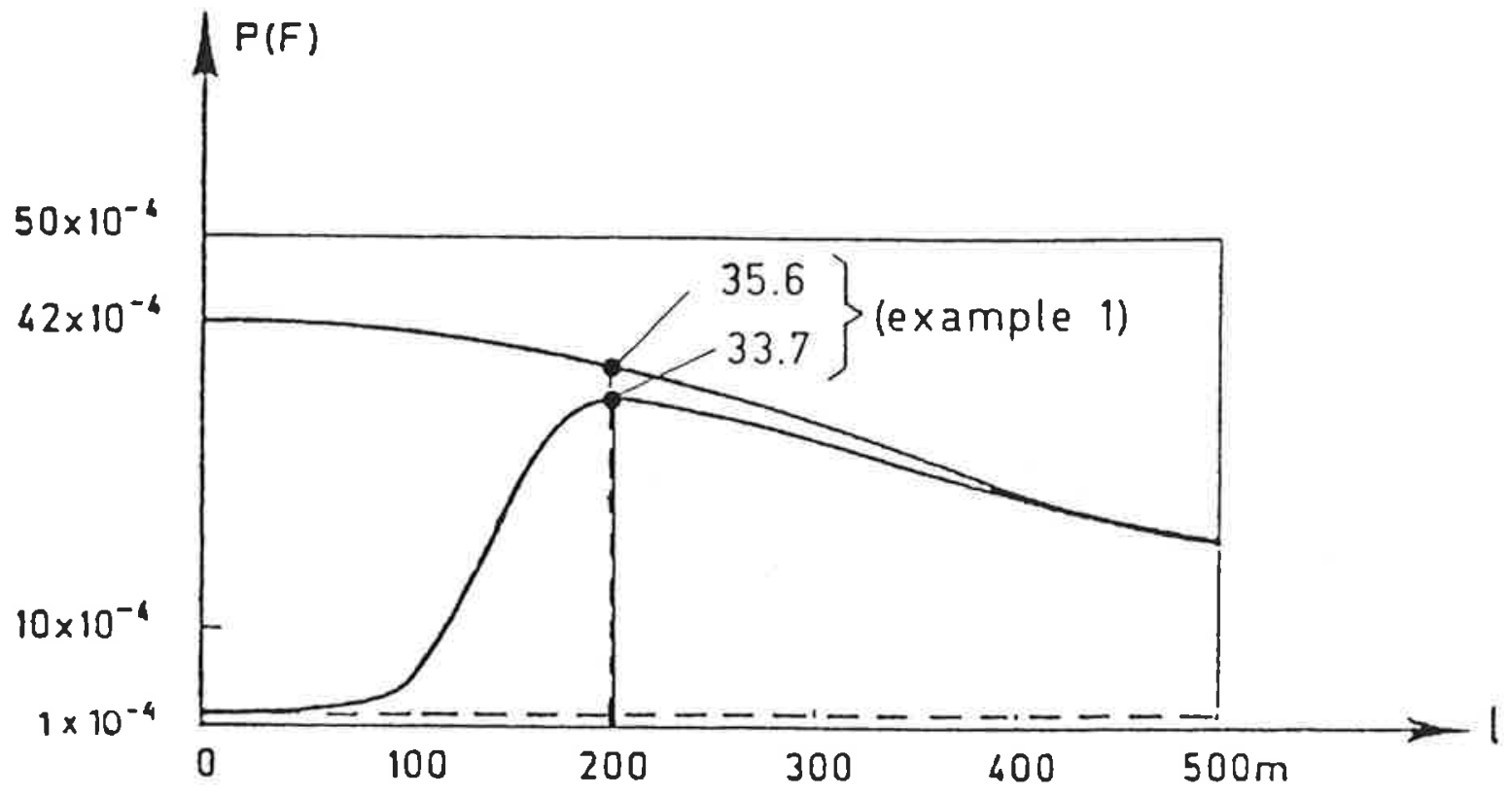

Fig. 3.6.3: Curves representing Ditlevsen upper and lower bound estimates for the series failure probability of a $10 \mathrm{~km}$ length of dyke as a functin of the choice of segment length (example 1). 
Figure 3.6.3 shows the Ditlevsen bounds as a function of $\ell$ for the example of section 3.6.2. From the result at $l=0$ we may conclude that the upperbound is $42 \times 10^{-4}$ and the lowerbound is $1 \times 10^{-4}$. Let us now see how we can improve these bounds: for $l>0$ the failure probability will decrease as additional correlation is introduced. This means that the upperbound for $\ell>0$ is worthless, but that the lower bound for $\ell>0$ still can be used as a lowerbound for $\ell=0$. So the best lowerbound is the one found for $l=200 \mathrm{~m}$, being the maximum. The final result thus is that the real failure probability lies between 34 and 42 $\times 10^{-4}$.

A direct continuous approach to calculating the upper bound of the series failure probability can be made from the theory of stochastic processes. In this approximation the reliability function $\mathrm{Z}$ is conceived as a continuous stochastic process. In analogy with the discrete approximation, we can suppose that the realization of $z$ at every $x$ location has been derived from the same population distribution and that the correlation between two realizations at $x$ and $x+h$ depends solely on the distance $h$. Such a process is referred to as a stationary process. The probability that in a stretch $0 \leq x \leq L_{d}$ a negative value of $Z$ occurs is then:

$P\left\{Z(x)<0\right.$ in $\left.0<x<I_{d}\right\}=$

$P\{Z(0)<0\}+P\left\{Z(0)>0\right.$ and $Z(x)+0$ in $\left.0<x<L_{d}\right\}$

$" \mathrm{Z}(\mathrm{x})+0$ at $0<\mathrm{x}<\mathrm{L}_{\mathrm{d}}$ " denotes the event that an $\mathrm{x}$ and $\Delta \mathrm{x}$ can be found such that $z(x-\Delta x)>0$ and $z(x+\Delta x)<0$. If the correlation between two $z$ realizations dies away rapidly, the event $" Z(0)>0$ " will be virtually independent of the event $" Z(x)+0$ at $0<x<L_{d}$ ", and we may therefore write:

$P\left(Z(x)<0\right.$ in $\left.0<x<L_{d}\right)=$

$P(Z(0)<0)+P(Z(0)>0) \cdot P\left(Z(x)+0\right.$ in $\left.0<x<L_{d}\right\}$

For processes having a normal (Gaussian) distribution the theory of stochastic processes yields a probability expression for the abovementioned event of $Z$ being negative $[3.27,3.28]$ : 
$P\left(Z(x)+0\right.$ in $\left.0<x<L_{d}\right\} \leq \frac{L_{d}}{2 \pi} \exp \left(-\frac{1}{2} \beta^{2}\right) \sqrt{ }-\rho^{\prime \prime}(0)$

where $\beta$ is the local reliability index, which is identical with the reliability index for a segment (see above) and $\rho$ is the correlation function of the process, which is the coefficient of correlation as a function of the distance $\Delta x$ between two points along the dyke. The double prime denotes the second-order derivative with respect to $\Delta x$. The following expression is therefore obtained for the probability of failure:

$\mathrm{P}\left\{Z(\mathrm{x})<0\right.$ in $\left.0<\mathrm{x}<\mathrm{L}_{\mathrm{d}}\right\} \leq \Phi(-\beta)+\frac{\mathrm{L}_{\mathrm{d}}}{2 \pi} \quad(\beta) \exp \left(-\frac{1}{2} \beta^{2}\right) \sqrt{ }-\rho^{\prime \prime}(0)$

This theory has been applied in the stochastic model for analysing the stability of slopes [3.19].

On applying this theory to the first of the foregoing worked examples, we find:

$\beta=3.72, \Phi(-\beta)=10^{-4}, \Phi(\beta)=1-10^{-4}$,

$\rho(\Delta \mathrm{x})=\exp -\left(\Delta \mathrm{x} / \mathrm{d}_{\mathrm{c}}\right)^{2}$, so $\rho^{\prime \prime}(0)=-2 / \mathrm{d}_{\mathrm{c}}^{2}$

with $\mathrm{d}_{\mathrm{c}}=500 \mathrm{~m}$ :

$P\left(Z(x)<0\right.$ in $\left.0<x<L_{d}\right) \leq 45.10^{-4}$

This result is substantially in agreement with the Ditlevsen upper bound for very small section lengths. Such agreement would suggest that the Ditlevsen upper bound in the limit case corresponds to the formulation which follows from the theory of continuous stochastic processes. It has indeed proved possible to derive formula (3.6.21) from the discrete theory. 


\section{CALCULATION OF THE INUNDATION CHARACTERISTICS}

\subsection{Introduction}

As already stated in Chapter 1, not only the probability of an undesirable event - in the present case more particularly the probability of inundation - is important, but also the consequence of the occurence of that event. This consequence may be expressed in, for example, material damage (or loss) or the number of lives lost. In order to estimate the extent of this it is necessary, among other particulars, to know how rapidly and to what depth the region in question will be flooded. In the present chapter this will be considered for the case of a river dyke.

In general, inundation can occur as a result of overflowing and/or wave overtopping of a flood defence structure or as a result of flow through a gap due to collapse of the structure. Some dyke collapse mechanisms have been dealt with in Chapter 3 .

The flow rate depends on the length of the dyke (in the case of overtopping), the behaviour (variation) of the river water level, the ground level or the water level in the polder protected by the dyke, and the size and shape of the gap in the dyke. The size and shape of the gap will in turn depend on the velocity of the inflowing water, the inflow duration, and the composition of the subsoil and the body of the dyke.

An analytical and a numerical method of determining the inflow rate are discussed in Section 4.2. For this purpose the discharge (rate of flow) of the river upstream of the gap or overflow zone is assumed to be constant. The gap in the dyke is assumed to have an unvarying configuration from the instant of breaching onward. Taking account of a timedependent river discharge and the development of a gap can be done by schematization in time steps in which, per interval of time, the discharge and the gap configuration can be treated as constant.

The behaviour of the flood wave in the river and the development of the gap are dealt with in Section 4.3. 


\subsection{Calculation of tl:e inundation behaviour for a given breach in a} river dyke and for overflowing

\subsubsection{Inundation depth and inundation speed}

If a river dyke is breached so that a gap is formed, or if water flows over the crest of the dyke, river water is discharged laterally into the polder. Let $Q(\tau)$ be the lateral discharge, where $Q$ represents the rate of flow and $\tau$ represents time. The total volume of river water that has been flowed into the polder at the instant $t$ is then:

$Q_{\text {tot }}(t)=t_{0}^{t} Q(\tau) d r$

where $t_{0}$ is the instant at which the lateral discharge commences. Furthermore, let $A(\xi)$ be the area of the endangered polder at level $\xi$ (see Figure 4.2.1), $h_{p}(t)$ the inundation depth at time $t$ and $h_{\text {po }}$ be the lowest point in the polder. Then the mass balance for the water that has flowed into the polder is:

$\int_{0}^{t} Q(\tau) d \tau={ }_{h_{p o}}^{h_{p}(t)} \int A(\xi) d \xi$

Equation (4.2.2) determines the inundation depth. The greatest inundation depth at the instant $t$ is $\left(h_{p}(t)-h_{p o}\right)$. The inundation speed is obtained by differentiation of equation (4.2.2) with respect to time:

$\frac{d h_{p}}{d t}=\frac{Q(t)}{A\left(h_{p}(t)\right)}$

The unknown quantity in these equations is the lateral discharge of river water $Q(t)$. Calculation procedures for this have been established and elaborated in connection with the worked example [4.1]. The basis of these procedures is that flow behavioural changes with time due to a time-dependent upstream discharge can be conceived as successive steady states. This implies that the time scale for variations in the upstream river level is large in relation to the adjustement times in which the 
flow adapts itself in consequence of these variations.

In the following, unless explicitely stated, no distinction will be drawn between narrow gaps in the dyke due to local collapse and overflowing because the river water level is higher than the crest of the dyke. The designation "spillway" in the present context relates to the lateral escape of river water into the polder, the crest level of the spillway being equal to that of the dyke itself or that of a gap in the dyke.

The level of the river bottom will be taken as the zero reference plane for height or levels.

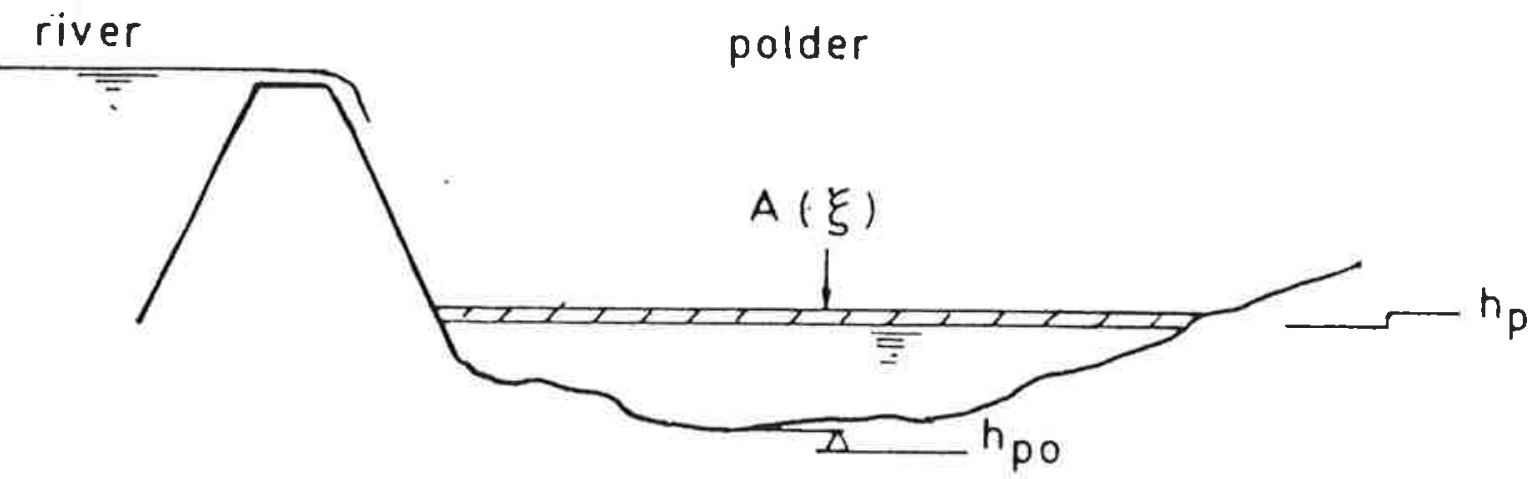

Fig. 4.2.1: Diagram defining a polder.

\subsubsection{Basic equations for river discharge and lateral discharge via a} spillway

The discharge of the river is described by means of equations of conservation of mass and momentum. For steady-state flow these equations for a river with a rectangular flow cross-section are as follows (see Figure 4.2.2): 
Conservation of mass:

B $\frac{\partial}{\partial s}(h \cdot v)+q(s ;=0$

and conservation of momentum:

$\frac{\partial}{\partial s}\left(\frac{v^{2}}{2 g}+h\right)=I_{b}-\frac{v^{2}}{c^{2} R}$

In these equations $h=h(s)$ is the river water level, $B$ the width of the flow cross-section, $v$ the mean flow velocity, $s$ the space coordinate along the axis of the river (the flow direction of the river is taken as the positive s-direction), $q$ the local lateral discharge or feed, $I_{b}$ the gradient of the river bed in the s-direction, $C$ the so-called Chezy factor, $R$ the hydraulic radius of the flow cross-section, and $g$ the acceleration of gravity. The hydraulic radius is defined as the ratio of the flow cross-s sctional area $(-\mathrm{hB})$ and the "wet" periphery of this area $(=B+2 h)$. For flow cross-sections where $B$ is large in relation to $h$ we have:

$\mathrm{R}=\frac{\mathrm{h} \cdot \mathrm{B}}{\mathrm{B}+2 \mathrm{~h}} \approx \mathrm{h}$

From these equations, in the case of uniform flow $(\partial / \partial s=0)$, we obtain for the river discharge, $Q_{r}$ :

$Q_{r}=h \cdot B \cdot v=h^{3 / 2}$ B $C \sqrt{ } I_{b}$

or:

$h=\left(\frac{Q_{r}}{B C \sqrt{I_{b}}}\right)^{2 / 3}$

where $h$ is called the equilibrium depth. 


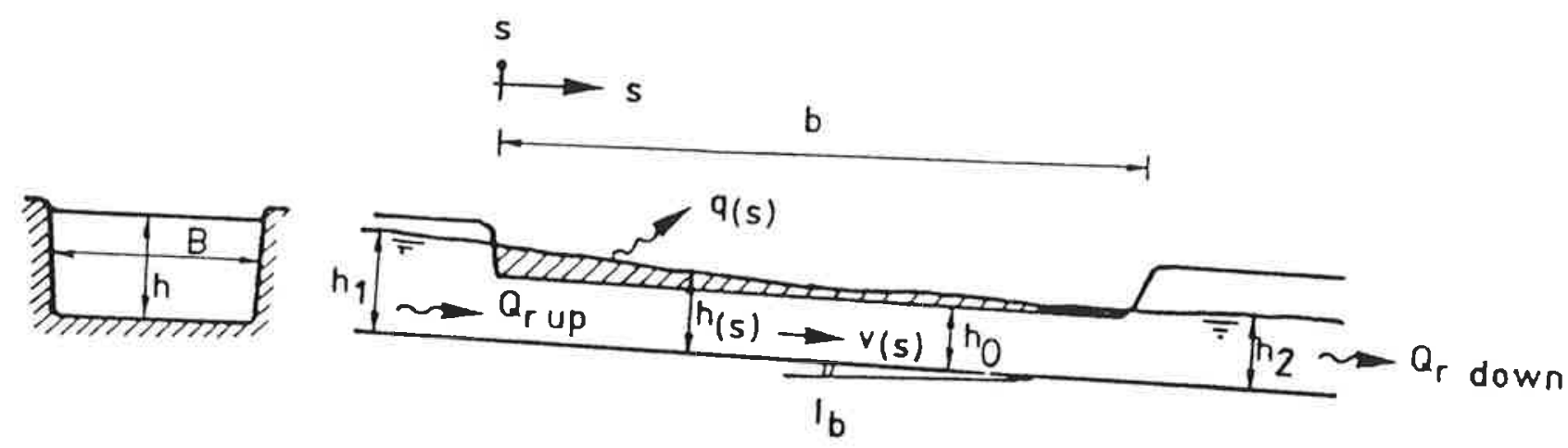

Fig. 4.2.2: Diagram defining a river and lateral spillway.

The lateral discharge over a spillway can be calculated with the aid of the formulae for a free-nappe weir:

$q(s)=\left(\frac{2}{3}\right)^{3 / 2}\left(h(s)-h_{0}\right)^{3 / 2} \sqrt{g} \quad$ if $h_{p}<h_{0}+\frac{2}{3}\left(h(s)-h_{0}\right)$

and for a submerged weir:

$q(s)=\left(h_{p}-h_{0}\right) \sqrt{\left\{2 g\left(h(s)-h_{p}\right)\right\}}$ if $h_{p}>h_{0}+\frac{2}{3}\left(h(s)-h_{0}\right)$

In both the above formulae the coefficient of discharge of the weir (or spillway) has been taken equal to 1:0. The total discharge is equal to:

$Q=s_{0}^{s_{0}^{+b}} q(s) d s$

where $b$ is the length of the spillway and $s_{0}$ the location of the beginning of the spillway at the upstream end. For very short spillways it is assumed that the lateral discharge $q(s)$ can be represented by a value which is constant in the s-direction. 
Two cases are to be distinguished, namely:

1. The total lateral discharge from the river is so great that the river head at the spillway drops down to the crest level of the spillway. This occurs at very long spillways. The downstream equilibrium depth is then equal to the difference between the spillway crest level and the level of the river bed. The discharge over the spillway can be calculated quite simply as the difference between the upstream and the downstream discharge of the river, both calculated according to formula (4.2.7):

$Q=Q_{r_{\text {up }}}-Q_{r_{\text {down }}}=\left\{h_{1}^{3 / 2}-h_{o}^{3 / 2}\right\} B C \sqrt{ } I_{b}$

where $h_{1}$ is the river level upstream and $h_{0}$ the crest level.

2. The downstream water level of the river is not known. In this case the lateral discharge is insufficient to cause a drop of the river head to the crest level of the spillway. The lowering of the river head must be calculated by solving the basic equations. Two procedures for performing this calculation have been developed and will be described below. With the aid of these procedures it is also possible to check the assumption on which the calculation according to equation (4.2.12) is based.

\subsubsection{Discrete approximation for a very short spillway}

A constant river head equal to the downstream river level is assumed to occur along the length of the spillway. The governing equations are then:

$\mathrm{Q}=\mathrm{b} \mathrm{q}=\mathrm{Q}_{\mathrm{r}_{\text {up }}}-\mathrm{Q}_{\mathrm{r}_{\text {down }}}=\left(\mathrm{h}_{1}^{3 / 2}-\mathrm{h}_{2}^{3 / 2}\right)$ B $\mathrm{C} \sqrt{ } \mathrm{I}_{\mathrm{b}}$

where $h_{2}$ is the downstream water level in the river and $b$ is the length of the spillway (see Figure 4.2.3). The discharge q per unit length of the spillway is calculated with the aid of formulae (4.2.9) or (4.2.10), 
where $h(s)$ is replaced by $h_{2}$. Suppose that the upstream river head is $h_{1}$. Then the downstream discharge and the lateral discharge can be calculated with these equations. The method is applicable to narrow gaps caused by breaching of the dyke in consequence of the mechanisms dealt with in Chapter 3.

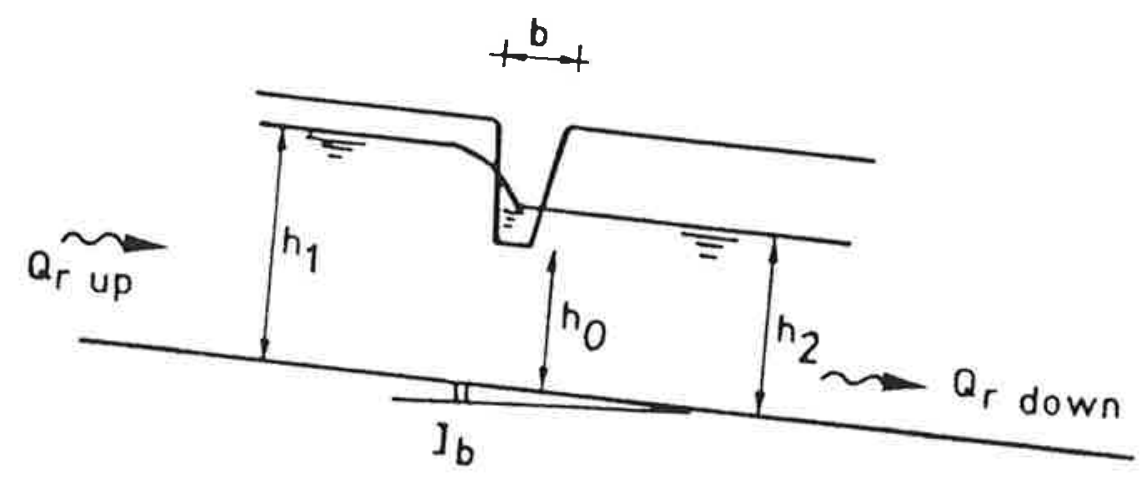

Fig. 4.2.3: Discrete method for a very short spillway.

\subsubsection{Discrete approximation for long spillways}

In the approximate method the length of the spillway is divided into $n$ sections. At the boundaries of the sections the lateral discharge is conceived as concentrated at nodes (see Figure 4.2.4). The discharge at each of the nodes is calculated with formula (4.2.9) or (4.2.10). The lowering of the river head within each of the sections is calculated with the ald of the following procedure.

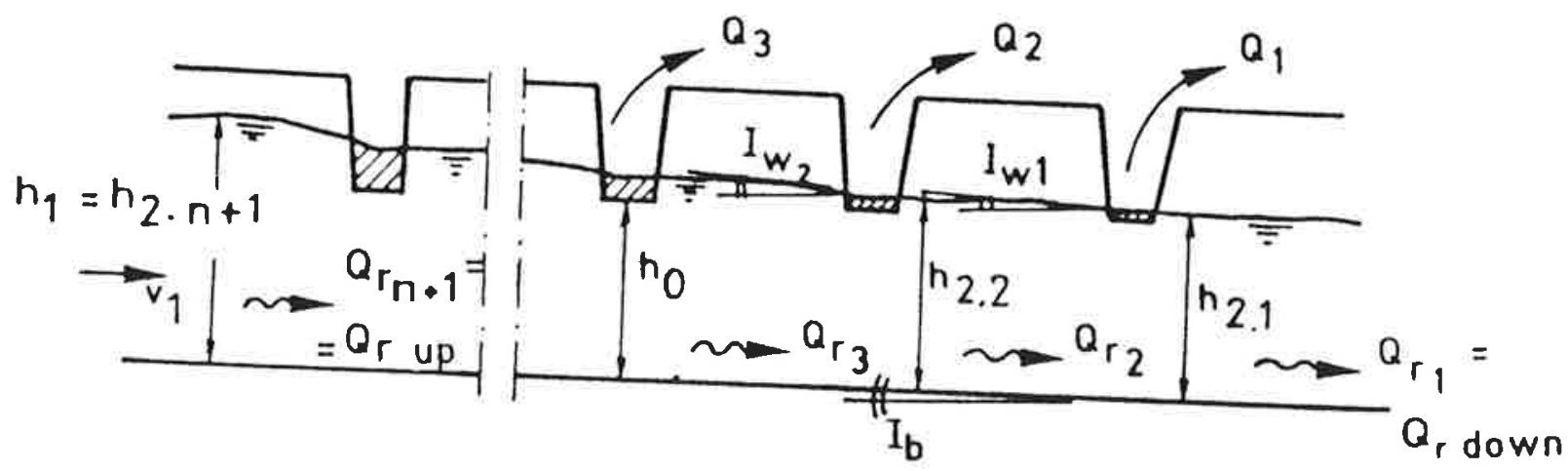

fig. 4.2.4: Simulation of a long spillway. 
This procedure is based on a water level on the upstream side of the section and a water level on the downstream side (see Figure 4.2.5). Let $I_{w}$ denote the slope of the water surface. Then the following relationship exists:

$h_{1} \simeq h_{2}+\left(I_{w}-I_{b}\right) L_{v}$

where $L_{v}$ is the length of the spillway section. The gradient $I_{w}$ is calculated from equation (4.2.5), neglecting the velocity head:

$\frac{d h}{d s} \simeq-I_{w}+I_{b} \simeq I_{b}-\frac{v^{2}}{c^{2} R} \simeq I_{b}-\frac{Q_{r}^{2}}{B^{2} c^{2} h^{3}}$

therefore:

$I_{w} \simeq \frac{Q_{r}^{2}}{B^{2} C^{2} h^{3}}$

Hence it follows that:

$h_{1} \simeq h_{2}+\left(\frac{Q_{r}^{2}}{B^{2} c^{2} h^{3}}-I_{b}\right) L_{v}$

For a chain of spillway sections with lateral discharge concentrated at the section boundaries we find, using the formulae for the abovementioned calculation procedure, the following algorithm for calculating the hydraulic grade line and the total discharge over the spillway (see Figure 4.2.4):

- Choose a value for $h_{2.1}\left(>h_{0}\right)$, whence follow the lateral discharge $Q_{1}$ with the aid of the formulae (4.2.9) or (4.2.10) and (4.2.11) with spillway length $\mathrm{b} / \mathrm{n}$. The discharge of the river $\mathrm{Q}_{\mathrm{r} 2}$ is obtained from $\mathrm{h}_{2.1}$ by applying formula (4.2.7).

- Then: $Q_{r_{2}}=Q_{r_{1}}+Q_{1}$ and $I_{w 1}=Q_{r_{2}}^{2} /\left(B^{2} C^{2} h_{2.1}^{3}\right)$

- Hence follows: $h_{2.2} \simeq h_{2.1}+\left(I_{w 1}-I_{b}\right) L_{v}$, where $L_{v}=b / n$, and $Q_{2}$ is calculated from this.

- From this is calculated $\mathrm{Q}_{\mathrm{r} 3}$, and so on. 
The process is repeated untill $Q_{r_{n+1}}$ is found. By trial and error a value of $h_{2.1}$ mist be found for which $Q_{r_{n+1}} \simeq Q_{r_{u p}}$. By summation of the associated $Q_{1}$ the lateral discharge over the spillway is obtained.

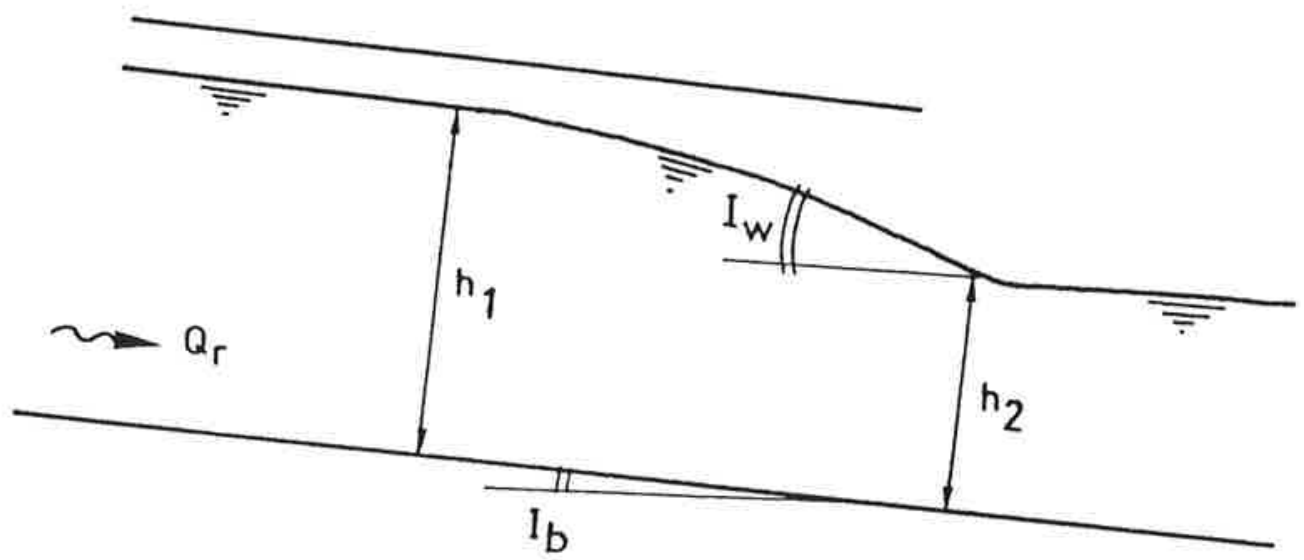

Fig. 4.2.5: Calculation of a spillway section.

\subsubsection{Analytical approximation}

If the following assumptions are satisfied:

$\frac{h_{1}-h_{2}}{h_{1}} \ll 1$

where $h_{2}$ is the river head downstream of the spillway and the velocity share in the energy head is small in relation to the pressure head and the potential head, i.e.:

$\mathrm{h}+\frac{\mathrm{v}^{2}}{2 \mathrm{~g}} \simeq \mathrm{h}$

the basic equations for river discharge and spillway discharge can be linearized. This opens the way to an analytical solution. 
For a free-nappe spillway (formula 4.2.9) the following formulae are found for the lateral discharge (see Figure 4.2.6 for explanation of the notation employed):

$\frac{\mathrm{Q}}{\mathrm{Q}_{\mathrm{r}}}=3 / 2\left(1-\mathrm{h}_{2} / \mathrm{h}_{1}\right)$

where $h_{2}$ is given by:

$\frac{h_{2}-h_{0}}{h_{1}-h_{o}}=\frac{\rho e^{\lambda_{2} b}\left(\lambda_{1}-\lambda_{2}\right)}{\lambda_{1}^{2}-\lambda_{2}^{2} e^{\left(\lambda_{2}-\lambda_{1}\right) b}}$

in which:

$\rho=3 \mathrm{I}_{\mathrm{b}} / \mathrm{h}_{1}$

$\lambda_{1,2}=\frac{1}{2} \rho\{1 \pm \sqrt{ }(1+\beta)\}$

$\beta-2(2 / 3)^{7 / 2} \cdot \frac{h_{1} \sqrt{ }\left(g\left(h_{1}-h_{0}\right)\right)}{I_{b} v_{1} B}$

where $v_{1}$ is the flow velocity associated with $h_{1}$.

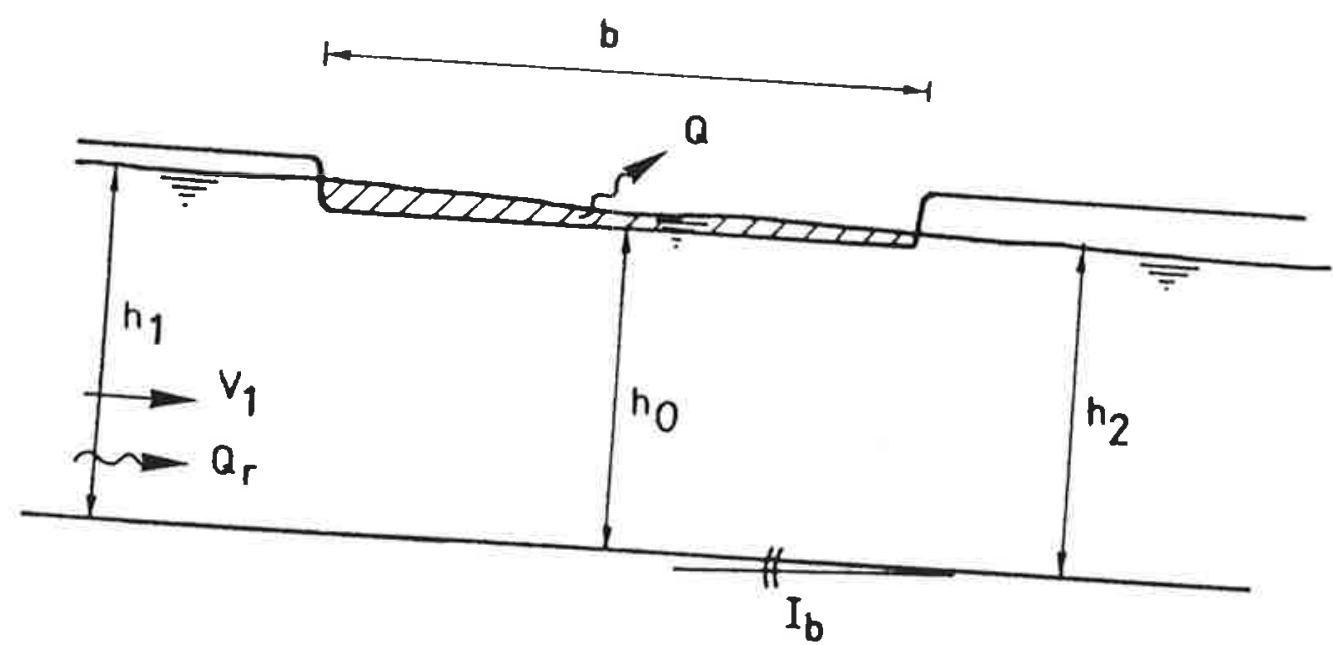

Fig. 4.2.6: Notation employed in the analytical solution. 
In [4.2] tables have been compiled with which, employing three dimensionless parameters characterizing the river and the spillway, the drops of the river head and the discharge over the spillway can be determined.

\subsection{Time-dependence of upstream discharge and lateral discharge}

\subsubsection{Form and duration of water levels associated with flood discharge}

A boundary condition for calculating lateral discharge over a spillway is the behaviour of the upstream water level $h_{1}(t)$ during flood flow in the river. In connection with the worked example, the form and duration of the discharge of the Upper Rhine at Lobith under flood (maximum discharge) conditions were investigated [4.3]. This investigation showed that a single-crested flood wave as a function of time, $Q_{r}(t)$, can be characterized by the sum of a constant basic discharge, $Q_{\text {ro, and }}$ parabolic wave crest:

$Q_{r}(t)=Q_{r o}+\left(\hat{Q}_{E}-Q_{r o}\right)\left(t-T_{0}\right)\left(T-t+T_{0}\right) / T^{2}$

where $T_{0} \leq t \leq T_{0}+t$, while for different $t: Q_{r}(t)=Q_{r o}$. Here $Q_{r}(t)$ denotes the instanteneous flood discharge, $\hat{Q}_{r}$ the maximum discharge, $Q_{r o}$ the constant basic discharge, $T$ the length of time during which the flood discharge exceeds the basic discharge, and $\mathrm{T}_{0}$ the instant at which the flood discharge begins.

Multi-crested discharge functions can be obtained by schematizing each of the separate wave crests to a parabola and then superimposing.

Both the magnitude of the maximum discharge and the duration $T$ can be conceived as stochastic variables in a probabilistic analysis of a river dyke. The probatility distribution function of the maximum discharge can be determined from observed relative frequencies of maximum discharges in the past. From observations in the Upper Rhine it emerges that the maximum discharge in that river can satisfactorily be described with the aid of Weibull distribution: 
$P\left(\hat{Q}_{r}<X\right)=1-e^{-\left(X-A_{0}\right) / C_{0}}$ if $X>0$

The probability distribution of the durations $T$ can likewise be derived from the statistically observed continuously consecutive periods during which a river discharge exceeds a certain value. The relative frequency distribution thus found suggests a log-normal distribution. For the Rhine discharges an expected duration of 15 days was found, with a coefficient of variation equal to 1.0 .

For a probabilistic analysis it is moreover of importance to investigate the correlation, if any, between the maximum discharge and the duration. In the investigation referred to, admittedly on the basis of only a limited number of data, a weak negative correlation $(-0.20)$ was found. This result justifies the assumption of uncorrelated maximum discharge and flood discharge duration in a probabilistic analysis.

\subsubsection{Development of a gap in a dyke}

At present is only possible to give quantitative indications of the way in which, when a dyke is breached, a gap and associated flow channel form and subsequently develop. As yet, very little is known about this.

A gap through which water flows into the polder begins after the occurence of one or more of the collapse mechanisms described in section 3.2 to 3.5 . Because of the high velocity with which the water rushes in, the gap is quickly enlarged by scour, so that the inflow increases. In course of time, as a result of the rising water level in the inundated polder, the hydraulic fall and therefore the flow velocity decrease, so that the current can then no longer transport soil from the bottom of the gap.

The highest velocities occur, not in the actual gap, but behind it (see Figure 4.3.1). 


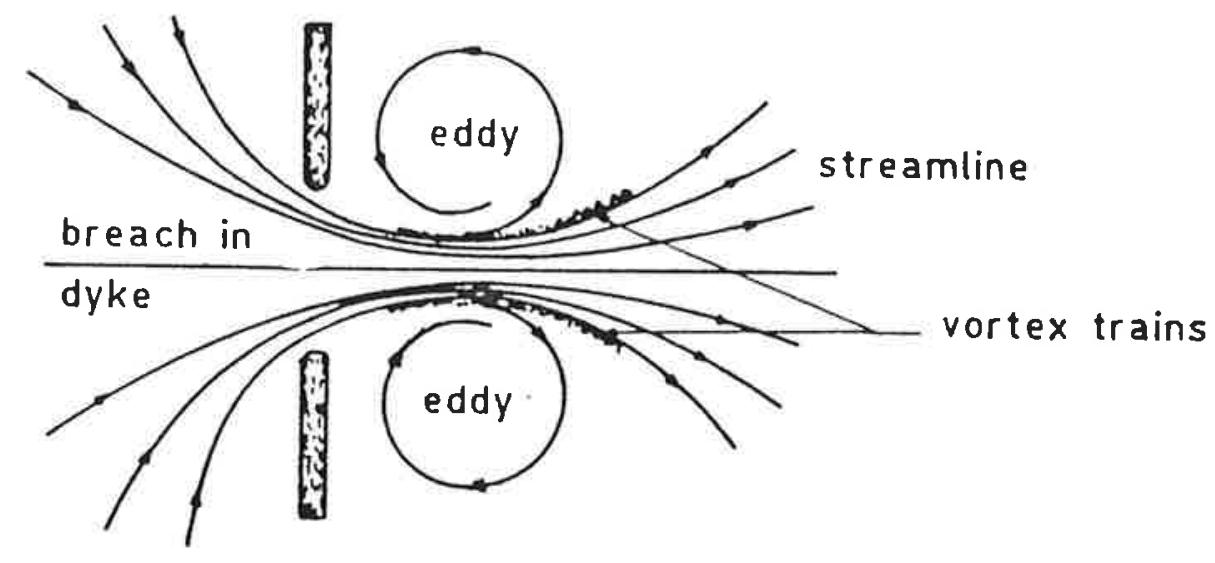

Fig. 4.3.1: Flow pattern associated with a breach in a dyke.

Contraction of the streamlines occurs in the gap. The current flowing through the gap produces large eddies in the almost stagnant water behind it (this does not apply to the situation at the start of inundation). These eddies cause even more pronounced contraction at some distance from the gap, and the highest flow velocities occur there. Deep-penetrating dangerous little vortices develop at the boundaries between the main flow and the large eddies. These so-called vortex trains cause scour.

The sparse available information on the growth of gaps and flow channels associated with the breaching of dykes is in general rather vague. Only a few cases have been recorded in which the growth of the width of the gap as a function of time is tolerably known [4.4]. Two cases are represented in Figure 4.3.2. What is especially notable in this diagram is the difference in the rates of growth and in the ultimate width of the gaps. Both of these variables depend on a number of factors, including the composition of the dyke, and of the subsoil, the area of the polder, the hydraulic fall, the polder level, and the presence of foreland or foreshore. In the case of sea dykes it is to be noted that the currents varying with the tidal movements have the most destructive effect, giving rise to extensively branching systems of large and small channels. In this field much research leading to quantitative models has to be done. 


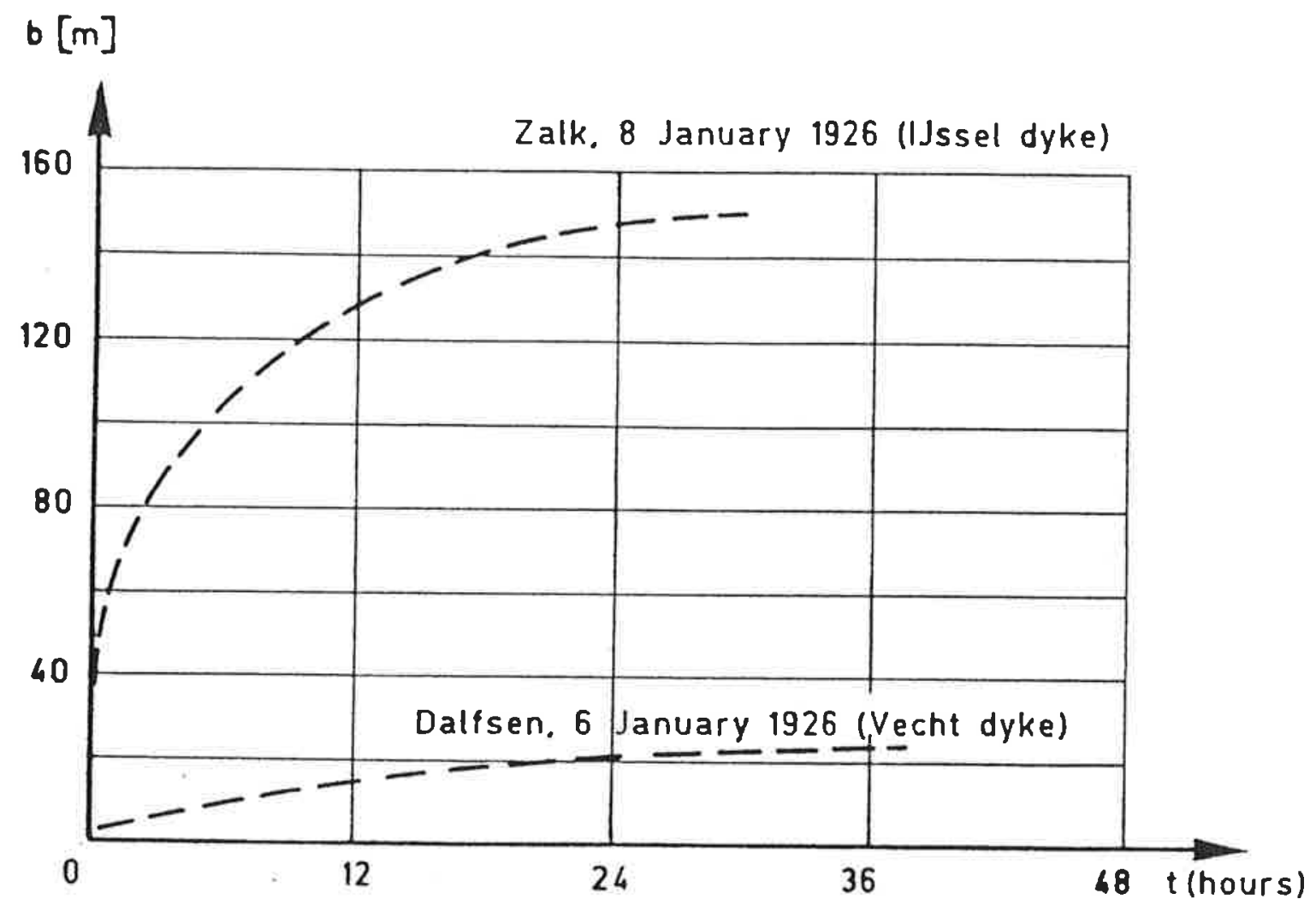

Fig. 4.3.2: Growth of gap width $b$ in the case of two dyke breaches [4.4]. 


\section{CALCULATION OF DAMAGE IN THE EVENT OF A GIVEN INUNDATION}

\subsection{Introduction}

For carrying out a risk analysis of flood defence structures it is necessary, among other information, to know what consequences the failure of the structure will have. What it is therefore desired to establish is the relation between the effect (failure of a dyke or other flood defence) and the consequence.

When a flood defence structure fails, water from the sea, a lake, a river or some other watercourse flows into the region which that structure was intended to protect. In the great majority of cases, inundation of the region will then occur. Only if the quantity of inflowing water is small, so that it can be accomodated by the existing storage capacity in open water and by pumping, no inundation will occur. Even so, damage to the dyke may then ensue, e.g., in the form of damage to the protective covering in the event of overflowing or wave overtopping .

If inundation occurs, "damage" will result. In this context "damage" is to be understood in its most comprehensive sense. It refers not only to material damage and loss, but also to casualities (dead and injured persons), distress and hardship (the immaterial damage). In carrying out a risk analysis in which the total damage has to be determined, all damage items should be expressed in terms of the same units; this gives rise to many problems (see Chapter 6).

As regard the method of determining the damage a number of research projects have been carried out both in the Netherlands and abroad. The present chapter will be chiefly concerned with the investigation carried out by the Industrial Safety Division of MT-TNO at the request of Working Group 10 of TAW [5.1]. In addition, the investigations of Penning-Rowsel and Chatterton will be considered [5.2]. In the MT-TNO investigation attention has been focused more particularly on the 1953 flood disaster in the provinces of Zeeland and South-Holland. The inundation of the Wieringermeer in 1945 and the floods at TuindorpOostzaan in 1960 are also dealt with. 


\subsection{Factors determining inundation damage}

The damage caused by inundation is determined by a great many factors. In broad outline these can be subdivided as follows:

a. Factors which describe the inundation process and the circumstances during inundation: water level as a function of time, flow velocity, wind direction, wind force, duration of inundation, quality of water.

b. Factors relating to the characteristics of the inundated region: size, population, buildings, means of subsistence, warning and rescue facilities.

The factors mentioned in points $a$ and $b$ will now be briefly explained.

\section{Water level as a function of time}

A high water level will result in more victims and more damage. Ebb and flood movements may cause additional damage to buildings, particularly in the vicinity of gaps in dykes. A rapid rise in water level will result in more deaths.

\section{Flow velocity}

A high flow velocity will cause more damage to buildings, particularly in the vicinity of gaps in dykes.

\section{Wind force and wind direction}

More wind causes larger waves, so that more damage will result. Besides, rescue possibilities are adversely affected by much wind. The wind direction has an effect on raising the water level (wind setup). 


\section{Duration of inundation}

The duration of the inundation plays a part with regard to both material damage and immaterial damage. As a rule, material objects suffer greater damage according as they are in contact with water for a longer time or become partly or wholy saturated with water. Also, a long period of inundation increases the probability of greater distress and hardship or of people dying in consequence of exhaustion, disease or hunger.

\section{Quality of the water}

Polluted water will cause more damage than clean water. Also, sea water will have a different effect in terms of damage than fresh water.

\section{Weather conditions}

Besides wind direction and wind force, there are other important determining weather factors, including temperature, precipitation (rain, snow, etc.) or fog. These factors play a part in connection with the risk of disease or the survival chances of people and animals.

\section{Size of the polder}

The extent of the damage is closely bound up with the size of the polder. The size moreover plays a part in connection with the speed of inundation.

\section{Population}

The number of persons living in the polder is of direct importance with regard to the number of victims claimed by an inundation.

\section{Buildings}

The damage to buildings will depend on the nature of the buildings (low-, medium-, high-rise), the form of construction (masonry, monolithic concrete) and the building materials used. 


\section{Means of subsistence}

This comprises impairment of the use of the soil, such as damage to agriculture, industry, forestry, recreational facilities, etc.

\section{Warning possibilities}

If the possibilities for giving early warning against anticipated inundation are good, the probability of casualities is reduced. Also, plant and equipment and/or cattle can be removed to a safe place. Thus, damage will be less according as the warning system is better.

\section{Rescue possibilities}

Obviously, there will be less damage if the possibilities for rescue are better. Rescue facilities include carefully planned life-saving procedures, elevated escape routes, adequate available rescue equipment, etc.

\subsection{Number of deaths in the event of an inundation}

Estimating the number of victims likely to be claimed by a flood disaster is no simple problem, because a large number of factors are involved: see Section 5.2. Data from elsewhere or from earlier times cannot be directly utilized with regard to present-day conditions in the Netherlands. Besides, it will not be possible quantitatively to determine from the known data all the relationships existing between the relevant factors and the number of victims.

In the research sponsored by Working Group 10 of the TAW [5.1] attention was first focused on the data relating to the storm tide disaster of 1953. Generally speaking, these data yield little information on the relationships as envisaged in Section 5.2. From the various commemorative publications and reported interviews the following picture emerges:

a. The municipalities most seriously affected in terms of deaths by 
drowning were engulfed in a short time. Most of them were situated behind dykes facing away from the north-west wind, which were lower and weaker than the dykes along the northern shore of the islands.

b. Most deaths by drowning occured in the outskirts of those places; at Dreischor and Burgh indeed all such deaths occured in the outlying areas. These were often situated at a lower level than the central area, which therefore remained dry for a longer time and where the element of surprise (also because of better communication) played a less dominant part.

c. Some municipalities (especially large ones) on the coast suffered relatively few losses.

of the inundation parameters which, so far as their effect is concerned, call most for investigation - namely, the indundation depth and the inundation speed - attention has been focused chiefly on the inundation depth. Since it is, for most of the municipalities, now known whether the persons who were drowned were resident in the central areas or in the outskirts, the present considerations are based on the number of deaths in the municipality as a whole. This number, referred to the number of inhabitants, gives the "drowning fraction" (proportion of the population killed by drowning).

For some municipalities, however, it has been possible to deduce from on-the-spot information how many deaths due to drowning occured in the central area and how many in the outskirts of the village; two drowning fractions were calculated from this information.

Figure 5.3.1 shows a rough relationship between the inundation depth and the drowning fraction.

From the scatter of the points plotted in the diagram it is apparent that other factors have also played a major part. From the descriptions of events at the time the impression emerges that those factors certainly include.

a. the location in relation to the gaps in the dykes;

b. the speed of inundation;

c. the accessibility of relative safe places of refuge;

d. the speed with which help arrives. 


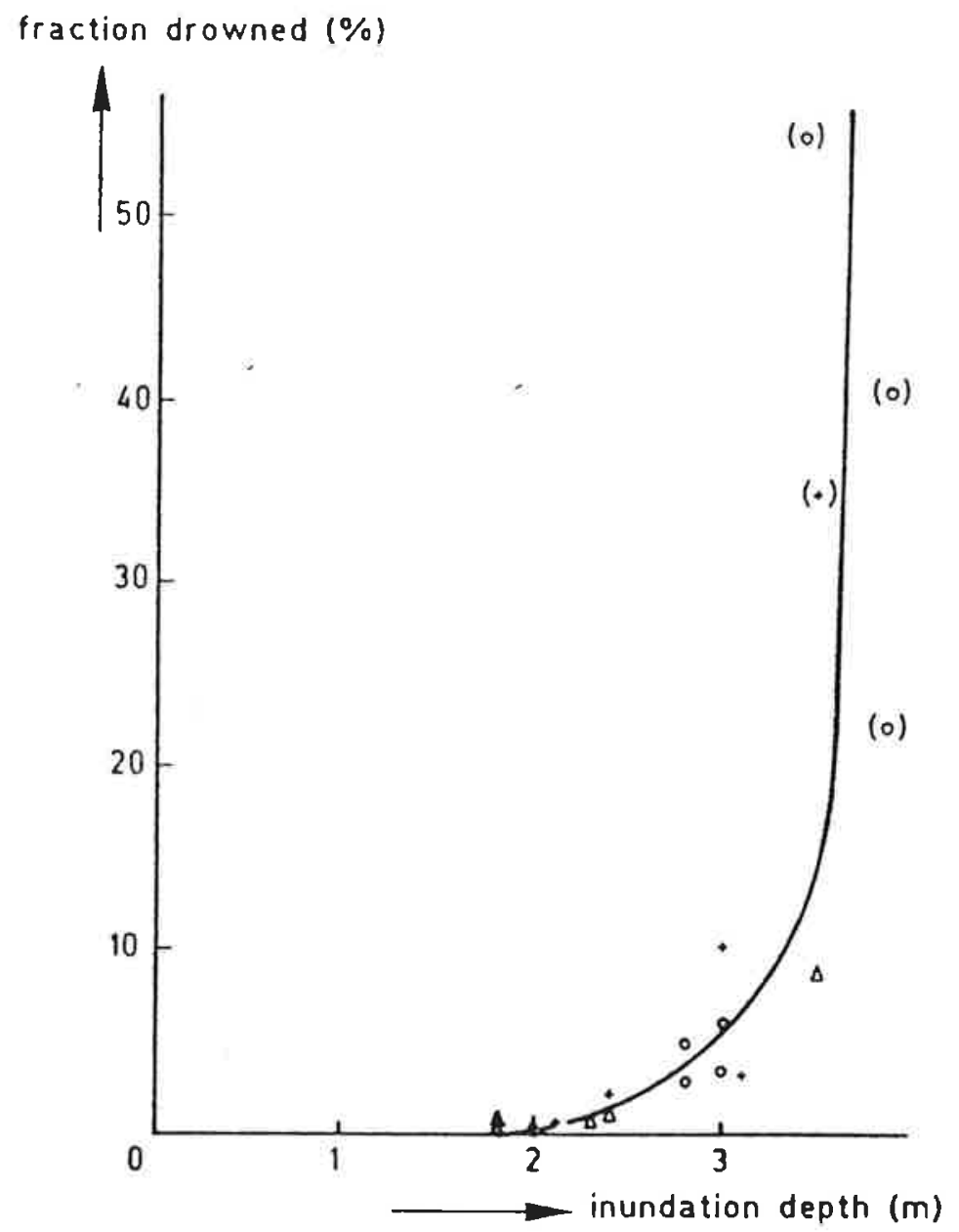

Fig. 5.3.1: Fraction of person drowned (proportion of the population) as a function of the inundation depth during the flood tide of 1 February 1953.

o municipalities on Schouwen-Duiveland

+ municipalities on Goeree-Overflakkee

$\Delta$ municipalities not on these islands

In the situation of 1953, the likelihood of drowning greatly increased when the inundation depth was more then $2.5 \mathrm{~m}$, more particularly for inhabitants of villages and hamlets located in a polder directly relying for its protection on the main dyke, i.e., where there was no inner (secondary) dyke or other relatively high-level ground in the vicinity. For a more quantitative assessment it is necessary to base oneself on information obtained from the municipalities which were struck by the storm tide disaster of 1953. It may then be possible to break down the 
recorded deaths by drowning in some of them into deaths in the central area and in the outskirts of the village respectively.

As for the other inundations mentioned in this report, it is to be noted that they claimed no victims by drowning; in the case of the Wieringermeer in 1945 the inhabitants had been warned in good time; the inundation at Tuindorp-Oostzaan in 1960 flooded the region only to a limited depth $(1.5 \mathrm{~m})$.

It has already been noted that data from former times are not directly valid with regard to the present situation. Since 1953 quite a number of changes have occured in the factors affecting the number of victims in the event of an inundation.

For one thing, the possibilities for early warning have greatly increased thanks to modern means of communication. Besides, a storm tide, but especially a flood wave in a river, is now quantitatively much better predictable.

Facilities for rescue and evacuation have also greatly improved. The municipalities along the coast and along the major rivers have emergency schemes for coping with flood disasters, including evacuation plans. Also, there have been changes in the nature of the buildings and building construction systems since 1953; the low-rise buildings have given place to taller structures. In the regions affected by the flood disaster there existed only low-rise buildings, so that there was no opportunity to take refuge in higher residential buildings. Present-day building construction systems are in general better able to withstand the onslaught of fast-flowing water. In the vicinity of the gaps in the dykes the danger of collapse of the buildings would thus be reduced.

\subsection{Material damage associated with an inundation}

The extent of the material damage in the event of inundation depends on the inundation parameters mentioned in section 5.2 and on the type of object that suffers damage. It is important to know what the relations are between the said parameters and the damage to an object.

In the study carried out by MT-TNO [5.1] the damage has been determined 
as the product of two quantities, namely, the maximum possible damage $S_{\max }$ and the damage factor $c_{i}(d)$ :

$S=c_{i}(d) \cdot S_{\max }$

The maximum possible damage (or loss) corresponds to the replacement value of the object concerned. The damage factor $c_{i}$ (d) has a value between 0 and 1 which indicates the degree of destruction. This factor depends on the category (i) to which property is assignable and on the inundation parameters. In the present stage of the investigation only the relationship between $c_{i}$ and the inundation depth $d$ is considered.

Before explaining this method with the aid of examples, the following will first be dealt with:

a) the possible classification of property and possessions into categories;

b) the damage factors.

\subsubsection{Classification of property into categories}

In its publication entitled "Calculation of material loss caused by inundation in February 1953" [5.3-in Dutch] the Netherlands Central Bureau of Statistics adopted the following classifications:

A. Property to be reckoned as part of the national wealth:

Agricultural estates

Non-agricultural estates

Industry, trade, banking

Transport (motor vehicles, railways; tramways, postal and tele-

communication services, shipping)

Houses, farms, cottages

B. Property not to be reckoned as part of the national wealth:

Dykes, roads, pumping stations

Schools

Churches, town halls

Furniture, clothing 
The Provincial Government of Gelderland has adopted the following classification for "Calculation of inundation loss for the Province of Gelderland" [5.4-in Dutch]:

A. Damage to dwellings, household effects and private cars

B. Damage to agriculture

C. Damage to industry and services

The classification adopted by Penning-Rowsell and Chatterton [5.2] corresponds in broad outline to this last-mentioned one.

For each category of property a subdivision into a number of loss items may be applied; see the examples after Section 5.4.2.

\subsubsection{Damage factors}

By a damage factor is understood the relationship between the inundation parameters, on the one hand, and the degree of destruction, on the other. In the event of total destruction the damage factor is equal to 1. Some damage factors have been deduced from the data of 1953 . Here again, with regard to the inundation parameters only the depth of inundation has been considered.

In Figures 5.4.1 and 5.4.2 some damage factors for houses and farms and several other categories are represented graphically. Damage factors have also been determined by Penning-Rowsell and Chatterton. Some relationships for particular categories of property and goods are given in Figures 5.4.3 and 5.4.4. The general picture to emerge is that the damage factor shows an approximately linear increase with the inundation depth up to a certain value. Ultimately the value 1 is attained for all the factors.

\section{Examples of loss calculation for given inundation depth}

The notation adopted in these examples is as follows:

$s_{\max }=$ maximum damage, expressed as loss in guilders per $\mathrm{m}^{2}$ of area

$c_{i}(d)=$ damage factor depending on $d$

$\mathrm{d} \quad=$ inundation depth in meters

$s=$ damage (loss) for given inundation depth $=c_{i}(d) \cdot s_{\max }$ in guilders per $\mathrm{m}^{2}$ of area 


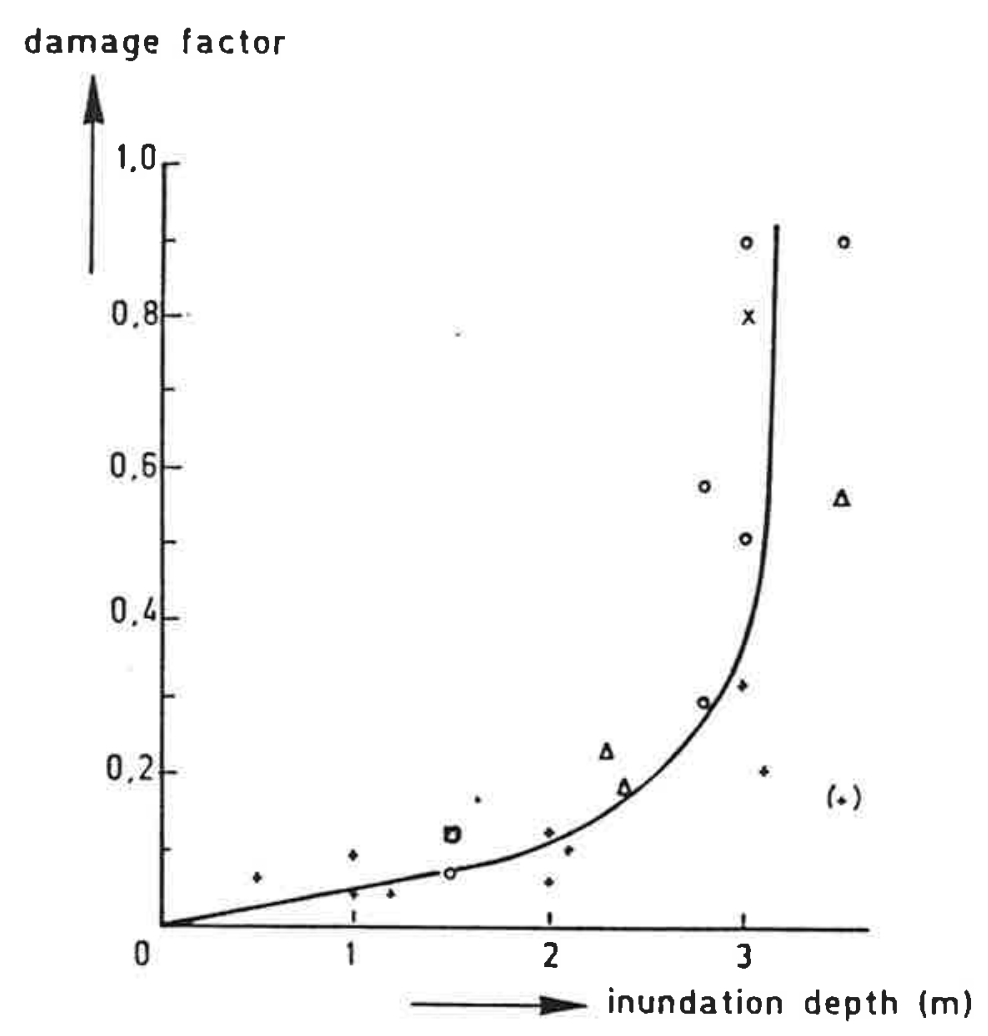

Fig. 5.4.1:

Damage factor for houses and farms (proportion of the replacement value after writing-off) as a

function of the inundation depth during the storm tide of 1 February 1953.

- municipalities on Schouwen-Duiveland

+ municipalities on Goeree-Overflakkee

$\Delta$ municipalities not on these islands

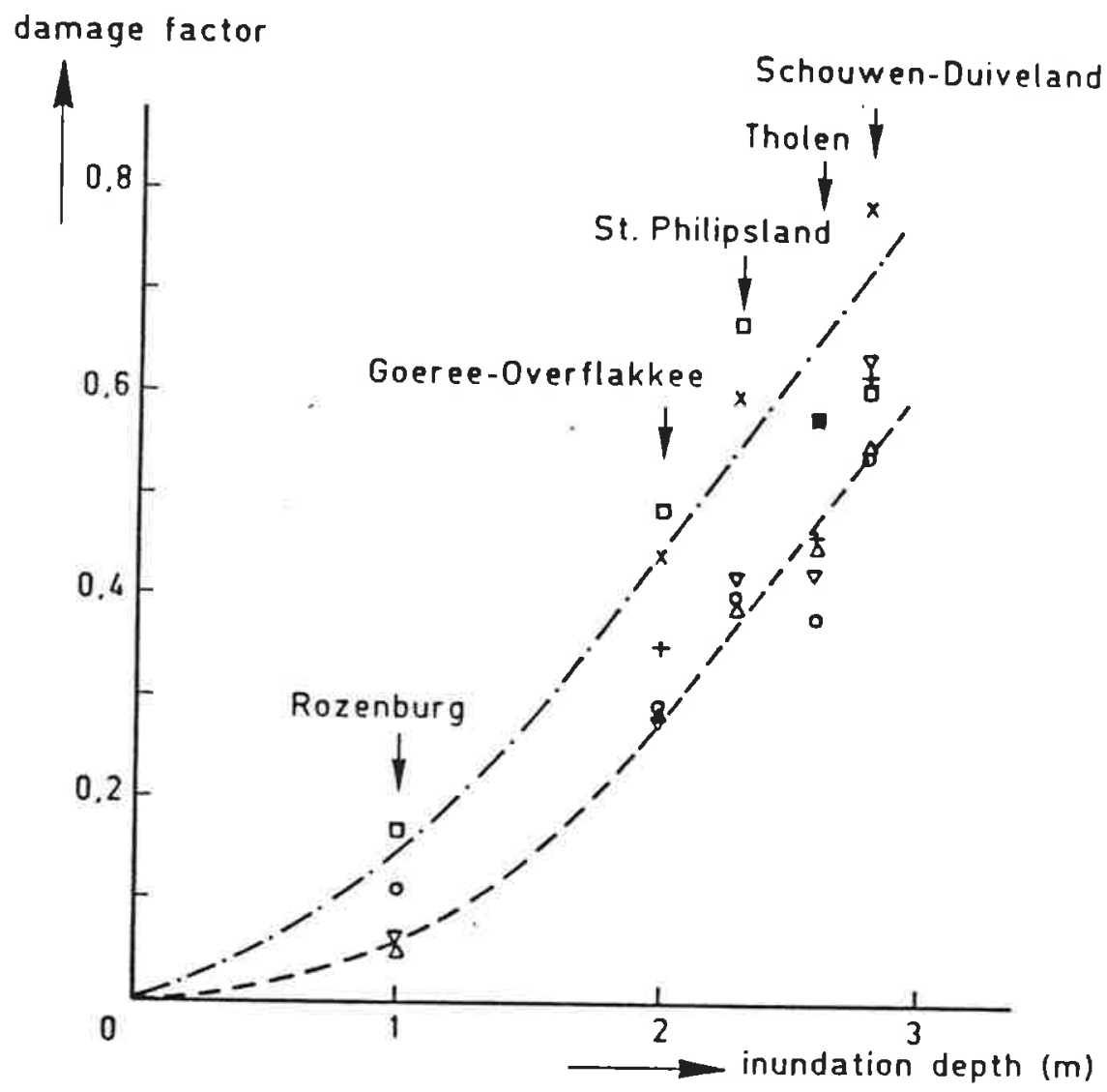

Fig. 5.4.2:

Average damage factor (proportion of the replacement value after writing-off) as a function of the inundation depth during the storm tide of 1 February 1953.

+ inventory: agriculture

$\boldsymbol{x}$ inventory: industry, trade, transport

a industrial stocks

- industrial and commercial buildings

$\Delta$ dwellings

$\nabla$ household effects 


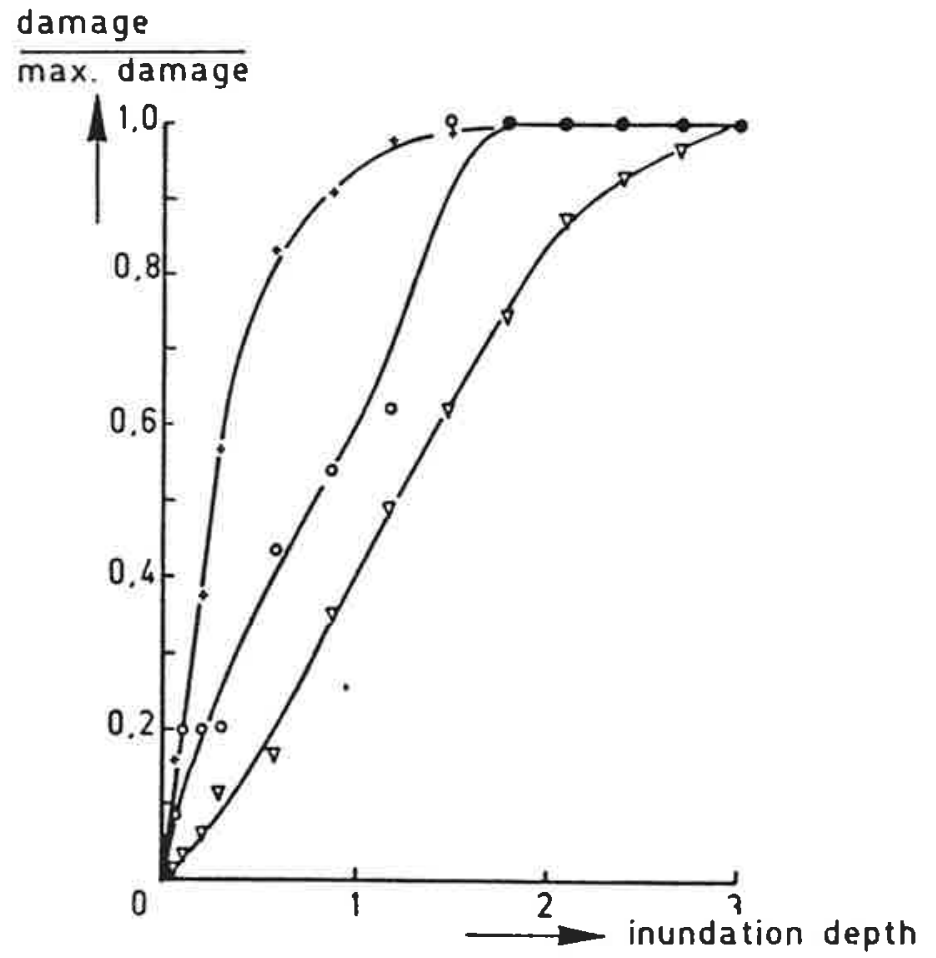

Fig. 5.4.3: Relative damage to dwellings, household effects and agricultural buildings according to Penning-Rowsell and Chatterton 5.2 .

\section{+ inventories}

- buildings (dwellings)

$\checkmark$ agricultural buildings

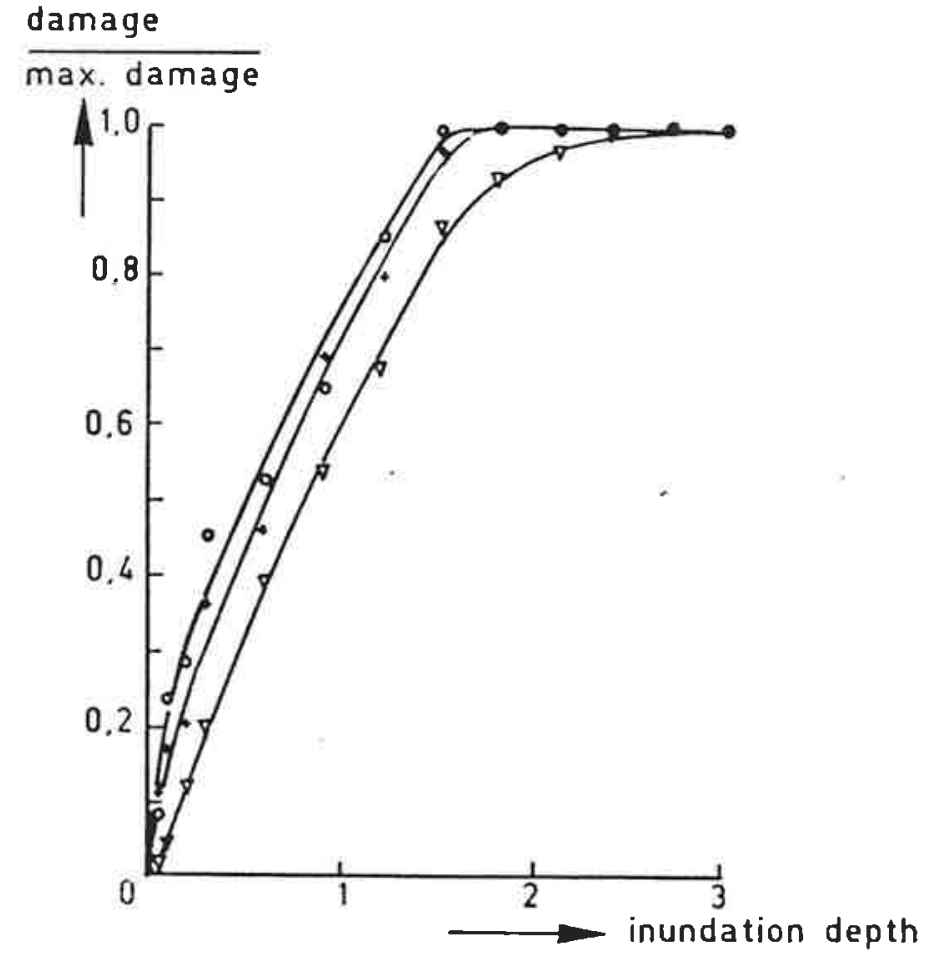

Fig. 5.4.4: Relative damage to commercial commodities and office buildings according to Penning- Rowsell and Chatterton 5.2 .

+ office buildings

- retail services

$\nabla$ retail shops 
The examples relate to agricultural ( $i=1$ ), industrial $(i=2)$ and built-up areas $(i=3)$. The values of $c_{i}(d)$ have mostly been obtained from Figures 5.4.1 and 5.4.2. The values for the maximum damage have been adopted from [5.1]. The cost of evacuation and dyke repair has not been taken into account in the calculations.

Example 1: Damage affecting agricultural areas ( $i=1)$

The loss associated with damage to an average agricultural area for inundation depths of 1,2 and $3 \mathrm{~m}$ can be calculated as shown in Table 5.4.1. Losses affecting other property and goods in these areas should be added to the figures thus arrived at.

Table 5.4.1: Damages to agricultural areas (guilders $/ \mathrm{m}^{2}$ ).

\begin{tabular}{|c|c|c|c|c|c|c|c|}
\hline \multirow[b]{2}{*}{ Category } & \multirow[b]{2}{*}{$s_{\max }$} & \multicolumn{2}{|c|}{$\mathrm{d}=1 \mathrm{~m}$} & \multicolumn{2}{|c|}{$\mathrm{d}=2 \mathrm{~m}$} & \multicolumn{2}{|c|}{$\mathrm{d}=3 \mathrm{~m}$} \\
\hline & & $c_{1}(1)$ & s & $c_{1}(2)$ & $\mathbf{s}$ & $c_{1}(3)$ & s \\
\hline $\begin{array}{l}1 \text { Infrastructural re- } \\
\text { habilitation }\end{array}$ & 0.47 & 1.0 & 0.47 & 1.0 & 0.47 & 1.0 & 0.47 \\
\hline 2 Crops and products & 0.53 & 1.0 & 0.53 & 1.0 & 0.53 & 1.0 & 0.53 \\
\hline 3 Livestock & 0.30 & 0.03 & 0.01 & 0.07 & 0.02 & 0.27 & 0.08 \\
\hline 4 Inventory & 0.20 & 0.05 & 0.01 & 0.10 & 0.02 & 0.30 & 0.06 \\
\hline 5 Plant and equipment & 0.06 & 1.0 & 0.06 & 1.0 & 0.06 & 1.00 & 0.06 \\
\hline Total for river areas & & & 1.08 & & 1.10 & & 1.20 \\
\hline 6 Desalination & 0.04 & 1.0 & 0.04 & 1.0 & 0.04 & 1.0 & 0.04 \\
\hline 7 Recultivation & 0.33 & 1.0 & 0.33 & 1.0 & 0.33 & 1.0 & 0.33 \\
\hline Total for maritime areas & & & 1.45 & & 1.47 & & 1.57 \\
\hline
\end{tabular}

\section{Example 2: Damage affecting industrial areas ( $i=2)$}

It is estimated that about 35.000 ha of land is used for industry employing about 926.000 people, i.e., on average about 26.5 persons per ha are engaged in industry. 
The losses associated with damage due to inundation are divided into:

- direct losses (due to damage affecting buildings, machinery, vehicles);

- indirect losses (interrupted production).

The formula applied here to the direct losses is:

$s_{\operatorname{dir}}=5.11 \mathrm{c}(\mathrm{d}) \sum_{\mathrm{b}} \mathrm{W}_{\mathrm{b}} \mathrm{I}_{\mathrm{b}}$

where:

$c(d)=$ damage factor (averaged over all categories)

$\mathrm{W}_{\mathrm{b}}$ - number of persons employed in branch of industry $\mathrm{b}$

$I_{b}$ - investment per employee per year in that branch of industry

For the indirect losses:

$s_{\text {indir }}=t_{i} \sum_{b} W_{b} P_{b}$

where:

$t_{i}=$ period of non-productivity in months

$\mathrm{P}_{\mathrm{b}}=$ productivity value per employee in branch of industry $\mathrm{b}$

If the value of $\sum_{b} W_{p} I_{p}$ per $m^{2}$ of industrial area is put at 24 guilders per year and that of $\sum_{b} W_{p} P_{b}$ at 16 guilders per month, then for inundation depths of 1,2 and $3 \mathrm{~m}$ for an average industrial area the values shown in Table 5.4 .2 are arrived at. 
Table 5.4.2: Average damages to industrial areas (guilders $/ \mathrm{m}^{2}$ ).

\begin{tabular}{|c|c|c|c|c|c|c|c|}
\hline \multirow[b]{2}{*}{ category } & \multirow[b]{2}{*}{$s_{\max }$} & \multicolumn{2}{|c|}{$\mathrm{d}=1 \mathrm{~m}$} & \multicolumn{2}{|c|}{$\mathrm{d}=2 \mathrm{~m}$} & \multicolumn{2}{|c|}{$\mathrm{d}=3 \mathrm{~m}$} \\
\hline & & $c_{2}(1)$ & $s$ & $c_{2}(2)$ & s & $c_{2}(3)$ & $s$ \\
\hline direct losses & 123 & 0.1 & 12 & 0.16 & 20 & 0.22 & 27 \\
\hline $\begin{array}{l}\text { indirect losses } \\
t_{i}=1 \text { month }\end{array}$ & 16 & 1.0 & 16 & 1.0 & 16 & 1.0 & 16 \\
\hline total for river areas & 139 & & 28 & & 36 & & 43 \\
\hline direct losses & 123 & 0.10 & 12 & 0.16 & 20 & 0.72 & 89 \\
\hline $\begin{array}{l}\text { indirect losses } \\
t_{i}=4 \text { months }\end{array}$ & 64 & 0.5 & 32 & 0.75 & 48 & 1.0 & 64 \\
\hline total for maritime areas & 187 & & 44 & & 68 & & 153 \\
\hline
\end{tabular}

Example 3: Damage affecting built-up areas (excluding industrial areas ( $i=3)$

According to the Central Bureau of Statistics [5.3], built-up areas can be classified as follows with regard to the purposes for which they are used:

Number of ha (1977)

$\begin{array}{lr}\text { Social/cultural facilities } & 17215 \\ \text { Other public facilities } & 6234 \\ \text { Commerce } & 3225 \\ \text { Services sector } & 5651 \\ \text { Residential area } & 181646 \\ \text { Mixed residential/work } & -5398 \\ \text { Total } & 219369\end{array}$

To make an accurate estimate of the loss resulting from a possible inundation, the loss incurred in each of the above-mentioned sectors would have to be estimated separately. However, an approximate estimate 
can be made by assuming this to be the sum of the losses relating to:
a. buildings;
b. household effects;
c. vehicles;
d. commerce
e. cost of evacuation

The loss accounts for inundations of 1,2 and $3 \mathrm{~m}$ are given in Table 5.4.3.

Table 5.4.3: Damages to built-up areas (guilders $/ \mathrm{m}^{2}$ ).

\begin{tabular}{|c|c|c|c|c|c|c|c|}
\hline \multirow[b]{2}{*}{ Category } & \multirow[b]{2}{*}{$s_{\max }$} & \multicolumn{2}{|c|}{$\mathrm{d}=1 \mathrm{~m}$} & \multicolumn{2}{|c|}{$\mathrm{d}=2 \mathrm{~m}$} & \multicolumn{2}{|c|}{$\mathrm{d}=3 \mathrm{~m}$} \\
\hline & & $c_{3}(1)$ & $\mathbf{s}$ & $c_{3}(2)$ & s & $c_{3}(3)$ & s \\
\hline 1 Dwellings & 180 & 0.05 & 9 & 0.11 & 20 & 0.35 & 63 \\
\hline 2 Household effects & 60 & 0.47 & 28 & 0.5 & 30 & 0.66 & 40 \\
\hline 3 Vehicles & 16 & 0.5 & 8 & 1.0 & 16 & 1.0 & 16 \\
\hline 4 Trade and services & 28 & 0.2 & 6 & 0.25 & 7 & 0.32 & 9 \\
\hline 5 Evacuation & 25 & 1.0 & 25 & 1.0 & 25 & 1.0 & 25 \\
\hline Total for river areas & & & 76 & & 98 & & 153 \\
\hline 1 Dwellings & 180 & 0.05 & 9 & 0.11 & 20 & 0.35 & 63 \\
\hline 2 Household effects & 60 & 0.47 & 28 & 0.5 & 30 & 0.66 & 40 \\
\hline 3 Vehicles & 16 & 0.5 & 8 & 1.0 & 16 & 1.0 & 16 \\
\hline 4 Trade and services & 35 & 0.23 & 8 & 0.34 & 12 & 0.8 & 28 \\
\hline 5 Evacuation & 25 & 1.0 & 25 & 1.0 & 25 & 1.0 & 25 \\
\hline Total for maritime areas & & & 78 & & 103 & & 172 \\
\hline
\end{tabular}




\section{DESIGN CRITERIA}

\subsection{Introduction}

Calculation of the probability of failure of a system of flood defence works inevitably comes up against the question as to what probability of failure is acceptable.

Even though the calculated failure probability can only to a limited extent be conceived as a "frequentistic" probability in the sense of an inundation occuring once in $\mathrm{N}$ years, such a relation will nevertheless be established. Hence it is advisable on the one hand, to adjust the calculation of failure probability as much as possible to the assumptions made and, on the other, to conceive a standard or norm for the acceptable probability, so that a framework serviceable for discussion in the social context is ready to hand.

The theory which is applied to calculating the probability of failure of flood defences - dykes, in particular - having been presented in the preceeding chapters, this chapter will offer some considerations on the acceptable risk. By risk is understood the mathematical expectation of the consequences of inundation (mathematically: probability $\mathrm{x}$ consequence).

In this context two points of view will be examined. First, the point of view of the individual who considers whether a particular risk is acceptable to himself. Second, the point of view of society which judges the question whether the probability of a particular accident is sufficiently low. These two approaches each lead to their own conclusions.

Finally, to apply the line of reasoning adopted here, it is necessary to schematize the consequence of an inundation. The consequence has so many facets - fear, distress, damage to one's home, loss of cattle, damage to shops and factories, injury and loss of life - that these can hardly be incoporated in a model approach.to the problem. In the present study the consequence of an inundation is simplified to a loss expressed in money (possibly including a valuation for lost human lives) or to the number of people that perish. 


\subsection{Personally acceptable level of risk}

The smallest component of the socially accepted level of risk is the personal assessment of risks by the individual. In the personal sphere the appraisal, i.e., balancing the desired benefits against the risk associated with them, is often accomplished quickly and unconsciously. Also, a correction is quickly made if the appraisal turns out to be incorrect.

The result of an attempt to establish a model of this appraisal procedure is represented in Figure 6.2.1, presupposing an objective rational balancing of the benefit - both the direct personal and the social benefit - against the risk of expected loss (probability times consequence).

The probability component of the risk is estimated on the basis of the individual's own experience or of the reported experience of others. Some idea of the possible consequences is also derived from these sources. That is why forming a personal opinion with regard to new activities is often difficult due to lack of historical data. In such cases the information is derived from pronouncements by "experts" and form the visible degree of protection.

An important aspect is the degree of voluntariness with which the risk is endured. In the case of non-voluntariness the individual can make his appraisal in accordance with his own set of standards, but any adjustment of the choice in the event of an unfavourable result is outside his sphere of influence. The two points compel him to adopt a sceptical attitude towards non-voluntary risks.

The aspect of non-voluntariness together with the non-availability of historical data and the lack of clarity as to the nature of the benefit to be gained may explain the social resistance to modern sources of energy such as LNG and nuclear energy.

Psychometric research has so far not attained the desired object, namely, operationalization of the model presented in Figure 6.2.1. A solution could consist in presuming the appraisal process of each individual to be consistent and in considering that the result of this process can yield an indication of his preferences. In a schematization of "the consequence" consisting in losing one's life the statistics of 
causes of death $\mathrm{p}$ :-ovide a source which reveals the average result of the individual appraisals of benefit and risk.

An unavoidable risk is the probability of dying from natural causes. In the Western countries this probability for a person under 60 years of age is about $10^{-3}$ per year.

For other activities the personal acceptance of risk is arrived at by dividing the annual number of deaths by the number of participants in the activity concerned.

The personal risk levels for some activities are indicated in Figure 6.2.2. The fact that these figures are stable over the years and are approximately equal for the Western countries would seem to indicate a consistent pattern of preference.

The ranking of the risk levels is not surprising either. The probability of losing one's life in normal daily activities such as motoring or working in a factory is one or two orders of magnitude lower than the normal probability of dying. Only a purely voluntary activity such as mountaineering entails a higher risk.

In view of the consistency and the stability - apart from a slightly downward trend due to technical progress - of the death risks presented, it would appear permissible to deduce therefrom a guideline for decisions with regard to the personally acceptable risk. 


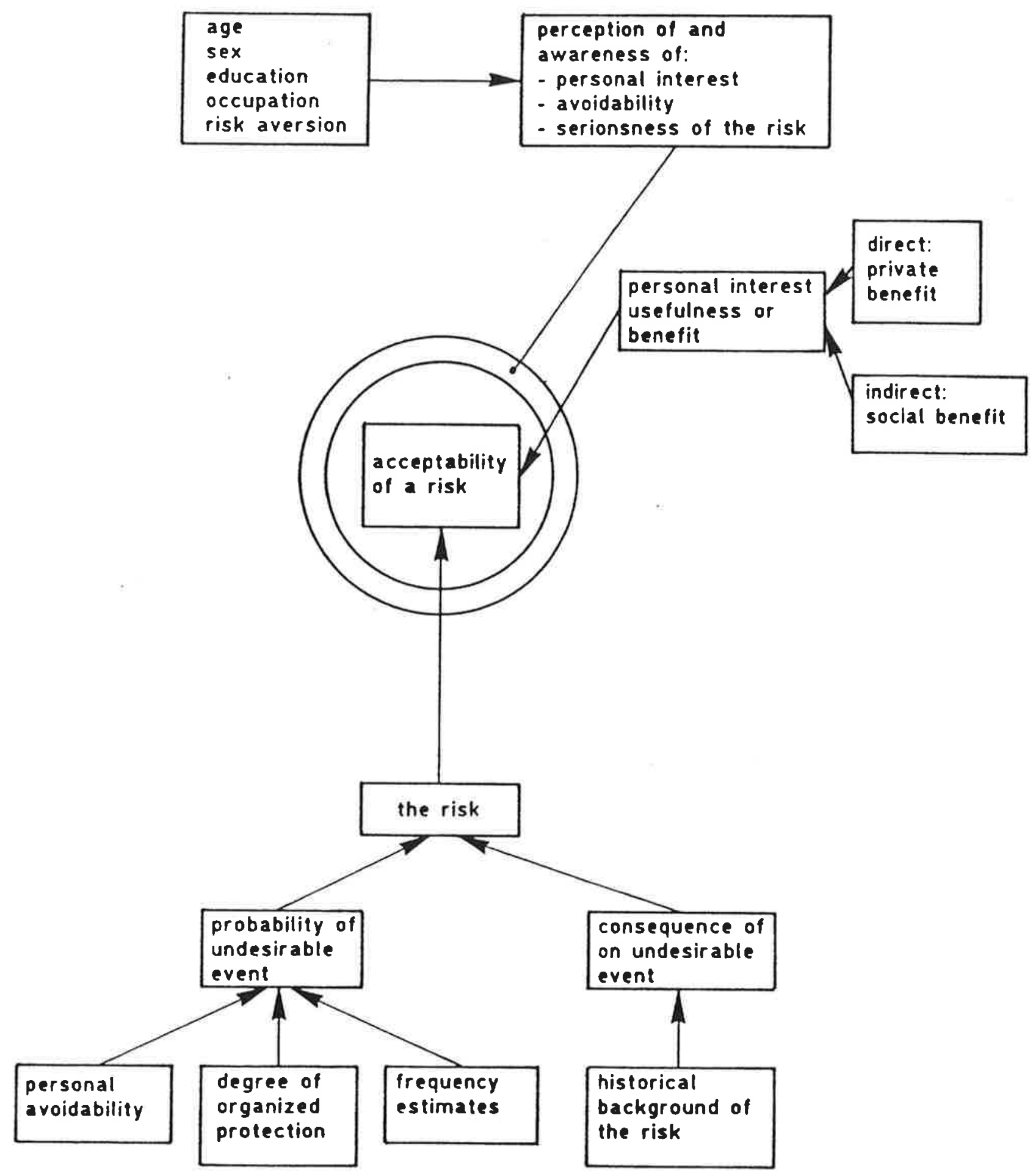

Fig. 6.2.1: Theoretical ranking of the assessment variables of the acceptability of risks in the individual sphere. 


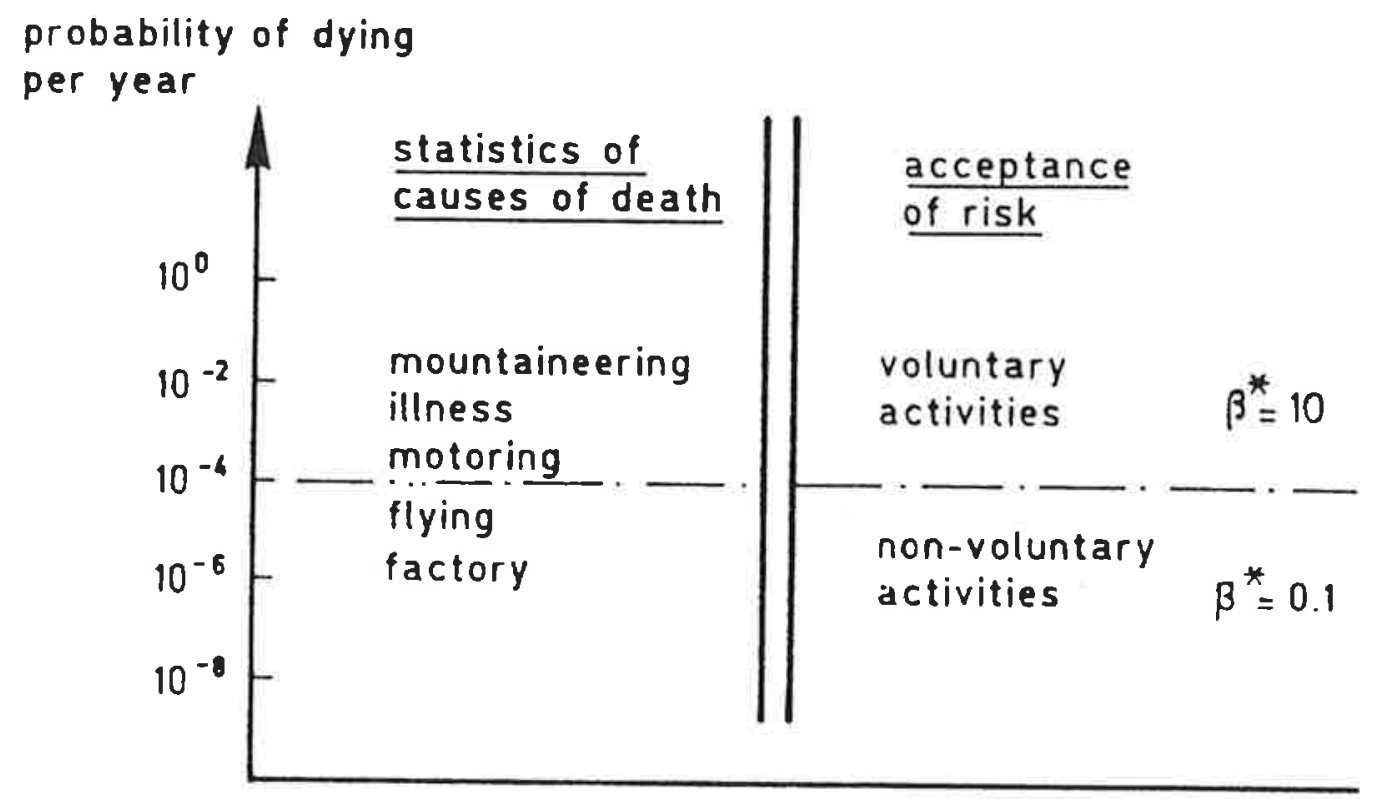

Fig. 6.2.2: Person risks in Western countries, deduced from the statistics of causes of death, referred to the number of participants per activity.

The permissible probability of an accident associated with activity i is:

$P_{f_{i}}=\frac{\beta^{*} \cdot 10^{-4}}{P_{d} \mid f_{i}} \quad[1 /$ year $]$

where $P_{d \mid f_{i}}$ denotes the probability of being killed in the event of an accident.

In this expression the discretion factor $\beta^{*}$ varies with the degree of voluntariness with which the activity is undertaken and ranges from 10 in the case of complete freedom of choice to 0.1 in the case of an imposed risk. 


\subsection{Socially acceptable leve 1 of risk}

What a democratic society accepts in terms of risks is in principle the aggregate, or sum total, of all individual appraisals. The aggregated version of the model presented in Figure 6.2.1 would have to provide the answer.

Although it can be said that, at the social level, for every project in the widest sense the social benefits are balanced against the social costs (including risk), this process of appraisal cannot be made explicit. The social optimization process is accomplished in a tentative way, by trial and error, in which governing bodies make a choice and the further course of events shows how wise this choice was.

If a socially acceptable risk level must be determined for a particular project, a solution can be reached only via considerable simplification of the problem.

One way to achieve this is to schematize the problem to a mathematicaleconomic decision problem by expressing all consequences of the disaster in terms of money. The second approach consists in deducing from accident statistics an acceptable level of risk, while limiting the consequence of the disaster to the number of deaths.

\section{Standard of appraisal based on mathematical-economic optimization}

The mathematical decision problem has been formulated by Van Danzig for the inundation of Central Holland in the Delta Commission's report $[6.1]$.

To simplify the problem the height of the dyke is assumed to be a deterministic quantity. Furthermore, the only failure mechanism considered here is overtopping, i.e., inundation of the polder will occur as soon as the storm tide level rises above the crest level of the dyke.

The probability of this event can be deduced quite simply from the highwater exceedance line (see 3.2.2, although the notation is different): 
$P\left(S_{v}>h_{0}\right)=\bar{F}_{S_{v}}\left(h_{0}\right)=e^{-\frac{h_{0}-\alpha}{\beta}}$

where:

$\mathrm{S}_{\mathrm{v}} \quad=$ storm tide level

ho $\quad=$ height of dyke

$\alpha, \beta=$ constants

$\overline{\mathrm{F}}_{\mathrm{S}_{\mathrm{v}}}\left(\mathrm{h}_{\mathrm{o}}\right)=$ complement of $\mathrm{F}_{\mathrm{S}_{\mathrm{v}}}\left(\mathrm{h}_{\mathrm{o}}\right)$

If the dyke is overtopped and the polder is flooded, the total damage (loss) inflicted on buildings, stocks, cattle and means of production is $S$. The mathematical expectation of this loss in each year is the product of the inundation probability and the loss $\mathrm{S}$. In the first

approximation, loss of income, loss of human lives, etc. are not taken into account.

The cash value of the expected loss over the service life (N) is a measure for the total loss.

To limit the risk the dyke can be heightened (see Figure 6.3.1). The cost of this safety measure is partly constant and partly in approximate proportion to the increase in height. The total cost is the sum of the cost of heightening the dyke and the cash value of the expected loss.

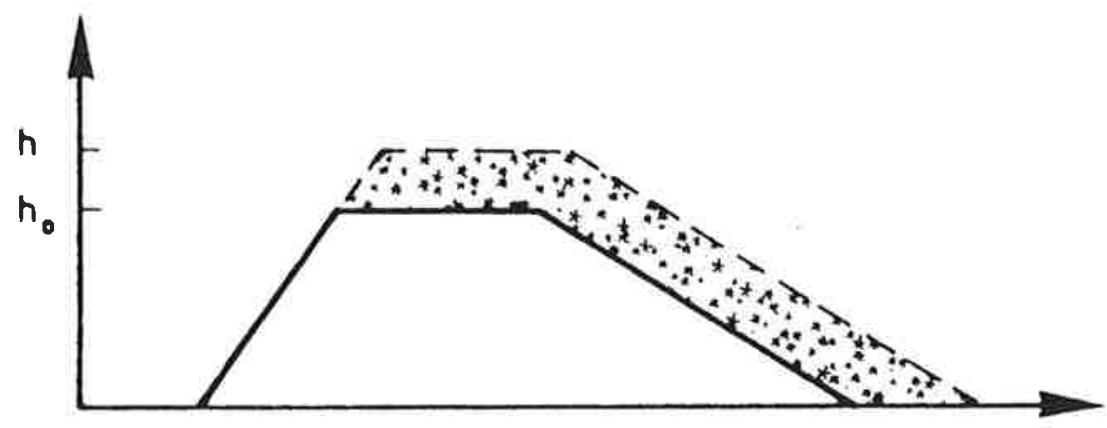

Fig. 6.3.1: Quantity of earthmoving for heightening a dyke.

The optimal height of the dyke (see also figure 6.3.2) is determined by a differentiation with respect to the decision variable $h_{0}$ in order to arrive at the minimum total cost. 
The optimal height of the dyke, $h_{0 . o p t}$, and the optimal failure probability, $\mathrm{P}_{\mathrm{f} \text { opt }}$, can be determined with the aid of the following formulae (see $[6.3]$ ):

$h_{0 . \text { opt }}=\alpha+\beta \ln \left(\frac{S}{I^{\prime} \beta\left(r^{\prime}-g\right)}\right) \quad P_{f_{\text {opt }}}=\frac{I^{\prime} \beta\left(r^{\prime}-g\right)}{S}$

where:

$I^{\prime}=$ cost per meter of height increase of the dyke

$r^{\prime}=$ real state of interest

g $=$ growth rate of the economy

$\alpha, \beta=$ constants

$S \quad=$ total damage costs

It is notable that neither the cost of mobilization of resources for heightening the dyke, $I_{0}$, nor the present (already existing) height of the dyke, $h_{0}$, occur in the expression for the optimal probability of failure.

Yet this cost item does play a part if it has to be decided whether heightening the dyke is economically advantageous or whether it is wiser to leave things as they are. To make this decision the two alternatives must be compared in terms of total cost involved. The total cost of dyke heightening can be calculated. It is equal to the cost of increasing the height to $h_{\text {o.opt }}$ plus the cash value of the then existing risk.

Heightening the dyke will be undertaken only if (see Figure 6.3.2) the total cost that this alternative involves is less then the cash value of the risk in the old situation. 


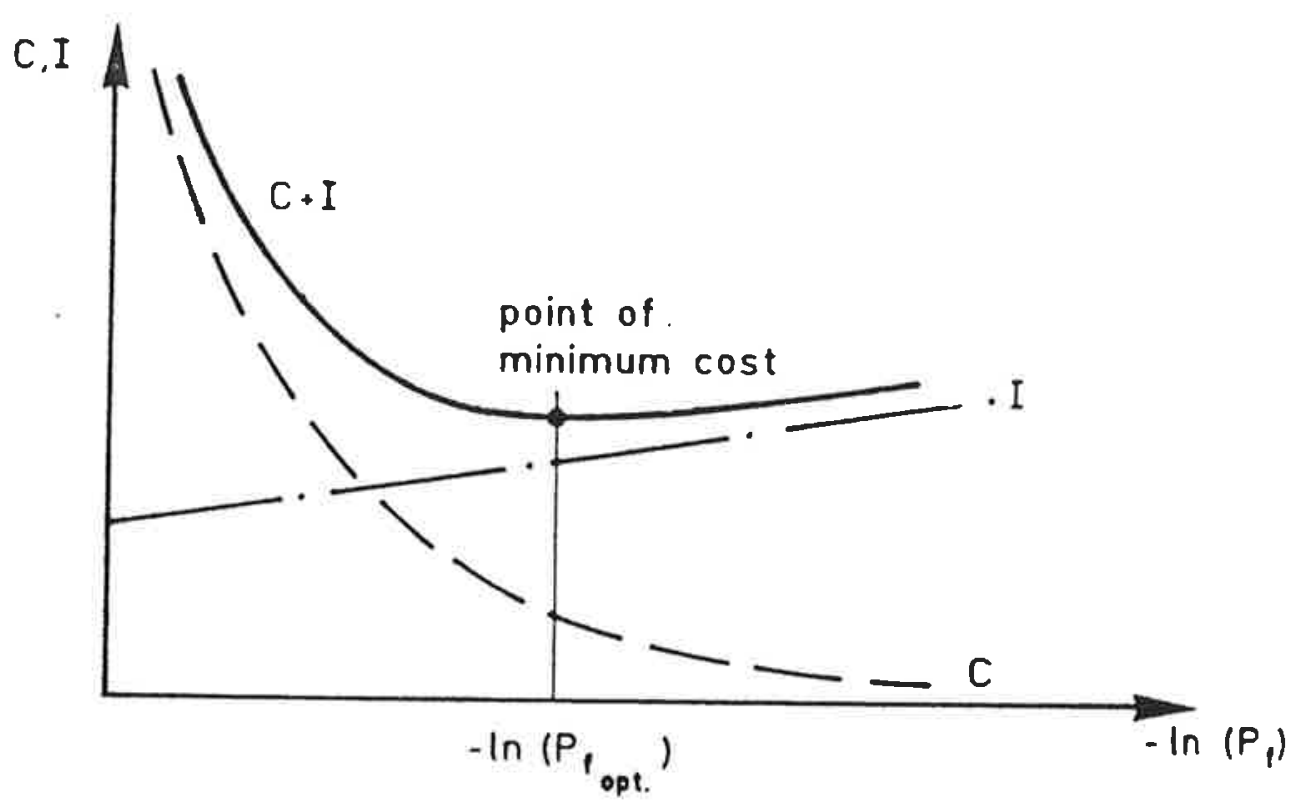

Fig. 6.3.2: Determining the optimal height of a dyke.

$I$ = investment, $c$ - cash value of expected loss.

\section{Example}

The constants adopted for the Delta Plan in 1954 had the following values:

$$
\begin{aligned}
S & =24.2 \times 10^{9} \text { guilders } \\
r^{\prime}-g & =0.015 \\
I^{\prime} & =40.1 \times 10^{6} \text { guilders } / \mathrm{m} \\
\alpha \quad & =1.96 \mathrm{~m}
\end{aligned}
$$

$$
\begin{aligned}
& \beta=0.33 \mathrm{~m} \\
& \mathrm{~h}_{0}=3.25 \mathrm{~m} \\
& \mathrm{I}_{0}=110 \times 10^{6} \text { guilders }
\end{aligned}
$$

From these values followed a dyke height and failure probability of, respectively:

$h_{o . o p t}-5.82 \mathrm{~m}$ and $\mathrm{P}_{\mathrm{fopt}}=8 \times 10^{-6}$ per year

If, despite ethical objections to such an approach, a human life is rated at an amount $s$, an insight of the effect of this upon the optimal 
failure probability is obtained. For this purpose the amount for material damage is increased to:

$P_{d \mid f} \cdot N_{P} \cdot s+s$

where:

$P_{d \mid f}=$ probability of death in the event of failure

$\mathrm{N}_{\mathrm{P}}$ = number of inhabitants involved

$s=$ cost of human life

The expression derived for the optimal failure probability is altered in consequence of this adjustment of the total loss amount:

$P_{f_{\text {opt }}}=\frac{I^{\prime} \beta\left(r^{\prime}-g\right)}{P_{d \mid f} \cdot N_{P} \cdot s+S}$

It is seen that the optimal failure probability shows a downward trend with increasing number of victims. With this addition, however, the problem of the value of a human life has been introduced. Numerous approximations for this are to be found in the literature. In the present study it is proposed that the value of a human life be equated to the cash value of the net national product per inhabitant of the Netherlands.

Working Group 10 of the TAW is furthermore of the opinion that in as sessing acceptable levels of risk, it is advisable to take the possible loss of lives into account in economic terms.

The affordability of safety measures in the context of the national income remains assured if the method described here is adopted as a guiding principle.

A limitation of the mathematical-economic approach is that it presupposes the total loss in the event of failure to be small in relation to the economy as a whole. Indeed it is, in a sense, the confidence in the economy as a whole that makes repair a meaningful proposition. In the case of very severe damage (heavy loss) the attitude of neutrality with respect to risk, as pressumed in the calculations, would no longer be valid. 


\section{Example}

By way of illustration the calculation of the height of the dykes around Central Holland can be extended to an evaluation relating to the number of victims.

The following values are chosen for the constants:

$\mathrm{P}_{\mathrm{d} \mid \mathrm{f}}=10^{-2}$ per year

$\mathrm{N}_{\mathrm{p}}=5 \times 10^{6}$ persons

$s^{\mathrm{p}}=10^{5}$ guilde. $\mathrm{s} /$ person

The optimal dyke helght and failure probability are:

$h_{o . o p t}=5.89 \mathrm{~m}$ and $P_{f_{\text {opt }}}=6.8 \times 10^{-6}$ per year

so that in this example the effect of the loss of human lives is limited to $62 \mathrm{~mm}$ height of the dykes (see previous example). Even if the value $\mathrm{s}$ of a life is increased tenfold, the influence remains limited:

$h_{o . o p t}=6.19 \mathrm{~m}$ and $P_{f_{\text {opt }}}=2.7 \times 10^{-6}$ per year

In fact, the fornula for the optimal failure probability consists of two parts.

An initial value which depends on the material damage or loss:

$$
P_{f_{\text {opt }}}=\frac{I^{\prime} \beta\left(r^{\prime}-g\right)}{S}
$$

and an asymptote to which the function tends with increasing number of fatal casualities:

$$
P_{f_{\text {opt }}}=\frac{I^{\prime} \beta\left(r^{\prime}-g\right)}{P_{d \mid f} N_{P} \cdot s}
$$


If the optimal failure probability is plotted as a function of the number of fatal casualities for the numerical values adopted in this example, Figure 6.3.3 is obtained. The sensitivity of the optimal failure probability to the price of a human life $\left(\mathrm{s}=10^{5}\right.$ and $10^{6}$ guilders) is also indicated in this diagram.

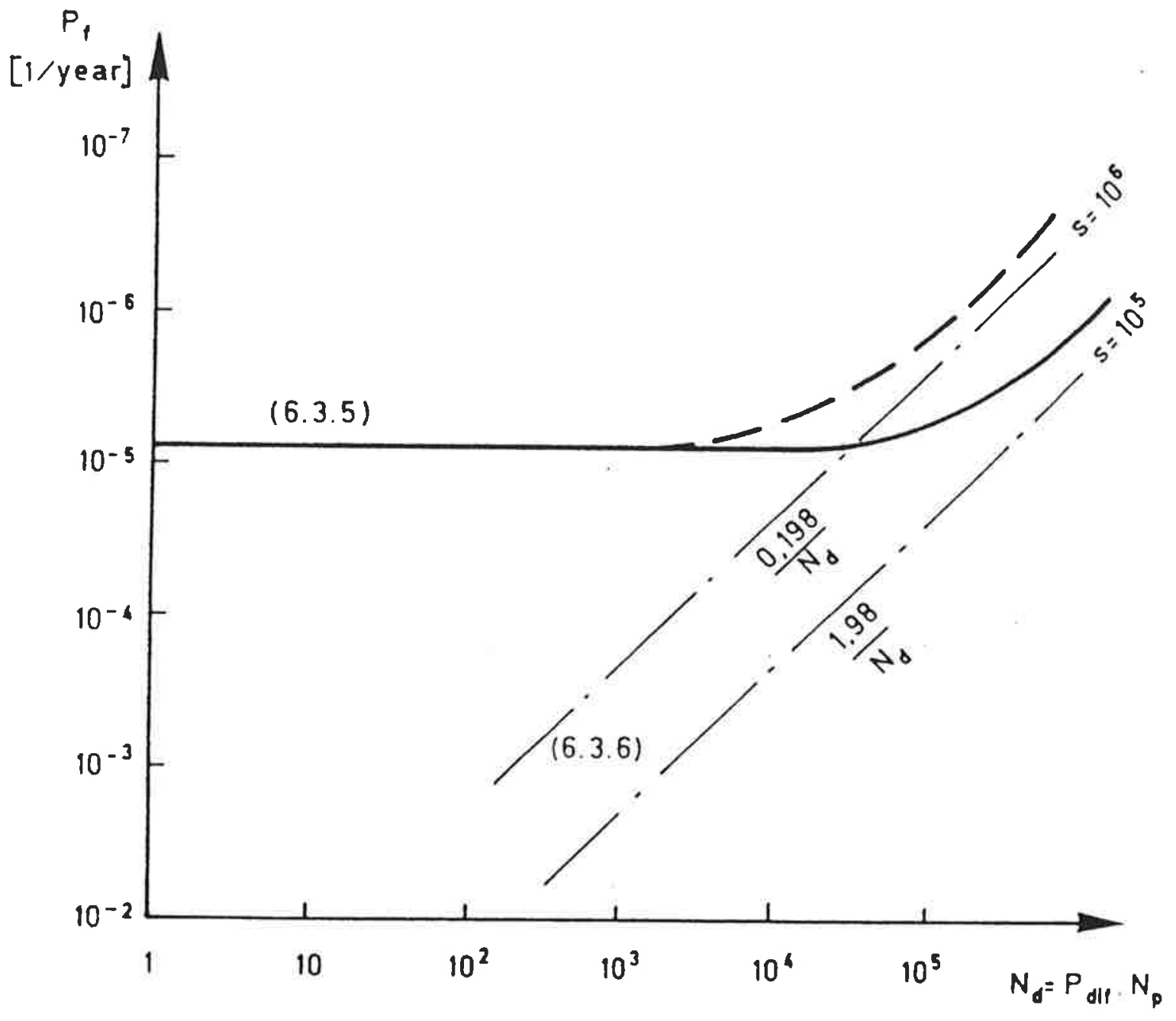

Fig. 6.3.3: Economic-optimal failure probability as a function of the number of deaths resulting from an inundation of Central Holland. 


\section{Standard of appraisal based on accident statistics}

The second approach to determining the socially acceptable level of risk starts from the proposition that the result of a social process of risk appraisal is reflected in the accident statistics. It seeks to derive a set of standards from these. The number of fatal accidents in the Netherlands in 1976 is shown in Table 6.3.1.

A standard of appraisal, or norm, for socially acceptable risks should be based on a model for the social perception of risk. With the aid of this model it should be possible to show that the particularly low probability of fatal accidents is perceptible to members of the community. Secondly, the models should be able to explain the inverse proportionality between the permissible probability of an accident and the number of deaths involved.

As a model hypothesis in the present study it is assumed that an individual assesses the social risk level on the basis of the events within his circle of acquaintances. Assuming for the moment that the average circle of fairly close acquaitances can be put at 100 persons, the probability of a death occuring within that circle in consequence of natural causes is equal to:

$P($ death $)=10^{-3}$ to $10^{-2} \times 100=0.1$ to 1.0 per year

Similarly, the probability of one death among the acquaintances due to a road accident is:

1972: $P($ death $)=\frac{3300}{13 \times 10^{6}} \times 100=2.5 \times 10^{-2}=$ approx. $1 / 40$ per year 1976: $P($ death $)=\frac{2170}{13 \times 10^{6}} \times 100=1.7 \times 10^{-2}=$ approx. $1 / 57$ per year 1980: $\mathrm{P}($ death $)=\frac{2200}{14 \times 10^{6}} \times 100=1.4 \times 10^{-2}=$ approx. $1 / 72$ per year 
Through the instrument of the circle of acquaintances the particularly low probabilities of a fatal accident, which appear socially acceptable, are made perceptible. The recurrence time is within the order of magnitude of a human life span.

In seeking to establish a norm for the acceptable level of risk for civil engineering structures it is more realistic to base oneself on the

Table 6.3.1: Number of deaths due to accidents in the Netherlands in 1976 (based on $13.10^{6}$ people).

\begin{tabular}{|c|c|c|}
\hline Situation & number of deaths & probability \\
\hline in the home younger than 70 & 808 & \\
\hline older than 70 & 1368 & \\
\hline in the street & 134 & \\
\hline on railway crossings & 36 & \\
\hline public buildings & 20 & \\
\hline institutions & 79 & \\
\hline \multirow[t]{2}{*}{ public waterways } & 377 & \\
\hline & 2822 & $2 \times 10^{-4}$ \\
\hline factories & 106 & \\
\hline on board ships & 2 & \\
\hline at sea & 1 & \\
\hline sea- and airports & 8 & \\
\hline railway accidents & 67 & \\
\hline \multirow[t]{2}{*}{ in the open country } & 24 & \\
\hline & 208 & $5.5 \times 10^{-5}$ \\
\hline \multirow{3}{*}{$\begin{array}{l}\text { road accidents } \\
\text { sport and leisure }\end{array}$} & 3300 & \\
\hline & 33 & \\
\hline & 2303 & $1.65 \times 10^{-4}$ \\
\hline not known & 299 & $1.64 \times 10^{-5}$ \\
\hline total & 5562 & $4.0 \times 10^{-4}$ \\
\hline
\end{tabular}


number of deaths due to causes other than road accidents and accidents in the home.

The probability of a death occuring within the circle of acquaintances due to a non-voluntary activity in the factory, on board ship, at sea, etc. is approximately equal to:

$P($ death $)=\frac{208 \times 100}{14 \times 10^{6}}=1.4 \times 10^{-3}$ per year

If this observation-based frequency is adopted as the norm for assessing the safety of activity $i$, then with due regard to $\beta *=0.1$ for the nonvoluntary character:

$\frac{\Sigma \mathrm{N}_{\mathrm{P}_{\mathbf{i}}} \cdot \mathrm{P}_{\mathrm{d} \mid \mathrm{f}_{\mathbf{i}}} \cdot \mathrm{P}_{\mathrm{f}_{\mathbf{i}}} \cdot 100}{14.10^{6}}<\beta^{\star} \times 1.4 \times 10^{-2}$

On rearranging this expression, and adopting a comparatively arbitrary distribution over for example 20 categories of activities, the following norm is obtained for an activity i in situations pertinent to the Netherlands:

$P_{f_{i}}<\frac{\beta^{*} \times 1.4 \times 10^{-2} 14 \times 10^{6}}{N_{P_{i}} \cdot P_{d \mid f_{i}} \times 100 \times 20} \approx \frac{\beta^{*} \cdot 100}{N_{P_{i}} \cdot P_{d} \mid f_{i}}$

This norm should be interpreted in the sense that an activity is permissible so long as it can be expected to claim fewer than $\beta^{*} .100$ deaths per year. The model applying the circle of acquaintances as the individual's instrument of observation justifies an inverse proportionality between acceptable failure probability and number of deaths.

The narm proposed here does not, however, distinguish between two activities with the following danger aspects: 


\begin{tabular}{|l|llrll|}
\cline { 2 - 5 } \multicolumn{1}{c|}{} & \multicolumn{1}{c|}{$\mathrm{P}_{\mathrm{f}_{i}}$} & $\mathrm{x}$ & $\mathrm{N}_{\mathrm{d}_{i}}$ & $=$ & $\mathrm{E}\left(\mathrm{N}_{\mathrm{di}}\right)$ \\
\hline 1 & 1.0 & $\mathrm{x}$ & 100 & $=100$ \\
2 & 0.001 & $\mathrm{x}$ & 100000 & $=$ & 100 \\
\hline
\end{tabular}

Although $\mathrm{E}\left(\mathrm{N}_{\mathrm{di}}\right)$, the mathematical expectation of the number of victims, is the same in both cases, in the first case the number of lives lost would be 100, whereas in the event of the second accident occuring the number would be 100000 . This palpable difference is mathematically manifested only in the dispersion of the number of deaths, which can be represented with the aid of the binominal distribution:

\begin{tabular}{|l|llc|}
\cline { 2 - 4 } \multicolumn{1}{c|}{} & $\mathrm{E}\left(\mathrm{N}_{\mathrm{di}}\right)$ & $\sigma^{2}\left(\mathrm{~N}_{\mathrm{di}}\right)=\mathrm{P}_{\mathrm{f}_{\mathrm{i}}} \cdot\left(1-\mathrm{P}_{\mathrm{f}_{i}}\right) \cdot \mathrm{N}_{\mathrm{di}}$ & $\sigma\left(\mathrm{N}_{\mathrm{di}}\right)$ \\
\hline 1 & 100 & $1.0 \times(1-1.0) \times 100$ & 0 \\
2 & 100 & $0.001 \times(1-0.001) \times 100000$ & 10 \\
\hline
\end{tabular}

The aversion to the second case can be represented mathematically by adding a reliability requirement to compliance with the norm. For this purpose, depending on the reliability requirement imposed, the mathematical expectation of the number of deaths, $\mathrm{E}\left(\mathrm{N}_{\mathrm{di}}\right)$, is increased by the desired multiple of the standard deviation before the situation is tested against the norm:

$\mathrm{E}\left(\mathrm{N}_{\mathrm{di}}\right)+\mathrm{k} \cdot \sigma\left(\mathrm{N}_{\mathrm{di}}\right)<\beta^{*} \cdot 100$

where:

$\mathrm{k}=$ reliability index following from $\Phi(-\mathrm{k})$ (see table 2.2.1)

$\Phi(-k)=$ reliability requirement

For a correct determination of the mathematical expectation and the standard deviation of the number of deaths occuring annually in the 
context of activity $i$, it is necessary also to take into account in how many independent places $\mathrm{N}_{A}$ the activity under consideration is carried out. The number of such indepedent places is of no influence on the expectation of the number of deaths, but it does affect the dispersion of this. After some rearrangement we obtain the result for the permissible probability of failure, which has been plotted for a number of values of $\mathrm{N}_{\mathrm{A}}$ and of the discretion factor $\beta *$ in Figure 6.3.4. A value of 99.98 has provisionally been adopted for the reliability requirement $\Phi(-k)$, whence $k=3$.

For large values of $\mathrm{N}_{\mathrm{A}}$ formula (6.3.9) degenerates into a simple norm in which the acceptable probability of failure is inversely proportional to the number of deaths (see [6.2]):

$P_{f_{i}}<\frac{\beta^{*} 100}{N_{P_{i}} \cdot P_{d} \mid f_{i}}$

For $\mathrm{N}_{\mathrm{A}}=1$ the requirement is more rigorous, but the formula retains a simple form (see [6.2]):

$P_{f_{i}}<\frac{\beta *^{2} \cdot 100^{2} \cdot N_{A}}{k^{2}\left(N_{P_{i}} \cdot P_{d \mid f_{i}}\right)^{2}}$

The more than proportional decrease in the permitted failure probability with the number of deaths $N_{p i} \cdot P_{d \mid f_{i}}$ is founded on the reliablity requirement - in turn based on risk aversion - with regard to the expected number of deaths.

Other explanations for a more than proportional decrease in the failure probability may be:

1. Economy of scale in the protection of a larger number of people. Exercises based on the econometric calculation method likewise lead to lower failure probabilities for greater consequences.

2. The effect of the social channels of communication is more intense in 
response to 100 deaths all at once than to $100 \times 1$ death. The cause lies in economy of scale in politics and the press.

3. The social disruption is more than proportional to $P_{d / f_{i}}$. If an accident results in the deaths of 1 of of a social entity, its further functioning remains possible. But if, say, $50 \%$ of the person concerned lose their lives, the social structure is disrupted and the continued existence of the organization as a whole becomes doubtful, even though half the number of individuals survived the accident.

These considerations have not found expression in the model presented here, however.

In order to test the model against what is considered to be acceptable in the Netherlands, some activities have been plotted in the same kind of diagram (Figure 6.3.5). The probability of an accident or the failure of a system is represented on the vertical axes; the number of deaths arising from the accident or failure is represented on the horizontal axes. Thus, the probability of inundation of Central Holland, as envisaged in the guidelines drawn up by the Delta Commission, is of the order of $10^{-4}$. If Central Holland is inundated, the number of deaths will be of the order of 10,000 .

If every motor car in the Netherlands is involved in a serious accident, the number of deaths resulting from this is approximately $4 \times 10^{6}$. However, the probability of an accident is $2 \times 10^{-4}$ per car.

The lines sloping at $45^{\circ}$ in Figure 6.3 .5 each correspond to a constant mathematical expectation of the number of deaths. For example, about 100 persons are expected to die in industrial accidents each year. The mathematical expectation of the number of deaths due to inundation of Central Holland is $10^{-4} \times 10^{4}=1.0$. The expectation of the number of deaths in motoring accidents is approximately 1500.

The norm derived in this way turns out to be somewhat more stringent than is allowed in reality.

In view of the agreement between the norm for the socially accepted risk, as derived in the present study, for the proposed values of $\beta *$ and a reliability requirement of 99.98 an adjustment of the provisionally adopted values does not appear necessary. 
Henceforth the following values will therefore always be applied:

$\beta^{*} \quad=10$ : voluntary activity

$\beta^{*}=1.0$ : neutral activity

$\beta^{*}=0.1:$ non-voluntary activity

$\Phi(-k)=99.98$ : reliability requirement, whence $k-3$

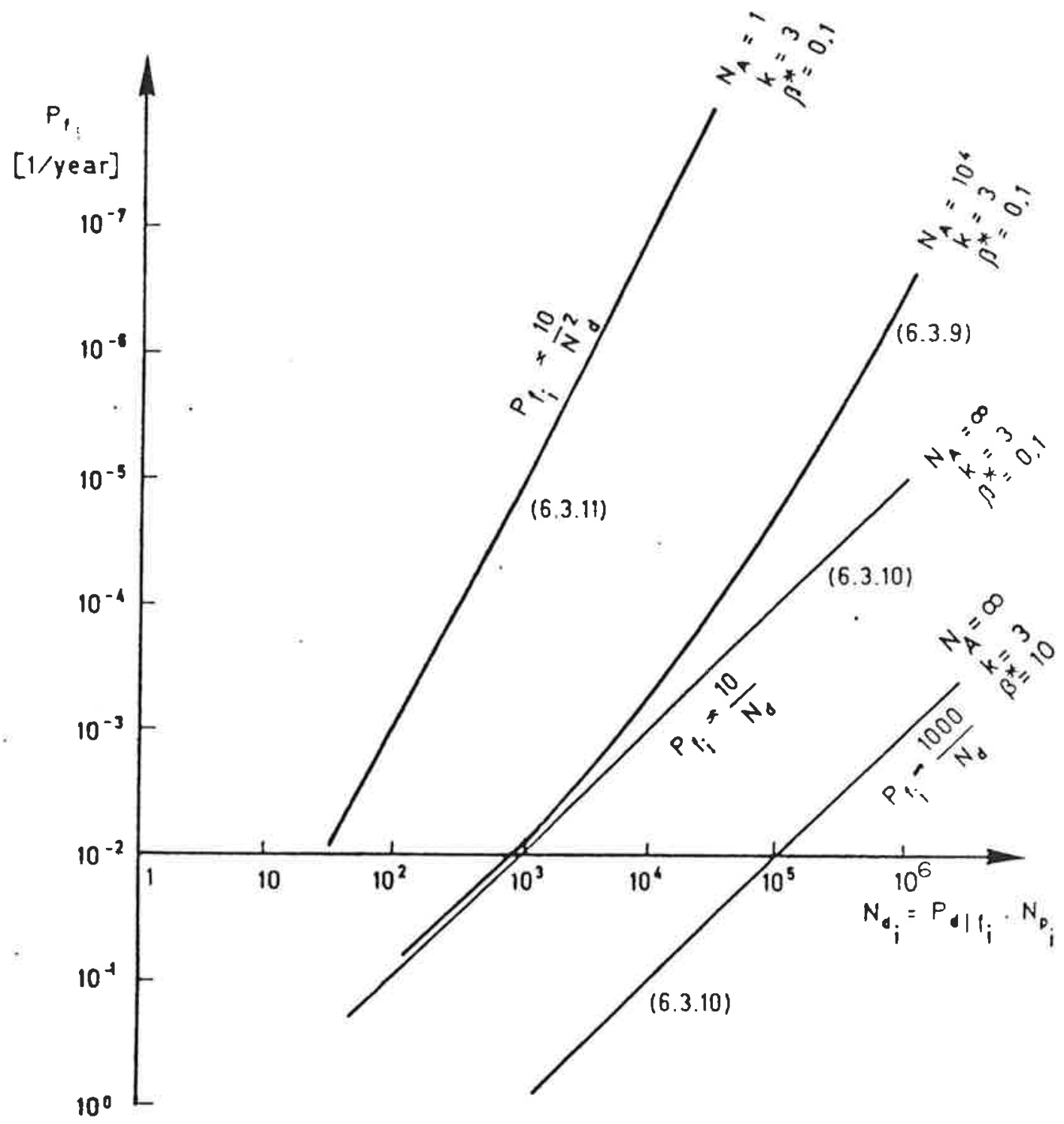

Fig. 6.3.4: Trend of the social safety norm for some values of $\beta$ * and $\mathrm{N}_{\mathrm{A}}$; the probability of an accident is marked on the vertical axis; the horizontal axis indicates the number of deaths if the accident probability is 1.0 . 


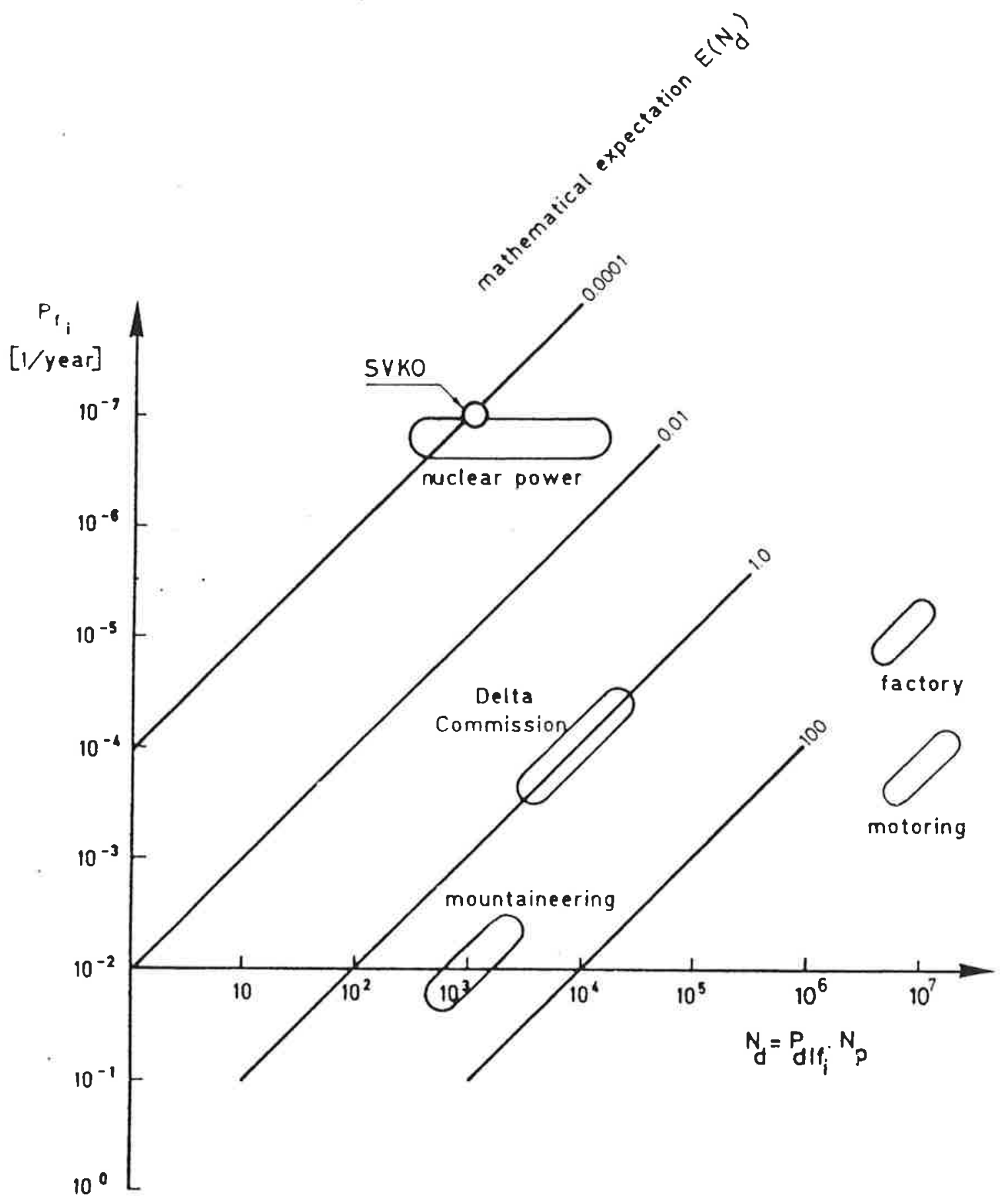

Fig. 6.3.5: Position of some activities in the Netherlands; the probability of an accident per system is marked on the vertical axis; the horizontal axis indicates the number of deaths if the accident probability is 1.0 . 


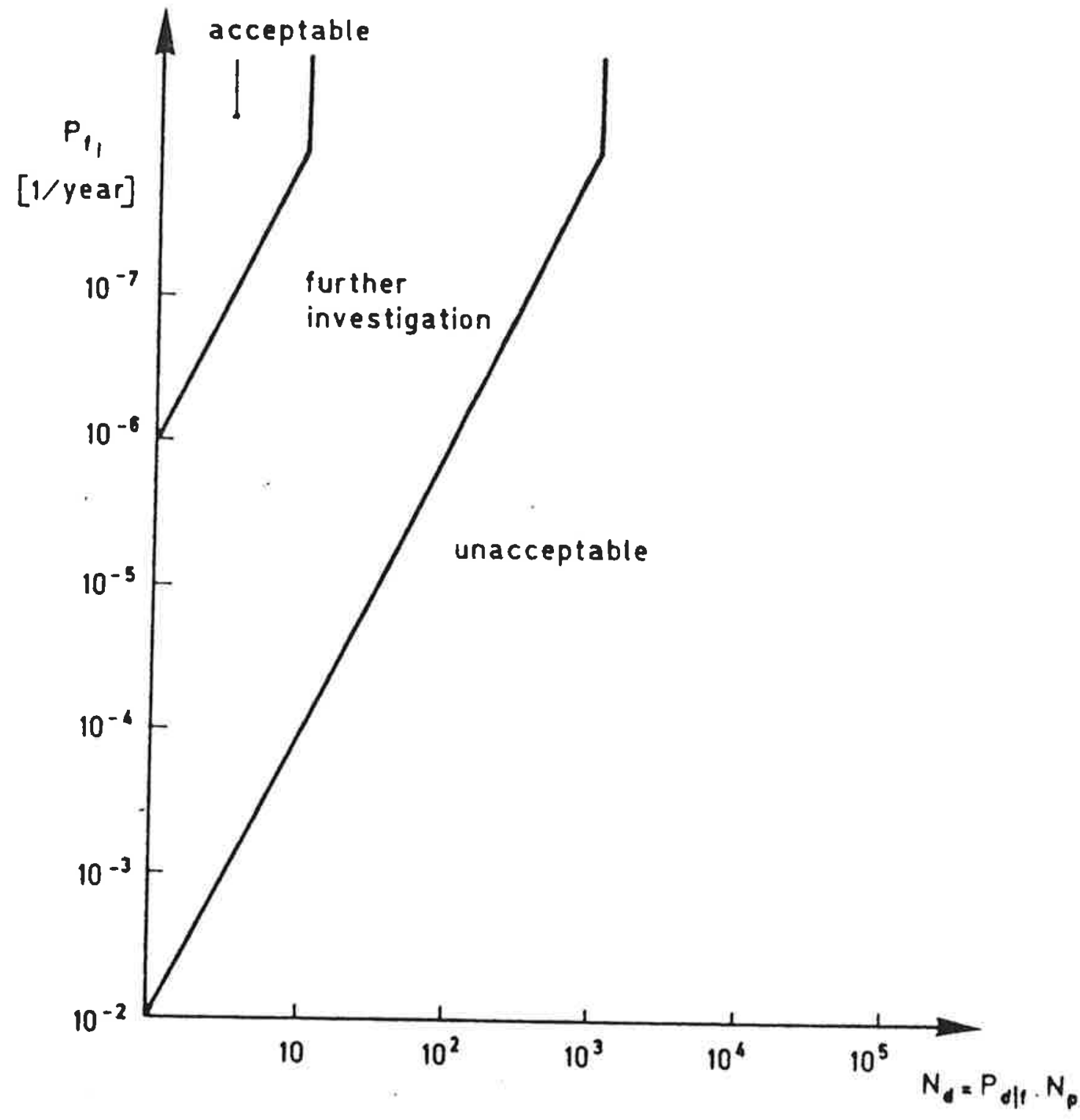

Fig. 6.3.6: Acceptability of group risks according to the Note on Environmental Norms of the Province of Groningen; the diagram is intended for the assessment of possible accidents resulting in large numbers of deaths [6.3]. 


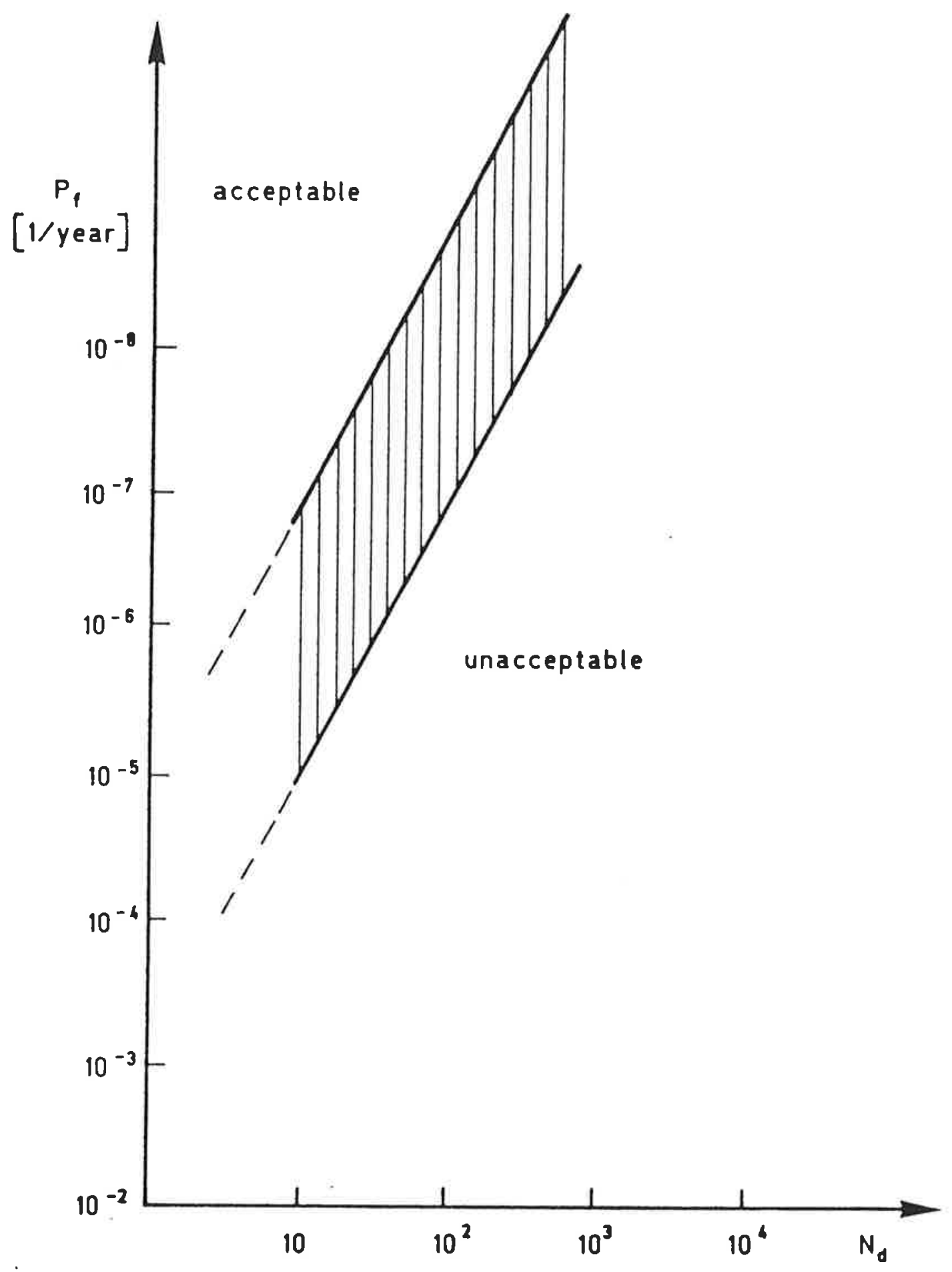

Fig. 6.3.7: Acceptability of group risks as deduced from the LPG Integral Note ( 18233 Nos. 1 and 2 ). This norm must be complemented with a maximum personal risk of $10^{-6}-10^{-7}$ per year [6.4]. 


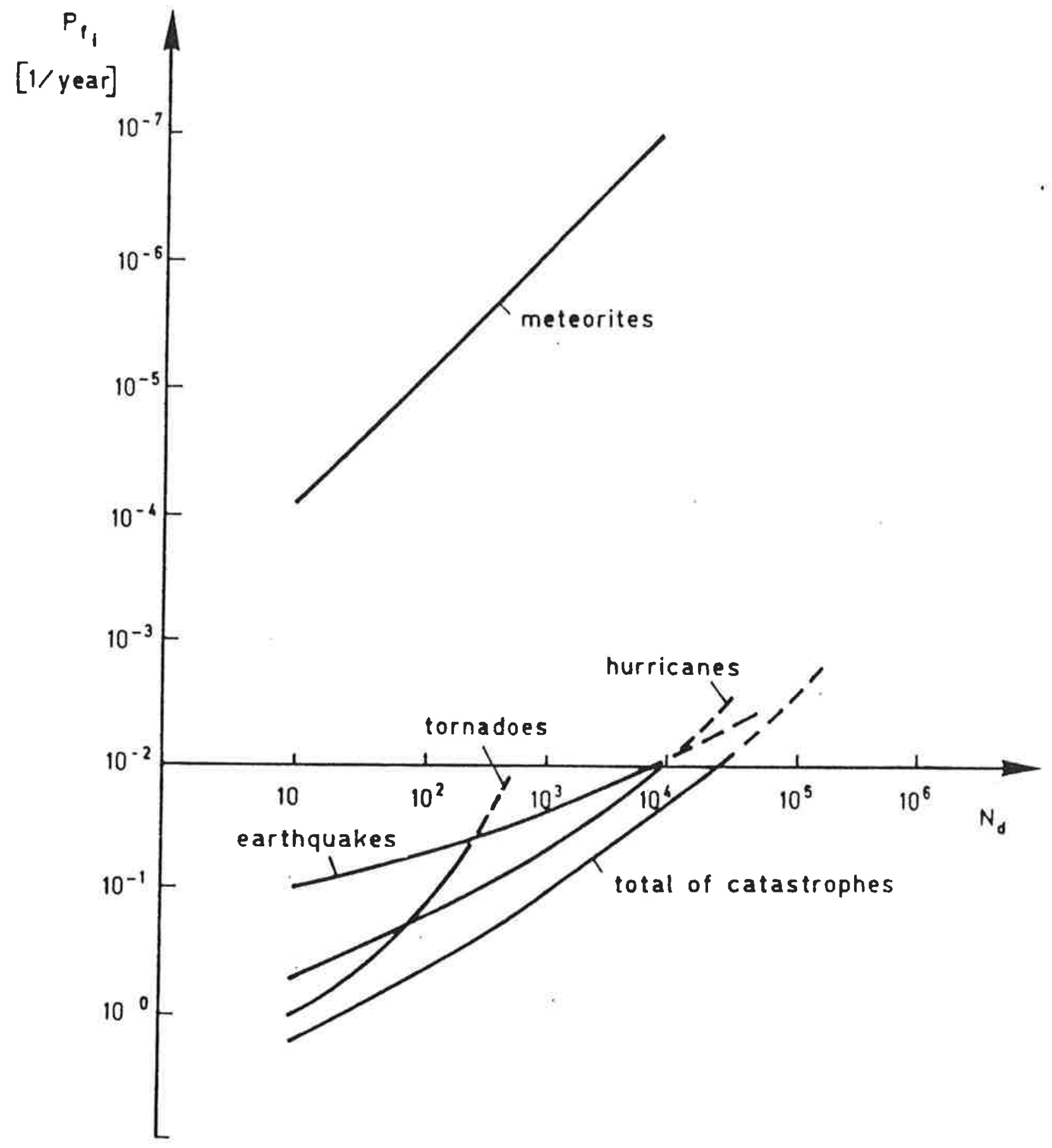

Fig. 6.3.8: Frequency of fatal accidents due to natural castastrophes in the United States. 
Other social organizations and authorities have also made pronouncements on the socially acceptable risk. This, the Environment Note of the Province of Gronir.gen [6.3] and the LPG Integral Study of the Ministry for Public Housing and Regional Planning express view on this subject $[6.4]$.

For the purpose of comparison the essentials of these two approaches are represented graphically in diagrams as adopted in this study. It is notable that both approaches assume a proportionality between the acceptable probability of failure and the square of the number of deaths.

The social acceptability of risks according to the Environment Note of the Province of Groningen [6.3] is represented in Figure 6.3.6.

The recent norm established in the LPG Integral study is represented in Figure 6.3.7.

These norms for the group risk are much more stringent than the concepts developed in the present study. A disaster resulting in 10.000 deaths is entirely unacceptable, so that in the light of this assessment the flood defences of Central Holland would need improvement forthwith.

Finally, Figure 6.3.8 gives the diagram contained in the Rasmussen report, showing the frequency of fatal accidents due to natural catastrophes in the United States. From this widely cited diagram it appears that in that country the risk due to natural phenomena is an order of magnitude higher than the risk considered acceptable with regard to human activities. In other words, risky human activities make only a small contribution to the overall level of risk.

The possibly different perception by the general population of risks associated with human activities (industry, nuclear energy) as against risks associated with natural events (earthquake, inundation, hurricane) is not incorporated in the mathematical description of the socially accepted risk in this section. 


\subsection{A concept of acceptable risk}

Several concepts of determining the acceptable level of risk have been presented in the foregoing section. One approach, based on accident statistics, has been given for the personally acceptable level of risk. The socially acceptable level of risk has been approached in two ways. First, the mathematical-economic approach of the material risks weighed against the cost of safeguarding against them. Second, an approach based on a model of social perception of risk.

In assessing the vafety of a polder three approaches should therefore be investigated:

- The personally acceptable risk which a member of the community is on average prepared to accept. In simplified form this risk is represented by:

$P_{f_{i}}<\frac{\beta^{*} \cdot 10^{-4}}{P_{d} \mid f_{i}}$

where:

$\beta *$ - discretion factor, ranging from 0.1 to 10 depending on the degree of voluntariness

$P_{d \mid f_{i}}=$ probability of death in the event of failure

- The economically optimal level of risk, in connection with which the value of a human life must be taken into account. An objective measure of the value of a human life is the cash value of the net national product per head.

The optimal level is attained if the marginal cost of safety measures is just equal to the marginal benefit.

- The socially acceptable level of risk, on the basis of the assumed risk aversion model, which leads to the following evaluation of the acceptable probability of failure for two limiting cases: 


$$
\begin{aligned}
P_{f_{i}}<\frac{\beta^{*} \cdot 100}{P_{d \mid f_{i}} \cdot N_{P}} & \text { for } N_{A} \gg \frac{1}{P_{f_{i}}} \\
P_{f_{i}}<\frac{\beta^{* 2} \cdot 100^{2} N_{A}}{k^{2}\left(P_{\left.d \mid f_{i} \cdot N_{P}\right)^{2}}\right.} & \text { for } N_{A} \ll \frac{1}{P_{f_{i}}}
\end{aligned}
$$

where:

$\mathrm{N}_{\mathrm{A}}=$ number of places where the activity occurs

$\beta^{*}=$ discretion factor, ranging from 0.1 to 10

$N_{p}=$ number of participants

The most rigorous of the three criteria should be adopted as the governing criterion.

In this context it is to be noted that, from macro-economic considerations, it is not advisable to depart in many cases and greatly from the economically optimal level of safety. The degree of safety to be provided could otherwise become unaffordably expensive.

To illustrate the proposed procedure, it has been applied to Central Holland. The results are represented in Figure 6.4.1.

From the personal point of view an inundation probability of $10^{-2}$ is acceptable. Economically speaking (assuming $3.10^{4}$ casualties in the case of inundation) the acceptable probability equals $5 \times 10^{-6}$. Basing oneself on the social point of view expressed by $(6.4 .3)$ a value of $10^{-8}$ is obtained. Note that the present aim is somewhere between $10^{-5}$ and $10^{-4}$. This safety level is even lower than the economic optimum and far lower than accepted by society for new risks as LNG or nuclear power plants. 


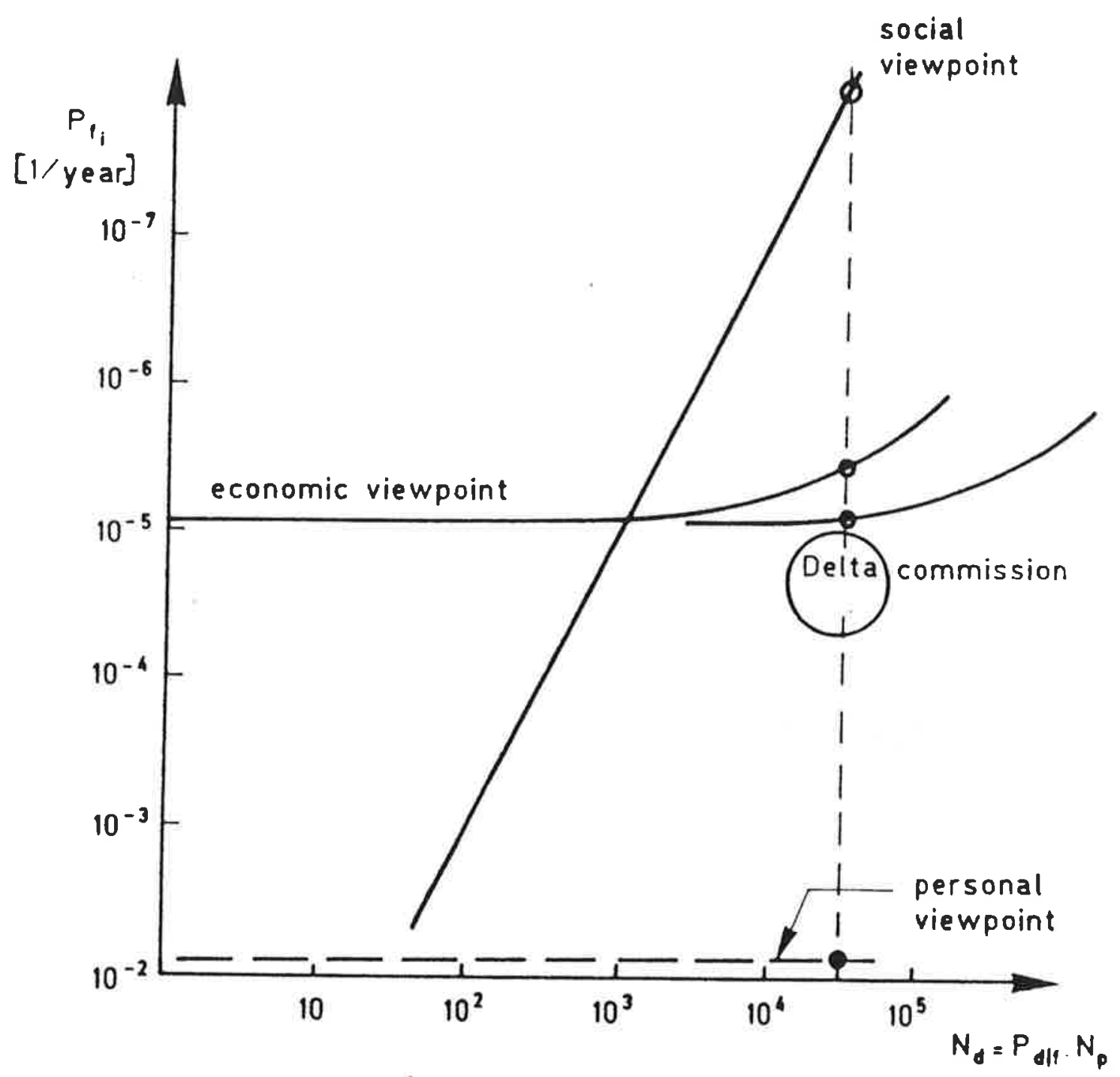

Fig. 6.4.1: Application of the three safety requirements to Central Holland. 


\subsection{Some practical considerations in connection with the standard of appraisal adopted}

In practice a great many considerations may influence the standard of appraisal, or norm, to be adopted for safety. The hazard to a polder from two different water regimes (e.g., a sea and a river), an absolute upper limit to the amount of money available for dyke improvement, or a policy inspired by other criteria (e.g., environment), are examples of such considerations.

If a polder is at risk from two sides, the probability of inundations will be between the bounds:

$\max _{i=1}^{2}\left(P_{f_{i}}\right\}<P_{f_{\text {syst }}}<\sum_{i=1}^{2} P_{f_{i}}$

where $P_{f_{i}}$ is the failure probability of dyke $i$.

The probability of inundation is equal to the lower bound if failure of both dykes is completely correlated (for example, two branches of the same river). If there is complete independence, i.e., no correlation, the upper bound is virtually attained.

Now if, on the basis of the considerations advanced in the preceding section, the acceptable inundation probability has been set at $P_{f}$, then for complete dependence the requisite safety of the dyke is directly found as:

$\mathrm{P}_{\mathrm{f}_{1}}=\mathrm{P}_{\mathrm{f}_{2}}<\mathrm{P}_{\mathrm{facc}}$

In the event of independence, however, the choice is indeterminated because a criterion of division is lacking. But even so:

$\sum_{i=1}^{2} P_{f_{i}}<P_{f_{\text {acc }}}$ 
To adopt equal division between the two dykes appears obvious. Yet this is not an optimal choice, as will become apparent below.

If the amount of money available for dyke improvement is limited and insufficient to achieve compliance with the norm imposed, there likewise arises a problem for which a sensible solution is not directly discernible. The same applies to the situation where one dyke is not allowed to be modified, e.g., for environmental reasons. In the case of complete correlation, improvement of the other dyke is meaningful only to the level where the two dykes are equally safe, even though this level is not in fact acceptable. If there is no correlation between the two dykes as regards failure, improvement of one dyke always results in a reduction of the probability of inundation. If the dyke which is not allowed to be improved does not satisfy the norm $P_{\text {acc' }}$, the requisite safety for the whole polder is unattainable. Will heightening the other dyke then serve a useful purpose?

The only approach in Section 6.4 that can provide answers to the above questions is the econometric modelling of the problem.

The only failure mechanism considered here is "overflowing", while it is moreover presupposed that the dyke heights (crest levels) $h_{01}$ and $h_{o 2}$ have deterministic values, so that the probability of failure is determined by the high-water exceedance lines:

$P_{f_{1}}=\bar{F}_{S_{v 1}}\left(h_{o 1}\right)=e^{-\frac{h_{o i}-\alpha}{\beta}}$

$P_{f_{2}}=\bar{F}_{S_{v 2}}\left(h_{o 2}\right)=e^{-\frac{h_{o 2}-\gamma}{\delta}}$

The capital investment that can be made in the two dykes is a function of the height:

$$
I=I_{0}+I_{1} h_{01}+I_{2} h_{02}
$$


The total cost function for the cases "dependent water levels" and "independent water levels", respectively is:

$$
\begin{aligned}
& C_{\text {TOT }}=I_{0}+I_{1} h_{01}+I_{2} h_{o 2}+\frac{S}{\left(r^{\prime}-g\right)} \max \left\{P_{f_{1}}, P_{f_{2}}\right\} \\
& C_{\text {TOT }}=I_{0}+I_{1} h_{01}+I_{2} h_{o 2}+\frac{S}{\left(r^{\prime}-g\right)}\left(P_{f_{1}}+P_{f_{2}}\right)
\end{aligned}
$$

The optimal safeties of the dykes can be determined by minimization of the cost $\mathrm{C}_{\text {TOT }}$.

In the case of dependence:

$P_{f_{\text {syst }} \text { opt }}=\frac{\left(I_{1} \beta+I_{2} \delta\right)\left(r^{\prime}-g\right)}{S}=P_{f_{1}}-P_{f_{2}}$

In the case of independence:

$\mathrm{P}_{\mathrm{f}_{\text {syst }} \text { opt }}=\frac{I_{1} \beta\left(r^{\prime}-g\right)}{S}+\frac{I_{2} \delta\left(r^{\prime}-g\right)}{S}$

$\mathrm{P}_{\mathrm{f}_{\text {opt }}}=\frac{\mathrm{I}_{1} \beta\left(\mathrm{r}^{\prime}-\mathrm{g}\right)}{\mathrm{S}}$

$P_{f_{2 o p t}}=\frac{I_{2} \delta\left(r^{\prime}-g\right)}{S}$

It is notable that the optimal probability of inundation of the polder is the same for both cases. With dependence, the optimal probability of overflowing is the same for both dykes. With independence, this is not so. The optimal overflowing probabilities are in a fixed ratio to each other: 
$\frac{\mathrm{P}_{\mathrm{f}_{1}}}{\mathrm{P}_{\mathrm{f}_{2}}}=\frac{\mathrm{I}_{1} \beta}{\mathrm{I}_{2} \delta}$

Even in a case were budgetary restrictions prevent optimal dyke heightening the econometric modelling approach provides an answer if these restrictions are taken into account in it.

On working out the problem it is found that the safety of the polder is increased to the extent that the budget allows it.

In the case of dependence:

$P_{f_{\text {syst }} \text { opt }}=(1+\lambda) \frac{\left(I_{1} \beta+I_{s} \delta\right)\left(r^{\prime}-g\right)}{S}=P_{f_{1}}=P_{f_{2}}$

where $\lambda$ is a value so as to exhaust the budget $\lambda>0$ ).

In the case of independence:

$\mathrm{P}_{\mathrm{f}_{\text {syst opt }}}=(1+\lambda)\left\{\frac{\mathrm{I}_{1} \beta\left(\mathrm{r}^{\prime}-g\right)}{\mathrm{S}}+\frac{\mathrm{I}_{2} \delta\left(\mathrm{r}^{\prime}-\mathrm{g}\right)}{\mathrm{S}}\right\}$

$P_{f_{1}}=(1+\lambda)\left\{\frac{I_{1} \beta\left(r^{\prime}-g\right)}{S}\right\}$

$P_{f_{2}}=(1+\lambda)\left\{\frac{I_{2} \delta\left(r^{\prime}-g\right)}{S}\right\}$

The conclusions already drawn are not affected by the budgetary restrictions. The restrictions are taken into account by increasing all the economically optimal failure probabilities by a factor $(1+\lambda)$ of such magnitude that the budget is still just sufficient for the dyke heightenings.

In the case of an overriding objection (e.g., environmental or scenic conservation) against increasing the height of one of the two dykes 
there is the question whether, and to what extent, it is meaningful to increase the height of the other.

With complete dependence, heightening the other dyke is meaningful only if that dyke is less safe then the "inviolable" dyke. Further adding to the height will not improve the safety of the polder. On the other hand, with independence, any heightening of the dyke which is allowed to be modified will result in greater safety. Further working-out of the problem shows that, from the economic point of view, heightening to the optimum already mentioned is still rational:

$P_{f_{2} \text { opt }}=\frac{I_{2} \delta\left(r^{\prime}-g\right)}{S}$

The probability of inundation of the polder now attains the value:

$\mathrm{P}_{\mathrm{f}_{\text {syst }}}=\mathrm{P}_{f_{1}}+\frac{\mathrm{I}_{2} \delta\left(I^{\prime}-g\right)}{\mathrm{S}}$

An application of the concepts developed in this section has led to the assertion that the permissible probability of failure of the range of dunes that protects Central Holland against the sea is $10^{-5}$ per year. On the basis of the drastic simplification that the breachings of all the sea defences around Central Holland in conjunction with the storm tide level as the principal hazard are completely dependent events, the probability of inundation can be calculated from:

$P_{f_{\text {syst }}}=\max _{i=1}^{M}\left\{P_{f_{i}}\right\}$

Put into words, this means that the chain of sea defences is no stronger than its weakest links. Now if - disregarding the dunes - the storm tide level is imagined as raised to above the design water level of the dykes, it appears that the dykes located downwind are the first to be overtopped. For Central Holland these axe the dykes along the right bank 
of the River Maas. When the storm tide level has risen about $0.70 \mathrm{~m}$ above the design water level, the safety margin (Section 1.2) has been consumed and water begins to flow over the top of the dyke. The probability of such a storm tide is $10^{-5}$.

It is notable that this probability roughly corresponds to the economic optimum calculated in Section 6.4 .

Reverting to the dunes as sea defences, it can be inferred that in the given situation of dependence there is no point in seeking to increase the safety of the dunes above a failure probability of $10^{-5}$. This choice therefore does not in fact involve any application of a norm for the permissible probability of inundation. It is intended merely to tie up with the flood defence situation which has been established in consequence of applying the Delta Commission's guidelines. In conformity with this consideration the general rule is that the probability of the breaching of dunes should be less by a factor of 10 than the frequency of exceedance of the design water level indicated by the Delta Commission (including economic reduction).

However, in the event of a social consensus being reached that his value of the inundation probability is too high, it will necessitate upgrading of the whole sea defence system. 


\section{WORKED EXAMPLE}

Several of the preceding chapters have dealt with subjects which are relevant to the design of soundly conceived flood defence structures. The present chapter is devoted to an example relating to the design of a river dyke and incorporating the said subjects. The design procedure will be demonstrated with the aid of this example. A detailed description is given in [7.1]: "A probabilistic dyke design" (in Dutch).

\subsection{Statement of problem}

The problem to be tackled in this example is the design of a river dyke for the protection of a particular region. The design must be so contrived that ths sum of the dyke construction cost and the expected loss (due to inundation damage) in the protected region is a minimum. Expressed in formula form the total cost $\mathrm{C}_{\mathrm{TOT}}$ is:

$$
\mathrm{C}_{\mathrm{TOT}}=\mathrm{C}_{\mathrm{CONST}}+\mathrm{E}(\mathrm{S})
$$

where:

$\mathrm{C}_{\text {CONST }}=$ cost of construction of the dyke

$\mathrm{E}(\mathrm{S})=$ capitalized loss expectation (probability $\mathrm{x}$ loss, capitalized and summed)

The primary optinization parameters chosen for the dyke are its height (crest level) $h_{0}$ and its angle of slope $\alpha$ (assumed to be the same for the outer and the inner slope). The cost of inspection, maintenance and repair of the dyke is not taken into consideration. The rate of interest and the service life of the dyke are taken into account, however.

The dyke to be designed and the region it is destined to protect are shown schematically in Figure 7.1.1. Here follows further information on the river, the river dyke, the protected region and the failure mechanisms considered. 

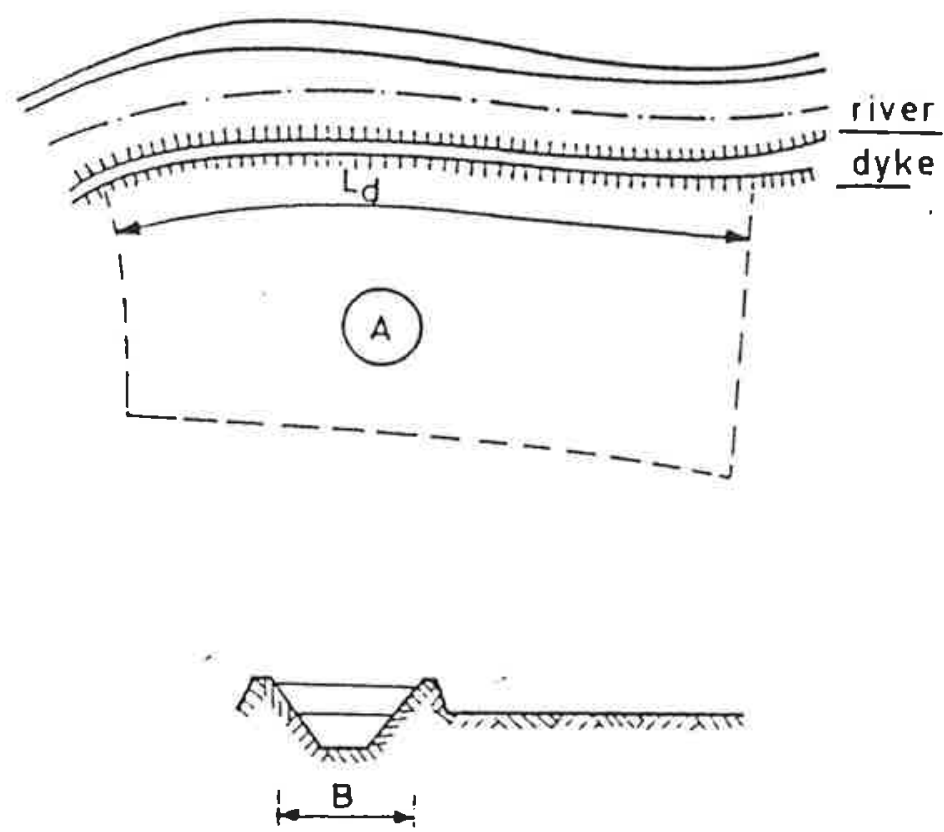

Fig. 7.1.1: Plan of river and dyke.

\section{River}

With the exception of a single flood wave, the water level in the river is assumed to pose no hazard throughout the year; see Figure 7.1.2.

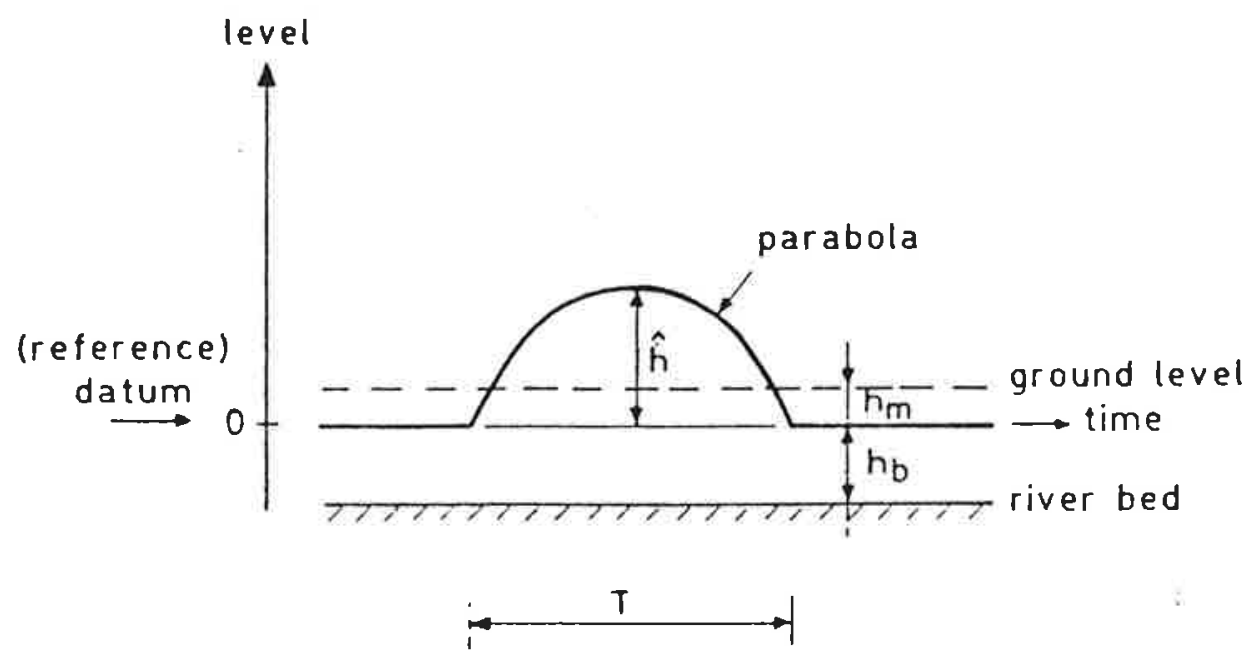

Fig. 7.1.2: Shape of the flood wave and indication of water level. 
The shape of the flood wave is parabolic. Furthermore, the width $B$ of the river is assumed to be constant at $400 \mathrm{~m}$. The bottom level $\mathrm{h}_{\mathrm{b}}$ of the river is $3.5 \mathrm{~m}$ below reference datum. The gradient of the river bed is assumed to be $I_{b}=10^{-4}$, and the Chezy constant is taken as $\mathrm{C}=40 \mathrm{\alpha m} / \mathrm{s}$.

\section{River dyke}

The length of the dyke $L_{d}$ is $20 \mathrm{~km}$. Its schematized cross-section is shown in Figure 7.1.3. It is symmetrical in shape, consisting of a sand body whose outer slope is provided with a covering layer of clay. The crest of the dyke is at a level $h_{0}$ above reference level; the width across the crest is $b_{k}=3 \mathrm{~m}$; the width across the base is $L_{2}$. The subsoil consists of sand with a $3.5 \mathrm{~m}$ thick overlying layer of clay. The slopes form an angle $\alpha$ with the horizontal.

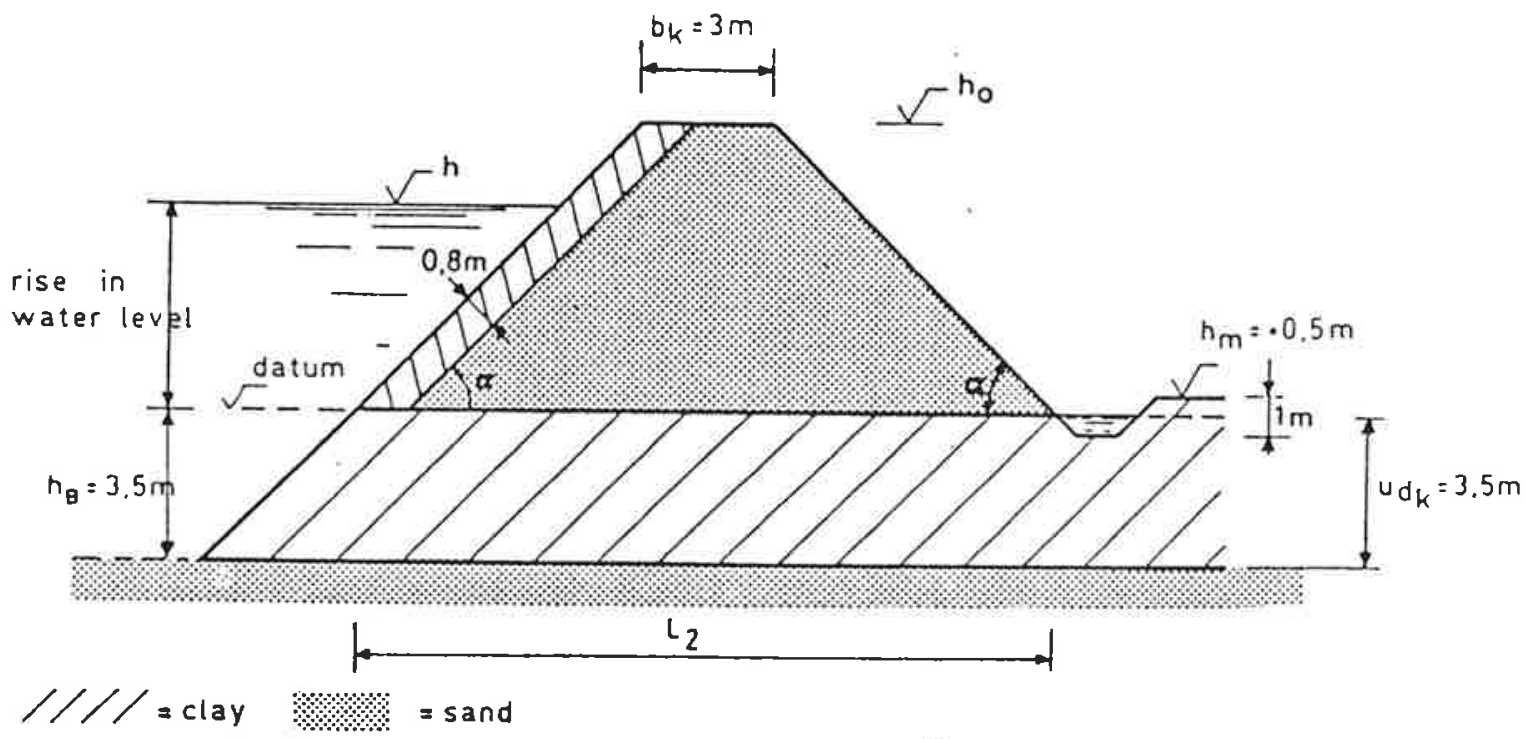

Fig. 7.1.3: Cross-section through the dyke.

If desired, a foreland (or winter bed) can be created on the outer (i.e., riverward) side of the dyke by locating the dyke farther landward. The width of the foreland is $L_{1}$. 


\section{Protected region}

The protected region has an area $A=200 \mathrm{~km}^{2}$ and is located entirely at the level $h_{m}=+0.5 \mathrm{~m}$. A proportion $\alpha_{1} A$ of the region is assumed to be used for residential occupation, a proportion of $\alpha_{2} A$ for agriculture and the remainder $\alpha_{3} A$ for industry. The factors $\alpha_{1}, \alpha_{2}$ and $\alpha_{3}$ are respective $0.06,0.93$ and 0.01 . For the purpose of the inundation calculations the region is assumed to contain no - intended or accidental - floodwater retaining structures within it.

\section{Failure mechanisms considered}

It is assumed that inundation can occur in either two ways:

a. As a result of overtopping of the dyke without collapse thereof.

b. As a result of breaching of the dyke.

The following mechanisms causing a dyke breaching are considered:

- macro-instability of the inner slope;

- piping;

- micro-instability of the inner slope.

In actual practice, more mechanisms will have to be taken into account.

\subsection{Stochastic variables}

Table 7.1 presents a review of all the variables. Most of them are deterministic. The stochastic variables will be examined below.

\section{A. Flood wave in the river}

- Highest water level $\hat{h}$ :

In accordance with common practice, the highest water level $\hat{h}$ is assumed to conform to an exponent distribution (extreme type III for minima) or Weibull distribution with $k=1$, see [7.1] and chapter 3 . 
Adopting $\mu_{\hat{h}}=3 \mathrm{~m}$ and $\sigma_{\hat{\lambda}}=0.9$ the cumulative distribution function of $\hat{h}$ becomes exponential.

$$
F_{h}^{\wedge}(5)=1-e^{-\frac{5-2,1}{0,9}}
$$

The probability density function is obtained by differentiation of (7.2.1). The two functions are plotted in Figure 7.2.1.
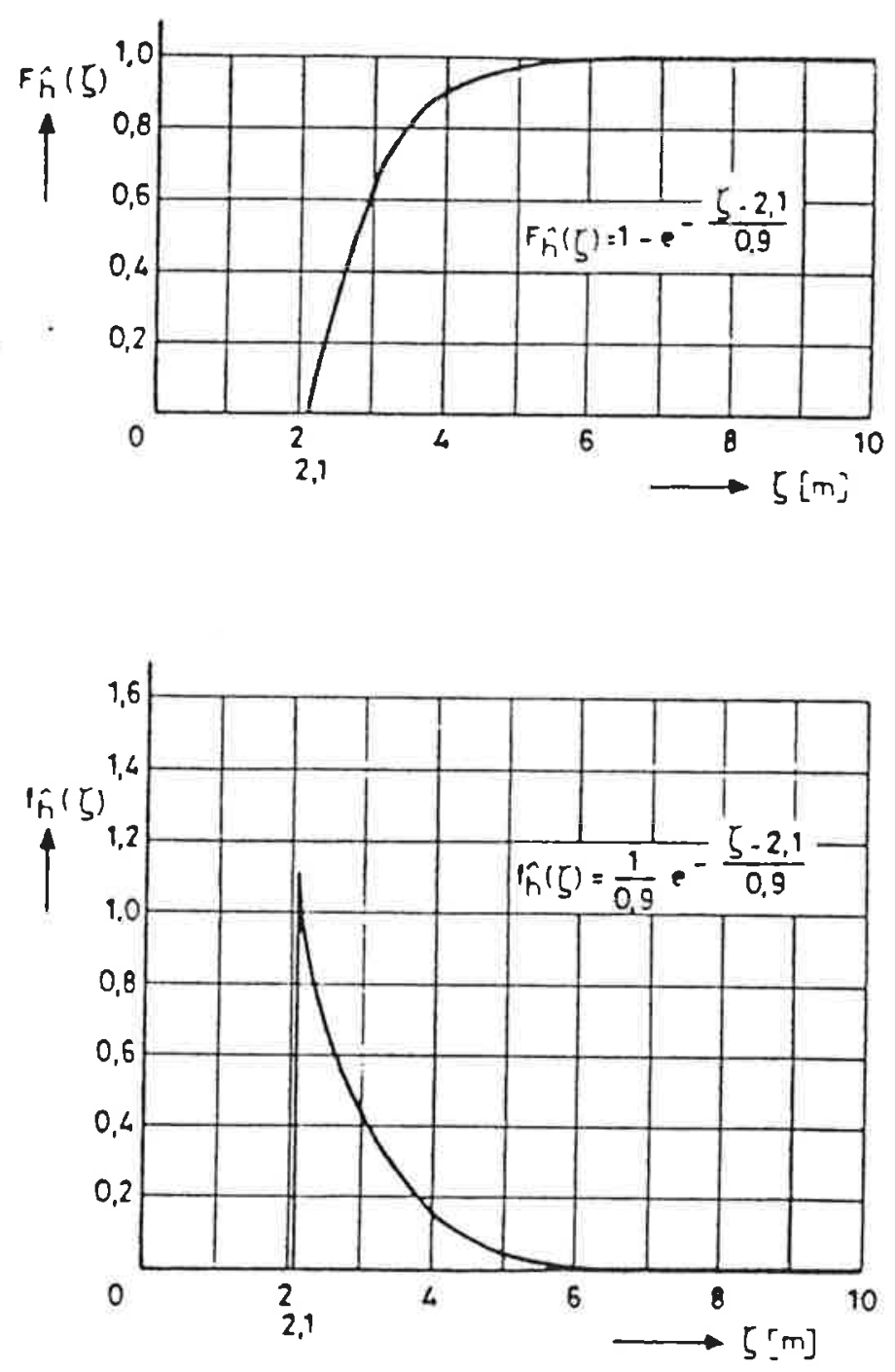

Fig. 7.2.1: Distribution function and probability density function of the highest water level. 
- Duration $T$ of the high water associated with the flood wave:

This duration $\mathrm{T}$ is assumed to conform a log-normal distribution. A study of the discharge data of the Rhine [7.1] has shown a lognormal distribution to be a reasonable assumption.

The probability density function of $\mathrm{T}$ then becomes:

$$
f_{T}(\tau)=\frac{1}{\tau \sigma_{y} \sqrt{ } 2 \pi} \cdot e^{-\frac{\left(\ln \tau-\mu_{y}\right)^{2}}{2 \sigma_{y}{ }^{2}}}
$$

where $\mathrm{y}=\ln \mathrm{T}$, while $\mathrm{y}$ is normally distributed; $\mu_{\mathrm{T}}$ has been taken as 7.5 days and $\sigma_{\mathrm{T}}$ as 4.5 days.

\section{B. Soil parameters}

The following parameters of sand as well as the clay are assumed to be stochastic:

$\mathrm{k} \quad-$ permeability

$\varphi \quad=$ angle of internal friction

$c^{\prime}=$ cohesion

$\lambda_{\text {eq }}=k_{k . e q} / d_{k . e q}=$ equivalent leakage factor of the layer of clay on the outer slope, taking account of perforations in this layer.

$k_{k . e q}=$ equivalent permeability of clay.

$\mathrm{d}_{\mathrm{k} . \mathrm{eq}}=$ equivalent thickness of the clay layer (see below).

The coefficients of variation in Table 7.1 are based on estimates; in an actual case it will be possible to provide a statistical basis for some variables, but for others it will still be necessary to rely on estimated values.

\section{Geometry parameters}

- Thickness of clay layer on outer slope: 
Table 7.2.1: Overview of the problem variables.

\begin{tabular}{|c|c|c|c|c|c|}
\hline$x$ & Description & Type & $\mu$ & & $\sigma / \mu$ \\
\hline - & & & & & \\
\hline $\mathrm{h}$ & highest water level (upstream) & E & 3 & m & 0.30 \\
\hline T & duration of high water & LN & 7.5 & days & 0.60 \\
\hline$c_{k}^{\prime}$ & cohesion (clay) & N & 10 & $\mathrm{kN} / \mathrm{m}^{2}$ & 0.20 \\
\hline$\Phi$ & angle of internal friction (clay) & N & $20-8$ & degrees & 0.20 \\
\hline$k_{k}^{k}$ & permeability (clay) & LN & $10^{-0}$ & $\mathrm{~m} / \mathrm{s}$ & 1.60 \\
\hline$c^{\prime}$ & cohesion (sand) & D & 0 & $\mathrm{kN} / \mathrm{m}^{2}$ & - \\
\hline$\Phi_{2}^{2}$ & angle of internal friction (: and) & $\mathrm{N}$ & $35-5$ & degreas & 0.10 \\
\hline $\mathrm{k}_{\mathrm{z}}^{2}$ & permeab111ty (sand) & LN & $10^{-5}$ & $\mathrm{~m} / \mathrm{s}$ & 0.50 \\
\hline$d_{k}$ & thickness of clay layer under dyke & $\mathrm{N}$ & 3.5 & $\mathrm{~m}$ & 0.2 \\
\hline$\lambda_{e q}^{k}$ & equivalent leakage factor of clay layer & & & & 1.0 \\
\hline & on outer slope $\left(-k_{k}, e q^{l d}, \theta q^{2}\right.$ & LN & $2.10^{-1}$ & $1 / 5$ & 1.0 \\
\hline b & width of breach A.eq K.eq & LN & 100 & m & 1.0 \\
\hline $\mathrm{m}$ & model factor (piptng) & $\mathbf{N}$ & 1.67 & & 0.2 \\
\hline $\mathrm{L}_{d}$ & length of dyke & $\mathrm{D}$ & 20 & $\mathrm{~km}_{2}$ & - \\
\hline$A^{d}$ & area of protected region (polder) & $\mathrm{D}$ & 200 & $\mathrm{~km}^{2}$ & - \\
\hline $\mathrm{h}_{\mathrm{m}}$ & ground level & D & 0.5 & $\mathrm{~m}$ & - \\
\hline$\alpha_{1}$ & bullt-up area fraction & $\mathrm{D}$ & 0.06 & & - \\
\hline$\alpha_{2}$ & agricultural area fraction & $\mathrm{D}$ & 0.93 & & - \\
\hline$\alpha_{3}^{2}$ & industrial area fraction & D & 0.01 & & - \\
\hline s & max. loss, residential, per unit area & $\mathrm{D}$ & 400 & guilders $/ \mathrm{m}^{2}$ & - \\
\hline$s_{2}^{1}$ & max. loss, agricultural, per unit area & D & 1 & gutlders $/ \mathrm{m}^{2}$ & - \\
\hline$s_{3}^{2}$ & max. loss, industrial, per unit area & $\mathrm{D}$ & 200 & guilders $/ \mathrm{m}^{2}$ & - \\
\hline$r^{3}$ & real rate of interest & $\mathrm{D}$ & 0.02 & & - \\
\hline$f_{b}$ & construction cost per unit volume & D & 10 & gutlders $/ m^{3}$ & - \\
\hline h & crest level (above datum) & $\mathrm{v}$ & 6 a 10 & m & - \\
\hline $\tan \alpha$ & angle of slope & $\mathrm{v}$ & $1: 2.5$ to $1: 5$ & & - \\
\hline$b_{k}$ & crest width & D & 3 & $\mathrm{~m}$ & - \\
\hline$\rho_{k}^{k}$ & density of clay (dry/wet) & D & $1400 / 1900$ & $\mathrm{~kg} / \mathrm{m}_{3}^{3}$ & - \\
\hline $0^{x}$ & density of sand (dry/wet) & D & $1600 / 2000$ & $\mathrm{~kg} / \mathrm{m}_{3}^{3}$ & - \\
\hline$\rho^{2}$ & density of water & $\mathrm{D}$ & 1000 & $\mathrm{~kg} / \mathrm{m}^{3}$ & - \\
\hline $\mathrm{B}^{*}$ & width of river & $D$ & 400 & $\mathrm{~m}$ & - \\
\hline$h_{b}$ & distance from reference datur to river bed & $\mathrm{D}$ & 3.5 & m & - \\
\hline$b_{8}$ & bottom width of ditch & $\mathrm{D}$ & 1.0 & $\mathrm{~m}$ & - \\
\hline $\mathrm{b}_{\mathrm{s}}{ }^{\circ}$ & distance from reference datum to bottom of ditch & $\mathrm{D}$ & 0.50 & $\mathrm{~m}_{0.5}$ & - \\
\hline$c^{3}$ & Chezy's constant & $D$ & $40-4$ & $\mathrm{~m} / \mathrm{s}$ & - \\
\hline$I_{b}$. & gradient of river bed & $\mathrm{D}$ & $10^{-4}$ & & - \\
\hline $8^{b}$ & acceleration of gravity & $\mathrm{D}$ & 10 & $\mathrm{~m} / \mathrm{s}^{\mathrm{s}}$ & - \\
\hline $\mathrm{L}_{1}$ & width of foreland & $\mathrm{D} / \mathrm{V}$ & o/var. & m & - \\
\hline$n^{2}$ & porosity (pore ratio) of sand & $\mathrm{D}$ & 0.4 & & - \\
\hline$c_{L}$ & creep ratio (Lane) & $\mathrm{D}$ & 6 & & - \\
\hline
\end{tabular}

$D=$ deterministic

$E$ - exponential (extreme III with $k=1$ )

$\mathrm{LN}=$ lognormal

$\mathrm{N}=$ normal

$V=\operatorname{variable}(\operatorname{design} \operatorname{variable})$ 
The thickness of this layer is important with regard to the permeability thereof. The effect of variation in the thickness is combined with the permeability of the clay:

$$
\lambda_{\text {eq }}=k_{\mathrm{k} . \mathrm{eq}} / \mathrm{d}_{\mathrm{k} . \mathrm{eq}}
$$

- Thickness of clay layer under the dyke:

The layer of clay on which the dyke rests is of variable thickness, assumed to conform to a normal distribution. The mean thickness is taken as $3.5 \mathrm{~m}$, and the coefficient of variation as 0.2 .

\section{Mode1 factor for piping}

In connection vith the piping mechanism a model factor is introduced in order, among other purposes, to represent the variation in the results (see Section 3.5.2). This factor is used in Lane's criterion. The distribution is of the normal type with $\mu=1.67$ and $v=0.2$.

\section{E. Width of the breach}

The width of the breach in the dyke may vary greatly. There is an almost complete lack of reliable data. The distribution is assumed to be of the log-normal type. The mean width is taken as $100 \mathrm{~m}$, and the coefficient of variation as 1.0 .

\subsection{Calculation procedure}

\subsubsection{Optimization of the dyke design}

As stated in Section 7.1, the total cost $\mathrm{C}_{\text {TOT }}$ must be optimized. For this purpose it is necessary to determine the minimum of: 


$$
\mathrm{C}_{\mathrm{TOT}}=\mathrm{C}_{\mathrm{CONST}}+\mathrm{E}(\mathrm{S})
$$

by an appropriate choice of the design parameters $h_{0}$ and $\tan \alpha$. In the investigation the minimum has been determined by assigning a limited number of discrete values to $h_{0}$ and $\tan \alpha$, namely, $h_{0}=6,7,8,9$ and $10 \mathrm{~m}$ and $\tan \alpha=1: 2.5,1: 3,1: 3.5,1: 4$ and $1: 5$.

\subsubsection{Cost of construction}

The cost of construction of the dyke is assumed to be dependent only on the volume of the body of the dyke. The formula for calculating the cost of construction then becomes:

$\mathrm{C}_{\text {CONST }}=\mathrm{I}_{\mathrm{d}} \cdot \mathrm{h}_{\mathrm{o}}\left(\mathrm{h}_{\mathrm{o}} \operatorname{cotg} \alpha+\mathrm{b}_{\mathrm{k}}\right) \mathrm{f}_{\mathrm{b}}$

where:

$\mathrm{L}_{\mathrm{d}}=$ length of the dyke $=20 \mathrm{~km}$

$h_{0}=$ height of dyke (crest level above dataum) (design parameter)

$\operatorname{tg} \alpha=$ slopes of the dyke (design parameter) (inner and outer slope)

$b_{k}=$ crest width $=3 \mathrm{~m}$

$f_{b}=$ cost of construction per unit volume

\subsubsection{Capitalized loss expectation}

In the event of failure of the dyke, inundation will occur, resulting in a particular amount of damage or loss $\mathrm{S}$. As for the inundation parameters, $S$ is assumed to be dependent solely on the depth of inundation $d$.

The loss expectation in the year $i$ is:

$E(S)=P\left(F_{i}\right) \times S$

where $P\left(F_{i}\right)$ is the probability of failure in the year $i$ and $S$ is the loss that occurs.

Taking account of the real rate of interest and the intended service life of the dyke, the capitalized loss expectation can be written as: 
$E(S)=\sum_{i=1}^{N} \frac{P\left(F_{i}\right) S}{\left(1+r^{\prime}\right)}$

where $r^{\prime}$ is the real rate of interest and $N$ the intended service life.

If $N$ is large and $P\left(F_{i}\right)$ is constant over the years, $E(S)$ can alternatively be written as:

$E(S)=\frac{1}{r^{\prime}} P\left(F_{i}\right) S$

$E(S)=\frac{1}{r^{\prime}} \int_{0}^{\infty} S(d=\delta) \cdot f_{d}(\delta) \underline{d} \delta$

where $f_{d}(\delta)$ is the probability density function of the inundation depth d (see figure 7.3.1).

\subsubsection{Loss as a function of inundation depth}

If inundation occurs, damage and therefore loss will be incurred in the region protected by the dyke. In the present case only the loss associated with damage affecting dwellings, agriculture and industry will be considered. It will be assumed to depend only on the inundation depth and on the size and manner of use of the polder. The following formula has been used for calculating the loss:

$S=A \underset{i=1}{3} \alpha_{i} s_{i} c_{i}(d=\delta)$

where:

A $\quad$ total ared of the protected region

$\alpha_{i} \quad=$ proportion of the area used for the categories: residential $(i=1)$, agriculture $(i=2)$, industry $(i=3)$

$\mathrm{s}_{i} \quad=$ maximum possible loss for category $i$

$c_{i}(d)=$ damage factor as a function of the inundation depth $d$ for category $i$; the damage factors as functions of $d$ are represented in Figure 7.3.2 


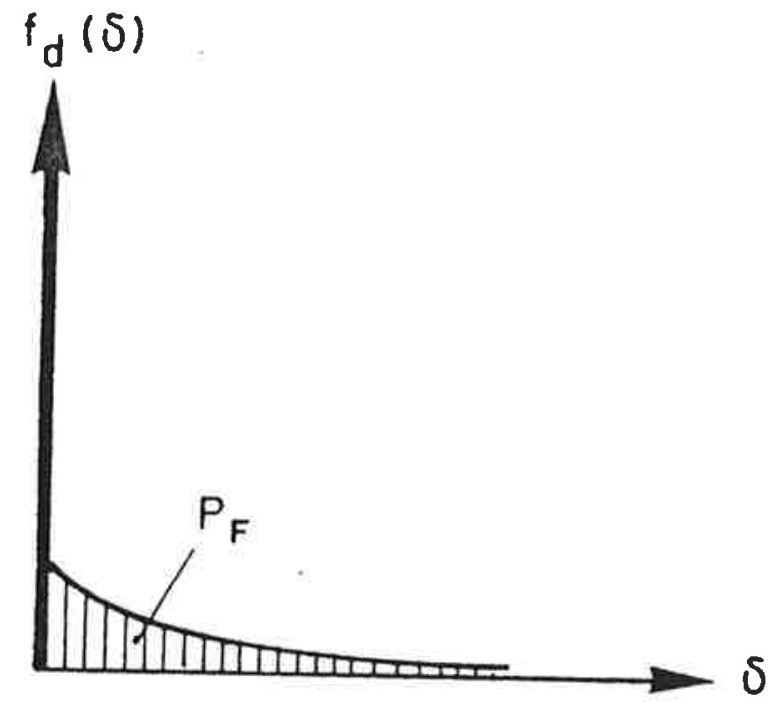

Fig. 7.3.1: Probability density function for the inundation depth.

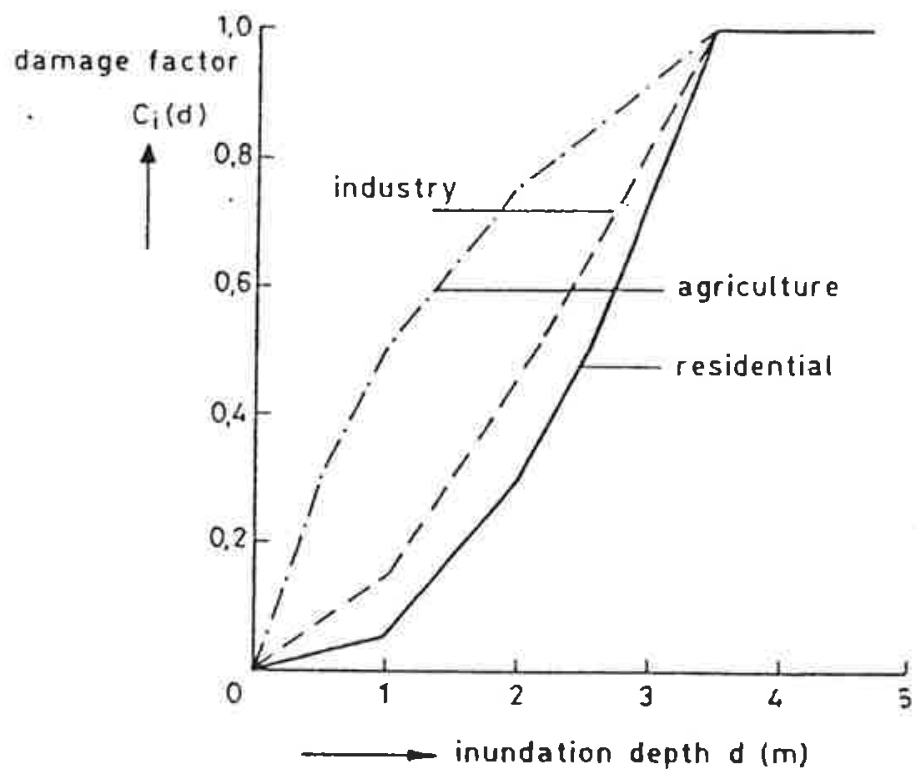

Fig. 7.3.2: Damage factors associated with inundation.

\subsubsection{Inundation depth}

From the instant of failure of the dyke, which is taken as the instant when the value of the reliability function $Z$ becomes less than zero, water from the river is assumed to flow into the protected region. The inundation depth $d$ is therefore a function of time $t$. The maximum inundation depth has always been adopted for the loss calculation.

\subsubsection{Probability density function for inundation depth}

Given the formulae derived for the inundation depth d (see chapter 4), the probability density function $f_{d}(\delta)$ needed for the calculation of 
$E(S)$ (see formula 7.3.4) can be calculated. The procedure is that the probability $d>\delta$ has been determined for a number of values of $\delta$. The probability density function then follows in principle from:

$f_{d}(\delta)=\frac{\underline{d F}_{d}(\delta)}{\underline{d} \delta}=\frac{P\{d>\delta\}-P\{d>\delta+\Delta \delta\}}{\Delta \delta}$

The probabilities $\mathrm{P}\{\mathrm{d}>\delta\}$ have been calculated with the aid of a level II analysis in accordance with the Approximate Full Distribution Approach (AFDA) (see [2.1] to [2.4]). For this purpose the PROBAB computer program of TNO-IBBC has been used. For calculating the probabiity $\mathrm{P}\{\mathrm{d}>\delta\}$ it has already been assumed that the dyke fails. What is actually calculated is therefore:

$P\{d>\delta$ and failure $\}$

This means that the probability of a composite event has to be calculated. Various methods for doing this are conceivable (see Section 2.3).

\subsubsection{Computational scheme}

For an individual mechanism the calculation procedure consists basically in determining successively for each chosen design combination ( $h_{0}$, $\tan \alpha)$ :

- The probability of failure $P\left\{Z_{i}<0\right\}$.

- $\mathrm{P}\left\{\mathrm{Z}_{\mathrm{o}}<0\right\}=\mathrm{P}\{\mathrm{d}>\delta\}$ for the various values of $\delta(0.25-3.5 \mathrm{~m})$.

- The correlation coefficient $\rho\left(Z_{0} Z_{i}\right)$ for the various values of $\delta$.

- The probability $\mathrm{P}\left\{\mathrm{Z}_{\mathrm{i}}<0\right.$ and $\left.\mathrm{d}>\delta\right\}=\overline{\mathrm{F}}_{\mathrm{d}}(\delta)$.

- The probability density function $f_{d}(\delta)$

- The loss expectition $E(S)$ according to (7.3.4).

- The cost of construction $\mathrm{C}_{\text {CONST }}$ according to (7.3.2).

- The total cost $\mathrm{C}_{\mathrm{TOT}}=\mathrm{C}_{\mathrm{CONST}}+\mathrm{E}(\mathrm{S})(7.3 .1)$.

The true optimum can be determined only if the mechanisms are combined. Primarily, the mechanisms have been dealt with separately. 


\subsection{Results per mechanism}

\subsubsection{Overflowing}

The mechanism of overflowing (overtopping by high water level) is illustrated schematically in Figure 7.4.1.

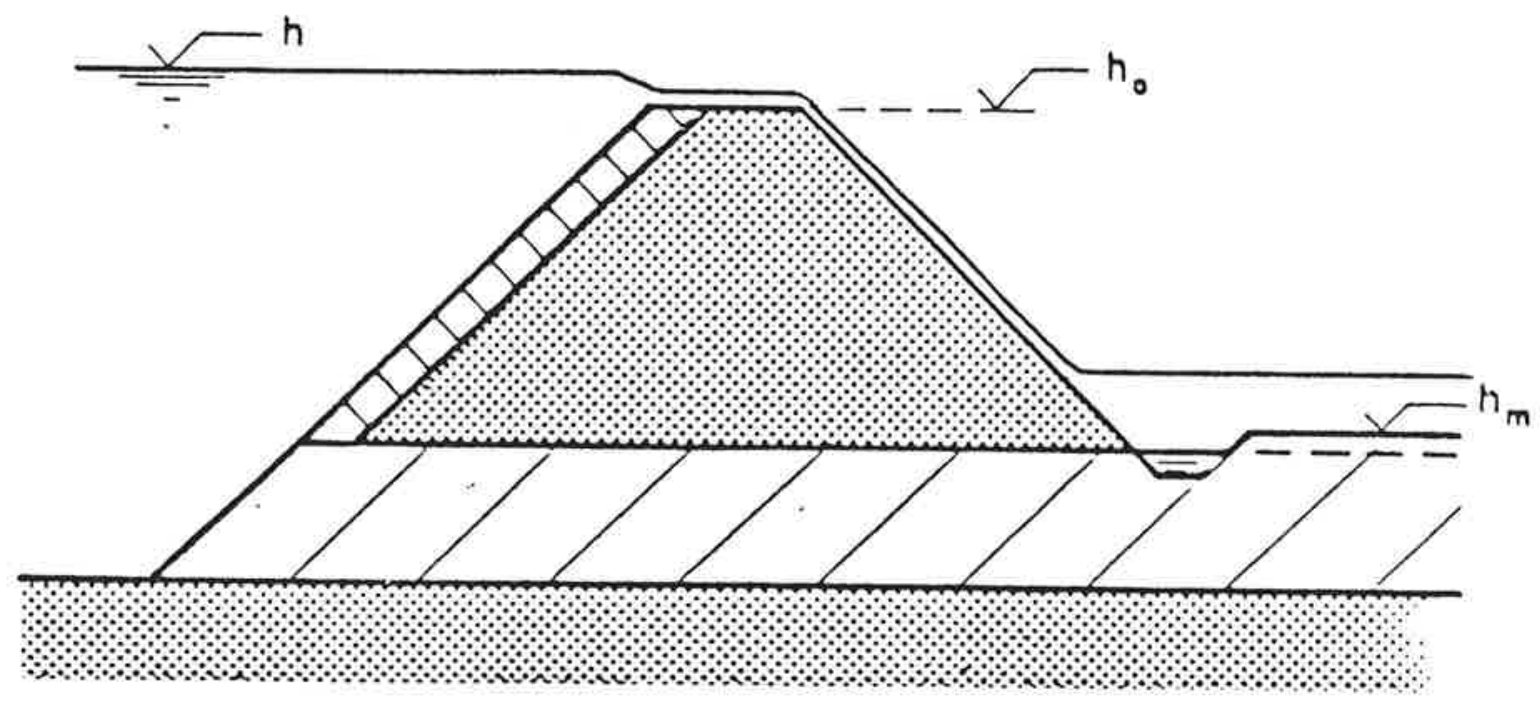

Fig. 7.4.1: Mechanism of overflowing.

a. Failure probability:

Failure can be said to occur if the water level in the river becomes higher than the crest level of the dyke, or if $\hat{h}>h_{0}$. The reliability function $z_{1}$ is then:

$\mathrm{z}_{1}=\mathrm{h}_{0}-\hat{\mathrm{h}}$

This simple mechanism can easily be analysed by manul calculation: 
$P($ failure $)=P\left(z_{1}<0\right)=1-P\left(\hat{h}<h_{0}\right\}=1-F_{h}\left(h_{0}\right)=e^{-\frac{h_{0}-2.1}{0.9}}$

The failure probability as a function of the crest level $h_{0}$ is represented in Figure 7.4.2.

b. Probability density function of inundation depth:

On working out the formulae in Section 4.2 and the shape of the flood wave, the maximum inundation depth $d$ is obtained from:

$d=\frac{C \cdot B \cdot / I}{A} \int_{t_{b}}^{t_{e}}\left(\left(4 \hat{h} t \frac{(T-t)}{T^{2}}+h_{b}\right)^{3 / 2}-\left(h_{o}+h_{b}\right)^{3 / 2}\right) d t$

The integration limits $t_{b}$ and $t_{e}$ (see Figure 7.4.3) can be calculated from:

$t_{e, b}-\frac{T}{2}\left[1 \pm \sqrt{ }\left\{1-\left(h_{0} \hat{h}\right)\right\}\right]$

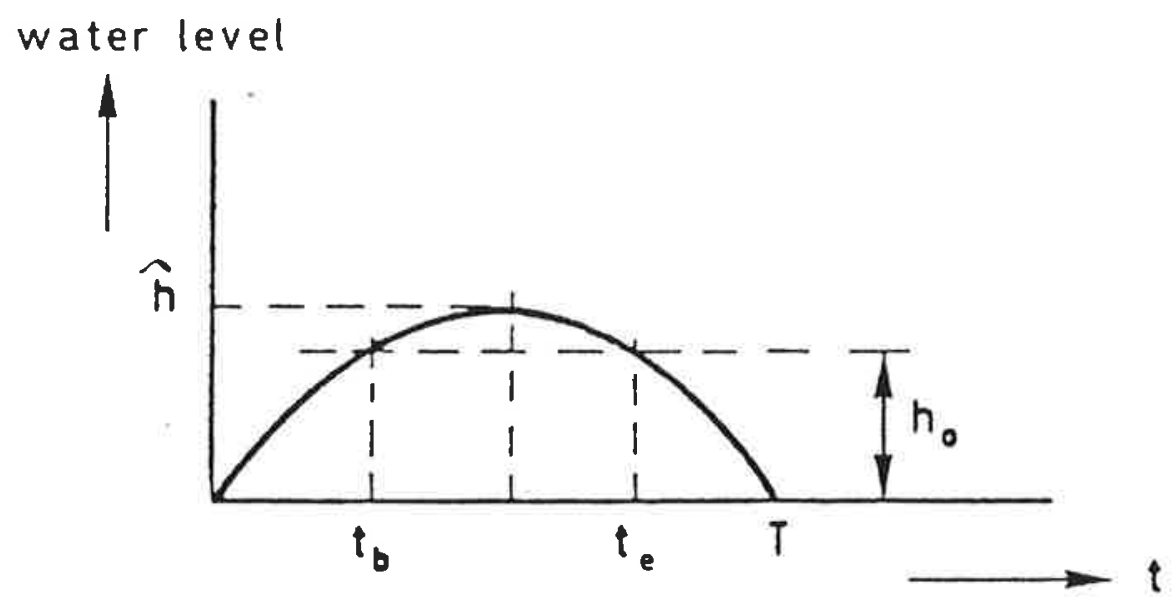

Fig. 7.4.3: Location of the limits of integration $t_{b}$ and $t_{e}$ for the mechanism of overflowing.

The submerged weir situation does not occur with the dyke crest levels under consideration.

From the formula for determining the inundation depth it follows that with this mechanism the condition $\hat{h}>h_{0}$ ( failure) has already been satisfied. 


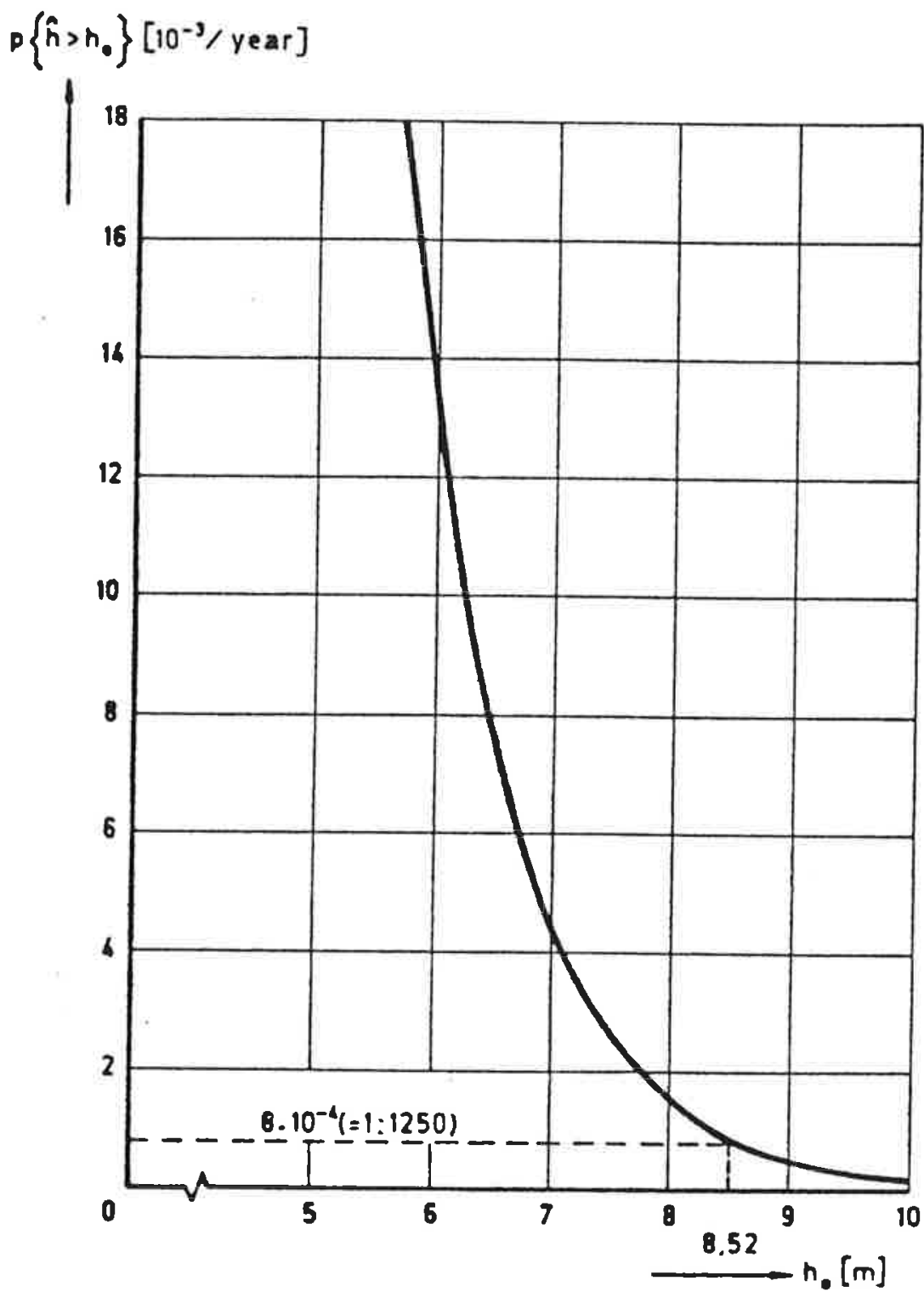

Fig. 7.4.2: Failure probability as a function of $h_{0}$ for the mechanism of overflowing. 
c. Optimum crest level:

For the 1:3 slope the curves for the cost of construction and for the loss expectation are plotted as functions of the crest level $h_{0}$ in Figure 7.4.4. For this slope the optimum crest level is $9.25 \mathrm{~m}$. For the other slopes the optimum crest levels are also indicated in Figure 7.4.4.

Some comments on the results:

- The variation in optimum crest level is small: $h_{\text {o.opt }}=8.75$ for a $1: 5$ slope and $h_{\text {o.opt }}=9.25$ for a $1: 2.5$ slope

- Since the probability of failure depends solely on the crest level $h_{0}$, the optimum cost is of course least for the steepest slope.

\subsubsection{Macro-instability of inner slope}

Figure 7.4.5 schematically shows the mechanism of macro-instability of the inner slope. The phreatic line in the dyke is schematized to a straight line.

a. Failure probability:

Besides the PROBAB program of TNO, the STAGROM and PROSTAB programs of Delft Geotechnics have likewise been used for determining the probability of failure.

Calculations for circular surfaces of sliding are performed with the two last-mentioned programs. These calculations yield, among other results, the stability factor $F$, which is defined as:

$\mathrm{F}=\mathrm{M}_{\text {resisting }} / \mathrm{M}_{\text {overturning }}$

The reliability function can then be written as:

$\mathrm{z}_{2}=\mathrm{F}-1$

The procedure described in Section 2.2 has been used for determining the failure probability (level II analysis making use of "the design point"). 


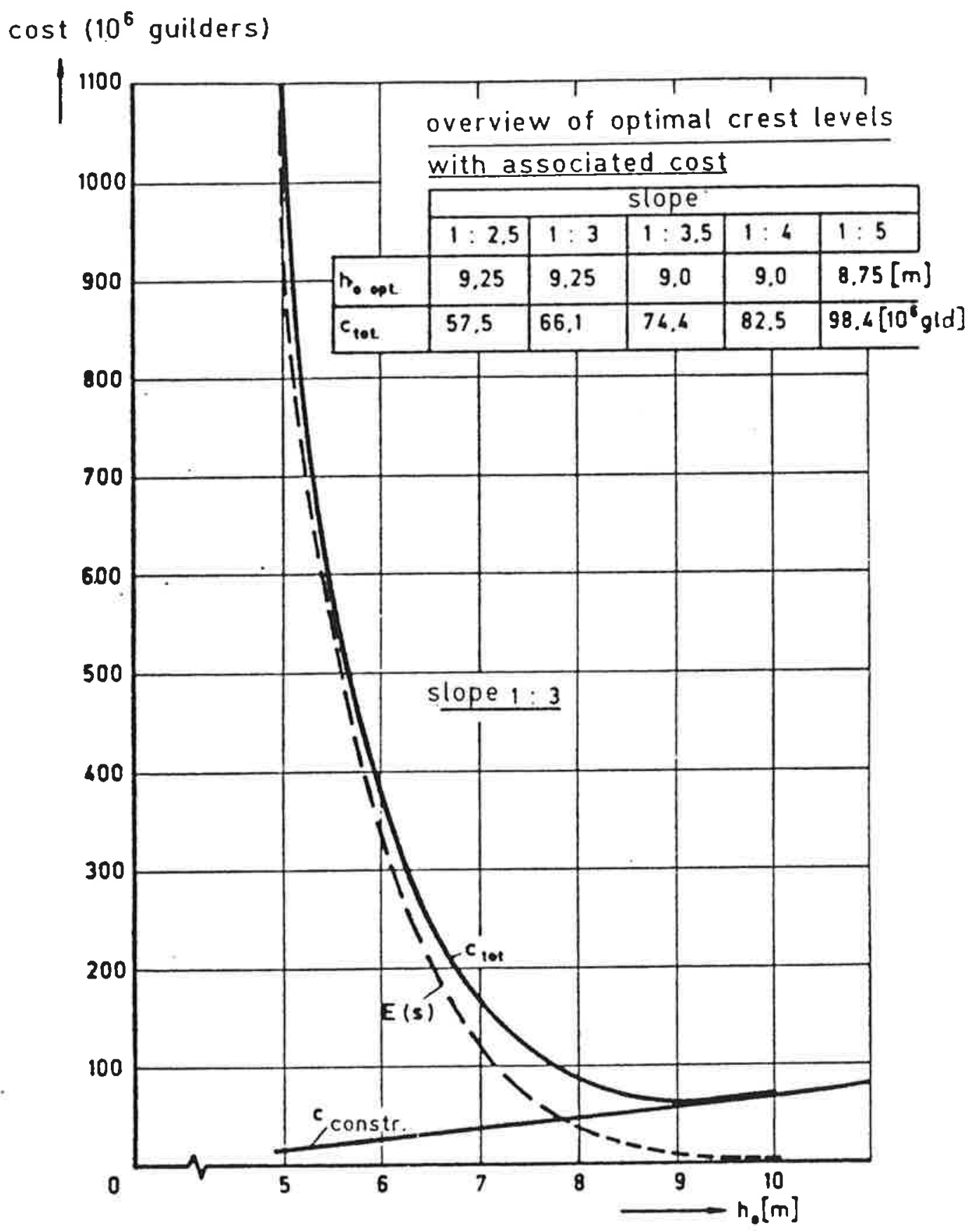

Fig. 7.4.4: Cost as a function of $h_{0}$ for the mechanism of overflowing (slope 1:3). 


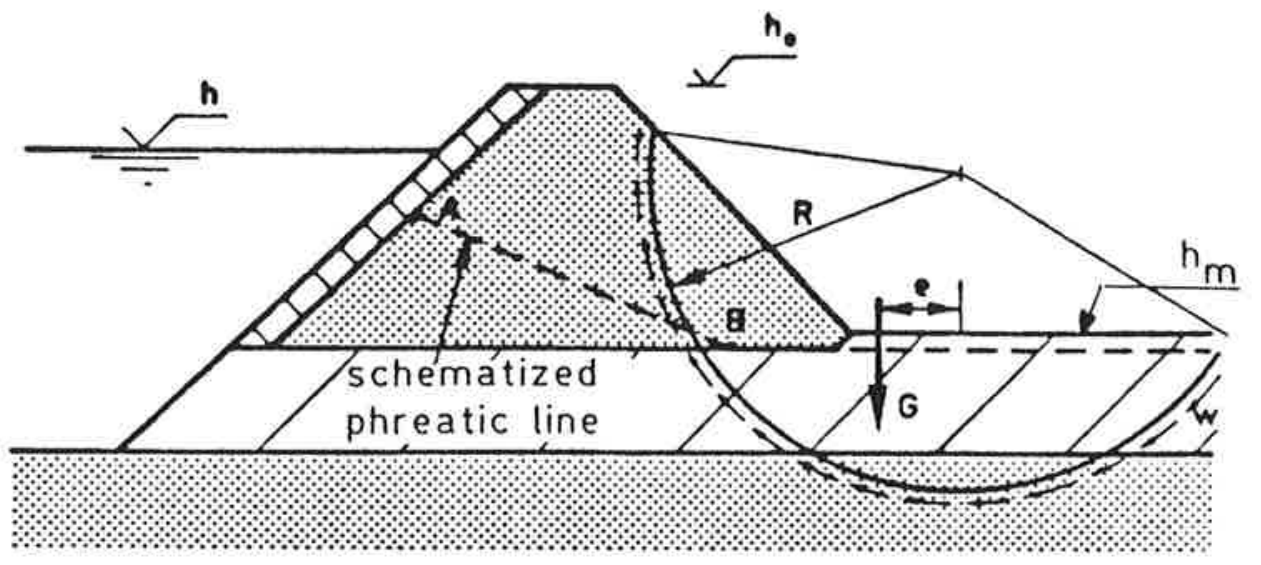

Fig. 7.4.5: Mechanism of macro-instability of the inner slope.

The results of the calculations for the failure probability are given in Figure 7.4.6.

Some comments on these results:

- The level of the failure probabilities is low $\left(\ll 8 \times 10^{-4} /\right.$ year).

- As was to be expected, the failure probability increases with increasing crest level. The reasons for this are:

- the phreatic line does not affect the governing circle of sliding for the crest heights and angles of slope considered;

- the disturbing moment increases relatively more rapidly than the resisting moment when the crest height increases.

- The failure probability undergoes no further increase from a particular crest level onwards. The reason for this is that the crest is then no longer within the governing circle of sliding.

b. Probability derisity function of inundation depth:

The maximum inundation depth $d$ can be found from the formulea in Section 4.2. For the free-nappe weir. The result is (no deduction given):

$d=\frac{2 / 3 /(2 / 3 g)}{A} \int_{t_{b}}^{t_{e}} b\left(h_{2}-h_{m}\right)^{3 / 2} d t$ 


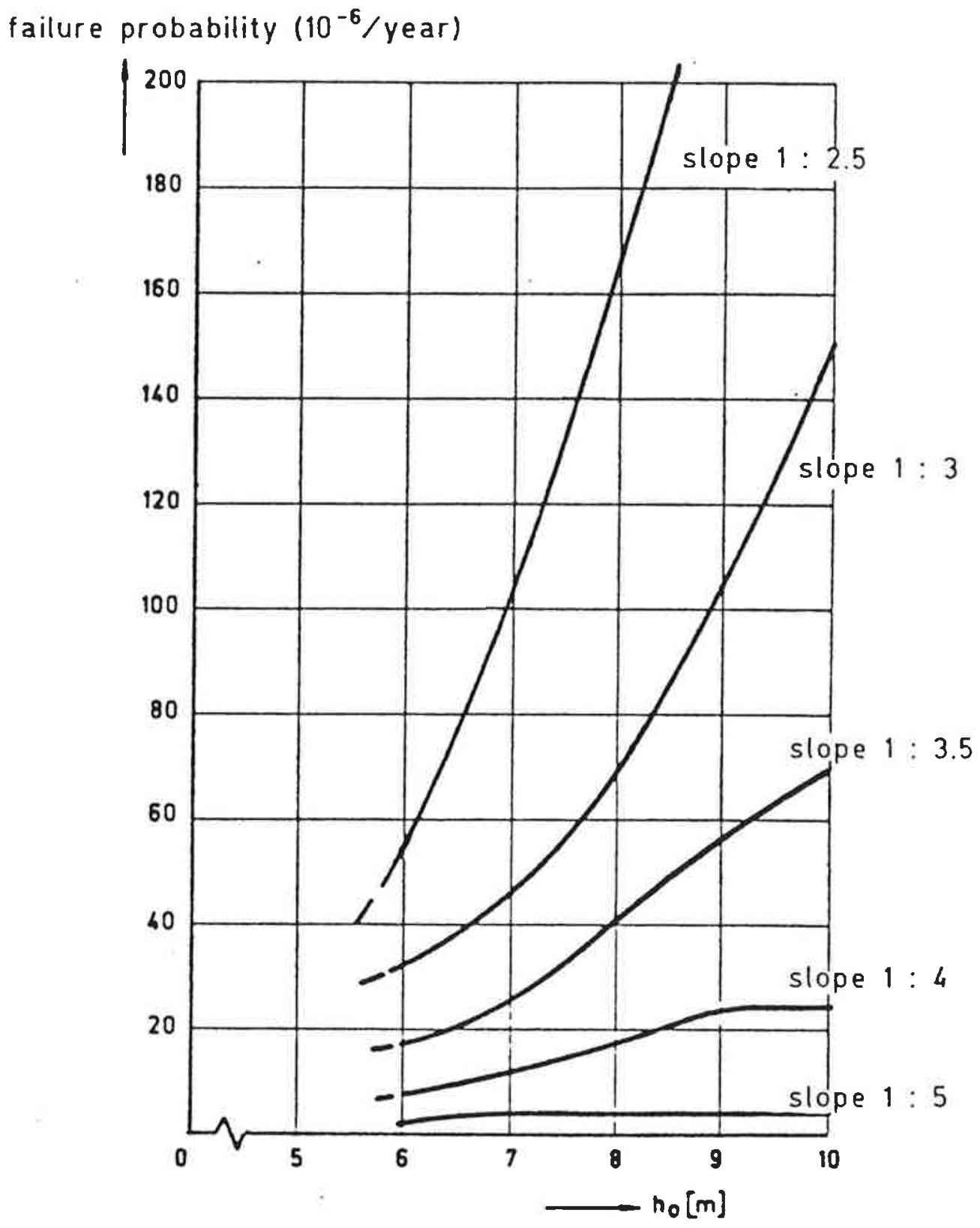

Fig. 7.4.6: Failure probability as a function of $h_{0}$ for the mechanism of macro-instability of the inner slope. (Note: failure probabilities are low). 
The value of $h_{2}$ can be solved from:

$$
\left(h_{1}+h_{b}\right)^{3 / 2}=\frac{2 / 3 /(2 / 3 g)}{C \cdot B \cdot \sqrt{I}} \text { b. }\left(h_{2}-h_{m}\right)^{3 / 2}+\left(h_{2}+h_{b}\right)^{3 / 2}
$$

The limits of integration $t_{b}$ and $t_{e}$ have been taken as follows:

$t_{b}=$ instant at which the river attains its highest water level

$t_{e}=$ instant at which the overflow changes from free-nappe to submerged weir; this situation occurs if:

$$
\mathrm{d}=\frac{2}{3}\left(\mathrm{~h}_{2}-\mathrm{h}_{\mathrm{m}}\right)
$$

For the submerged weir:

$d(d)=\frac{d 2 g}{A} \cdot$ b.d. $\quad \sqrt{ }\left(\left(h_{2}-h_{m}\right)-d\right\} d t$

In this formula, too, $h_{2}$ must be solved from the continuity equation:

$$
\left(h_{1}+h_{b}\right)^{3 / 2}-\frac{/(2 g)}{C \cdot B \cdot \propto I} \text { b.d } \sqrt{ }\left(\left(h_{2}-h_{m}\right)-d\right)+\left(h_{2}+h_{b}\right)^{3 / 2}
$$

The whole procedure has an iterative character.

The calculation is stopped as soon as $\left(d+h_{m}\right)=h_{2}$.

c. Optimal crest level:

The total cost for the angles of slope under consideration are represented as functions of the crest level $h_{0}$ in Figure 7.4.7. It appears from this diagram that the cost optimum has not been found for any of the dyke profiles considered. Crest levels lower than $6 \mathrm{~m}$ have not been included here. The low costs make them irrelevant. 


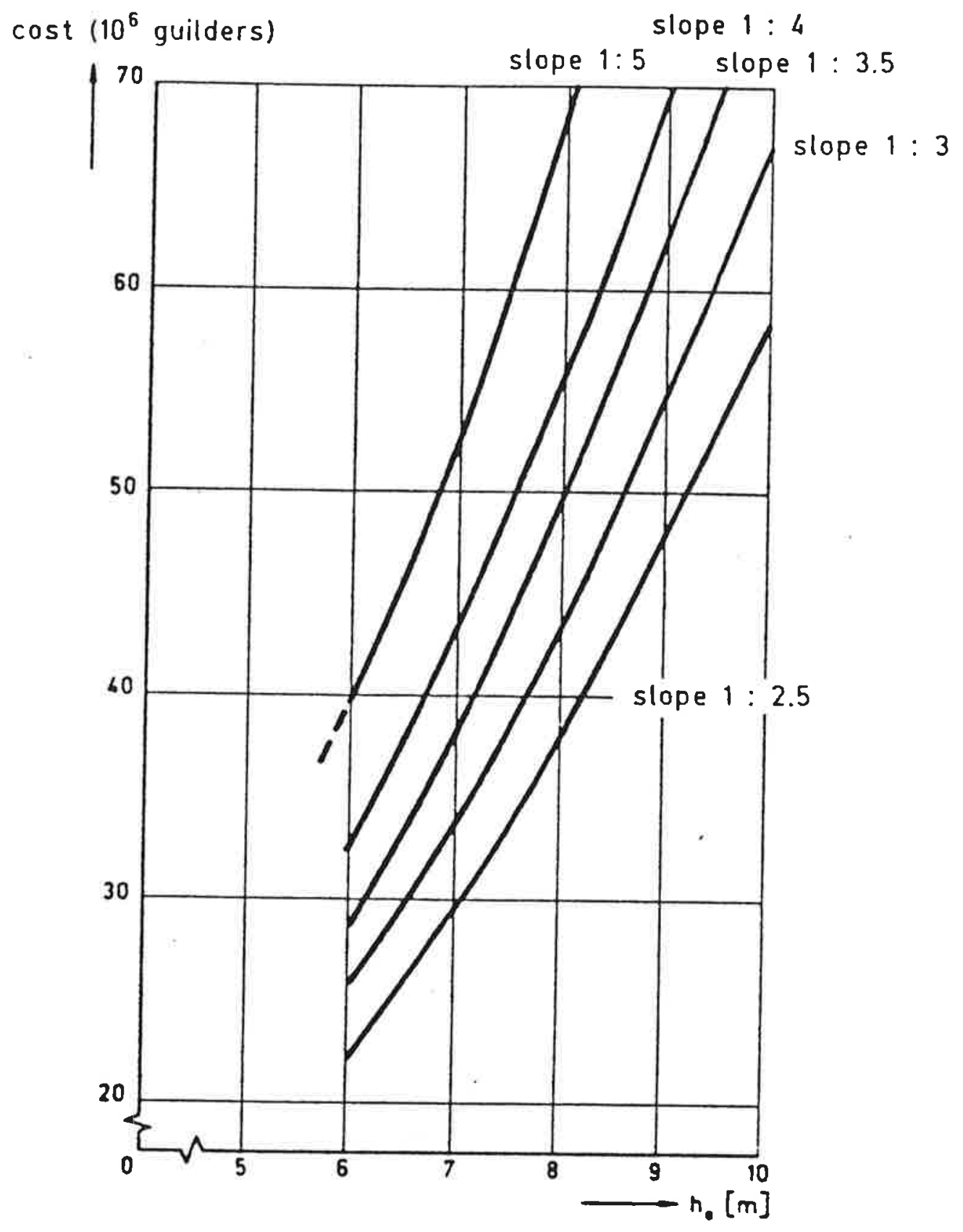

Fig. 7.4.7: cost as a function of $h_{0}$ for the mechanism of macro-instability of the inner slope. 


\subsubsection{Piping}

The mechanism associated with piping is shown schematically in Figure 7.4 .8 .

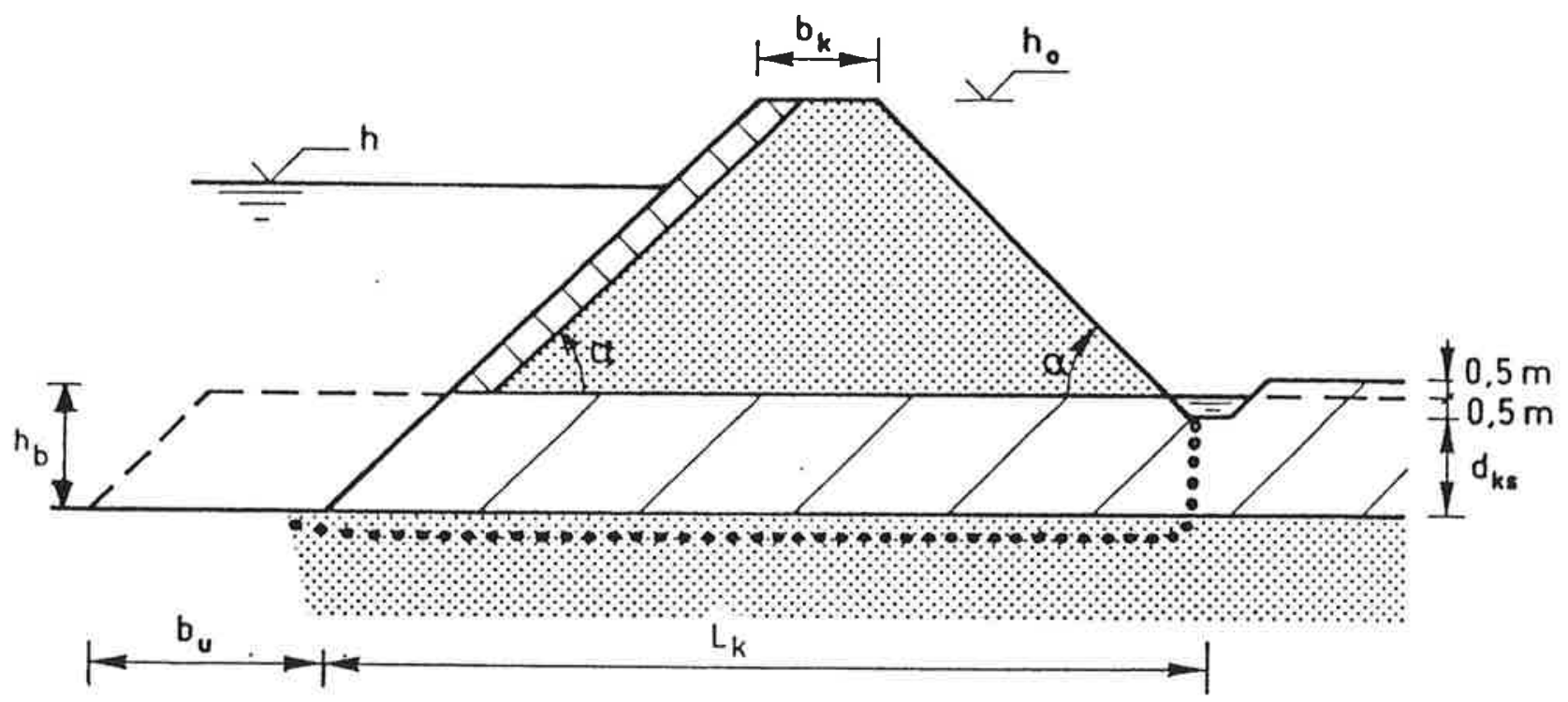

Fig. 7.4.8: Mechanism of piping.

a. Failure probability:

For the failure mechanism of piping to occur, two conditions must be satisfied (see Section 3.5.1):

1. The bottom of the ditch must rupture.

2. Continuous transport of sand must take place.

The reliability function $Z$ that follows from the first condition will then be (see 3.5.8):

$z_{3.1}=\rho_{n k} g \cdot d_{k s . e f f}-\rho_{w} \cdot g\left(\hat{h}+h_{b}\right)$

where $\rho_{\mathrm{nk}}$ is the density of the wet clay; $\mathrm{d}_{\mathrm{ks} \text {.eff }}$ is the (effective) thickness of the layer of clay under the bottom of the ditch to be adopted in the calculation.

After the bottom of the ditch has ruptured, a sand-bearing spring may 
be formed. In order to assess whether this will occur, Lane's criterion in a somewhat modified form has been adopted. Piping is assumed to occur if:

$h>m\left(\frac{\mathrm{L}_{\mathrm{k}}}{18}+\frac{\mathrm{d}_{\mathrm{ks}}}{6}\right) \quad\left(\mathrm{h}>\mathrm{h}_{\mathrm{kr}}\right)$

where:

$I_{k}=$ seepage path length (see Figure 7.4.8)

$\mathrm{m}=\mathrm{a}$ model factor

$d_{k s}=$ thickness of clay layer under bottom of ditch

The reliability function $z_{3.2}$ is therefore:

$z_{3.2}=m\left(\frac{L_{k}}{18}+\frac{d_{k s}}{6}\right)-\hat{h}$

The dyke fails if $z_{3.1}<0$ and $z_{3.2}<0$. From the function for $z_{3.2}$ it appears that the occurence or non-occurence of a sand-bearing spring is determined chiefly by the seepage path length $L_{k}$.

Accordingly, in Figure 7.4.9 the failure probability has been plotted as a function of $\mathrm{L}_{\mathrm{k}}$. The diagram shows that for a seepage path length of less then about $90 \mathrm{~m}$ the failure probability varies greatly in response to a variation in $L_{k}$.

b. Probability density function of inundation depth:

The maximum inundation depth $d$ again follows from the formulae in Section 4.2.

- For the free-nappe weir the following values have been adopted for the limits of integration of formula (7.4.6):

$t_{b}=\frac{T}{2}\left\{1-J\left(1-\frac{e}{h}\right)\right\}$

where $e$ is the value of the water level which occurs at the instant when the two reliability functions $\left(z_{3.1}\right.$ and $\left.z_{3.2}\right)$ are no longer 
failure probability $\left(10^{-3} /\right.$ year $)$

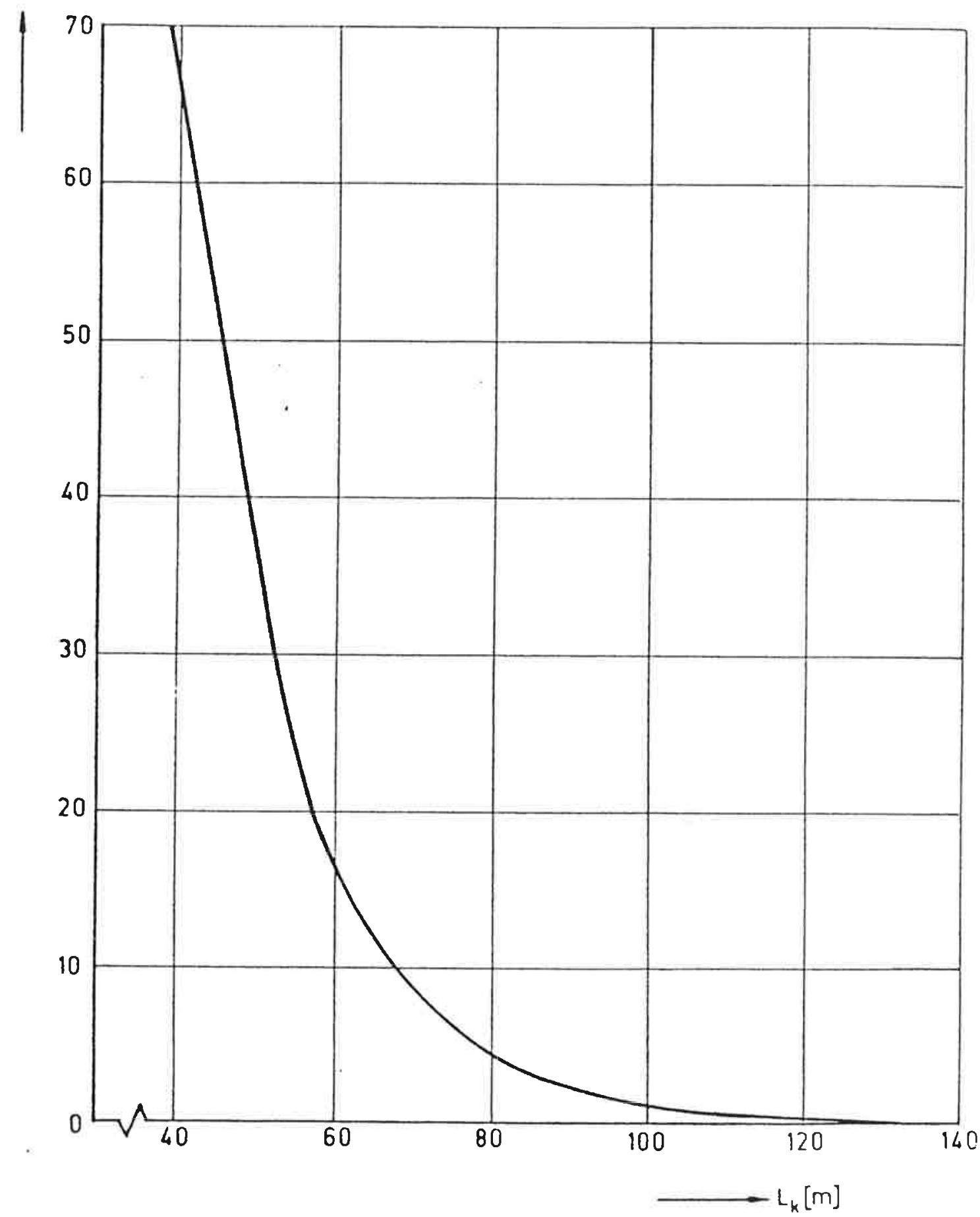

Fig. 7.4.9: Failure probability as a function of $\mathrm{L}_{\mathrm{k}}$ for the mechanism of piping. 
positive; $t_{e}=$ instant at which the submerged weir situation is reached.

- For the submerged weir the formulae (7.4.8) and (7.4.9) are applicable.

c. Optimal crest level (if there is no foreland):

In figure 7.4.10 the loss expectation is represented as a function of the seepage path length $\mathrm{L}_{\mathrm{k}}$. For the angles of slope under consideration the points of mininum total cost are also indicated in that diagram. The dyke profile corresponding to the lowest optimal cost is the one with a 1:5 slope. The optimal crest levels associated with the chosen angles of slope are likewise given in Figure 7.4.10. For the slopes steeper than 1:5 the optimal crest levels range from high to very high.

d. Optimal crest level for dyke with foreland:

As stated in point a of this section, failure of the dyke is governed by the seepage path length $\mathrm{L}_{\mathrm{k}}$ and the thickness $\mathrm{d}_{\mathrm{ks}}$ of the layer of clay under the bottom of the ditch.

From the results mentioned in point $c$ of this section it appears that the seepage path length is of major influence on the probability of failure. A long seepage path can be created by providing a foreland zone in front of the dyke. In that case the crest level and the angle of slope will be determined by the other mechanisms for which the said parameters do affect the failure probability.

\subsubsection{Micro-instability of inner slope}

Figure 7.4.11 schematically shows the mechanism of micro-instability of the inner slope.

a. Failure probability:

The dyke is assumed to fail (collapse) if so much material is moved from the inner slope to the toe that the crest of the dyke is affected. As shown in Figure 7.4.11, this means that the level of point $A$ attains the crest level $h_{0}$. 


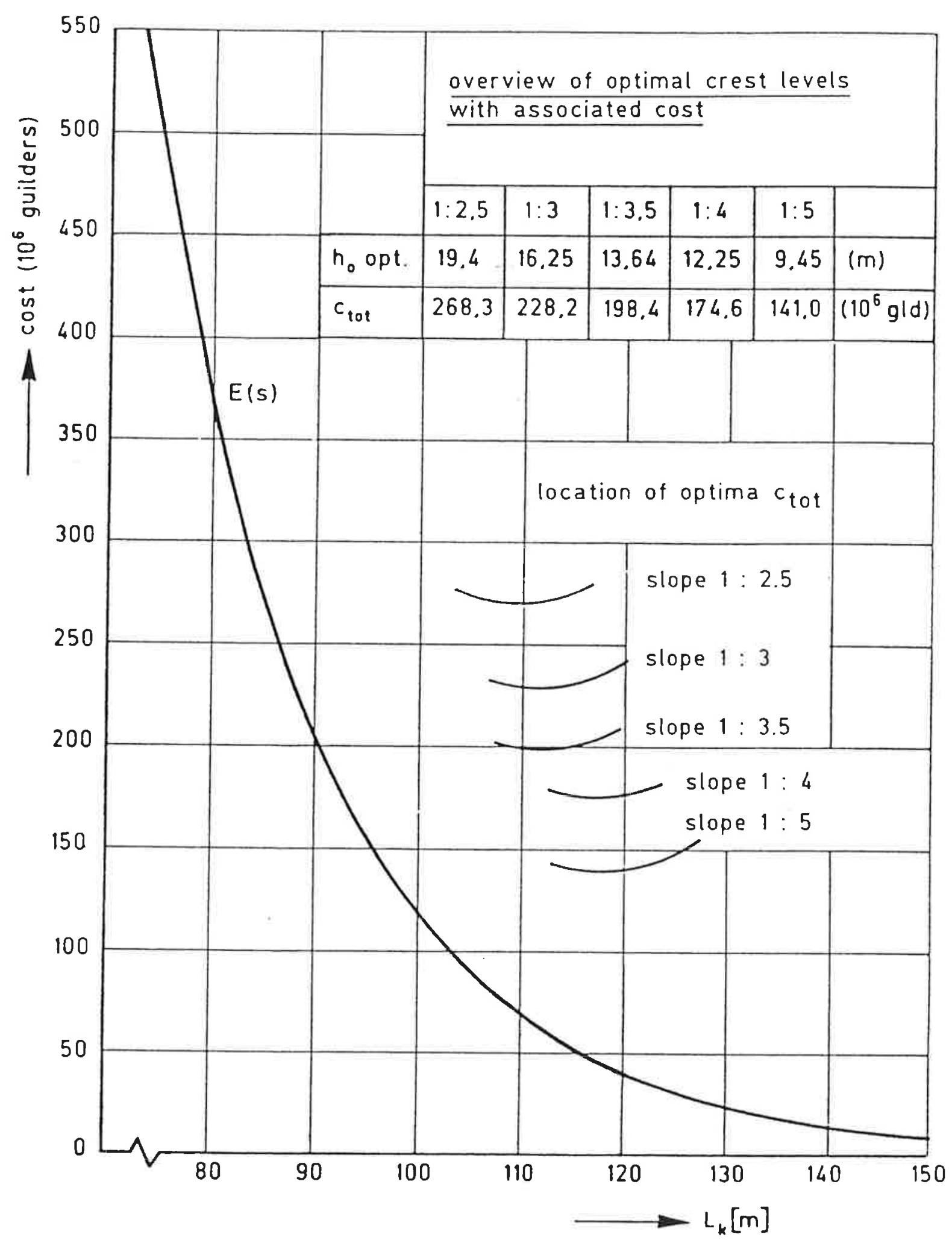

Fig. 7.4.10: Cost as a function of $L_{1}$ for the mechanism of piping (without foreland). 


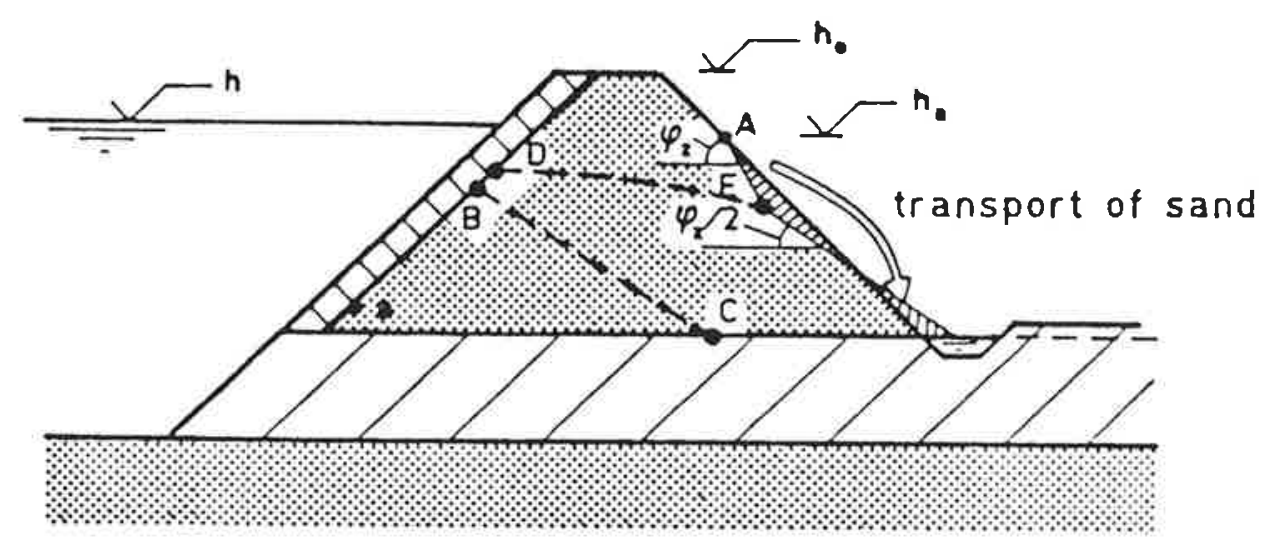

$B-C=$ schematized phreatic line during development of instability

\section{$D-E=$ phreatic line after formation of a seepage surface}

Fig. 7.4.11: Mechanism of micro-instability of the inner slope.

The reliability function for failure is:

$z_{4}-h_{0}-h_{a}$

A note compiled by Delft Geotechnics [7.2] has been used for the determination of $h_{a}$.

The results of the calculations are presented in Figure 7.4.12. The calculations have been performed only for the $1: 2.5$ and $1: 3$ slopes, the reason being that for these steep slopes already very low failure probabilities were found in comparison with the overtopping and the piping mechanisms. (Gentler slopes will give even lower probabilities).

b. Probability deasity function of inundation depth:

The procedure ior determining $\mathrm{f}_{\mathrm{d}}(\delta)$ is similar to that applied in connection with macro-instability and with piping. 


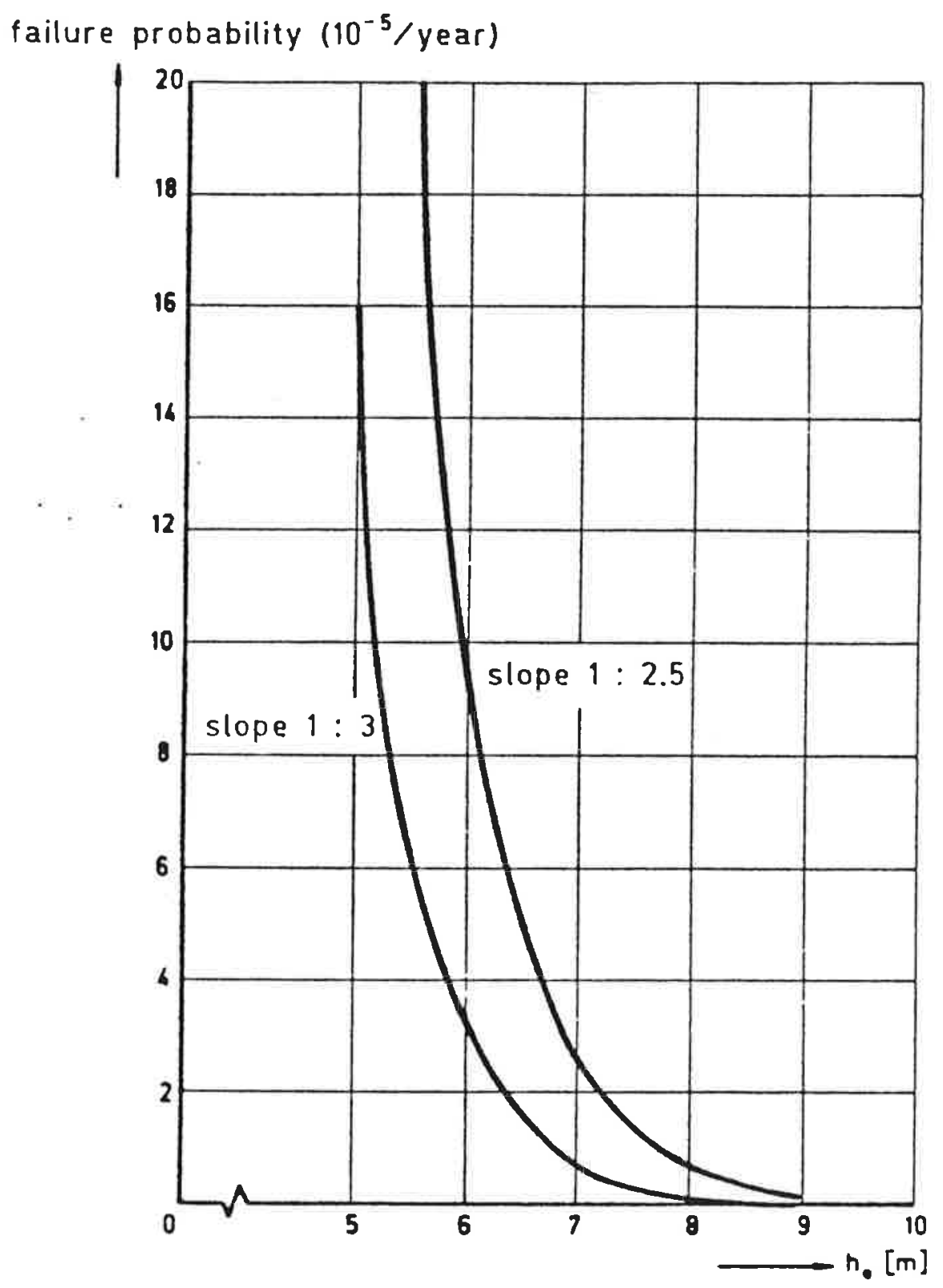

Fig. 7.4.12: Failure probability as a function of $h_{0}$ for the mechanism of micro-instability of the inner slope. 
- For the free-nappe weir the following values have been adopted for the limits of integration:

$t_{b}$ - instant at which the highest water level occurs behind the clay covering on the outer slope $=\frac{2}{3} \mathrm{~T}$;

$t_{e}=$ instant at which the submerged weir situation is reached.

- For the submerged weir the formulae (7.4.8) and (7.4.9) are applicable.

c. Optimal crest level:

For the two angles of slope considered, the cost of construction, the loss expectation and the sum of these two cost figures have been plotted against $h_{0}$ in Figure 7.4.13. The optimal cost for the $1: 2.5$ slope hardly differs from that for the $1: 3$ slope.

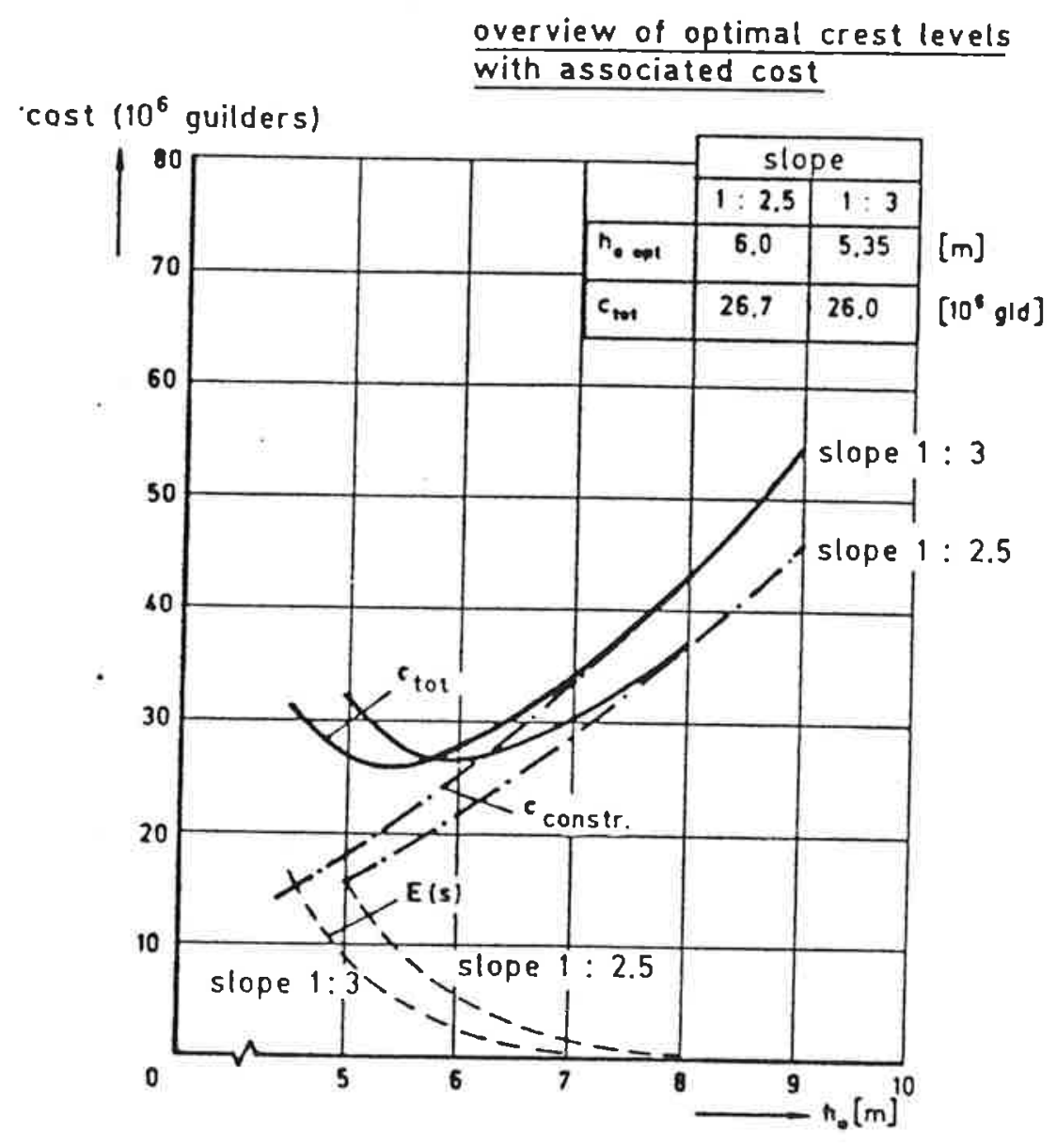

Fig. 7.4.13: Cost as a function of $h_{0}$ for the mechanism of micro-instability of the inner slope. 


\subsection{Combined failure probability of the dyke}

From the results of the individual mechanisms it appears that the failure probabilities associated with the macro-instability and microinstability mecharisms are low in relation with those associated with overtopping and piping. For this reason the combined failure probability has been determined (assuming independency) only for the two lastmentioned mechanisms. The results of the calculations are given in Table 7.5.1. The lowest failure probability is found to be associated with the highest dyke with the flattest slopes.

Table 7.5.1: Overview of failure probabilities of the dyke ( $10^{-3} /$ year).

\begin{tabular}{|rrrrrr|}
\hline \multicolumn{5}{|c|}{ SLOPE } \\
\hline $\mathrm{h}_{\mathrm{o}}$ & $1: 2.5$ & $1: 3$ & $1: 3.5$ & $1: 4$ & $1: 4.5$ \\
\hline $6 \mathrm{~m}$ & 56,23 & 37,47 & 24,47 & 18,74 & 14,65 \\
$7 \mathrm{~m}$ & 41,58 & 22,11 & 12,65 & 8,82 & 5,33 \\
$8 \mathrm{~m}$ & 28,94 & 13,95 & 7,17 & 4,35 & 2,16 \\
$9 \mathrm{~m}$ & 20,0 & 8,76 & 4,50 & 2,42 & 0,96 \\
$10 \mathrm{~m}$ & 13,77 & 6,11 & 2,73 & 1,25 & 0,47 \\
\hline
\end{tabular}

\subsection{Optimal dyke design}

The optimal dyke design has been determined with the aid of an upper bound approximation. The loss expectations associated with the mechanisms under consideration have been summed per design variant. The total cost can then be expressed by the formula:

$$
\mathrm{C}_{\text {TOT }}=\mathrm{C}_{\text {CONST }}+\sum_{i=1}^{4} E(s)_{i}
$$

The optimal design is found for a crest level of $h_{0}=10 \mathrm{~m}$ and a slope of 1:5. This low angle of slope is governed more particularly by the piping mechanism. Of course, it may well be asked whether this is indeed 
the most sensible approach. It is likely that the problem of piping could be tackled more economically by installing sheet pile walls or providing a foreland.

In order to gain insight into the effect of creating a foreland, the total cost has been determined also for a foreland $100 \mathrm{~m}$ in width $\left(\mathrm{L}_{1}=\right.$ $100 \mathrm{~m})$. The effect of the piping mechanism is then found to be considerably reduced. The new optimum corresponds to $h_{0}=9 \mathrm{~m}$ and $a$ slope of $1: 2.5$. The slope now is determined by macro-instability and not by piping. To decide which solution is the most economical, a price for the foreland must be introduced. In the study which has been carried out it emerges that for a cost of 30.000 guilders for each meter that the dyke is sited farther landward, i.e., for each meter of foreland provided, the optimal crest level is $h_{0}=9 \mathrm{~m}$ for a $1: 2.5$ slope. In this case the total cost is less than half of the design without foreland.

\subsection{Conclusions}

Some conclusions to be drawn from the research are:

a. From the treatment of the mechanisms under consideration in this chapter it can be concluded that in dealing with the safety and the optimization of a flood defence structure, more particularly a dyke, it is possible to involve many more factors in the risk analysis than just the factor "water level". It also emerges that the optimization of a dyke on the basis of the sum of the cost of dyke construction and loss expectation (associated with flood damage) is feasible.

b. In carrying out level II calculations with the PROBAB computer program it appeared that convergence problems may be encountered with the complicated reliability functions. These problems may sometimes be caused by details. The compiler of the reliability functions should therefore be familiar with the operation of a program performing level II calculations.

The following conclusions relate to the results yielded by the calculations. The reader should bear in mind that they are valid only within the limits set by the chosen fundamental assumptions (geometry of the dyke, materials, mechanisms). In actual practice different solutions and different limitations will often apply. 
c. If no foreland is provided, only two of the four mechanisms considered play a significant part with regard to the failure probability of the dyke, namely, overtopping and piping.

d. If no foreland is provided, the optimal dyke design corresponds to $h_{0}$ $=10 \mathrm{~m}$ and a 1:5 slope. The governing mechanism for this design variant is piping. Under certain conditions it is more economical to create a foreland.

e. In the case where the dyke has a foreland in front of it, a steep slope is permissible, because of the then very low probability of instability of the inner slope. The presence of a clay covering on the outer slope of the dyke is very effective with regard to water penetration and to the degree of development of the phreatic surface. Because of this the probability of instability of the inner slope (macro- and micro-instability) is low, in spite of the fact that a considerable permeability of the covering due to plant roots, drying, or the activities of burrowing animals has been taken into account.

f. Restriction of the loss expectation associated with the mechanisms considered here can obviously be achieved as follows:

- For overtopping: a sufficiently high crest level $h_{0}$.

- For macro- and micro-instability of the inner slope: a good clay covering on the outer slope.

- For piping: providing a foreland. 


\section{APPLICATIONS IN PRACTICE}

\section{$8.1 \quad$ Introduction}

A classification of reliability analyses at levels I, II and II has been given in Chapter 2. It has been explained that for the purposes of routine design practice the level II and level III calculations are usually too time-consuming. In general, the designer will have to restrict himself to a level I calculation, i.e., making use of characteristic values and factors (margins) of safety. It has further been explained in Chapter 2 that the values of these safety factors can be deduced from calculations being "externally deterministic", a number of advantages are nevertheless gained. More particularly, a certain explicitly defined level of safety must be adopted as the starting point. This makes it possible to differentiate between the safety levels in a fairly rational and consistent manner, especially in relation to the extent of the damage or loss to be expected in the event of failure.

The thinking which has led to backing the partial factors of safety with level II calculations has hitherto been given practical expression chiefly through the codes and regulations for the design and construction of concrete, steel and timber structures. In the Netherlands the project "Safety of structures" [8.1] for establishing the load factors for the TGB-Algemeen (TGB-General Principles) code of 1985 was recently carried out. At European level this line of thought likewise lies at the basis of the series of Eurocodes, of which more particularly the code "Foundations" is of importance with regard to hydraulic engineering practice. In the Netherlands, some standards relating to civil engineering hydraulics in which this approach has to be a greater or lesser extent been adopted have also appeared in recent years. Some of these will be reviewed here.

Via the codes and regulations and through the linkage between the levels I and II, probabilistic considerations have therefore gained an important entrance into engineering design practice. In many cases, however, more direct use is moreover made of probabilistic calculations and arguments. Mostly these are special cases: important structures such as, for example, the Eastern Scheldt Storm Surge Barrier or special 
projects not covered by existing codes or regulations. Sometimes the probabilistic approach is then confined to an analysis of the loads, but in other cases it is taken much further. A few such examples will also be briefly considered here.

\subsection{Eurocodes}

In a European international context, activities directed at establishing a series of codes of practice for building and civil engineering structures are currently in progress. The aim is that every member country of the European Community will harmonise its national codes and standards as closely as possible to these Eurocodes. The latter moreover play an important part in international commerce.

The following Eurocodes are to be published:

EC 1 - General and uniform guidelines

EC 2 - Reinforced concrete structure

EC 3 - Stee1 structures

EC 4 - Composite structures

EC 5 - Timber structures

EC 6 - Masonry structures

EC 7 - Foundations

EC 8 - Earthquakes

In Eurocode 1 it is stated in general terms what requirements a structure must fulfill and how this can be achieved by appropriate design and construction. In principle the level I analysis (on the basis of characteristic values and partial factors of safety) is recommended as the most suitable design procedure for structures of the usual kind. The level I analysis is, for this purpose, considered as a simplification of the level II analysis and should in principle be derived from it.

This line of thought is continued in Eurocode 7, which is concerned 
with soil mechanics. The code bases itself on the concept of "limit state design" and works this out in the direction of a level I design procedure. Other possibilities are explicitely allowed, however. More particularly the code leaves room for the more conventional methods, permitting conventional estimates of strength and load as "design values".

Because of this, in many cases the degree of safety in soil mechanics is, in the near future, bound to remain less clear-cut than in the sphere of steel or concrete construction. This lack of clarity must in part be attributed to the rather complicated series and parallel effects which are more prominently encountered in soil mechanics than in other spheres of civil engineering. From this point of view, too, there is therefore every reason to continue the research into the effect of local variations in strength. Only then will safety considerations in connection with soil mechanics be likely to attain a degree of clarity comparable to those relating to steel or concrete.

\subsection{TAW Recommendations for the Design of River Dykes}

These recommendations [8.2] start from a permissible probability of inundation of $1 / 1250=8 \times 10^{-4}$ per year. The Commission on River Dykes has stated that this criterion means that the dykes in question must exactly be able to retain a water level associated with a discharge of $16500 \mathrm{~m}^{3} / \mathrm{s}$ of the Rhine at Lobith (this being a level with a probability of being exceeded once per 1250 years). In the code this has been translated into the following fundamental requirements:

1. The height of the dyke (crest level) should be at least equal to a water level associated with a discharge of $16500 \mathrm{~m}^{3} / \mathrm{s}$ (GHW = governing high water level) plus the extra height to be provided as a margin of safeiy.

2. The probability of the dyke being breached by wave action at a water level lower than GHW should be less than $8 \times 10^{-5}$ per year.

3. The probability of breaching due to other mechanisms (piping, sliding) should be less than $8 \times 10^{-6}$ per year. 
The calculations for the "other mechanisms" are performed in principle with the aid of a level I analysis. The values of the partial factors of safety are not backed up by level II calculations. In determining the factors the consequences of failure are taken into account, however. For example, the factor associated with the assessment of the stability of the outer slope for falling water level is assigned a lower value than the factor associated with the stability of the inner slope at high water level.

\subsection{TAW Recomendations for Dunes}

The Recomendations for Dunes [8.3] of the Technical Advisory Committee for Dykes and Flood Defences (TAW) bases itself on a failure probability of $10^{-5}$ per year. It is clearly indicated that this choice applies to a reference line perpendicular to the coastline. The failure probability of a long stretch or of several stretches of dunes is therefore higher (because of the length effect), though it is not known how much higher.

Dune erosion is calculated on the basis of seven stochastic basic variables. A practical procedure for the purpose has been devised with the aid of level II calculations. In this approach the general theory outlined in chapter 2 has, it is true, not been precisely adhered to, but the differences are not important. In any case it has been endeavoured to formulate a procedure in such a manner that the deviations from the stated target value for the failure probability will remain acceptably small, even for widely differing cases. Briefly summarized, this procedure is as follows:

1. The water level is fixed at the level with a $5 \times 10^{-5}$ per year probability of being exceeded (or, as defined in the code: the water level with a $10^{-4}$ frequency of being exceeded plus two-thirds of the decimation interval).

2. The wave height is taken as equal to the wave height with the maximum probability density at the water level defined above. 
3. For the median sand grain diameter $D_{50}$ a mean value and a standard deviation are determined at each location. The value to be adopted as the grain diameter in the calculation is then:

$$
\begin{aligned}
& D_{50 . c a l c}=\mu\left(D_{50}\right)\left\{1-5 v^{2}\left(D_{50}\right)\right\} \\
& V\left(D_{50}\right)=\text { coefficient of variation of } D_{50}
\end{aligned}
$$

4. The initial (cross-sectional) profile is determined in a number of locations by measurement in accordance with a standardized procedure. Next, a reduction is applied to the average profile in such a way that there is $\sigma^{2}(\mathrm{Vol}) / c_{0}$ less sand present, where $\sigma\left(V_{0}\right)$ is the standard deviation of the volume of sand in $\mathrm{m}^{3} / \mathrm{m}$ and $c_{0}$ has the value of $275 \mathrm{~m}^{3} / \mathrm{m}$.

5. Then the dune erosion is calculated with the DUROS computer program. To this exosion must thereupon be added the effect of the storm tide duration, the surges and the model uncertainty. This effect is quantified as a quantity of sand with a volume equal to $255 \mathrm{~m}^{3} / \mathrm{m}$ of the erosion already calculated, with the addition of $20 \mathrm{~m}^{3} / \mathrm{m}$.

\subsection{Safety considerations relating to the lock at Vlaardingen}

In close collaboration with Working Group 10 of the TAW, COW advised the Polder Board of Delfland concerning safety of a lock in the 0ld Harbour of Vlaardingen. This lock is a part of the water defence system. Working Group 10 considers that a dyke not exposed to wave action is allowed to have a failure probability of $10^{-5}$ per year. (Complying with the Delta norm: "water level with exceedance probability of $10^{-4}$ per year plus a minimum safety margin of $0.50 \mathrm{~m}^{n}$.) For this reason a failure probability of $10^{-5}$ for the gates of the lock was adopted. So far as the concrete and steel design aspects is concerned, it is considered that this level of probability can be attained by application of the relevant design codes (TGB, VB, etc.). Next, a target value of $10^{-6}$ was established for the lock operating aspects. 
Various aspects of lock or dock gate operation were compared with one another with the aid of a fault tree analysis (see Figure 8.5.1):

- Single set of gates with one operating team.

- Single set of gates with two operating teams.

- Single set of gates with one operating team and automatic reserve system.

- Navigation lock.

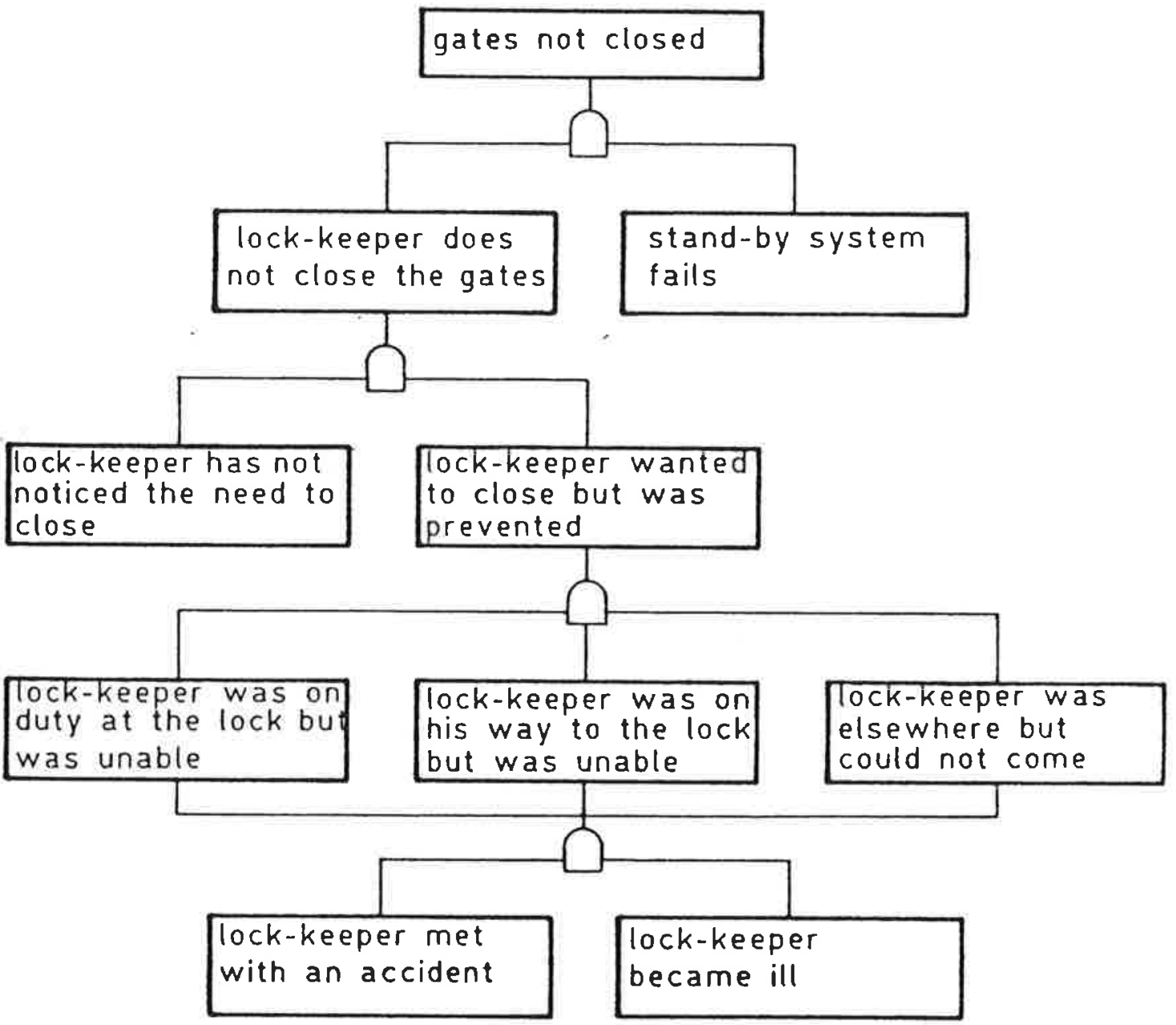

Fig. 8.5.1: Fault tree for the closure of the lock at vlaardingen. (Single set of gates with one operating team).

Furthermore, the influence of the highest water level at which operation of the gates is still possible was taken into account. On the basis of a probability of human failibility of $10^{-4}$ to $10^{-3}$ per action $\left(10^{-2}\right.$ to $10^{-1}$ per year) it was concluded that two-team operation would in any case be necessary. However, preference was expressed for an automatic reserve system or for the alternative of a navigation lock. 


\subsection{Easter Scheldt Storm Surge Barrier}

A major civil engineering project such as the Storm Surge Barrier in the Eastern Scheldt warrants a careful and elaborate design procedure. As part of this procedure, probabilitistic calculations were used for dealing with various aspects. In this respect the fault tree for the barrier as a whole has become most widely known. The main tree of this fault tree is represented in Figure 8.6.1. The importance of this tree was that the designers thoroughly examined the question as to where the weakest links in the barrier, as regards reliability and as regards consequence could be expected. Civil engineering, mechanical engineering and management engineering aspects were integrally assessed. The ultimate aim of the tree was to make possible the construction of a storm tide barrier with a failure probability of $10^{-7}$ per year. To achieve this, some radical changes were made in the original design, particularly with regard to operation and management.

Calculations of a more detailed nature were carried out for various parts of the design process. More particularly, the analysis of the foundation and the analysis of the hydraulic boundary conditions should be mentioned in this context. The design of the sill and rubble mound dam was strongly influenced by the probabilistic method.

\subsection{Dykes around the Easter Scheldt (Barcon)}

In determining the desired degree of safety, the management of the Storm Surge Barrier and that of the dykes around the Easter Scheldt, "The Barcon Working Group" took its cue from the developments within the TAW Working Group 10 and the code of practice for Dunes [8.4]. The approach adopted is therefore based on a permissible failure probability equal to about 108 of the design frequency according to the Delta Standard, i.e., $2.5 \times 10^{-5}$ per year. This probability applies explicitly to an island or a ring of dykes.

However, Barcon also investigated what result would emerge from applying the formulae of Chapter 6. Starting from $\beta *=0.1, k=3, N_{d}=1000$ and $P_{d \mid f}=10^{-2}$, the rollowing is found: 


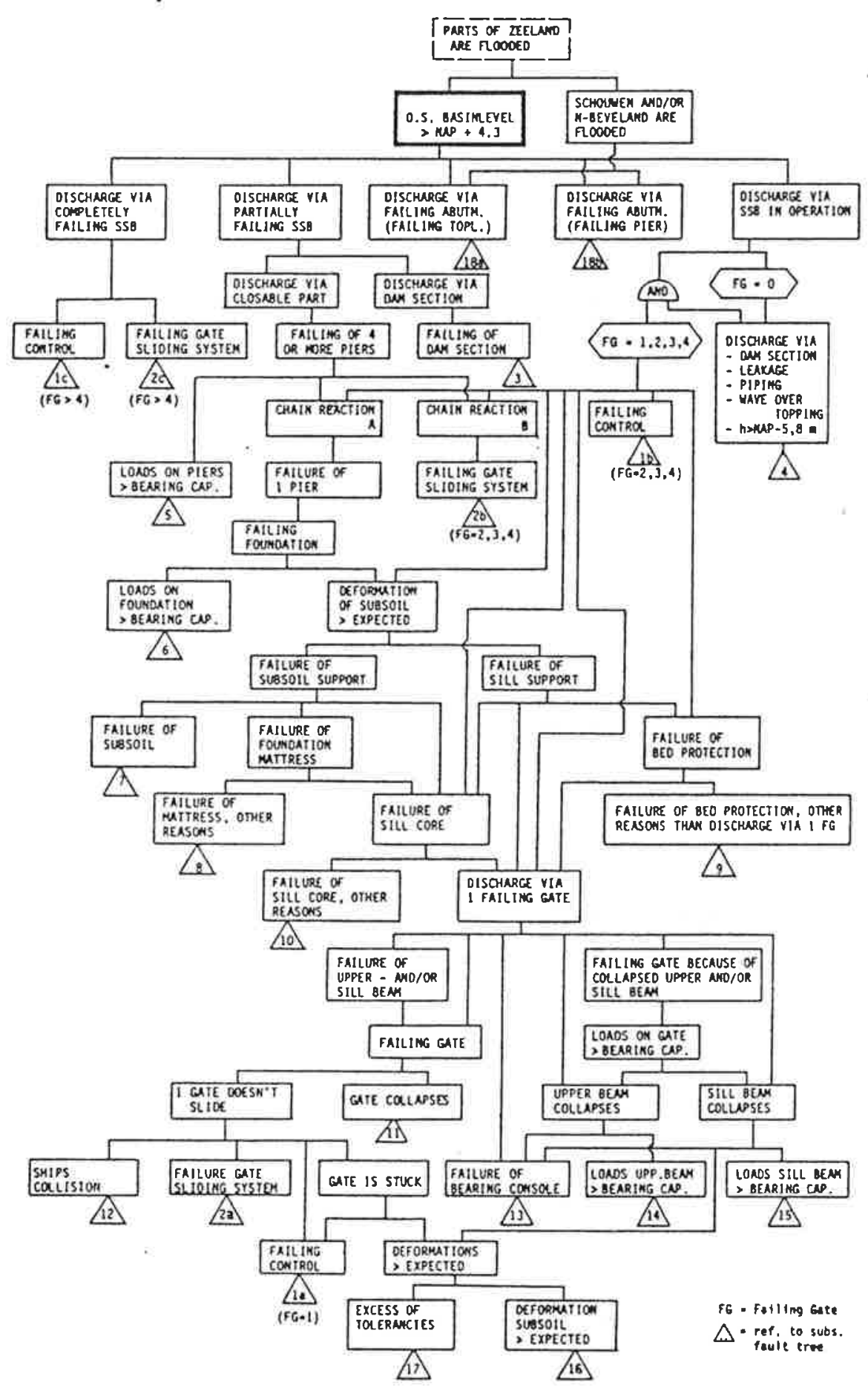

Fig. 8.6.1: Main fault tree of the Easter Scheldt Storm Surge Barrier (ESSTB). 
Personally acceptable risk: $1.0 \times 10^{-3}$ per year

Socially acceptable risk : $1.0 \times 10^{-5}$ per year

It appears that the socially acceptable risk is close to the value recommended by Working Group 10 and Barcon. There is, however, a considerable difference with respect to the target value for the Eastern Scheld Storm Surge Barrier: $10^{-7}$ per year.

Since the main purpose of the infrastructure around the Oosterschelde basin and the management of the barrier and dykes is to reduce the probability of inundation to "Delta level", a value of $2.5 \times 10^{-5}$ per year has been adopted. On the basis of this requirement various management strategies were investigated, and it was considered what additional measures (dyke strengthening operations) would have to be taken. For this purpose, fault trees and level II calculations were extensively used [8.5]. An economic analysis was carried out for damage to slopes.

\subsection{Pumped Storage Scheme in the IJsselmeer}

The preliminary design of a pumped energy storage in the IJsselmeer is of considerable interest from the viewpoint of risk analysis [8.6]. This is, primarily because of the special problems associated with estimating the consequences of a possible breaching of the water-retaining enclosure: how large will the breach be, how high a tidal wave will occur on the IJsselmeer, in what locations around the lake will the dykes be overtopped, and will those dykes collapse?

But of greater interest is the question of the acceptability of the risk. If the scheme is judged as a high dam structure, a failure probability of $10^{-5}-10^{-6}$ per year would have to be considered (code for LPG) or indeed, in view of the probable number of victims, the scheme would have to be rated as "unacceptable" by the criteria of the Environmental Note of the Province of Groningen [6.3]. The scheme (even if never carried into effect) thus provides a useful test for bringing the different rating scales of risk analysis closer together. 
9. CONCLUSIONS AND RECOMMENDATIONS

\subsection{Conclusions}

1. Probabilistic considerations are increasingly being applied in actual practice. For civil engineering structures, for example, this is apparent from the use of level II calculations for backing up the partial factors of safety applied in standards and codes for the design of structures (TGB 1985, Eurocodes). Direct probabilistic approaches have increasingly become the rule in connection with the assessment of special structures (nuclear power stations, storage tanks for hazardous substances).

2. In the sphere of flood defences, more particularly in the case of dykes, dunes, dams, etc. probabilistic approaches more and more often provide the basis for design and management standards. Examples are:

- TAW Directive for dune erosion;

- TAW Directive for river dykes.

In the case of some special hydraulic engineering structures such tools as risk analysis and reliability analysis have been extensily employed. The following examples may be mentioned:

- The design and construction of the Eastern Scheldt Storm Surge Barrier.

- The closure strategy of the Eastern Scheldt Storm Surge Barrier.

- A study relating to pumped storage hydroelectric power generation.

3. With regard to the setting of standards for the requisite level of safety of flood defences, TAW's Working Group 10 has developed a philosophy which is embodied in the report entitled "Some considerations on an acceptable level of risk in the Netherlands" and in Chapter 6 of the present report. Although there are still many open questions, the results have already been used in the operational management of the storm surge barrier, the safety system around the Eastern Scheldt and the study relating to pumped storage hydroelectric power generation. 
4. The worked example presented in the context of the investigation reported here shows that in considering the safety and in optimizing a flood defence structure it is indeed possible to bring more stochastic parameters than just the water level into the risk analysis .

With regard to this conclusion it must be noted that the system which has been optimized comprises only one water-retaining element, namely, a river dyke. The number of failure mechanisms is confined to four and only one form of dyke is considered. The length effect has been left out of account.

5. On the basis of experience gained it can be expected that the assessment of a complex flood defence system (comprising dyke segments, dunes, sheet pile walls, locks, etc.) with the aid of a probabilistic analysis is no simple matter. Both from the point of view of theory and the point of view of actual application on approach of this kind will still demand much effort. All the same, parts of the study that has been performed are already being given practical effect. The study can be expected gradually to yield more and more results applicable to design and management.

\subsection{Recommendations}

It is apparent from the foregoing that the results of this research are increasingly being applied in practice. It has also been noted that probabilistic approaches cannot as yet be ranked among the routine tools of assessment of complex flood defence systems, though the need for these in actual practice is increasing. The Working Group is accordingly of the opinion that the study should be continued and makes the following recommendations:

1. (Further) development of models for known failure mechanisms and searching for possible mechanisms still unknown.

2. Analysis of various types of flood defence structures, taking account of the models envisaged in point 1 , and carrying out calculations relating to leingth effect and correlations. 
3. Development of methods (approaches) for determining the probability of inundation of a region protected by a system of flood defences and of methods for determining the optimal design for a water-retaining element or a flood defence system.

4. Carrying out a sensitivity analysis, per type of flood defence structure, of all the relevant factors, with a view to cost optimization of the design and, on the basis thereof, establishing priorities for further research into limit states and parameters.

5. Further investigation is moreover especially desirable with regard to:

- The relationship between the inundation parameters and the damage or loss due to inundation.

- The development behaviour of breaches and the flow of water through them.

- Verification in practice of models that have been established, more particularly by monitoring of the dyke sections for:

- quality of the external covering;

- phreatic surface within the dyke;

- sandbearing springs (piping).

- Interactions between failure mechanisms (trigger mechanisms).

- Statistical properties of parameters.

6. Dissemination of the information and knowledge gained, as also the "translation" of the results and insights yielded by the investigations into codes of practice for the design and management of flood defences.

The activities envisaged in points 1 and 5 should be carried out in close collaboration with other Working Groups of the TAW. In this context, Working Group 10 will play a co-ordinating role and will itself deal with the specifically probabilistic aspects.

These points should moreover be conceived as constituting a cycle which will have to be passed through several times. After point 4, activities should revert to point 1 , after which they should proceed further on the basis of the priorities that have been established. Therefore it is 
important not to spend too much time and effort on points 1 to 3 if particular models or methods turn out not to be available. It is better first to determine, via point 4, whether or not such matters are important.

The aspects calling for further investigation, indicated in point 5 , have emerged from the present study reported here. 


\section{REFERENCES}

[1.1] Rapport Deltacommissie (Report of Delta Commission, 'in Dutch'). Staatsuitgeverij 1960.

[1.2] Rapport Commissie Rivierdijken (Report of Commission on River Dykes, ' in Dutch').

The Hague, March 1977.

[1.3] Rapport Voorwerkgroep "Probabilistische methode" (Report of the preliminary Working Group 'Probabilistic Design', 'in Dutch'). S-79.063, cow, March 1979.

[1.4] Nota inzake een methode voor het beoordelen van de veiligheid (A method of safety assessment, 'in Dutch').

Provinciale Waterstaat Zuid-Holland (1980).

(PM 80-20).

[2.1] Vrouwenvelder, A. and Vrijling, J.

Probabilistisch Ontwerpen (Probabilistic Design, 'in Dutch'). Collegedictaat 63 (University Lecture Notes).

Delft Universit: of Technology, Department of Civil Engineering, 1985.

[2.2] Thoft-Christensen, $P$. and Baker, $M$.

Structural Reliability Theory and its Applications.

Springer Verlag, Berling, Heidelberg, New York.

[2.3] Schueller, G.I.

Einfuhrung in die Sicherheit und Zuverlassigkeit van Tragwerken.

Verlag von Wilhelm Ernst und Sohn, Munich 1981.

[2.4] Hallam, M.G., Heaf. N.I. and Wooton, I.R.

Rationalization of Safety and Serviceability factors in Structural

Codes

CIRIA Report No. 63, 1977.

[2.5] Ditlevsen, 0 .

Narrow Reliability Bounds for Structural Systems.

Journal of Structural Mechanics, Vo1. 1, No. 4, 1979.

[2.6] Stevenson, J. and Moses, F.

Reliability of Frame Structures.

Journal of Structural Division, ASCE, Nov. 1970. 
[3.1] Duiser J.A.

Een verkennend onderzoek naar methoden ter bepaling van de inundatieschade bij dijkdoorbraak; rapport 82-0644 van Industriele veiligheid van MT-TNO. (An inquiry in methods for the assessment of loss due to dyke failure, 'in Dutch').

[3.2] Rapport Deltacommissie (Report of Delta Commission, 'in Dutch') 1960, Staatsdr. 2 Uitg. Bedr.

[3.3] Bruinsma J. and Graaff J.V.d. Golfhoogte waterstandsrelatie t.p.v. de NAP - $20 \mathrm{~m} \mathrm{lijn} \mathrm{nabij} \mathrm{Hoek}$ van Holland. (Relation water level versus wave height at the NAP 20 m contour line at Hoek van Holland, 'in Dutch'). Rijkswaterstat WWKZ 82-G0259, The Hague, 1982.

[3.4] Vrijling J.K.

Een orienterend onderzoek naar de richtlijnen voor het ontwerp van zeeweringen van de Deltacommissie. (An inquiry into directives for the design of the sea defence by the Delta Commission, 'in Dutch'). Delft University of Technology, Dept. of Civil Eng., Hydraulic Eng. Division, Publ.no. 1370509, 1983.

[3.5] d'Angremond $K$, and Oorschot J.V.

The effect of wave energy spectra on wave run-up.

Coastal Eng. Conf., London, 1962.

[3.6] Battjes J.A.

Computation of set-up, longshore currents, run-up and overtopping, due to wind-generated waves.

Doctoral Thesis, Delft University of Technology, 1974.

\section{[3.7] Craig R.F.}

Soil Mechanics (student text), Van Nostrand Reinhold Company Ltd., London, 1974.

[3.8] Alonso E.E.

Risk Analysis of Slopes and its Application in Canadian Sensitive Clays, Geotechnique 26, No. 3, 1976.

[3.9] Meer M.Th. van der and Meermans W.

Stabiliteitsfactor en kans op afschuiven van grondlichamen.

(Stability factor and probability of failure for slopes, 'in Dutch').

Report Delft University of Technology, Dept. of Civil Eng., Hydraulic Eng. Division, 1984. 
[3.10] Wu T. and Kraft L.M.

Safety Analysis of Slopes, Journ. of the Soil Mech. and Found. Eng. Div., Proc. ASCE no SM2, Vo1. 96, 1970.

[3.11] Corne11 C.A.

First Order Uncertainty Analysis of Soil Deformation and Stability, Proc. 1st Int. Conf. on Appl. of Stat. and Prob. to Soil and Struct. Eng., Hong Kong, 1971.

[3.12] Morla Catalan J. and Corne1l C.A.

Earth Slope Reliability by a Level Crossing Method, Journ. Geot. Eng. Div., Proc. ASCE GT6, Vol. 102, 1976.

[3.13] Tang W.H, Yucemen M,S, and Ang A,H.S.

Probability based short term design of slopes, Journ. Can. Geot. Soc., Vol. 13, 1976.

[3.14] Vanmarcke E.

Reliability of Earth Slopes, Journ. Geot. Eng. Div., Proc. ASCE, GT11 Vo1. 113, 1977.

[3.15] Veneziano D. and Antoniano J.

Reliability of slopes: Frequency Domain Method, Journ. Geot. Eng. Div., Proc. ASCE no. GT2, Vol. 105, 1979.

[3.16] Matsuo M. and Asaoka A.

A simplified procedure for updating stability risk of embankments from observation during construction, Proc. 4th Int. Conf. Appl. Prob. Stat. in Soil and Struct. Eng., Florence, 1983.

[3.17] Vanmarcke, E.

Probabilistic Modeling of Soil Profiles, Journ. Geot. Eng. Div., Proc. ASCE GT11, Vo1. 103, 1977.

[3.18] Calle E.O.F.

Stabiliteit van taluds, een probabilistische benadering. (Stability of slopes, a probabilistic approach, 'in Dutch').

Voordracht cursus Rivierdijken en Boezemkaden, Stichting PATO, De1ft, 1983.

[3.19] Calle E.O.F.

Probabilistic Analysis of Stability of Earth Slopes, Proc. XI ICSMFE, San Francisco, 1985.

[3.20] Vrouwenvelder A.C.W.M. and Wubs A.J.

Een probabilistisch dijkontwerp. (A probabilistic dyke design, 'in Dutch'), TNO-IBBC Report B-85-64/64.3.0873, 1985. 
[3.21] Calle E.O.F.

LGM notities CO-263230/3, CO-263230/12, CO-263230/16 and CO263231/5, 1982/1983. (Memoranda on the phreatic line in dykes, 'in Dutch') .

[3.22] Calle E.O.F.

Tijdsafhankelijke positie van de freatische lijn in een dijk. (Time dependent phreatic line in a dyke, 'in Dutch'), LGM notitie CO$263230 / 16$.

[3.23] Rapport Voorwerkgroep "Probabilistische methode". (Report of the Preliminary Working Group 'Probabilistic Design', 'in Dutch').

[3.24] Rapport grondmechanisch onderzoek Oosterscheldedijken bij stagnante waterstanden - PROVO 81 (BARCON) - LGM CO-416338/42. (Soil Mechanics aspects of Eastern Scheldt dykes at constant water level, 'in Dutch'), October, 1983.

[3.25] De waarde van de regels van Bligh and Lane en nieuwe inzichten. Concept Leidraad Piping gevaar. (Evaluations of the Bligh and Lane Rules, New Developments, 'in Dutch').

[3.26] Wit J,M. de

Concept leidraad voor het ontwerpen van rivierdijken - Nov. 1982, TAW 2 COW/WWZO. (Draft Directive for the design of river dykes, 'in Dutch'). Febr. 1985 TAW 8 - Subwerkgroep rivierdijken.

[3.27] Klaver E. Kuiper B. and Vrouwenvelder A.C.W.M.

Random Vibrations. (in Dutch), 'in Dutch'.

Delft University of Technology, Dept. of Civil Eng.

[3.28] Papoulis A.

Probability, random variables and stochastic processors; Mc. GrawHill, Kogakusha Ltd. (1965).

[3.29] Bligh, W.G.

The practical design of irrigation works, London-Constable-1912, 2nd ed.

[3.30] Lane, E.W.

Security from under-seepage. Masonry dams on earth foundations. Transactions of the ASCE no 100, 1935.

[4.1] Vrouwenvelder A.C.W.M. and Wubs A.J.

Een probabilistisch dijkontwerp. (A probabilistic dyke design, 'in Dutch'), TNO-IBBC Report B/-85-64/64.3.0873, 1985. 
[4.2] Calle E.O.F. and Dillingh D.

Berekening van golftopverlaging door een afvoerdebiet van zijdelingse overlaat langs een rivier bij hoogwaterafvoer. (River flow and discharge calculations for a lateral spillway, 'in Dutch'). May 1983.

[4.3] Vrouwenvelder A.C.W.M.

Vorm, duur en waterstanden en hoogwatergolven. (Shape, duration and Water Levels of flood waves, 'in Dutch'), Memo TNO-IBBC 83/110-bcVRO/LVM-D, 1983.

\section{[5.1] Duiser J.A.}

Een verkennend onderzoek naar methoden ter bepaling van de inundatieschade bij dijkdoorbraak. (An inquiry in methods for the assessment of loss due to dyke failure, 'in Dutch'). Report 82-0644 van Industriele Veiligheid van MT-TNO.

[5.2] Penning-Rowseli E.C. and Chatterton J.B. The benefits of flood alleviation. Saxon House, Teakfield Ltd., Westmead, 1977.

[5.3] Centraal Bureau voor de Statistiek, Statische en Economische Onderzoekingen. (Statistical and economical investigations, 'in Dutch'), Nieuwe Reeks $8 \mathrm{nr} .2$ (2e kwartaal 1985).

[5.4] Provinciale Griffie Gelderland, Berekening inundatieschade voor de provincie Gelderland. (Inundation damage in the Province of Gelderland, Statistics of the subsoil, 'in Dutch'). Aug. 1973.

[5.5] Centraal Bureau voor de Statistiek.

Bodemstatistiek, deel 5: Nederland 1976-1978 (Staatsdrukkerij 1980) Statistics of subsoil, part 5, The Netherlands 1976-1978,

' in Dutch').

[6.1] Rapport Deltacommissie. Het economische beslissingsprobleem inzake de beveiliging van Nederland tegen stormvloeden. (Report of Delta Commission, Part 3, Appendix II.2, The economic decision problem of Flood Defence in the Netherlands, 'in Dutch'). The Hague, 1960.

[6.2] TAW 10

Some considerations on an acceptable level of risk in the Netterlands.

[6.3] Nota Milieunormen. (Environment note 'in Dutch'). Provincie Groningen, 1979. 
[6.4] Ministry of Housing and Regional Planning, LPG Integral Study ('in Dutch').

[7.1] Vrouwenvelder A.C.W.M. and Wubs A.J.

Een probabilistisch dijkontwerp (A probabilistic dyke design 'in Dutch'), IBBC-TNO Report B-85-64/64.3.0873, 1985.

[7.2] Calle E.O.F.

Uitwerking grenstoestand micro-instabiliteit. (Limit state microinstability, 'in Dutch'), LGM notitie C0-263230/14.

[8.1] Vrouwenvelder A.C.W.M. and Siemes A.

Veiligheid van Bouwconstructies. (Reliability of Building Structures, 'in Dutch').

TNO-IBBC Report. BI-84-36.

[8.2] TAW Leidraad voor het ontwerpen van rivierdijken. (TAW Recommendations for River Dykes).

Deel I: Bovenrivierengebied (1985).

[8.3] Graaff J. v.d.

Achtergronden van de TAW-Leidraad Duinafslag. (TAW Recommendations for Dunes, Background information, 'in Dutch').

Delft University of Technology, Dept. of Civil Eng.

[8.4] BARCON

Voorstel Veiligheidsfilosofie. (Safety philosophy, 'in Dutch'). RWS Notitie 840508.

[8.5] Veiligheidsaspecten van het beheer van de stormvloedkering in de Oosterschelde. (Safety Aspects of the Eastern Scheldt Storm Surge Barrier Management, 'in Dutch').

RWS, Werkgroep BARCON, Feb. 1985.

[8.6] Een veiligheidsnorm van PAC. (Safety Target for the pumped storage scheme, 'in Dutch').

Voorlopige studie RWS (Preliminary Report RWS). 